\title{
II. Linksbündnis im Schatten der Krise: Die Union des gauches 1932-1934
}

\section{Das Verhältnis von SFIO und Parti radical in den Jahren 1927 bis 1932}

\section{Die SFIO zwischen Scylla und Charybdis (1927-1932)}

Für die Sozialisten stellten die Jahre von 1927 bis Anfang 1932 einen ständigen Balanceakt zwischen politischer Taktik und Aufrechterhaltung der Parteidoktrin dar. Innerparteilich bedeutete dies eine permanente Auseinandersetzung zwischen dem rechten und linken Flügel der SFIO. Zur zentralen Frage geriet besonders in diesen Jahren die Diskussion um die Regierungsbeteiligung. Verschiedene Faktoren waren für das Verhalten der SFIO bestimmend. Zunächst mußte die sozialistische Partei nach dem Zerfall des Cartels wieder um ihre unabhängige Position ringen. Auf der einen Seite war zunächst das Verhältnis zum Parti radical zu bestimmen und auf der anderen Seite die Abgrenzung zur kommunistischen Partei festzulegen. Außerdem mußte ein Gleichgewicht zwischen dem rechten Flügel, den Anhängern einer Regierungsbeteiligung und dem linken Flügel, den Gegnern der Regierungsbeteiligung, gefunden werden, um die Einheit der Partei zu sichern.

Nachdem Poincaré im Juli 1926 mit einem Kabinett der Union nationale wieder die Regierung übernommen hatte, versuchte die SFIO bis zu den Wahlen von 1928 mit der Taktik der gemäßigten Opposition zu operieren, die sie durch Stimmenthaltungen ${ }^{1}$ praktizierte. Diese politische Praxis bot sich aus zweierlei Gründen an. Zum einen konnten die Sozialisten damit zu ihrer Unabhängigkeit zurückfinden und zum anderen wäre eine rigide Oppositionspolitik angesichts des Erfolges Poincarés ${ }^{2}$ mehr als unpopulär gewesen und hätte sich besonders bei den Wahlen 1928 negativ auf die Sozialisten ausgewirkt. Diese Zeitspanne von Juli 1926 bis Mai 1928 nutzte besonders Léon Blum, der zu Beginn des Jahres 1927 zunächst in einer Artikelserie des Populaire das Verhältnis zum Parti radical festlegte und danach auch die Position der SFIO gegenüber den Kommunisten bestimmte, zu einer Diskussion über die Parteistrategie.

1 Die Taktik der gemäßigten Opposition, d.h. die Neutralität, empfahl Léon Blum seiner Partei bereits auf dem Parteitag von Clermond-Ferrand, der vom 23.-26.5. 1926 stattfand. Jedoch rief dies sowohl den Widerspruch des rechten wie auch des linken Parteiflügels hervor, wenn dieser Protest auch unterschiedlich motiviert war. Denn der rechte Flügel wollte die Regierung unterstützen, während der linke Flügel sich für die offensive Opposition aussprach. Siehe hierzu die Berichte zum Parteitag in Le Populaire vom 23.-28. 5. 1926.

2 Immerhin galt Poincaré als Garant für die Währungsstabilisierung und die Wiederherstellung der französischen Staatsfinanzen. 
Diese Standortbestimmung schien nicht nur aus parteiinternen Gründen erforderlich, sondern sie war vor allem auch durch die Kritik des Parti radical und der Kommunisten an der SFIO notwendig geworden. Der Parti radical hatte, nachdem einige seiner Mitglieder dem Kabinett der Union nationale beigetreten waren, schwere innere Auseinandersetzungen und Spannungen zu überstehen ${ }^{3}$. Denn ein größerer Teil der Parteibasis wollte nach wie vor an einer linksrepublikanischen Cartelmehrheit festhalten. Da sich aber die Sozialisten nicht an Regierungen beteiligten und auch die kleineren Gruppierungen ${ }^{4}$ keine linksrepublikanische Mehrheit garantierten, zog der Parti radical besonders die Sozialisten für sein eigenes Dilemma zur Verantwortung und beschuldigte die SFIO, die Hauptschuld für das Scheitern des Cartelexperimentes zu tragen ${ }^{5}$.

Daß dieses Verhalten geradezu eine Reaktion herausforderte, lag auf der Hand. Blum widersprach der Ansicht des Parti radical und legte die Sichtweise der Sozialisten in einer Artikelserie des Populaire vom 31. Januar bis 20. Februar 19276 unter dem Titel „Les Radicaux et nous“ dar?.

Hier versuchte Blum, zunächst die Cartelerfahrung aus der Sicht der Sozialisten zu schildern. Der wichtigste Punkt bei dieser analytischen Rückschau schien für ihn zu sein, daß die Sozialisten nach der Wahl von 1924 nicht wirklich um eine Regierungsbeteiligung von Herriot gebeten worden seien, sondern vielmehr die Mehrheit der führenden Radicaux nur eine Regierungsunterstützung der Sozialisten gewünscht hätte. Blum unterstrich, daß die SFIO die Regierung Herriot trotzdem wie eine sozialistische Regierung verteidigt habe. Léon Blum war sich sehr wohl der vorhandenen programmatischen Divergenz zwischen den Radikalen und den Sozialisten bewußt. Er regte schließlich an, daß beide Parteien trotz der Divergenz der Ziele und der Widersprüche ihrer Doktrinen über eine Koordination ihrer Aktionen nachdenken sollten, da beide Parteien gemeinsame Gegner hätten. In einem Leitartikel vom 5. Februar 19278 unterließ es Blum nicht, trotz der zuvor geäußerten Gedanken über eine eventuelle Zusammenarbeit, eine deutliche Abgrenzung der Sozialisten vom Radikalsozialismus vorzunehmen. Denn Blum definierte den Radikalsozialismus als Repräsentant einer politischen Form, die sich durch langsame und fortlaufende Reformen auszeichne, während der Sozialismus der SFIO eine soziale Umwälzung verfolge, die nicht durch eine Reihe von Reformen erzielt werden könne. Summa summarum sah Blum durchaus im Einsatz für die politische Freiheit, die „pacification“ und die sozialen Reformen eine Möglichkeit zur Zusammenarbeit zwischen den Radikalsozialisten und den

3 Vgl. hier z. B. A.N., Paris, F/7/12955, vom Januar 1927, p. 2.

4 Besonders die Gauche radicale hatte immer wieder die Cartelmehrheit aufgebrochen. Vgl. hierzu besonders Fallbeispiel I.

5 Vgl. zur Kritik an den Sozialisten die verschiedenen Redebeiträge, vor allem die Ausführungen von Franklin-Bouillon, auf dem Parteitag des Parti radical vom 14.-17. 10. 1926, besonders L'Oeuvre vom 16. 10. 1926, S. $1 / 2$.

6 Die Gedanken Blums aus dieser Artikelserie wurden in seiner Schrift Radicalisme et socialisme, Paris 1936, zusammengefaßt.

7 Die verschiedenen Artikel, die Blum zur Frage des Verhältnisses zwischen SFIO und Parti communiste vom 13.-25. 3. 1927 im Populaire verfaßt hatte, erschienen später unter dem Titel „Bolchevisme et socialisme". Außerdem sind Blums Ansichten zum obigen Thema auch in der Ausgabe L'Oeuvre de Léon Blum, Bd. 3.1., Paris 1972, S. 451-460 enthalten.

\& Le Populaire vom 5. 2. 1927, S. 1. 
Sozialisten gegeben. Aber auch hier nahm der führende Sozialist gleichzeitig eine Einschränkung vor, indem er betonte, daß das, was für die Radikalsozialisten Ziel, den Sozialisten nur Anfang und Mittel sei 9 .

Blum nahm nicht nur eine Abgrenzung zu den Radikalsozialisten, sondern auch zwischen den Kommunisten und den Sozialisten vor. Das Verhältnis zwischen Kommunisten und Sozialisten wurde von Blum in einer Serie von Leitartikeln im März 1927 thematisiert. Blum konzentrierte sich dabei auf den in seinen Augen zentralen Unterschied zwischen Sozialismus und Bolschewismus, dem die Sozialisten 1920 nicht gefolgt seien, da es zu unüberwindbaren Differenzen hinsichtlich der Konzepte "Revolution und Diktatur" gekommen sei. Die Kommunisten betrachteten die Machteroberung (conquête du pouvoir) bereits als gesellschaftsverändernde Revolution. In den Augen Blums verwechselten sie dabei jedoch die Machteroberung mit der eigentlichen Revolution. Blum urteilte deshalb über die Kommunisten, daß sie das Mittel mit dem Ziel verwechseln würden. Andererseits, so Blum, erkläre dies die Taktik der Kommunisten, die ganz auf die Eroberung der Macht ausgerichtet sei ${ }^{10}$. Hierin sah Blum den fundamentalen Unterschied, denn für die Sozialisten war die Machteroberung nicht die soziale Revolution, sondern der Sozialismus verfolge die Strategie, zunächst die Basis für die sozialen Veränderungen zu schaffen. Nach Auffassung der Sozialisten müsse die Revolution erst in den Köpfen der Menschen vorbereitet werden. Einen weiteren wichtigen Unterschied führte Blum ins Feld: Während der Sozialismus die Gewalt ablehne, stelle für den Bolschewismus Gewalt das einzige Mittel zur Befreiung dar ${ }^{11}$. Dennoch gab Blum der Hoffnung Ausdruck, daß es zu einer Versöhnung zwischen den Sozialisten und Kommunisten kommen könne und letztere bereit sein würden, ihre Fehleinschätzung zu revidieren, um in die „vieille maison“ $z u$ rückzukehren ${ }^{12}$.

Mit dieser Abgrenzung nach beiden Seiten versuchte Blum, die Sozialisten für den Wahlkampf 1928 wieder in Form und auf eine Linie zu bringen. Ein Faktor, der wesentlich zu der Entscheidung beitrug, daß die SFIO den Wahlkampf 1928 unabhängig antreten sollte, war die berechtigte Hoffnung auf eine Änderung des Wahlmodus, die auch tatsächlich am 12. Juli 1927 im Parlament nach langwierigen Debatten verabschiedet wurde. Zusammen mit den Stimmen des Parti radical 13 konnten sie das "scrutin d'arrondissement " ${ }^{14}$ durchsetzen. Obwohl sich letztlich

9 Vgl. dazu Le Populaire vom 6. 2. 1927, S. 1.

10 Vgl. Le Populaire vom 16. 3. 1927 und vom 17. 3. 1927, jeweils S. 1.

11 Vgl. Le Populaire vom 25. 3. 1927, S. 1.

12 Vgl. Le Populaire vom 13. 3. 1927, S. 1.

13 Bereits im Vorfeld der Abstimmung trafen sich die sozialistische und die radikalsozialistische Fraktionsgruppe, um eine gemeinsame Taktik abzusprechen; siehe dazu A.N. Paris, Notes Jean F/ 7/12955 vom 27. 6. 1927. Vgl. hierzu auch das Abstimmungsergebnis zur Wahlrechtsreform vom 12. 7. 1927 in Le Temps vom 13. 7. 1927, S. 3, wobei Radikalsozialisten und Sozialisten zusammenarbeiteten. Die Wahlrechtsreform zugunsten eines scrutin d'arrondissement mit zwei Wahlgängen wurde mit $320 \mathrm{zu} 234$ angenommen.

14 Zur Diskussion um die Wahlrechtsreform und besonders zum scrutin d'arrondissement siehe A.N. Paris, Notes Jean F/7/12955 vom 20. 5. 1927 und vom 27. 6. 1927. Dieses Wahlsystem wurde 1928 eingeführt und bis zum Ende der Dritten Republik beibehalten. Vgl. dazu A. Cole/P. Campbell, French Electoral Systems and Elections since 1789, Aldershot 1989, S. 67-70; R. Huard, Le suffrage universel en France (1848-1946), Aubier 1991, S. 231-237. Besonders in Cartelkreisen wurde dieser Wahlmodus befürwortet, da man sich vor allem vom zweiten Wahlgang große Erfolge ver- 
auch innerhalb der SFIO eine Mehrheit für diesen Wahlmodus entschieden hatte, offenbarte auch diese Diskussion erneut die Heterogenität der SFIO. Es wurde evident, daß eine Überwindung der innerparteilichen Gegensätze in der sozialistischen Partei ein aussichtsloses Unterfangen war. Da war einmal der rechte Flügel, der sich zwar zahlenmäßig immer noch in der Minderheit befand, dem aber überwiegend Fraktionsmitglieder angehörten, deren Stimme großes Gewicht hatte. Auf der anderen Seite befand sich der linke Flügel, der sich entweder für ein unabhängiges Auftreten oder für eine Kooperation mit den Kommunisten aussprach. Als führende Stimme dieses Flügels trat Zyromski auf, der sich in diesen Jahren immer wieder als Widerpart zu Blum verstand. Auf dem Parteitag von 1927 führte die Debatte um die Neubestimmung des Wahlmodus immerhin dazu, daß vier verschiedene Anträge ${ }^{15}$ heftig diskutiert wurden. Nur durch das massive Eingreifen Blums konnte eine Kompromißlösung gefunden werden ${ }^{16}$.

In engem Zusammenhang mit der Frage nach dem Wahlmodus stand dann auch die Diskussion um die geeignete Wahltaktik für 1928. Aufgrund einiger Nachwahlen ${ }^{17}$ und der Diskussion um die Einhaltung der republikanischen Disziplin, dem sogenannten „désistement ${ }^{\text {" } 18}$, kam es innerhalb der SFIO schon während des Jahres $1927 \mathrm{zu}$ anhaltenden, heftigen Diskussionen, die bereits die Frage der Wahltaktik für 1928 vorwegnahmen. Für den ersten Wahlgang gab es keine Probleme, denn darüber bestand innerhalb der SFIO ein Konsens: Die sozialistische Partei wollte im ersten Wahlgang einen unabhängigen Wahlkampf führen. Jedoch im Hinblick auf den zweiten Wahlgang herrschte innerhalb der SFIO je nach Flügel ein gewisser Meinungspluralismus. Folgende verschiedene Möglichkeiten des désistement wurden diskutiert: Zum einen formulierte Blum die Richtlinie, daß im zweiten Wahlgang der Sieg über den "reaktionären“ Kandidaten absolute Priorität habe. Wobei Blum zu den „reaktionären“ Kandidaten all jene rechnete, die die Regierung Herriot 1925 bekämpft und in der Finanzfrage zu Fall gebracht hatten. Hinsichtlich der Frage, wie sich die SFIO verhalten solle, falls der sozialistische Kandidat auf Platz zwei hinter einem kommunistischen oder radikalsozialistischen Kandidaten kommen sollte, hielt Blum es für ratsam, keine allgemein verbindliche Regelung festzulegen, sondern diese Entscheidung in die Kompetenz der Föderationen zu legen.

Dieser Lösungsvorschlag Blums war jedoch sehr umstritten, wie sich bereits im Vorfeld des außerordentlichen Parteitages der SFIO herauskristallisiert hatte und

sprach. Die Gemäßigten hingegen bekämpften dieses Wahlprinzip und besonders den zweiten Wahlgang, da sie darin nur Vorteile für die Sozialisten zu erkennen glaubten.

$15 \mathrm{Zu}$ den vier verschiedenen Anträgen siehe den $24^{e}$ Congrès National in Lyon vom 17.-20. 4. 1927,

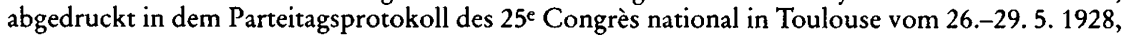
S. 5-11; Le Populaire vom 20. 4. 1927, S. $1 \mathrm{ff}$.

16 Antrag A entsprach dem Antrag, der von der linken Mitte (Faure, Longuet und Compère-Morel) bereits auf dem kleinen Parteitag der Föderation Seine eingebracht worden war und jedes Bündnis mit den Kommunisten und den Radikalsozialisten ablehnte, wobei sie mit letzteren ein temporäres gemeinsames Handeln akzeptierten; vgl. Le Populaire vom 17. 4. 1927, S. 1, 3.

17 Zu nennen ist hier z. B. die Nachwahl vom Juni 1927 im Département Aube, in der es über die Taktik des désistement zu größeren Auseinandersetzungen zwischen der $C A P$ und der Föderation Aube gekommen war; dazu ausführlich bei G. Ziebura, Blum, S. 380.

18 Das désistement gehörte zum Prinzip der „discipline républicaine"; es bedeutete, zugunsten des besser plazierten Kandidaten aus dem eigenen politischen Lager den eigenen Kandidaten im zweiten Wahlgang zurückzuziehen. 
besonders auf dem kleinen Parteitag der Föderation Seine am 18. Dezember 1927 offensichtlich geworden war, wo dieser Antrag Blums nur eine knappe Mehrheit der Stimmen auf sich vereinen konnte ${ }^{19}$.

Schließlich kam es Ende Dezember auf dem außerordentlichen Parteitag der SFIO, der vom 26. bis 29. Dezember 1927 stattfand, nach langen und heftigen Auseinandersetzungen, die mehrmals beinahe zum Bruch geführt hatten, immerhin zu einer recht knappen Mehrheit für die von Blum vorgeschlagene Lösung: „Deuxième Tour: Le Congrès fait confiance aux fédérations pour assurer le désistement au second tour, en faveur du candidat - à quelque formation politique qu'il appartienne qui a le plus de chances de battre la réaction, et d'une façon générale, pour prendre toutes les décisions nécessaires afin d'assurer l'échec de celleci $(\ldots .$.$) ." 20$

So konnte im Wahlkampf 1928 jede Föderation selbst entscheiden, wie sie die Praxis des désistement betrieb. Die Föderationen sprachen im zweiten Wahlgang an ihre Wähler mit den „Indications préférentielles"21 ihre Empfehlung aus. Die sonst größtenteils zentralistisch geführte Partei, die besonders bei Abstimmungen auf strenge Disziplin achtete, griff hier wiederum auf das ihr eigene dezentrale Element zurück ${ }^{22}$ und delegierte die Entscheidung an die einzelnen Föderationen, wie sie dies bereits im Wahlkampf von 1924 erfolgreich praktiziert hatte. Parteiintern war damit eine Lösung gefunden, die die Einheit der Sozialisten zu stärken schien. Extern hingegen wurde diese Lösung von den beiden Parteien, die sich auf dem linken Spektrum mit den Sozialisten messen mußten, unterschiedlich bewertet. Der Parti radical und die linksrepublikanische Presse nahmen die sozialistische Losung mit Wohlwollen auf; da sie aus dem Lager der linksrepublikanischen Kräfte als die aussichtsreichsten Kandidaten für den zweiten Wahlgang galten, hofften sie mit Hilfe der sozialistischen Wählerstimmen im zweiten Wahlgang gegen die konservativen Bewerber zu reüssieren ${ }^{23}$.

Die Kommunisten hingegen reagierten auf die sozialistische Entscheidung sehr enttäuscht und nutzten jede Gelegenheit, die SFIO zu attackieren. Denn sie hatten den Sozialisten erneut vorgeschlagen, gemeinsam in Form einer Einheitsfront ${ }^{24}$ bei den Wahlen von 1928 anzutreten. Dieses Angebot hatte eindeutig taktischen Charakter, denn es war so konzipiert gewesen, daß die Sozialisten es nur ablehnen konnten. Eine weitere Möglichkeit, die die Kommunisten sofort wahrnahmen, um die sozialistische Partei anzugreifen, bot ihnen die Rede Poincarés am 25. März 1928, in der dieser der SFIO wohlwollend bescheinigte, daß ihre Frak-

19 Vgl. dazu Le Populaire vom 19. 12. 1927, S. 1, 4.

20 Zur Resolution Blums für die Wahltaktik im ersten und zweiten Wahlgang siehe Le Populaire vom 30. 12. 1927, S. 1.

21 Auf dem außerordentlichen Parteitag der SFIO in Paris vom 26.-29. 12. 1927 kam es erneut zu heftigen Auseinandersetzungen über die Wahltaktik. Trotz einer sehr kontroversen Debatte konnte sich der Antrag Blums, der diesen Terminus beinhaltete, knapp behaupten. Dieser fand dann auch Eingang in die Wahlbroschüre "Notre tactique électorale pour les élections législatives de mai 1928“, Paris 1928. Zur Resolution Blums auf dem außerordentlichen Parteitag von 1927 siehe den $25^{\mathrm{e}}$ Congrès National 26.-30.5. 1928 in Toulouse, Paris 1928, S. 17.

22 Vgl. hier Teil A dieser Arbeit: Zur Parteientypologie der SFIO.

23 Gustave Téry äußerte sich hierzu sehr positiv in L'Oeuvre vom 2. 1. 1928, S. 1.

24 Zum Wahlaufruf des Parti communiste an die SFIO für eine Einheitsfront siehe L'Humanité vom 29. 3. 1928, S. 2; vom 2. 4. 1928, S. 2 und vom 4. 4. 1928, S. 1. 
tion eine loyale Opposition betrieben habe. Die Kommunisten warfen daraufhin der SFIO vor, daß sie Opposition nur zum Schein exerziere ${ }^{25}$. Als deutlichstes Zeichen der Gegnerschaft gegenüber den Sozialisten und insbesondere gegen Blum, dem herausragenden sozialistischen Repräsentanten, kann sicherlich der Kampf um das Mandat im 20. Pariser Arrondissement angesehen werden. Die kommunistische Partei leistete der Wahl Blums in diesem Wahlbezirk erbitterten Widerstand. Schließlich gelang es ihr, daß der kommunistische Kandidat sich gegen Blum im zweiten Wahlgang bei den Wählern durchsetzen konnte ${ }^{26}$.

Die Wahl von 1928 kann für die SFIO weder als eine Niederlage noch als ein besonderer Erfolg gewertet werden. Die sozialistische Partei erzielte ungefähr das Wahlergebnis, das sie bereits 191927 erringen konnte, also vor der Trennung von 1920. Allerdings hatte sich ihr Wählerprofil etwas verändert. Sie verlor die großen Industriezentren und damit die Stimmen der Arbeiter an die Kommunisten. Dafür konnte die SFIO in Südfrankreich neue Wähler hinzugewinnen ${ }^{28}$. Das bedeutete, daß die SFIO zum größten Konkurrenten des Parti radical im Kampf um die Wählerstimmen in der südfranzösischen Bauernschicht geworden war. Für die Zusammensetzung der sozialistischen Fraktion im Parlament hatte sich durch die Wahlen von 1928 eine zahlenmäßige Verschiebung in den Stärken der beiden Flügel ergeben. Der rechte Flügel der SFIO wurde größtenteils wiedergewählt und erhielt zusätzlich neue Abgeordnete. Damit hatte dieser Flügel, der sich dezidiert für die Übernahme von Regierungsverantworrung aussprach, parteiintern einen neuen Aufschwung erhalten und sich auch vergrößert. Diese Entwicklung sollte schon bald zu neuen Konflikten führen.

Wahlgewinner waren die politischen Kräfte der Rechten und der rechten Mitte, jedoch konnte auch der Parti radical durch den zweiten Wahlgang und das désistement der Sozialisten zugunsten des Parti radical eine beträchtliche Anzahl an Abgeordnetensitzen ${ }^{29}$ erringen. Durch diese beiden Faktoren, einmal die Erstarkung

25 Vgl. die harten Attacken der Kommunisten gegen die SFIO in: L'Humanité vom 26. 3. 1928, S. 1. Darin ein Zitat aus der Rede Poincarés: „Nous avions encore une opposition loyale qui, sans abandonner ses doctrines et sans jamais nous donner ses voix (...)." Dieses Urteil Poincarés nutzte der Parti communiste, um propagandistisch gegen die SFIO vorzugehen. Die Kommunisten verwendeten für ihre Propagandazwecke ein weiteres Zitat aus der Rede Poincarés, das den Parti communiste ursprünglich sehr belastete: „Nous n'avons eu aussi une opposition quotidienne et brutale, organisée non sans habileté, par la fraction communiste et faite surtout de surenchères systématiques." Die Kommunisten kolportierten dieses Zitat, um ihre Bedeutung als einzig wahre Oppositionspartei zu unterstreichen und um sich gegen die in ihren Augen verräterische $S F I O$ abzuheben.

26 Vgl. die erbitterte Propaganda gegen Blum, die so weit führte, daß seine Wahlveranstaltungen von Kommunisten gestört und gesprengt wurden, in L'Humanité vom 15.-29. 4. 1928. Der kommunistische Kandidat Duclos konnte sich im ersten Wahlgang mit 7714 und im zweiten Wahlgang mit 8199 Stimmen durchsetzen und somit die Wahl im 20 . Arrondissement für sich entscheiden.

27 Zum Vergleich siehe das Wahlergebnis von 1919 bei G. Lachapelle, Elections législatives du 16 novembre 1919, résultats officiels, Paris 1920; E. Bonnefous, Histoire politique, vol. 3, S. 69-71. Die Sitzverteilung im Parlament sah demnach folgendermaßen aus: Conservateurs 111 Parlamentssitze, Républicains de gauche 139, Républicains progressistes 126, Radicaux et radicaux-socialistes 138, Républicains socialistes 30 und SFIO 72 Sitze.

28 G. Lachapelle, Élections législatives 22-29 avril 1928. Résultats officiels, Paris 1928, hier besonders S. X. Die Radikalen konnten 123 und die Sozialisten 101 Sitze erringen.

29 Im zweiten Wahlgang gingen die Radikalen mit den Républicains socialistes und der SFIO in vielen Wahlbezirken ein Bündnis ein. Nur die Kommunisten beteiligten sich nicht an den Linksbündnissen und stellten ihre Kandidaten auch im zweiten Wahlgang allein auf. Es stimmten jedoch viele 
des rechten Flügels der $S F I O$ und zum anderen das trotz der Verluste ${ }^{30}$ relativ gute Abschneiden der Radikalen im zweiten Wahlgang, erhielt die Forderung nach einer linksrepublikanischen Kooperation erneut große Resonanz. Die Jahre von 1928 bis zum Beginn des Jahres 1932 waren vor allem geprägt von einem steten Ringen zwischen dem rechten Flügel der SFIO, der eine linksrepublikanische Mehrheit im Parlament befürwortete, und dem linken Flügel der SFIO, hier allen voran Léon Blum, der stets versuchte, die SFIO auf einem Kurs zu halten, der in erster Linie die Interessen der Partei zu wahren versprach ${ }^{31}$. Man kann von regelrechten Wellenbewegungen bezüglich dieser Thematik sprechen. Obwohl der linke Flügel des Parti radical zusammen mit dem rechten Flügel der SFIO durch die ihnen nahestehende Presse ${ }^{32}$ versucht hatte, den Boden für eine linksrepublikanische Mehrheit im Parlament zu bereiten, wehrte sich vor allem Léon Blum gegen diese Bestrebungen. Zur ersten größeren Auseinandersetzung zwischen den Flügeln kam es bereits im Juni/Juli 1928. Der linke Flügel des Parti radical warf dem sozialistischen Sprecher, Léon Blum, vor, durch seinen Einfluß auf die sozialistische Partei ${ }^{33}$ eine linksrepublikanische Mehrheit im Parlament zu vereiteln und damit gleichzeitig die Stabilität der Union nationale zu festigen ${ }^{34}$. Der angegriffene Blum hingegen beurteilte die politische Situation im französischen Parlament vollkommen gegensätzlich. Er forderte den Parti radical auf, aus der Koalition mit der Union nationale auszutreten und zusammen mit den Sozialisten zunächst eine solide Basis für eine starke gemeinsame Opposition zu schaffen, denn eine stabile linksrepublikanische Mehrheit konnte er zu diesem Zeitpunkt im Par-

Wähler, die im ersten Wahlgang noch für die Kommunisten gestimmt hatten, im zweiten Wahlgang für die Kandidaten der Sozialisten oder der Radikalsozialisten. Durch dieses indirekte Wahlbündnis bzw. durch die Politik des désistement im zweiten Wahlgang konnten 87 Kandidaten der Radikalsozialisten und 63 der Sozialisten die absolute Mehrheit erringen. Z.B. konnten sich in den Wahlkreisen Basses-Pyrénnés/Bayonne, in Somme/d'Abbeville und in Tarn-et-Garonne/Moissac jeweils die radikalsozialistischen Kandidaten durch den Rückzug des sozialistischen Mitstreiters durchsetzen. Vgl. dazu auch G. Lachapelle, Élections legislatives 1928, S. VI. und Le Temps vom 1. 5. 1928, S. $1-5$.

30 Insgesamt gesehen hatte der Parti radical 1928 einige Sitze im Vergleich zu 1924 verloren: 1924 konnten die Radikalsozialisten noch 139 Sitze erringen, während sie 1928 nur noch 123 Mandate erhielten.

31 So äußerte sich Blum unmittelbar nach der Wahl von 1928 in unmißverständlichem Ton, daß sich angesichts der Zusammensetzung des neu gewählten Parlaments sicherlich eine Politik des Bloc national durchsetzen werde und aus diesem Grund für die SFIO nur die Opposition in Frage komme; vgl. Le Populaire vom 4. 5. 1928, S. 1 und vom 8. 5. 1928, S. 1: „Nous devons maintenir le socialisme dans sa ligne doctrinale. “ Zur Position Blums siehe außerdem G. Ziebura, Blum, S. 388390.

32 Allen voran ist die Zeitung La Volonté zu nennen, die im August eine große Umfrage startete, um die Möglichkeiten einer neuen Mehrheit zu sondieren. Außerdem beschäftigten sich mit diesem Thema auch L'Oeuvre, La Lumière und L'Ere nouvelle.

33 A.N. Paris, Notes Jean F/7/12956/2 vom 8. 8. 1928. In diesem Dokument wird berichtet, daß die Kampagne Blums gegen den Parti radical in Pressekreisen sehr stark kritisiert worden ist. Außerdem zeichnete sich ab, daß der zahlenmäßig kleinere rechte Flügel der SFIO sich den Direktiven Blums widersetzen würde.

34 Zur Kritik am politischen Verhalten Blums aus Kreisen des Parti radical vgl. L'Ere nouvelle vom 9. 6. 1928, S. 1; hier wurde deutlich gemacht, daß programmatische Konvergenzen zwischen Parti radical und $S F I O$ vorhanden waren: „En politique extérieure, en politique sociale, le programme radical peut être accepté par n'importe quel membre du parti SFIO (...); dazu außerdem L'Ere nouvelle vom 14.6. 1928 und vom 17.6. 1928 sowie L'Oeuvre vom 8. 6. 1928; vom 11.6. 1928 und vom 14. 6. 1928, jeweils S. 1. 
lament nicht erkennen ${ }^{35}$. Vielmehr sah er unter den aktuellen Verhältnissen als Alternative zur Union nationale bestenfalls eine Mehrheit der concentration, die sich von der rechten Mitte bis zu den Sozialisten hätte erstrecken müssen. Eine Kooperation mit der rechten Mitte konnte Blum für die SFIO nicht akzeptieren. Eher empfahl er dem Parti radical, sich wieder mehr auf seine programmatischen Grundwerte zu besinnen und sich aus der Union nationale zu befreien. Die Radikalen hingegen drehten den Spieß um und argumentierten, daß eine Abkehr der Sozialisten von der Oppositionsrolle und Hinwendung zur linksrepublikanischen Kooperation sie vielmehr stärken und ihnen eine neue Dynamik verleihen würde ${ }^{36}$. Als die Radikalen auf ihrem legendären Parteitag in Angers im Oktober $1928^{37}$ den Beschluß faßten, ihre Minister aus dem Kabinett der Union nationale abzuberufen ${ }^{38}$, mußte die Regierung Poincaré am 6. November 1928 demissionieren $^{39}$. Durch diese Wende verstärkte sich der Druck auf die Sozialisten und die Diskussion um eine linksrepublikanische Mehrheit wurde heftiger denn je. Die darauffolgende Zeit kann als eine Auseinandersetzung zwischen dem Parti radical und der SFIO bezeichnet werden, die vor allem auch von der Krise des Parti radi$\mathrm{cal}^{40}$ geprägt wurde. Obwohl durch das Handeln des Parti radical Bewegung in die Diskussion um eine neue Kooperation zwischen Parti radical und SFIO gekommen war, stellte sich Blum gegen eine Zusammenarbeit mit dem Parti radical, die vom rechten Flügel der SFIO angestrebt wurde. Léon Blum führte für seine ablehnende Haltung zwei Gründe an: Erstens zweifelte er nach wie vor an der Möglichkeit einer stabilen Linksmehrheit im Parlament, und zweitens sah er eine zu große Konkurrenz zwischen dem Parti radical und der SFIO auf dem linken Parteienspektrum, wobei er dafür hauptsächlich die Profilkrise des Parti radical verantwortlich machte. Diese Argumentation schien sich für Blum im April 1929 zu bestätigen, als in Narbonne durch den Tod eines sozialistischen Abgeordneten eine Nachwahl notwendig geworden war ${ }^{41}$. Obwohl Narbonne als sicherer Wahlkreis der Sozialisten galt, stellte auch der Parti radical einen Kandidaten bei dieser Wahl auf. Nachdem die rechten Parteien keinen eigenen Vertreter präsentierten, unterstützten sie die Wahl des radikalsozialistischen Repräsentanten. Natürlich

35 Vergleiche die Artikel Blums zu diesem Thema in Le Populaire vom 9.6. 1928; 10.6. 1928; 12.6. 1928 und 13.6. 1928 sowie vom 1.7.1928; 11.-14. 7. 1928; und vom 20. 7. 1928, jeweils S. 1.

36 Vgl. z. B. Pierre du Clain in La Lumière vom 28. 7. 1928, S. 1.

37 Zum Parteitag vom 3.-5. 11. 1928 siehe die Parteitagsberichte in L'Oeuvre vom 3.-6.11. 1928 und die Parteitagsprotokolle von 1928 des $25^{\circ}$ Congrès du Parti républicain radical et radical-socialiste tenu à Angers les 3, 4 et 5 novembre 1928.

38 Obwohl die Mehrheit der Parteitagsdelegierten bereits abgereist war, berief Caillaux nochmals eine Sitzung ein, auf der eine Deklaration verabschiedet wurde, die festhielt, daß das Programm des Parti radical mit dem Kabinett der Union nationale nicht mehr vereinbar sei und deshalb die radikalsozialistischen Minister aus dem Kabinett Poincarés auszuscheiden hätten. Daraufhin traten Herriot, Sarraut, Queuille und Perrier als Minister zurück. Zu dieser umstrittenen Aktion siehe S. Berstein, Parti radical, vol. 2, S. 70-80 und auch Teil A dieser Arbeit. Zu den Vorgängen auf dem Parteitag in Angers vom Oktober 1928 und dem Rücktritt des Kabinetts Poincaré siehe A.N. Paris, Notes Jean F/7/12956/2 vom 6.11. 1928; Le Temps vom 7. 11. 1928, S. 1, 7.

39 Zum Rücktritt Poincarés siehe Le Temps vom 7.11. 1928, S. 6 und vom 8. 11. 1928, S. 1/2.

to Siehe dazu den nächsten Unterpunkt: Der Parti radical in den Jahren 1927 bis 1932.

41 Zu dieser Nachwahl siehe G. Ziebura, Blum, S. 393 f.; vgl. dazu auch die Diskussion darüber in der linksrepublikanischen Presse: Le Populaire vom 4. 3. 1929; 16. 3. 1929; 17. 3. 1929 und vom 18.3. 1929 sowie vom 10. 4. 1929; 11. 4. 1929; 14. 4. 1929 und 15. 4. 1929. Ebenso L'Oeuvre vom 29. 3. und 30. 3. 1929 sowie vom 4.-6. 4. 1929. 
führte das Verhalten des Parti radical bei den Sozialisten zu großen Irritationen und zeigte außerdem, daß beide Parteien zunehmend die gleichen Wählerschichten ansprachen. Blum sah sich durch diesen $Z$ wischenfall mehr denn je in seiner Ansicht bestätigt, daß eine langfristige und dauerhafte Linksmehrheit mit den Radikalen im Parlament nicht angezeigt sei, da sich der Parti radical durch die heftige Konkurrenz zwischen Parti radical und SFIO langfristig in die Mitte bzw. bis hin in die rechte Mitte bewege ${ }^{42}$, was er für einen großen politischen Fehler hielt. Blum unterstrich diese Position nochmals ausdrücklich in einer Rede in Carcassonne am 20. Oktober 192943: „C'est le phénomène le plus important de ces dernières années, mais est-ce que, le radicalisme croit pouvoir se défendre contre cette fatalité, en organisant contre nous le front unique de toutes les réactions et toutes les forces de réaction? Croit-il que ce sera par cette tactique qu'il pourra se sauver? Non! Il se condamne à mort, il ne peut se sauver que par la tactique contraire, et si vous regardez les dernières statistiques électorales, vous verrez qu'en même temps que le radicalisme subissait des pertes venant de nous, il réalisait des gains venant de l'est et de l'ouest dans des pays où il avait pris figure républicaine et laïque (...). Les radicaux se sont rendus compte que, dans l'état présent des choses, ce qu'on appelle la concentration à gauche, la concentration à droite, la concentration au centre, c'était tout bonnement l'Union nationale reconstituée et que ce ne pouvait être autre chose, car la concentration, c'est l'Union nationale sans M. Marin (...). “44

Obwohl sich der Parti radical nach dem Bruch mit dem Kabinett Poincaré teilweise oppositionell verhielt, konnte keine Linksmehrheit konstituiert werden. Nach verschiedenen Regierungswechseln von der rechten Mitte über eine Regierung der concentration unter Briand kam es schließlich am 2. November $1929 \mathrm{zu}$ einem sehr konservativen Kabinett Tardieu. Diese Entwicklung ließ die Kritik des Parti radical an der sozialistischen Partei nochmals heftig anschwellen ${ }^{45}$, und dies blieb nicht ohne Folgen.

Innerhalb der SFIO war es bereits im Herbst $1929 \mathrm{zu}$ einer ernsthaften Krise zwischen dem rechten und dem linken Flügel gekommen. Nachdem die Regierung Briand am 22. Oktober 1929 zurücktreten mußte $e^{46}$, wurde Daladier beauftragt, eine Regierung zu bilden. Er versuchte, mit Hilfe der Sozialisten dieser Auf-

42 Die Äußerungen Blums über das Verhältnis der SFIO zum Parti radical sind abgedruckt in Le Populaire vom 21.-23. 4. 1929 sowie vom 25.-27. 4. 1929, jeweils S. 1.

43 Zum Wortlaut dieser Rede siehe Le Populaire vom 22. 10. 1929, S. $1 / 2$.

44 Le Populaire vom 22. 10. 1932, S. 2.

$45 \mathrm{Vgl}$. dazu Artikel aus verschiedenen radikalsozialistischen Presseorganen, die sich mit einer $\mathrm{Zu}$ sammenarbeit zwischen Parti radical und SFIO kritisch auseinandersetzen; so z. B. La Dépêche de Toulouse vom 27. 10. 1929 und 29. 10. 1929; L'Oeuvre vom 28. 10. 1929 sowie vom 30.-31. 10. 1929; L'Ere nouvelle vom 28. 10. 1929 und vom 30.-31. 10. 1929, jeweils S. 1.

46 Briand wurde wegen der Ergebnisse der Haager Konferenz gestürzt, zu diesen zuletzt Ph. Heyde, Das Ende der Reparationen, S. 49-54. Briand hatte, um einen Antrag von Montigny abzuwehren, die Vertrauensfrage gestellt. Letzterer hatte gefordert eine außenpolitische Diskussion für den 15. 11. 1929 anzuberaumen. Dieser Antrag wurde mit 287 zu 277 Stimmen angenommen. Es stimmten hauptsächlich die Radikalsozialisten und die Sozialisten dafür. Briand hatte eine vorzeitige Diskussion um die Haager Ergebnisse abgelehnt, weil die Verhandlungen noch nicht abgeschlossen waren. Mit einer verfrühten Diskussion im Parlament sah er sich seiner Autorität und der Verhandlungsmittel bei den noch ausstehenden Verhandlungen beraubt. Vgl. zum Abstimmungsverhalten J.O., Chambre des Députés vom 22. 10. 1929, S. 2976 und Le Temps vom 24. 10. 1929, S. 4. 
forderung nachzukommen und unterbreitete der sozialistischen Fraktion ein Regierungsangebot, das diese nach langwierigen Debatten ${ }^{47}$ annahm.

Diese Antwort zog eine tiefe innerparteiliche Auseinandersetzung bei den Sozialisten nach sich. Der bereits seit längerem anhaltende Konflikt zwischen dem obersten Kontrollorgan der sozialistischen Partei, dem Comité administrative permanente $(C A P)$, und der Fraktion, brach erneut hervor. Im einberufenen Nationalrat kam es zu einem erbitterten Schlagabtausch zwischen den Anhängern und den Gegnern der Regierungsbeteiligung. Bracke, der als Sprecher der Gegner einer Regierungsbeteiligung auftrat, führte vor allem ins Feld, daß die Außenpolitik Briands nicht mit den außenpolitischen Überzeugungen der Sozialisten übereinstimme. Für noch sehr viel schwerwiegender hielt er, daß sich seiner Meinung nach eine Regierung aus Parti radical und SFIO im Parlament nicht als mehrheitsfähig erweisen würde ${ }^{48}$. Dem hielt Paul-Boncour stellvertretend für die Befürworter einer Regierungsbeteiligung entgegen, daß man eine Ablehnung der Regierungsbeteiligung gegenüber der eigenen Wählerklientel und der der Radikalsozialisten nicht verantworten könne. Außerdem könne die SFIO nur in der Regierungsverantwortung wirklich gestalterisch tätig sein. Ein Scheitern dieses Experimentes würde auch sehr große taktische Vorteile für die Sozialisten mit sich bringen ${ }^{49}$. Der Nationalrat wurde am 28. Oktober 192950, also unmittelbar nach dem Angebot Daladiers an die sozialistische Fraktion, einberufen. In der Geschichte der SFIO stellte das Abstimmungsergebnis der Fraktion eine Sensation dar, denn seit der Union sacrée ${ }^{51}$ war es nicht mehr zu einer Zusage für eine Regierungsbeteiligung gekommen. Wie nicht anders zu erwarten war, begegneten sich auf der Sitzung des Nationalrates zwei geschlossene Fronten. Nach hartnäckigen Auseinandersetzungen wurde zwischen dem Antrag des rechten Flügels ${ }^{52}$ und dem Antrag des linken Flügels ${ }^{53}$ abgestimmt. Das oberste Parteigremium CAP, das sich überwiegend aus Mitgliedern des linken Flügels zusammensetzte, votierte, wenn auch nur mit knapper Mehrheit, für die Ablehnung. Dennoch fügte sich der rechte Flügel nur sehr schwer in diese Entscheidung und warf dem Vorsitzenden der CAP Manipulation bei der Stimmauszählung und damit Verfälschung des Er-

47 Qualitativ war in der SFIO-Fraktion eine Mehrheit für die Regierungsbeteiligung vorhanden. Diese Gruppe verstand es, die Mehrheit der Fraktion auf ihre Seite zu ziehen. So blieb Blum, der als Gegner auftrat, mit einer Minderheit in der Fraktion zurück. Letztlich einigte sich der Exekutivausschuß der Fraktion mit 36 zu 12 Stimmen, das Angebot Daladiers anzunehmen, und forderte die CAP auf, den Nationalrat einzuberufen. Ausführlich zu diesen Vorgängen in A.N. Paris, Notes Jean F/7/12957 vom 25. 10. 1929; G. Ziebura, Blum, S. $397 \mathrm{ff} . \mathrm{Zu}$ den parteiinternen Auseinandersetzungen der SFIO siehe Le Populaire vom 28.-30. 10. 1929; dazu auch die Berichte in L'Oeuvre vom 27.-28. 10. 1929 und vom 30. 10. 1929, jeweils S. 1, 3 .

48 Ebenda.

49 Ebenda.

so Ausführliches zu den Debatten zwischen Befürwortern und Gegnern der Regierungsbeteiligung in der SFIO in Le Populaire vom 29.-30. 10. 1929, jeweils S. 1.

51 Der Begriff der Union sacrée tauchte in Le Temps am 4. 8. 1914 erstmals auf und drückte den Konsens bzw. die Koalition aller im Parlament vertretenen Parteien einschließlich der Sozialisten aus. Zum Begriff und Inhalt zuletzt Th. Raithel, Das ,Wunder" der inneren Einheit. Studien zur deutschen und französischen Öffentlichkeit bei Beginn des Ersten Weltkrieges, Bonn 1996, S. 284 ff.; S. $475 \mathrm{ff}$.

52 Zum Textlaut des Antrages von Renaudel siehe Le Populaire vom 30.10. 1929, S. 2 und L'Ere Nouvelle vom 30. 10. 1929, S. 3.

53 An diesem Antrag haben Faure und Bracke mitgearbeitet, zum Textlaut siehe ebenda. 
gebnisses vor ${ }^{54}$. Diese äußerst umstrittene Entscheidung offenbarte deutlich, daß die sonst so große innere Stärke der sozialistischen Partei, nämlich die Einhaltung der Disziplin, ernsthaft gefährdet war. Allein schon das Vorgehen der Fraktion im Vorfeld der Nationalratssitzung machte deutlich, daß die Fundamente der innerparteilichen Ordnung stark erschüttert waren, denn die Fraktion hatte sich mit ihrem Votum für das Angebot Daladiers über die bindende Kraft des Parteitagsbeschlusses hinweggesetzt, die ebenso wie die Disziplin zu den unumstrittenen Grundprinzipien der SFIO zählte und als konstitutiv für die sozialistische Einheit galt.

Der Widerstand des rechten Flügels der SFIO gegen die Ablehnung einer Regierungsbeteiligung hielt weiterhin an. Vertreter des rechten Flügels forderten die Einberufung eines außerordentlichen Parteitages, um auf diesem Forum über die umstrittene Entscheidung nach innerdemokratischem Prinzip diskutieren zu können. Das Kräftemessen zwischen der Fraktion und der CAP setzte sich auch in der Diskussion über die Festlegung des Termins für den einzuberufenden Parteitag fort. Die CAP, die den Termin festzulegen hatte, versuchte ein spätes Datum auszuwählen, da sie die Hoffnung hegte, daß sich in der Zwischenzeit die erregte Stimmung wieder beruhigen würde. So setzte sie die Einberufung des außerordentlichen Parteitages auf Ende Januar 1930 fest und ordnete außerdem eine Diskussion über die „Charte du Parti“"55 an. Mit dieser weiteren Maßnahme versprach man sich, die Disziplin der sozialistischen Partei erneut zu gewährleisten und damit die sozialistische Doktrin wieder eindeutig vor der Taktik in den Vordergrund zu rücken.

Die SFIO handelte sich mit dieser Absage an Daladier nicht nur innerparteiliche Spannungen, sondern ebenso heftige Vorwürfe des Parti radical ein, denn die Radikalsozialisten lasteten den Sozialisten an, daß sie durch ihr ablehnendes Verhalten die Regierungsbildung Tardieus zu verantworten hätten ${ }^{56}$. Blum, der wiederum als Sprecher der SFIO auftrat und die getroffene Entscheidung der Sozialisten rechtfertigte, unterstrich die Richtigkeit der Ablehnung, denn unter den gegebenen Umständen wäre eine mehrheitsfähige Regierung nur auf einer Basis der concentration möglich gewesen. Und dies hätte bedeutet, daß sie mit ihrer Unterstützung eine Regierung der concentration konsolidiert hätten, die sie bisher immer abgelehnt hatten. Damit hätten sie nicht nur leichtfertig einen wesentlichen Aspekt der sozialistischen Programmatik aufgegeben, sondern darüber hinaus wäre es auch zu einer Verwischung der Parteiprofile zwischen Parti radical und SFIO gekommen ${ }^{57}$. Eine Bestätigung seiner Argumentation sah Blum darin, daß die Regierung Tardieu eine breite Mehrheit hinter sich vereinigen konnte, da die-

54 Besonders Jules Moch, Anhänger des rechten Flügels, äußerte sich sehr kritisch gegenüber Jean Lebas, der seiner Meinung nach bei der Auszählung nicht korrekt verfahren war, in La Lumière vom 9. 11. 1929. Ausführlich zu diesen Auseinandersetzungen bei G. Ziebura, Blum, S. 400-403, besonders S. 400 f., Anm. 16.

55 Die Charte du Parti wurde auf dem Gründungsparteitag am 23. 4. 1905 vorgelegt und verabschiedet. Sie stellte eine Grundsatzerklärung der sozialistischen Kräfte dar, die sich 1905 auf dieser Basis zu einer Partei zusammengeschlossen hatten; vgl. L'Humanité vom 24. 4. 1905, S. 1.

56 Vergleiche hier z.B. L'Oeuvre vom 4. 11. und 7. 11. 1929, jeweils S. 1.

57 Le Populaire vom 31.10. 1929. Weitere Ausführungen Blums zur Rechtfertigung der sozialistischen Entscheidung in Le Populaire vom 10.-12.11. 1929, jeweils S. 1. 
ser von der Mitte ${ }^{58}$ bis zur linken Mitte ${ }^{59}$ Unterstützung erhielt. Für ein Kabinett, bestehend aus Radikalsozialisten und Sozialisten, konnte Blum in der aktuellen politischen Situation im Parlament definitiv keine Mehrheit erkennen.

Wie wichtig dieser außerordentliche Parteitag für beide Tendenzen der SFIO zu sein schien, zeigen die ausführlichen Debatten im Vorfeld dieses Parteitages, die in der sozialistischen Parteizeitung Le Populaire ausgetragen wurden. Zunächst erschienen hier im Dezember ausführliche Stellungnahmen des linken Parteiflügels, auch Blum sprach sich gegen eine Regierungsbeteiligung aus und wies alle persönlichen Angriffe entschieden zurück. Ab Januar 1930 konnten die Befürworter der Regierungsbeteiligung ihre Argumente ins Feld führen, allen voran Renaudel, der gleich mit einem Leitartikel am 1. Januar 1930 die Kampagne der „Participationnistes" eröffnete und dabei zur Legitimierung der Regierungsbeteiligung auf Kautsky verwies und zahlreiche Beispiele der europäischen sozialistischen Schwesterparteien und deren erfolgreicher Regierungsbeteiligungen anführte ${ }^{60}$. Ihren Argumenten standen die Anschauungen der "Antiparticipationnistes“, die Zyromski repräsentierte, entgegen. Renaudel bezog dazu ebenfalls in Le Populaire ${ }^{61}$ Stellung.

Ebenso wurden wie stets im Vorfeld von Parteitagen auch in den einzelnen Föderationen kleine Parteitage abgehalten, um eine gewisse Vorentscheidung zu treffen. Obwohl in den Föderationen stark für die Regierungsbeteiligung geworben worden war, zeichnete sich bei den Abstimmungen in den einzelnen Föderationen ein leichter Vorteil für die Gegner ab ${ }^{62}$. Dennoch war deutlich erkennbar, daß die stets heftig verteidigte Einheit der SFIO sehr stark gefährdet war. Entsprechend der Diskussionen, die bereits im Vorfeld des am 25. und 26. Januar 1930 abgehaltenen Parteitages stattgefunden hatten, begegneten sich beide Lager äußerst aufgeregt und angespannt. Es kam zu zwei größeren Auseinandersetzungen auf dem außerordentlichen Parteitag, auf dem jeder der beiden Flügel mit den ihm zur Verfügung stehenden Mitteln bis aufs äußerste für seine Position kämpfte. Auslöser für die fundamentale Auseinandersetzung war ein Antrag von Ramadier ${ }^{63}$ und Déat, die sich für eine Regierungsbeteiligung einsetzten. Sie forderten, daß gemäß den jetzigen innerparteilichen Verhältnissen eine neue Mandatsverteilung innerhalb der führenden Parteigremien auf dem nächsten ordentlichen Parteitag erfol-

58 Zum Abstimmungsergebnis vom 8. 11.1929 siehe Le Temps vom 10. 11. 1929, S. 4. Die Regierung Tardieu wurde mit 332 zu 253 Stimmen bestätigt. Aus der Mitte erhielt Tardieu Unterstützung von den parlamentarischen Gruppen Indépendants de gauche und Gauche radicale. Für Tardieu und sein Kabinett stimmten 18 Démocrates populaires, 100 Anhänger der Union républicaine démocratique, 29 der Action démocratique et sociale, 65 Républicains de gauche, 13 Vertreter der Gauche sociale et radicale, 44 der Gauche radicale, 7 Indépendants de gauche, 10 Républicains socialistes und 38 Députés indépendants.

59 Selbst die Républicains socialistes stimmten für die konservative Regierung Tardieu.

60 Vgl. Le Populaire vom 1.1. 1930, S. 1; vom 3. 1. 1930, S. 1; vom 4. 1. 1930, S. 1/2; vom 5. 1. 1930, S. 1; vom 6.1.1930, S. 1/2; vom 7.1. 1930, S. 1/2; vom 8. 1. 1930, S. $1 / 2$.

61 Vgl. die Artikel von Zyromski in Le Populaire vom 10.1. 1930, S. 1/2 und vom 13. 1. 1930, S. 1.

62 Siehe die Abstimmungstabelle mit den einzelnen Ergebnissen aus den Föderationen im Vorfeld des Parteitages der SFIO von 1930 in G. Ziebura, Blum, S. 412. Die Ergebnisse liegen auch in Le Populaire vom 13.1. 1930, S. 2, vom 14. 1. 1930, S. 2, vom 15. 1. 1930, S. 2, 5, vom 20. 1. 1930, S. 2, vom 21. 1. 1930, S. 2 vor.

63 Zum Resolutionsantrag von Ramadier siehe Le Populaire vom 26.1. 1930, S. 1. Diesen Antrag unterstützten auch Renaudel und Paul-Boncour. 
gen müsse. Durch diesen Vorstoß versprach sich der rechte Flügel eine Stärkung seines Einflusses innerhalb der Partei. Außerdem zeigt er, daß der rechte Flügel seinen Einfluß nicht nur in der CAP, sondern auch in der Parteizeitung Le Populaire wie auch im Parteisekretariat zu verstärken hoffte. Die Vertreter des linken Flügels, Faure, Zyromski und Bracke, wandten sich entschieden gegen diese Forderung. Sie legten einen Resolutionsentwurf ${ }^{64}$ vor, in dem sie zwar die proportionale Vertretung in den verschiedenen Führungsgremien anerkannten, jedoch dabei das Parteisekretariat davon ausschlossen, da die unterschiedlichen Positionen beider Flügel eine Arbeit im Parteisekretariat unmöglich machen würden. Eine Rückkehr des rechten Flügels ${ }^{65}$ in das oberste Parteigremium CAP sollte erst auf dem nächsten ordentlichen Parteitag vollzogen werden. Die proportionale Besetzung sollte auf der Grundlage des Abstimmungsergebnisses des nächsten Parteitages erfolgen. Für den linken Flügel der SFIO stellte der Antrag des rechten Flügels eindeutig einen Verstoß gegen das Parteistatut dar, denn die Besetzung von Parteiführungsgremien konnte nur auf einem ordentlichen Parteitag durchgeführt werden ${ }^{66}$. Als beide Anträge zur Abstimmung kamen, setzte sich der Resolutionsentwurf des linken Flügels mit 2059 gegen 147967 Stimmen durch.

Das zweite Thema, über das die Partei eine Entscheidung zu treffen hatte, war die Frage der Regierungsbeteiligung. Hatte bereits der erste Antrag den Resolutionsausschuß polarisiert, so löste der zweite noch viel heftigere Reaktionen aus. Da es ausgeschlossen war, sich auf einen Text zu einigen, kam es zur Abstimmung über zwei Resolutionstexte. Der eine Antrag war von Lebas vom linken Flügel eingereicht worden und wurde zunächst mit einigen heftig diskutierten Korrekturen versehen, bis sein endgültiger Inhalt feststand. In diesem Antrag wurde der Entschluß des Nationalrates vom 29. Oktober 1929 bestätigt und gleichzeitig bekräftigt, daß die Partei bereit sei, die Regierungsverantwortung allein zu übernehmen, bzw. an einer Koalitionsregierung unter sozialistischer Führung teilzunehmen. Der Antrag lehnte aber eine Koalition in der laufenden Legislaturperiode ab, bzw. gestattete sie nur im Falle von „circonstances exceptionnelles fermement reconnues", die dann allerdings von einem Parteitag oder dem Nationalrat ausdrücklich als solche bezeichnet werden müßten.

Dem stand der Resolutionsantrag von $\mathrm{Kahn}^{68}$ gegenüber, der sich für eine Koalitionsregierung ohne Einschränkungen aussprach. Der Resolutionsantrag von Lebas obsiegte in der Auseinandersetzung mit 2066 gegen 150769 Stimmen. Obwohl sich der linke Flügel auch bei der zweiten Abstimmung durchsetzen konnte und das demokratische Mehrheitsprinzip in der Partei nach wie vor anerkannt wurde, betonte Déat, der sich bei diesem außerordentlichen Parteitag äußerst en-

64 Zum Text dieser Resolution siehe Le Populaire vom 26. und 27. 1. 1930, jeweils S. 1.

65 Der rechte Flügel hatte wegen Meinungsverschiedenheiten über das Regierungsangebot Daladiers nach dem Parteitag vom 9.-12.6. 1929 das oberste Parteigremium CAP unter Protest verlassen. Vgl. dazu Le Populaire vom 13.6. 1929, S. 5 und auch Le Populaire vom 16.6. 1929, S. 1.

$66 \mathrm{Vgl}$. zu den Parteistatuten der SFIO ausführlich: Teil A/ Kapitel III dieser Untersuchung.

67 Le Populaire vom 27. 1. 1930, S. 1.

68 Zum Antrag von Kahn siehe Le Populaire vom 26. 1. 1930, S. 3 und vom 27. 1. 1930, S. 2.

69 Dazu Le Populaire vom 27. 1. 1930, S. 1. Ausführlich zu den parteiinternen Kämpfen auf diesem außerordentlichen Parteitag in Le Populaire vom 26.-28. 1. 1930, jeweils S. 1, 2, 3 und G. Ziebura, Blum, S. 409-412. 
gagiert an die Spitze des rechten Flügel gesetzt hatte, nachdrücklich, daß die rechte Minderheit in der SFIO weiterhin an ihren Positionen festhalten werde ${ }^{70}$. Außerdem unterließ er es nicht, daran zu erinnern, daß in dem obersten Parteigremium $C A P$ nicht mehr alle Tendenzen zu Wort kämen und es somit zukünftig bei stark umstrittenen Themen nicht mehr als letztgültige Entscheidungsinstanz fungieren solle. Nachdem bisher nach einer Abstimmung ein Protest dieser Schärfe noch nicht geäußert worden war, zeigte dies deutlich, daß sich die Fronten innerhalb der Partei verhärtet hatten und die Einheit ernsthaft gefährdet war. Um nicht noch größeren Schaden entstehen zu lassen, denn Faure reagierte für den linken Flügel auf die Äußerungen Déats ziemlich scharf ${ }^{71}$, wurde der Parteitag unter größter Eile beendet.

Wie die verschiedenen Berichte der sozialistischen Presse ${ }^{72}$ im Anschluß an den außerordentlichen Parteitag zeigen, hat dieses Ereignis in der Partei Spuren hinterlassen, denn die Mehrzahl der Föderationen kritisierte das Vorgehen Déats. Obwohl die Stimmung sehr aufgewühlt war, hoffte man, sich auf die innerparteilichen Grundprinzipien rückbesinnen zu können.

Als äußerst wichtig und deshalb erwähnenswert gilt das Urteil des Sekretärs der Sozialistischen Arbeiterinternationale (SAI), Friedrich Adler. Auch er erklärte die Einheit der sozialistischen Partei als absolut notwendige Grundlage, um Regierungsverantwortung mit entsprechendem Erfolg übernehmen zu können. Deshalb verurteilte er das vehemente Auftreten des rechten Parteiflügels, denn nur wenn auch der linke Flügel von dieser Maßnahme überzeugt und bereit dazu sei, könne, so Adler, eine Regierungsbeteiligung erfolgversprechend verlaufen. Die generelle Frage nach der Übernahme der Regierungsverantwortung durch die Sozialisten im französischen Parlament schätzte Adler als eine Frage der Zeit ein, die sich schon bald für die SFIO stellen würde, denn für ihn ergab sich diese Fragestellung als logische Konsequenz aus dem parlamentarischen System ${ }^{73}$. Daß die aktuelle Situation noch keine zwingende Verpflichtung zu einer Koalitionsregierung für die Sozialisten darstellte, erklärte Adler damit, daß das parlamentarische System Frankreichs im Augenblick noch andere Möglichkeiten zulasse, um regierungsfähige Mehrheiten zu bilden. Allerdings verschwieg auch Adler in seiner Analyse nicht die vorhandenen Gefahren, die sich für die Sozialisten aus einer Regierungsbeteiligung fast zwangsweise ergeben könnten: Die politische Propagandakraft der SFIO würde bei Übernahme der Regierungsverantwortung nachlassen, wie sich das z.B. stark bei den Sozialdemokraten in der Weimarer Republik

70 Zum Protest Déats vgl. Le Populaire vom 27. 1. 1930, S. 1.

71 Faures rigorose Antwort auf Déats Manifest ist abgedruckt in Le Populaire vom 27. 1. 1930, S. 2: "J'ai été violemment ému et choqué par les termes et par le ton de ce document. Dans un sentiment d'amitié, nous vous avons déjà plusieurs fois tendu la perche. Vous vous en êtes saisié, mais ça a été pour nous l'assener sur la tête (...). Je m'autorise de cela pour vous rappeler, puisque vous m'y obligez, que si vous n'êtes pas à la $C A P$, c'est parce que vous ne l'avez pas voulu; si vous n'écrivez pas plus régulièrement dans le Populaire, c'est parce que vous ne voulez pas (...).“

72 Vgl. dazu G. Ziebura, Blum, S. 413, Anm. 47, wo er auf einen Querschnitt der Kommentare aus den Reihen der sozialistischen Presse verweist.

73 Gemeint ist damit, daß die SFIO als Mehrheitenbeschafferin um eine Regierungsbeteiligung nicht herumkommen werde, da eine linksrepublikanische mehrheitsfähige Regierung ohne die SFIO langfristig keine Stabilität besitzen würde. 
gezeigt habe ${ }^{74}$. Um diesem Dilemma zu entgehen, riet Adler den Sozialisten, mit einem ausgeprägten Klassenbewußtsein aufzutreten. Aber genau darin lag für die Sozialisten eine weitere Gefahr, denn ein starkes Klassenbewußtsein schränkte die Möglichkeit einer Koalitionsleitung mit linksrepublikanischen Kräften stark ein. Gleichzeitig würden sie damit einer Blockade des parlamentarischen Systems Vorschub leisten oder, laut Adler, den rechten politischen Kräften zur Macht verhelfen ${ }^{75}$.

Schon bald nach diesen schweren parteiinternen Auseinandersetzungen um die Regierungsbeteiligung und, damit verbunden, um die Rolle der SFIO im Parlament, änderten sich die politischen Verhältnisse in Frankreich. Die Regierung Tardieu wurde am 17. Februar 193076 gestürzt. Für die SFIO brach nun eine dritte Phase in diesem Zeitraum von 1927 bis 1932 an. Die sozialistische Partei mußte ihre Taktik erneut einer Korrektur unterziehen, d.h. sie wandte sich ab von der rigiden und hin zur defensiven Opposition und damit langsam wieder zur Unterstützungspolitik. Nach dem Sturz des Kabinetts Tardieu standen im französischen Parlament zwei Möglichkeiten zur Disposition. Zum einen konnte ein Kabinett der concentration, bestehend aus der rechten und linken Mitte und der Rechten um Marin, also unter Ausschluß der beiden Linksparteien SFIO und Kommunisten, gebildet werden. Zum anderen gab es die Alternative eines Kabinetts, bestehend ausschließlich aus Mitgliedern des Parti radical, das von den Sozialisten unterstützt wurde. Blum, dessen Position innerhalb der Partei nach dem letzten Parteitag zunächst eine starke Schwächung erfahren hatte, konnte sich nun erneut Gehör verschaffen und plädierte angesichts der beiden Möglichkeiten für ein Kabinett der Radikalen mit sozialistischer Unterstützung. Er begründete dies damit, daß ein Kabinett der concentration langfristig für die französische Demokratie von Schaden sei77. Es kam am 21. Februar 1930 zur Bildung eines Kabinetts unter der Führung von Chautemps, und obwohl die sozialistische Fraktion für diese Regierung stimmte ${ }^{78}$, betonte Blum, daß dies nur aus der aktuellen politischen $\mathrm{Si}$ tuation heraus zu verstehen sei, d.h. um eine Neuauflage einer Regierung Tardieu zu verhindern ${ }^{79}$.

Die Zeit von 1930 bis Anfang 1932 war von zwei großen Entwicklungstendenzen geprägt: Zum einen fand eine weitere Polarisierung des Parteiensystems im französischen Parlament statt; dabei zeichnete sich immer mehr die Entwicklung

74 Die SPD zog sich zum ersten Mal nach dem desaströsen Wahlergebnis der „Weimarer Koalition“ am 6. 6. 1920 aus der Regierungsverantwortung zurück. Die "Weimarer Koalition“ konnte nur noch 44 Prozent der Stimmen erhalten, während sie bei der Wahl zur Nationalversammlung 78 Prozent der Wählerstimmen auf sich vereinigt hatte. Zu den Möglichkeiten der Koalitionsbildungen, die sich aus der Unvereinbarkeit der politischen Positionen von SPD und DVP ergab, siehe E. Kolb, Die Weimarer Republik, München 62002 , S. $72 \mathrm{f}$.

75 Vgl. dazu den Artikel von Friedrich Adler in La Vie socialiste vom 7. 2. 1930, S. 18/19 und G. Ziebura, Blum, S. 414/415.

76 Die Regicrung Tardieu wurde am 17.2. 1930 mit 286 zu 281 gestürzt. Tardieus Kabinett wurde durch eine Vertrauensfrage, die Finanzminister Chéron anlässlich finanzpolitischer Kontroversen in Abwesenheit des erkrankten Tardieu gestellt hatte, zu Fall gebracht; vgl. Le Temps vom 19. 2. 1930, S. 3 und das Abstimmungsergebnis auf S. 4.

77 Blum in seinen Leitartikeln in Le Populaire vom 30. 1. 1930, S. 1 und vom 2. 2. 1930, S. 1.

78 Zum Abstimmungsergebnis siehe Le Temps vom 27. 2. 1930, S. 4.

79 Vgl. dazu Le Populaire vom 19.2. und vom 20. 2. 1930 sowie vom 23. 2. 1930, jeweils S. 1; außerdem J.O., Chambre des Députés vom 25. 2. 1930, S. $819 \mathrm{f}$. 
zu rechten bis hin zu „reaktionären“ Regierungen ab. Zum anderen schien sich im Parti radical ebenfalls eine nicht unbedeutende Entwicklung durchzusetzen: Ein großer Teil des Parti radical arbeitete immer mehr auf eine Regierung der concentration hin. Nur noch der linke Flügel um Daladier hoffte auf eine Zusammenarbeit mit der SFIO. Dies hatte zur Folge, daß die SFIO ihre Taktik neu überdenken mußte. Der oben genannte Zeitraum kann deshalb auch als eine Phase der Auseinandersetzung zwischen dem Parti radical und der SFIO betrachtet werden. Die Sozialisten mußten sich auf die veränderten politischen Umstände einstellen, denn, wie Blum richtig analysierte, die konservative Regierung Tardieu versuchte langfristig, eine Polarisierung des französischen Parteiensystems zu erreichen ${ }^{80}$, d.h. eine Zweiteilung der Parteienlandschaft in Parteien der sozialen Revolution und Bewahrer der sozialen Ordnung. In diesem von Tardieu geplanten Koordinatensystem sah Blum für die radikalsozialistische Partei eine große Gefahr, denn sie war ihrer ganzen Tradition nach genau das Bindeglied zwischen beiden Blöcken, und für ihre Funktion als Mittlerposition wäre nach den Plänen Tardieus kein Platz mehr gewesen. In diesem Zusammenhang beunruhigte es Blum sehr, daß ein großer Teil der Radikalsozialisten nach der Mitte drängte, d.h. eine Regierungsbildung der concentration unter maßgeblicher Mitwirkung der Radikalsozialisten befürwortete.

Die SFIO sah es als ihre Aufgabe, die von Tardieu geplante Entwicklung aufzuhalten. Deshalb mußten die Sozialisten erneut ihr Verhältnis zum Parti radical klären. Erschwerend kam jedoch hinzu, daß eine gewisse Konkurrenz zwischen dem Parti radical und der SFIO in der Wählergunst entstanden war. So kam es auf dem Parteitag der Sozialisten in Bordeaux vom 8. bis 11. Juni 193081 erneut zu einer heftigen Debatte über das Verhältnis der Sozialisten zum Parti radical. Ausgelöst wurde diese durch eine Auseinandersetzung zwischen beiden Parteien bei den Nachwahlen in Bergerac. Im April hatte sich ein sozialistischer Kandidat im zweiten Wahlgang mit Hilfe von konservativen Stimmen gegen den radikalsozialistischen Konkurrenten durchsetzen können.

Obwohl das oberste Parteigremium, die CAP, der Föderation Dordogne empfohlen hatte, ihren Kandidaten zurückzuziehen, handelte diese gegen den Ratschlag. Der Vorfall sorgte zwischen den Sozialisten und dem Parti radical für große Verstimmung ${ }^{82}$. Dennoch appellierte Blum an beide Seiten, einzulenken, da ein Zerwürfnis zwischen den Radikalsozialisten und den Sozialisten letztlich nur der Regierung Tardieu zugute kommen würde.

In der Diskussion um das Verhältnis zum Parti radical brachen erneut die Flügelkämpfe in der SFIO aus. Auch dieses Mal mußte ein Kompromiß gefunden werden. So konnte Blum vermittelnd wirken, indem er die Losung ausgab, weder die Radikalsozialisten zu bekämpfen noch ein zu enges Bündnis mit ihnen einzugehen ${ }^{83}$. Denn sowohl das eine wie auch das andere würde letztlich der Demokra-

so G. Ziebura, Blum, S. 417/418.

81 Vgl. die Berichterstattung zu diesem Parteitag in Le Populaire vom 8.-11.6. 1930 jeweils S. 1, 2, 3, und auch die Parteitagsprotokolle des $27^{e}$ Congrès National à Bordeaux, 8.-11. 6. 1930, Paris 1930.

82 Vgl. dazu die in der Presse ausgetragenen Diskussionen zwischen beiden Parteien: Le Populaire vom 1.4. 1930 und vom 3. 4. 1930, jeweils S. 1 sowie L'Oeuvre vom 2. 4. 1930, 4. 4. 1930 und 20.4. 1930, jeweils S. 1, 3.

83 Le Populaire vom 9. 6. 1930, S. 1, 3. 
tie Frankreichs schaden. So sprach er sich für einen Mittelweg im Umgang mit dem Parti radical aus. Außerdem wurde die Rekrutierung des obersten Parteigremiums CAP, wie auf dem außerordentlichen Parteitag beschlossen, neu geregelt. Von den 25 Sitzen konnte der rechte Parteiflügel 12 für sich beanspruchen ${ }^{84}$. So war es nach den schweren parteiinternen Auseinandersetzungen gelungen, wieder eine gewisse Ruhe und Ordnung in die SFIO einkehren zu lassen. Aber auch andere konstruktive Faktoren trugen zur Stärkung der SFIO bei. So konnten sich bei den verschiedenen Nachwahlen vor allem sozialistische Kandidaten erfolgreich behaupten. Damit wuchs die Fraktion der SFIO sukzessive um weitere Mitglieder an. Dieser positive Trend schlug sich auch in der steigenden Zahl der Parteimitglieder nieder. Die Kommunistische Partei verlor zusehens Anhänger, die wieder in die $S F I O$ zurückkehrten ${ }^{85}$.

Nachdem sich nun parteiintern eine gewisse Ruhe eingestellt hatte, wurden die Sozialisten durch den Parti radical gezwungen, erneut über ihre politische Taktik nachzudenken. Mitte Oktober 1930 versuchte ein Teil des Parti radical unter der Führung Herriots, ${ }^{86}$ die Regierung Tardieu mit dem Ziel auszuschalten, selbst eine Regierung der concentration zu bilden, die von den Sozialisten unterstützt werden sollte.

Bereits am 4. Dezember $1930^{87}$ wurde die Regierung Tardieu aus dem Amt gedrängt und nun stellte sich die Frage, ob die Sozialisten die von einem Teil des Parti radical befürwortete Regierung der concentration zu unterstützen bereit waren, oder ob sie durch ihre Ablehnung vielmehr eine weitere Regierung Tardieu verantworten wollten. Die Sozialisten wurden durch diese neue Situation vor eine schwierige Entscheidung gestellt; letztlich beschlossen sie, das aus ihrer Sicht kleinere Übel in Kauf zu nehmen. So erklärten sie sich bereit, eine Regierung der concentration unter radikalsozialistischer Führung zu unterstützen, obwohl die Unterstützungspolitik für die Regierung Steeg innerhalb der SFIO wieder für Diskussionen zwischen den beiden Flügeln sorgte ${ }^{88}$. Erneut standen sich zwei Argumentationslinien gegenüber: Der rechte Flügel forderte eine stärkere Unterstützungspolitik, um damit auf jeden Fall eine Neuauflage der Regierung Tardieu zu vermeiden, während sich der linke Flügel der SFIO entschieden gegen eine Annahme des Haushaltsplanes aussprach. Immerhin war die sozialistische Partei nicht sehr lange diesem Spannungszustand ausgesetzt, denn bereits nach fünf Wochen wurde das Kabinett Steeg ${ }^{89}$ wieder von einer Regierung Tardieu-Laval abge-

84 Le Populaire vom 10.6. 1930, S. 2.

85 Vgl. dazu G. Ziebura, Blum, S. 417, und ebenda, Anm. 59. Folgendes Zahlenbeispiel zeigt die unterschiedlichen Entwicklungen in der Mitgliederzahl beider Parteien: 1931 konnte die SFIO 131000 Mitglieder aufweisen, während die Kommunisten nur noch über 30000 Mitglieder verfügten.

86 Diese Pläne wurden auf dem Parteitag des Parti radical vom 9.-12. 10. 1930 in Grenoble offenbart. Dazu L'Oeuvre vom 9.-13. 10. 1930, jeweils S. 1-4.

87 Die Regierung Tardieu wurde im Senat mit der Begründung gestürzt: „(...) le ministère Tardieu a été renversé par la Haute Assemblée sur la politique générale.“; vgl. Le Temps vom 6. 10. 1930, S. 1.

88 Vgl. hierzu die Debatten auf dem Nationalrat der SFIO vom 18.1. 1931, abgedruckt in Le Populaire vom 19. 1. 1931, S. 1, 3.

89 Die Regierung Steeg stürzte über eine Vertrauensfrage am 22.1. 1931; vgl. J.O., Chambre des Députés vom 22. 1. 1931, 2. Sitzung, S. 232. Zum namentlichen Abstimmungsergebnis ebenda, S. 239-240.; Le Temps vom 24. 1. 1931, S. 4. 
löst. Diese Regierung konnte, obwohl sie sehr weit rechts stand, eine stabile Mehrheit von 54 Stimmen auf sich vereinen ${ }^{90}$. Dieses Ergebnis wertete Léon Blum als ein deutliches Anzeichen ${ }^{91}$ dafür, daß sich die Öffnung des Parti radical in Richtung concentration nicht als geeignete Taktik für diese Partei erwiesen hatte. Denn die kleineren Gruppen im Parlament schienen mehr in eine Mitte-RechtsRichtung gegangen zu sein, als von einer starken Mitte-Links-Tendenz überzeugt zu sein.

Außerdem führte bei den Sozialisten die krasse Diskrepanz zwischen der rechten Mehrheit im Parlament und den erfolgreichen Kandidaturen sozialistischer Bewerber bei Nachwahlen dazu, daß sie ernsthaft über eine Auflösung des Parlaments nachdachten ${ }^{92}$. Bis zum Ende der Legislaturperiode galt die rechte Mehrheit im Parlament als äußerst stabil, und obwohl es zu Regierungswechseln kam, konstituierte sich jeweils kurze Zeit danach ein neues Kabinett in ähnlicher $\mathrm{Zu}$ sammensetzung ${ }^{33}$. Immerhin hatten diese Mehrheitsverhältnisse im französischen Parlament für die sozialistische Partei den Vorteil, daß sie sich in die Oppositionsrolle zurückziehen und damit in aller Ruhe auf die Wahlen von 1932 vorbereiten konnte, da es keine taktischen Auseinandersetzungen innerhalb der Partei aus tagespolitischen Gründen zu diskutieren gab. Die sozialistische Partei ging mit großen Hoffnungen in den Wahlkampf 1932, der in Kapitel 2 dieses Fallbeispiels näher untersucht wird.

\section{Der Kampf um die Richtung und die Einheit im Parti radical (1927-1932):} Verschiedene Optionen: Union des gauches - Concentration oder Unabhängigkeit

Als Herriot im Juli 1926 in das Kabinett Poincaré eintrat, setzte er sich mit diesem Schritt nicht nur persönlich großer Kritik aus, sondern stürzte auch den Parti radical in eine längere Krise. Daher galt es zunächst, auf dem Parteitag im Oktober 1926 die akute Spaltungsgefahr von der Partei abzuwenden. Die drei vorherrschenden Positionen im Parti radical, die sich vor allem in den Zeitungen L'Oeuvre ${ }^{94}$, L'Ere Nouvelle ${ }^{95}$ und La Dépêche de Toulouse ${ }^{96}$ niederschlugen, gaben bereits im Vorfeld des Parteitages ein Bild davon, welche Spannungen im Parti radical seit dem Eintritt Herriots in die Regierung Poincaré herrschten. Der linke Flügel des Parti radical, der traditionsgemäß an einer Union des gauches festhalten wollte, sah die Radikalsozialisten mit dem Handeln Herriots um den Wahlsieg

90 Die Regierung Laval-Tardieu wurde mit 312 zu 258 Stimmen am 30. 1. $1931 \mathrm{im}$ Amt bestätigt; vgl. J.O., Chambre des Députés vom 30. 1. 1931, S. 267 und zum namentlichen Abstimmungsergebnis, ebenda, S. 292/293, sowie Le Temps vom 1. 2. 1931, S. 4.

91 Vgl. dazu auch folgende Artikel von Blum in Le Populaire: 23.1. 1930, 29. 1. 1930, 1. 2. 1930, 8.10. 2. 1930, 12.-13.2. 1930, jeweils S. 1.

92 Le Populaire vom 26. 4. 1931, S. 1 .

93 Nach dem Sturz des Kabinett Steeg am 22. 1. 1931 wechselten sich verschiedene rechte Kabinette ab: Es folgte zunächst die erste und zweite Regierung Laval (vom 27.1.1931 bis 13.6.1931 und vom 13.6. 1931 bis 12.1. 1932), anschließend die dritte Regierung Laval vom 14.1. 1932-16. 2. 1932 und die dritte Regierung Tardieu vom 20.2. 1932-10.5. 1932; vgl. E. Bonnefous, Histoire politique, vol. 5, S. 430-433, bzw. die Kabinettslisten im Anhang dieser Arbeit.

94 Vgl. hier L'Oeuvre vom 1. 10. 1926, S. $1 / 2$.

95 Vgl. hier L'Ere nouvelle vom 7. 10. 1926, S. 1, vom 8. 10. 1926, S. 1/2, vom 9. 10. 1926, S. 1, vom 10.10.1926, S. 1, vom 13.10. 1926, S. 1 .

96 Vgl. La Dépêche de Toulouse vom 12. 10. 1926, S. 3 und vom 13. 10. 1926, S. 2/3. 
von 1924 gebracht, da nun die Wahlgegner wieder die Regierungsgeschäfte in Händen hielten - und dies mit radikalsozialistischer Unterstützung. Das Vorgehen Herriots wurde scharf kritisiert und dieser als Verräter bezeichnet. Einige forderten, daß er vom Parteivorsitz zurücktreten solle.

Caillaux, der spätestens seit dem Parteitag von 1925 als Gegenspieler Herriots auftrat, wandte sich gegen eine Beteiligung des Parti radical an einer Regierung der Union nationale, und strebte eine Regierung der concentration unter radikalsozialistischer Führung an. In einer Regierung der concentration sollten nach Caillaux weder die rechte Gruppe um Marin noch die Sozialisten berücksichtigt werden ${ }^{97}$.

Eine dritte Tendenz repräsentierte Franklin-Bouillon ${ }^{98}$, der sich sehr exponiert für eine rückhaltlose Unterstützung der Union nationale einsetzte.

Auf dem Parteitag des Parti radical von 1926 galt als oberstes Prinzip, eine Schadensbegrenzung zu erzielen. Zwei kritische Punkte mußten geklärt werden: Zum einen sollte der Eintritt der Radikalsozialisten in das Kabinett der Union nationale von der Gesamtpartei nachträglich bestätigt werden. Zum anderen stand die Wahl des Parteivorsitzenden auf dem Programm. Gerade diese mußte äußerst vorsichtig und ernsthaft behandelt werden, da sie einen hohen Grad an Aussagekraft über den Zustand der Partei hatte.

Das erste Problem, d.h. die offizielle Absegnung des Regierungseintrittes der radikalen Mitglieder in das Kabinett Poincaré, konnte relativ zügig gelöst werden. Obwohl der linke Flügel, repräsentiert von Malvy und Bouyssou, formaliter protestierte, wurde die Resolution einstimmig beschlossen ${ }^{99}$. Da die radikalsozialistischen Abgeordneten über den vorgenommenen politischen Richtungswechsel relativ verunsichert und um die Einhaltung der Abstimmungsdisziplin weiterhin bemüht waren, forderten sie vom Parteitag eine Direktive für ihr zukünftiges Verhalten bis zum Ende der Legislaturperiode ${ }^{100}$. In der Schlußresolution konnte eine Lösung gefunden werden, mit der die beiden großen Fronten im Parti radical versöhnt werden sollten. Darin wurde betont, daß die Beteiligung am Kabinett Poincaré der momentanen Krise Rechnung trage, aber ansonsten beanspruche der Parti radical weiterhin für die Zukunft die Führungsrolle in einer Regierung. In engstem Zusammenhang damit stand natürlich die Diskussion um die politische Ausrichtung des Parti radical, die auch in der Schlußresolution ihren Niederschlag gefunden hat. Die Unterstützung der Union nationale wurde zwar unterstrichen, aber gleichzeitig hielt man auch fest, daß das zukünftige Ziel weiterhin eine Cartelregierung sei101. Diese Kompromißformel offenbarte das eigentliche Dilemma des Parti radical, nämlich die zunehmende Heterogenität, die die Partei schwer belastete. Diese Schlußresolution stellte keine wirkliche Lösung dar, sondern versuchte nur, vorübergehend eine endgültige Entscheidung zu verschieben.

97 Caillaux auf dem Parteitag des Parti radical; vgl. L'Oeuvre vom 15. 10. 1926, S. 1, 3.

${ }^{88}$ Franklin-Bouillon trat dezidiert für eine Union nationale ein und griff die SFIO besonders scharf an; vgl. L'Oeuvre vom 16. 10. 1926, S. 2.

${ }^{99}$ L'Oeuvre vom 16. 10. 1926, S. 2.

100 L'Oeuvre vom 15. 10. 1926, S. $1 / 2$.

101 Zum Text der Schlußresolution siehe L'Oeuvre vom 18. 10. 1926, S. 4. 
Wie diese Schlußresolution war auch die Wahl des Parteivorsitzenden vom Geist des Kompromisses geprägt. Verschiedene Personen, die jeweils für eine Tendenz im Parti radical standen, waren für den Parteivorsitz im Gespräch. Deshalb war es um so wichtiger, einen Kandidaten zu finden, mit dem alle drei Richtungen innerhalb der Partei einverstanden waren ${ }^{102}$. Immerhin glaubte man in der Person Maurice Sarrauts ${ }^{103}$ einen Mann des Ausgleichs gefunden zu haben, der dieses wichtige Kriterium erfüllen konnte. Er galt als Persönlichkeit im Parti radical, dem eine Versöhnung der verschiedenen Tendenzen gelingen konnte. Maurice Sarraut wurde zum neuen Parteivorsitzenden gewählt ${ }^{104}$, doch sollte er dieses Amt nur für ein Jahr bekleiden. Er betonte, nur vorübergehend den Parteivorsitz zu übernehmen, bis sich die Partei entschieden habe, welche politische Richtung sie einschlagen wolle. Die Wahl Sarrauts wurde in der Presse als Sieg Poincarés gewertet, denn der Bruder von Maurice, Albert Sarraut ${ }^{105}$, hatte ein Ministeramt im Kabinett der Union nationale übernommen. Obwohl Maurice Sarraut zum Parteivorsitzenden gewählt worden war, kam es in der radikalsozialistischen Fraktion zu Auseinandersetzungen bzw. zum Protest gegen die Regierung Poincaré. Einige Fraktionsmitglieder des linken Flügels, wie z. B. Daladier und Dumesnil, wollten unter der Führung von Léon Meyer 106 eine eigene Fraktion mit dem Namen „Gauche radical-socialiste" gründen. Dieses Ansinnen wurde aber von der Parteiführung zurückgewiesen.

Maurice Sarraut wurde gleich zu Beginn seiner Amtszeit mit dieser Aktion signalisiert, daß der linke Flügel sich nur sehr schwer mit der Politik der Union nationale abfinden würde. Dennoch bot die Politik Poincarés in verschiedenen politischen Feldern, wie z.B. der Außenpolitik oder der Kultur- und Sozialpolitik $^{107}$, für die Radikalsozialisten einige Teilerfolge. Aber die wichtigste politische Reform stellte für sie zweifelsohne die Wahlrechtsänderung dar. In der sehr bewegten Wahlrechtsdebatte sprachen sie sich eindeutig für das scrutin d'arrondissement aus, da sie hofften, sich damit aus dem Zwang der Wahlkoalitionen befreien zu können ${ }^{108}$.

Um den Gegensatz zwischen den Unterstützungsbefürwortern und den Gegnern an der mehrheitlich linksorientierten Parteibasis etwas auszugleichen, versuchte Maurice Sarraut, die Tradition der radikalsozialistischen Doktrin neu zu stärken und zu beleben, aber auch gegen links abzugrenzen. Natürlich konnte dabei eine Auseinandersetzung mit dem früheren politischen Partner, der SFIO, nicht ausbleiben. Kurze Zeit nach der Wahl von Maurice Sarraut kam es zwischen

102 Es wurden auch Malvy und Renoult als potentielle Kandidaten für das Amt des Parteivorsitzenden genannt; siehe L'Oeuvre vom 16. 10. 1926, S. 2.

$103 \mathrm{Zu}$ Maurice Sarraut vgl. J. Jolly, Dictionnaire, vol. 8, S. 2962-2963.

${ }^{104}$ Herriot und Daladier wurden zu Ehrenvorsitzenden ernannt. Zur Wahl des Parteivorsitzenden auf dem Parteitag von 1926 siehe L'Oeuvre vom 17. 10. 1926, S. 1.

$105 \mathrm{Zu}$ Albert Sarraut vgl. J. Jolly, Dictionnaire, vol. 8, S. 2960-2962.

$106 \mathrm{Zu}$ Léon Meyer vgl. J. Jolly, Dictionnaire, vol. 7, S. 2450.

107 Die Radikalsozialisten werteten vor allem die Außenpolitik, insbesondere die Fortsetzung der deutsch-französischen Annäherung, und die Finanzpolitik des Kabinetts Poincaré als sehr erfolgreich; vgl. dazu E. Bonnefous, Histoire politique, vol. 4, S. 184-195.

108 Maurice Sarraut wurde einstimmig vom Comité exécutif in seinem Urteil unterstützt: „La coalition deviendrait une règle pour les partis avec le maintien de la loi actuelle et les entrainerait aux pires abdications."; L'Ere Nouvelle vom 20. 1. 1927, S. 1. 
ihm und Léon Blum zum Schlagabtausch. Maurice Sarraut beschrieb in einem Interview, das in der Revue de Paris 109 erschien, die Rolle und die Politik des Parti radical in der Regierung der Union nationale. Er charakterisierte den Parti radical als eine Partei, die eine Mittlerfunktion zwischen politischen Extremen zu erfüllen hatte: „Il est un parti compensateur entre les extremités de gauche et l'égoisme social des conservateurs; il s'efforce par sa tâche quotidienne d'arracher à cet égoisme des conquêtes qui permettent le mieux-être des travailleurs et leur assurent la justice." 110

In diesen wenigen Sätzen klang auch Kritik am Kommunismus an, die Sarraut im Laufe des Interviews noch deutlicher artikulierte. Jedoch versuchte er zunächst, keine öffentliche Auseinandersetzung mit der SFIO zu führen, und betonte lediglich, daß er keinen Unterschied in der Natur, sondern nur in der Methode, dem Temperament und dem Gefühlshaushalt zwischen dem Parti radical und der SFIO sehe. Die Radikalsozialisten, so Sarraut, würden von der Gesellschaft ausgehen so, wie sie sei, und sie würden sie langsam und in Etappen zu verbessern versuchen, die Sozialisten hingegen wollten die Gesellschaft revolutionieren. Sarraut betonte aber abschließend, daß beide Parteien, trotz fundamentaler Unterschiede, in der Praxis eigentlich dasselbe Ziel verfolgen würden, nämlich „la suppression du salariat et la limitation des abus de la propriété."111 Durch dieses Resümee wurde offensichtlich, daß sich beide Parteien trotz heftiger Auseinandersetzung mittlerweile in einigen Bereichen nahe gekommen waren und sich eine gewisse Konkurrenz eingestellt hatte. So wollte Sarraut sich nicht von den sozialistischen Attacken, die in den Wochen nach dem Wechsel des Parti radical in das Kabinett der Union nationale einsetzten, provozieren lassen, da der Radikalsozialismus seine traditionelle Zusammenarbeit mit den Sozialisten nicht vollkommen unmöglich machen wollte.

Blum hingegen bezog in seiner Broschüre „Radicalisme et Socialisme“ Stellung zu den Ausführungen Sarrauts über die Gemeinsamkeiten und Unterschiede beider Parteien. Er widersprach Sarraut bezüglich des Ziels beider Parteien und wies die von Sarraut genannten Gemeinsamkeiten von SFIO und Parti radical entschieden zurück. Beide sprächen zwar von ,suppresssion du salariat, disparition du différents", würden aber, so Blum, inhaltlich darunter etwas vollkommen Unterschiedliches verstehen: "Je pense que la croyance à la seule efficacité d'un progrès continu, d'une part, la croyance à la nécessité d'une transformation révolutionnaire, de l'autre, répresentent entre les radicaux et nous tout autre chose qu'une différence de tempérament ou de sentiment, et que cette divergence correspond à une contrariété profonde des doctrines." 112 Die Kritik Blums am Parti radical gipfelte in dem vernichtenden Schlußresümee, daß die radikalsozialistische Partei ein überholtes Modell darstelle, da es ihr nicht gelungen sei, mit ihren politischen Konzeptionen die Nachkriegsprobleme zu bewältigen. Der Parti radical habe damit bewiesen, daß er eine Partei der Vergangenheit sei, der nun seine Funktion an

112 Blum in: Derselbe, Radicalisme et socialisme, Paris 1936, S. 12/13. 
die SFIO abzutreten habe, die eine Partei der Zukunft verkörpere und die Blum als „seul héritier légitime de la Révolution française" 113 bezeichnete.

Diese rigorose Kritik traf den Parti radical in einem zentralen Punkt seiner Parteikultur, denn die republikanische Idee hatte er stets für sich reklamiert und damit den Anspruch erhoben, der wahre Erbe der Französischen Revolution und der Motor der Dritten Republik zu sein ${ }^{114}$. Es war selbstredend, daß die Radikalsozialisten diese massive Attacke Blums nicht unbeantwortet lassen konnten. $\mathrm{Zu}$ nächst reagierte vor allem die Zeitung L'Ere nouvelle ziemlich irritiert auf diese scharfe Polemik von Blum und griff diesen persönlich an. Sie warf ihm vor, die Union des gauches zu verhindern: „Le socialisme à la Karl Marx, revu, corrigé, édulcoré et remis au gout du jour par M. Blum n'est pas une doctrine française. “115

Nach dem Parteitag der Sozialisten vom 17. bis 20. April 1927116 in Lyon nahm die Kritik des Parti radical an den Sozialisten nochmals zu, denn die Sozialisten hatten abermals jede Zusammenarbeit mit anderen Parteien abgelehnt. Die Radikalsozialisten quittierten diese Entscheidung mit dem Vorwurf, daß die SFIO sich entscheiden müsse, ob sie eine theorielastige Partei bleiben oder doch endlich eine reformistische Partei werden wolle, die auch Regierungsverantwortung übernehmen und damit aktiv am politischen Leben teilnehmen könne ${ }^{117}$. Die Entscheidung der Sozialisten stärkte den rechten und mittleren Flügel im Parti radical. Die rechtsliberale Alliance Démocratique versuchte erneut, den Parti radical für eine Zusammenarbeit zu gewinnen. Dennoch lehnte Maurice Sarraut dieses Angebot mit dem Hinweis auf grundlegende programmatische Differenzen zwischen den Radikalen und der Alliance Démocratique ab ${ }^{118}$ und entschied damit zugunsten des linken Parteiflügels. Franklin-Bouillon, der als Sprecher des rechten Flügels das Angebot der Alliance Démocratique begrüßt hatte, hoffte aber auf dem Parteitag vom 27. bis 30. Oktober 1927119 diese Option nochmals zur Diskussion stellen zu können.

Der Parteitag des Parti radical von 1927 kann als Weichenstellung vor allem für das Wahljahr 1928 gesehen werden. Die führenden Köpfe der Partei versuchten

113 Ebenda, S. 22-24, hier besonders S. 22: „Presque toutes les formules qui répresent pour eux l'héritage de la Revolution de 89 conduisent à nous, dès qu'on cherche à en épuiser le contenu. C'est, par exemple, en poussant à bout l'idée de l'égalité politique que Jaurès a été d'abord orienté vers le socialisme. C'est en ce sens que le socialisme a pu se porter pour l'hériter légitime de la Révolution française."

114 Zum Selbstverständnis und der Doktrin der Radicaux in der frühen Dritten Republik siehe D. Mollenhauer, Auf der Suche nach der "wahren Republik“, S. 186-214; F. Buisson, La politique radicale. Étude sur les doctrines du Parti radical et radical-socialiste, Paris 1908; Alain, Éléments d'une doctrine radicale, Paris 1925.

115 L'Ere nouvelle vom 9. 2. 1927, S. 1.

116 Zum Parteitag der SFIO siehe Le Populaire vom 17. 4.-21. 4. 1927, jeweils S. 1, 2, 3. Vgl. auch das Parteitagsprotokoll 24e Congrès National à Lyon de 17.-20. avril 1927, Paris 1927.

11) Vgl. hierzu die Kritik an der SFIO z. B. in La Dépêche de Toulouse vom 26. 5. 1927, S. 1; L'Ere nouvelle vom 30. 7. 1927, S. 1.

118 Vgl. die Artikel von Maurice Sarraut in La Dépêche de Toulouse vom 9. 8. 1927 und 27. 8. 1927, jeweils S. 1, in denen er vor allem die unterschiedlichen Positionen von Parti radical und Alliance Démocratique bezüglich der Gewerkschaften, der Forderung nach dem Acht-Stundentag sowie nach dem richtigem Steuersystem und den Staatsmonopolen unterstrich.

119 Zum Parteitag des Parti radical von 1927 siehe L'Oeuvre vom 27. 10.-31. 10. 1927, jeweils S. 1, 2, 3. Vgl. dazu auch das Parteitagsprotokoll 24e Congrès du Parti radical et radical-socialiste à Paris de 27.-31. 10. 1927, Paris 1927. 
jeweils, ihrem Konzept in der Partei zum Durchbruch zu verhelfen. Der Parteitag geriet zu einem Kampf zwischen dem engagierten Exponenten des rechten Flügels, Franklin-Bouillon, und den anderen beiden Strömungen innerhalb des Parti radical. Bereits einige Tage vor Beginn des Parteitages versuchte Franklin-Bouillon, das Terrain für die „Unionistes“ abzustecken, also für die Gruppe im Parti radical, die eine politische Zusammenarbeit mit der Union nationale dauerhaft anstrebte und damit die politische Ausrichtung der Partei neu zu definieren versuchte. Franklin-Bouillon begründete diese politische Erneuerung damit, daß die Doktrin des Parti radical, die aus der Vorkriegszeit stamme, nicht mehr zur Bewältigung der neuen wirtschaftlichen, durch den Krieg bedingten Veränderungen genüge ${ }^{120}$. Er stieß mit seiner Argumentation auf den Widerstand anderer führender Persönlichkeiten des Parti radical, die aus taktischen Gründen für die Wahlen von 1928 für eine Zusammenarbeit mit den Parteien der Union des gauches votierten. So kam es auf dem Parteitag von 1927 zur Machtprobe, denn Franklin-Bouillon drohte, falls er mit seiner Option für die Union nationale scheitere, den rechten Flügel ${ }^{121}$, den er repräsentierte, abzuspalten. Zur Schlüsselfrage in diesem Machtkampf geriet vor allem die Wahl des neuen Parteivorsitzenden; hier entschied sich definitiv, welche Richtung innerhalb des Parti radical für die nächsten Jahre tonangebend werden sollte. Beide Entscheidungen standen in unmittelbarem Zusammenhang. Zunächst konnten sich die Wahltaktiker, die ein Zusammenwirken mit der Union des gauches befürworteten, durchsetzen, und erstaunlicherweise wurde sogar der Beschluß gefaßt, Gremien einzurichten ${ }^{122}$, deren Aufgabe es war, die korrekte Umsetzung und Einhaltung dieses Parteitagsbeschlusses zu gewährleisten, d.h. Kandidaten des Parti radical sollten nur auf Listen der Union des gauches zu den Wahlen von 1928 antreten. Erneut zeigte sich in diesem Punkt der ansonsten relativ liberale Parti radical im Gegensatz zu den Sozialisten, die die Aufstellung der Kandidaten an die einzelnen Föderationen delegiert hatten, äußerst zentralistisch.

Im Vorfeld der Wahl zum Parteivorsitzenden zeichnete sich dann ab, daß der rechte Flügel um Franklin-Bouillon keine Rolle spielen würde. Zunächst schien Camille Chautemps der aussichtsreichste Kandidat für das Präsidentenamt zu sein, denn er galt als Mann des Ausgleichs. Mit ihm wäre die Fortsetzung der bisherigen Politik - temporäre Allianz mit der Union nationale und gleichzeitige Wahlkoalition mit der Union des gauches - gewährleistet gewesen. Allerdings änderte sich das Bild bereits am ersten Tag des Parteitages, da Franklin-Bouillon mit seinem massiven Druck die Parteibasis, die größtenteils zum linken Flügel zählte, gegen sich aufbrachte. Mit der erneuten Diskussion über die Spaltung der Partei lieferten die „Unionistes“ um Franklin-Bouillon dem linken Flügel neue Argumente, der nun forderte, daß der Parti radical nach Abspaltung der "Unionistes“ die momentane Kompromißpolitik beenden solle. Damit wäre dann der Weg für die Wiederaufnahme der eigentlichen politischen Leitlinie - ein Bündnis mit der

120 Franklin-Bouillon sprach sich dezidiert für die Union nationale aus, so z. B. in La Dépêche de Toulouse vom 25. 10. 1927, S. 1 und vom 28. 10. 1927, S. 3; aber auch in L'Oeuvre vom 29. 10. 1927, S. $1-3$.

121 L'Oeuvre vom 30. 10. 1927, S. 1-3.

122 Zur Resolution des Parteitages siehe L'Oeuvre vom 31. 10. 1927, S. 1-3. 
Union des gauches 123 - freigegeben worden. Da Chautemps, der selbst eher zum gemäßigten Flügel des Parti radical gehörte, einen Kurswechsel nach links nicht mitragen wollte, zog er seine Kandidatur für den Parteivorsitz zurück ${ }^{124}$.

Der Rückzug Chautemps löste hinter den parteipolitischen Kulissen sehr große Aktivität aus, da nun die Kandidatur Daladiers immer wahrscheinlicher wurde. Im Grunde kam es zu einer Neuauflage der Auseinandersetzungen zwischen Herriot und Caillaux, die den Parteitag von 1925 in Nizza dominiert hatten, freilich mit dem entscheidenden Unterschied, daß Caillaux dieses Mal den Kampf um den Führungsanspruch in der Partei für sich entschied und in einer Art Frontenverkehrung den Wortführer des linken Flügels unterstützte. Er ließ durch eine Reihe von Parteimitgliedern aus seinem Umfeld, wie z. B. durch Jean Montigny, bei Daladier vorfühlen. Er konnte ihn zu einer Kandidatur bewegen und ihm den Weg zum Erfolg ebnen. Mit Daladier als Parteivorsitzenden war klar, daß der Parti radical dem Kabinett der Union nationale bald seine Unterstützung versagen würde. Dies war indirekt auch eine Niederlage für Herriot, der diese Politik zu verantworten hatte. Immerhin wollte der auf Ausgleich bedachte Flügel um Herriot und Maurice Sarraut noch eine Gegenmaßnahme ergreifen und versuchte, den gemäßigten Senator Dalbiez ${ }^{125}$ als Gegenkandidaten zu gewinnen. Obwohl dieser sich zunächst bereit erklärt hatte, verzichtete er kurze Zeit später, da Caillaux ihm angedroht hatte, daß er persönlich gegen ihn zur Wahl um den Parteivorsitz antreten werde. Daraufhin zog Dalbiez sich zurück und für Daladier war der Weg zum Parteivorsitz frei126. Er wurde am 29. Oktober 1927 mit 620 von 794 Stimmen zum Parteivorsitzenden gewählt; der Kreis um Herriot hatte ihm seine Stimmen versagt. Immerhin bezeichneten die Zeitungen des linken Flügels des Parti radical, die die Wahl Daladiers begrüßten, ihn als den Mann, der die Partei, auf der Basis der traditionellen politischen Zusammenarbeit mit den linksrepublikanischen Kräften, im Rahmen der Union des gauches erneuern könne. Nach der Wahl Daladiers wurden die wichtigsten Parteiposten ${ }^{127}$ fast alle mit Anhängern des linken Flügels besetzt; der Parti radical hatte einen Linksruck vollzogen.

Obwohl sich mit Daladier als neuem Parteivorsitzenden nun offiziell die Waage in der Partei zugunsten der linken Tendenz geneigt hatte, stand ihr mit der Gruppe um Herriot und den Brüdern Albert und Maurice Sarraut ein personell sehr gewichtiger gemäßigter Flügel gegenüber. Die gemäßigte Tendenz strebte nach wie vor eine politische Ausrichtung des Parti radical in die Mitte, also in Richtung concentration, an.

Der Parti radical trat im ersten Wahlgang 1928, hauptsächlich auch bedingt durch die Änderung des Wahlmodus von 1927, ohne Wahlkoalition an. Die meisten ihrer Kandidaten führten den Wahlkampf aber im Namen Poincarés. Serge Berstein schreibt das nur mittelmäßige Abschneiden der Radikalsozialisten von 1928 vor allem dem Widerspruch zu, den die Partei zu überbrücken hatte. Einer-

${ }^{123}$ L'Oeuvre vom 29. 10. 1927, S. $1 / 2$.

124 L'Oeuvre vom 30. 10. 1927, S. 2.

$125 \mathrm{Zu}$ Victor Dalbiez vgl. J. Jolly, Dictionnaire, vol. 3, S. 1216-1218.

126 Daladier wurde am 29. 10. 1927 mit 620 von 794 Stimmen zum Parteivorsitzenden des Parti radical gewählt; vgl. L'Oeuvre vom 30. 10. 1927, S. 2.

127 Vgl. hierzu S. Berstein, Parti radical, vol. 2, S. 49, der einige namhafte Beispiele anführt. 
seits fühlte sich der Parti radical der linken Theorie verpflichtet und andererseits orientierte er sich im tagespolitischen Geschäft immer mehr an den Kräften der rechten Mitte ${ }^{128}$.

Wie sehr diese Heterogenität zur Instabilität innerhalb der Partei und ihres politischen Handelns führte, wurde besonders evident, als die Regierung Poincaré die Vertrauensfrage stellte. Anlaß für diese Vertrauensfrage war ein Antrag der sozialistischen Fraktion, die für einige kommunistische Abgeordnete, die wegen scharfer Presseartikel gegen die Regierung der Union nationale verhaftet worden waren, die Immunität forderte. Die parlamentarische Gruppe des Parti radical zerfiel bei dieser Abstimmung über die Vertrauensfrage in drei Teile: ein Teil stimmte für die Regierung, ein zweiter votierte dagegen und ein dritter enthielt sich der Stimme129. Diese Abstimmung galt als ein Parameter für die akute Spaltungsgefahr, der der Parti radical seit langem ausgesetzt war. Jene angespannte Situation, die die politische Arbeit der radikalsozialistischen Fraktion belastete, bedurfte einer dringlichen Lösung, die auf dem Parteitag 1928 in Angers gefunden werden sollte. Erneut galt es, die Frage zu diskutieren, ob der Parti radical weiterhin der Regierung Poincaré seine Unterstützung gewähren sollte. Caillaux nutzte die Haushaltsdebatte, um eine Klärung dieser Angelegenheit herbeizuführen. Bereits im Vorfeld des Parteitages, der vom 3. bis 5. November 1928 abgehalten wurde, versuchte Caillaux, die Partei gegen Herriot einzunehmen, denn dessen Forderung nach dem Rückzug der Radikalsozialisten aus der Regierung war in erster Linie gegen Herriot gerichtet. Immerhin hatte dies zur Folge, daß die Mehrheit der Föderationen auf ihren vorausgehenden Parteitagen für den Austritt der radikalsozialistischen Minister aus der derzeitigen Regierung stimmte. Albert Sarraut versuchte mit einer gezielten Zeitungskampagne Stimmung gegen einen Austritt der radikalen Minister aus dem Kabinett der Union nationale zu machen ${ }^{130}$. Auch auf diesem Parteitag von 1928 kristallisierte sich ein Zweikampf zwischen Herriot und Caillaux heraus. Nachdem Herriot zunächst die Zustimmung des Parteitages für die weitere Zusammenarbeit mit dem Kabinett der Union nationale hatte erwirken können, gelang es Caillaux nach der vorzeitigen Abreise Herriots einen Parteitagsbeschluß durchzusetzen, der zu einer Sprengung der Regierungskoalition führen mußte. Herriot sah sich desavouiert, die radikalsozialistischen Minister demissionierten. Nach dem Parteitag von Nizza 1925 war es 1928 nochmals gelungen, eine Regierung zu Fall zu bringen. 1925 mußte Painlevé zurücktreten, da er nicht mehr auf die Unterstützung des Parti radical zählen

128 Die Wahlen von 1928 haben die politischen Kräfte der rechten Mitte gewonnen. Das Wahlergebnis kann als Bestätigung der Politik Poincarés gewertet werden. Die Kommunisten erhielten 1064000 Stimmen, die Sozialisten 1698000 , die Radikalsozialisten 1645000 und die Républicains socialistes 410000 Stimmen. Hingegen bekamen die Républicains de gauche und die Radicaux indépendants 2145000 Stimmen, die Union républicaine démocratique, die Démocrates populaires und die Conservateurs 2379000 Stimmen. Ausführliches zum Wahlergebnis von 1928 bei G. Lachapelle, Eléctions législatives 22-29 avril 1928, résultats officiels, Paris 1928; Derselbe, Les régimes électoraux, Paris 1934.

$129 \mathrm{Zu}$ den beiden Abstimmungsergebnissen hinsichtlich dieser Thematik siehe J.O., Chambre des Députés vom 12. 1. 1928, S. 38; Le Temps vom 14. 1. 1928, S. 3/4.

$130 \mathrm{Vgl}$. z. B. La Dépêche de Toulouse vom 23. 10. 1928. S. 1, und auch L'Oeuvre vom 28. 10. 1928, S. 1. Albert Sarraut sprach sich für eine Fortsetzung der Zusammenarbeit innerhalb des Kabinettes der Union nationale aus, damit die Finanzreformen in Ruhe fortgeführt werden konnten. 
konnte. Der Rücktritt der Regierung Poincaré 1928 brachte Caillaux sehr viel Kritik ein, nicht nur im Parti radical, sondern auch in der Öffentlichkeit ${ }^{131}$.

Mit dem Parteitagsbeschluß von Angers zeigte sich deutlich, daß der Parteivorsitzende die Partei nicht im Griff hatte. Das Verdienst und die Stärke Herriots lag bis Juli 1926 darin, daß er es verstanden hatte, nach dem Krieg die heterogene Partei auf seinen politischen Kurs einzuschwören. 1927 bzw. 1928 konkurrierten in Wirklichkeit drei einflußreiche Persönlichkeiten um den Führungsanspruch innerhalb des Parti radical. Obwohl Daladier auf dem Parteitag von 1927 zum Parteivorsitzenden gewählt worden war, ist es ihm nicht gelungen, die Partei auch wirklich zu führen. Daladier galt bis 1926 als politischer Ziehsohn Herriots, wurde aber nach dessen Eintritt in das Kabinett der Union nationale von Caillaux protegiert. Daladier war einer der führenden Köpfe der jüngeren Generation, die sich besonders ab 1926 innerhalb des Parti radical immer stärker Gehör verschafften. Die meisten der jüngeren Generation waren Vertreter der intellektuellen Jeunes Turcs, die den Parti radical nicht nur programmatisch, sondern auch organisatorisch erneuern wollten.

Der Wechsel im Parteivorsitz von Herriot zu Daladier zog vor allem auch in organisatorischer Hinsicht große Konsequenzen nach sich. In den Jahren von 1927 bis 1931 versuchte Daladier mit großer Vehemenz und einer überzeugten Gruppe von Mitarbeitern, die Organisationsstrukturen des Parti radical zentralistisch zu gestalten und zu verwalten. Den Reformversuchen Daladiers und seiner Mitarbeiter war ein gewisser Erfolg beschieden. Der Parti radical konnte einen deutlichen Zuwachs an Mitgliedern und neu entstandenen Föderationen verbuchen; dieser Mitgliederanstieg war bisher in der Geschichte der Partei unerreicht. Der Parti radical war nun unter dem Parteivorsitz Daladiers in allen Départements sehr gut vertreten. Die größeren strukturellen Schwächen, die in einigen Départements unmittelbar nach dem Krieg aufgetreten waren, galten damit als überwunden ${ }^{132}$. Trotz dieser Erfolge mußte Daladier zur Kenntnis nehmen, daß es zwischen den wichtigsten Parteiorganen, wie Parteivorsitz, Comité exécutif und Fraktion, große Differenzen gab. Die Fraktion berief sich auf das traditionelle Verständnis vom Abgeordneten und wehrte sich vehement gegen ein vorgeschriebenes Abstimmungsverhalten. Besonders hier wurde der Unterschied zwischen Herriot und Daladier im Parteivorsitz deutlich, denn Herriot war die Einhaltung der Disziplin in der Fraktion größtenteils gelungen. Neben der Einhaltung der Abstimmungsdisziplin gab es ein weiteres Problem, mit dem Daladier zu kämpfen hatte: die verbindliche Umsetzung der Parteitagsbeschlüsse durch die Fraktion

Die Fraktion wehrte sich massiv gegen die Disziplinierungsversuche Daladiers, die dieser mit Hilfe des Comité exécutif durchzusetzen hoffte. Es kam mehrfach $z u$ Auseinandersetzungen zwischen den Parlamentariern und der Parteispitze, die jedes Mal durch das Zerfallen der Fraktion in drei Richtungen bei Abstimmungen ausgelöst wurden. Es sollen hier nur stellvertretend einige Beispiele genannt werden. Z.B. spaltete sich die radikalsozialistische Fraktion bei der Abstimmung am

131 Z.B. Le Temps vom 7. 11. 1928, S. 1, 4; La Dépêche de Toulouse vom 7. 11. 1928, S. 1.

132 Vgl. die Beschreibung der Parteistrukturen in der unmittelbaren Nachkriegszeit bei S. Berstein, Parti radical, vol. 1, S. $177-258$. 
5. Dezember 1927133, als es um die Frage der Einberufung der Reservisten ging, in drei Lager: ein Teil stimmte dafür, ein anderer dagegen, ein dritter enthielt sich.

Ein erster Disziplinierungsversuch Daladiers nach seiner Wahl zum Parteivorsitzenden verlief erfolglos, dennoch wagte er nach der Parlamentswahl von 1928, die seine Position in der Partei gestärkt hatte, einen zweiten Versuch. Ende Mai 1928 ließ Daladier im Comité exécutif über den Antrag abstimmen, daß die Fraktion in ihrem Abstimmungsverhalten den Beschlüssen des letzten Parteitags Rechnung zu tragen habe ${ }^{134}$. Aber auch diese Maßnahme blieb ohne erwünschte Wirkung. Am eklatantesten wurde der Gegensatz zwischen dem Teil der Abgeordneten, der seine Unabhängigkeit bewahren wollte, und dem Comité exécutif, das die Fraktion an ihre Weisungen zu binden versuchte, in der ersten Abstimmung nach dem Parteitagsbeschluß von Angers 1928: Nach dem Rücktritt der vier radikalsozialistischen Minister aus dem Kabinett der Union nationale konstituierte Poincaré ein neues Kabinett ${ }^{135}$. Bei der Bestätigung dieser neuen Regierung kam es bei der radikalsozialistischen Fraktion wiederum zu einer Dreiteilung der Voten: 107 Abgeordnete des Parti radical entsprachen der Vorgabe des Parteitagsbeschlusses und enthielten sich der Stimme, sieben votierten gegen die Regierung und acht stimmten für das neue Kabinett ${ }^{136}$. Diejenigen, die für die Regierung gestimmt hatten, reichten bei der Parteispitze nach ihrem Votum auch ein Austrittsgesuch ein ${ }^{137}$, da sie wider den Parteitagsbeschluß gehandelt hatten. Innerhalb der Fraktion jedoch zog ihr Handeln keine Konsequenzen nach sich, sie blieben weiterhin Mitglieder der parlamentarischen Gruppe des Parti radical. Das Verhalten der Fraktion konnte als Protest gegen die Parteispitze und ihre Anweisungen verstanden werden. Am 3. Dezember 1928, während einer Sitzung des Comité exécutif, wurden die Abgeordneten, die für die Regierung votiert hatten, angeklagt. Bertrand Nogaro ${ }^{138}$ verteidigte zusammen mit Julien Durand ${ }^{139}$ die Haltung der acht Abgeordneten und hielt eine Grundsatzrede gegen die Einforderung der absoluten Abstimmungsdisziplin, die jedoch bei den Mitgliedern der Föderation Seine auf entschiedenen Protest stieß. Immerhin gelang es Daladier, diese Sitzung mit einem Beschluß, der fast einstimmig gefaßt wurde, zu beenden. Der Beschluß nahm die Abstimmungsdisziplin in die Parteitagsbeschlüsse von 1928 auf und besaß damit für die Parteimitglieder Verbindlichkeit ${ }^{140}$. Doch damit war der nächste innerparteiliche Konflikt vorprogrammiert. Als die Fraktion des Parti radical

133 Die Abstimmung zur Einberufung der Reservisten (Artikel 15) vom 2.12.1927 findet sich in J.O., Chambre des Députés vom 2. 12. 1927, S. 3495. Die vorausgehende Diskussion darüber in der Abgeordnetenkammer ist ebenfalls abgedruckt in J.O., Chambre des Députés vom 2.12. 1927, S. 3488-3495; sowie in Le Temps vom 4. 12. 1927, S. 3.

${ }^{134}$ La Dépêche de Toulouse vom 31. 5. 1928, S. 1; L'Oeuvre vom 31. 5. 1928, S. 1.

135 Das fünfte Kabinett Poincaré konstituierte sich am 11.11. 1928 und wurde am 16.11.1928 mit 330 zu 129 bestätigt. Die Mehrheit der Radikalsozialisten enthielt sich; die SFIO-Abgeordneten stimmten dagegen. Zum Abstimmungsverhalten siehe Le Temps vom 17. 11. 1928, S. 3.

136 Zum namentlichen Abstimmungsergebnis siehe Le Temps vom 17. 11. 1928, S. 4.

${ }_{137}$ L'Oeuvre vom 16. 11. 1928, S. 1; L'Ere nouvelle vom 16.11. 1928, S. 1.

${ }_{138} \mathrm{Zu}$ Nogaro vgl. J. Jolly, Dictionnaire, vol. 7, S. 2569-2570.

$139 \mathrm{Zu}$ Julien Durand vgl. Ebenda, vol. 4, S. 1589-1591.

140 Vgl. La Parole vom 11. 12. 1928, S. 1; und vom 3. 12. und 4. 12. 1928, S. 1; L'Oeuvre vom 4. 12. 1928, S. 4. 
Ende Januar 1929 beschloß ${ }^{141}$, die seit November 1928 praktizierte Taktik der Stimmenthaltung aufzugeben und sich statt dessen offen in die Opposition zu begeben, weigerten sich sieben Abgeordnete, ihr Mißtrauen gegen die Regierung auszusprechen. Daraufhin verhängte das Comité exécutif gegen vier der sieben Abgeordneten den Parteiausschluß. Die übrigen drei mußten sich vor dem Disziplinarausschuß verantworten ${ }^{142}$. Die Fraktion kritisierte das Vorgehen des Comité exécutif sehr scharf und protestierte gleichzeitig in ihrem Sprachorgan $\mathrm{La} \mathrm{Pa}$ role ${ }^{143}$ äußerst heftig. Erneut trat Nogaro als einer der wichtigsten Sprecher für die Fraktion auf, der in erster Linie das eigenmächtige Handeln des Comité exécutif, das ohne vorherige Absprache mit der Fraktion erfolgt war, verurteilte. Es scheint allen Beteiligten klar gewesen zu sein, daß der Konflikt zwischen Fraktion und Parteispitze im Parti radical an der Frage der Abstimmungsdisziplin eskalieren mußte, da damit an einem Kernelement der radikalen Doktrin ${ }^{144}$, nämlich der Unabhängigkeit des Abgeordneten, gerüttelt wurde. Nogaro verteidigte deshalb diese mit allem Nachdruck, da er wußte, daß die Entscheidung des Konfliktes definitiv über die Richtung innerhalb des Parti radical bestimmen würde. Nogaro wies eine von der Parteiführung vorgeschriebene Abstimmungsdisziplin zurück und betonte, daß das Handeln des radikalsozialistischen Abgeordneten nur drei bindenden Grundsätzen unterläge: 1) dem taktischen Prinzip, 2) dem juristischen Prinzip und 3) dem philosophischen Prinzip.

Unter dem taktischen Prinzip verstand Nogaro folgendes: Eine vorgeschriebene Disziplin würde nur zu weiteren Ausschlüssen bei den radikalsozialistischen Abgeordneten führen, was letztlich eine Schwächung der Fraktionsstärke bedeuten und, damit verbunden, das politische Gewicht der Partei verringern würde.

Das juristische Prinzip beinhaltete die These, daß der Abgeordnete in erster Linie in der Verantwortung seiner Wähler stehe und erst in zweiter Linie der Partei verpflichtet sei. Deshalb begründete Nogaro das Abweichen eines radikalsozialistischen Abgeordneten von der Mehrheit seiner Fraktion folgendermaßen: "Quand un parlementaire se sépare de la majorité de ses collègues pour un vote politique important c'est, le plus souvent, parce qu'il croit ne pouvoir aller à l'encontre de la volonté de ses mandants." 145

Die dritte Begründung, die Nogaro unter philosophischem Gesichtspunkt anführte, betraf die Forderung nach freier und kritischer Entscheidung des Abgeordneten, der ein vorgeschriebenes Abstimmungsverhalten diametral entgegenstand. Deshalb postulierte Nogaro in guter radikaler Tradition: „Il n'y a rien à mon sens de plus contraire à l'ésprit démocratique qu'une discipline aveugle excluant l'ésprit critique et la conscience individuelle. “146 Dieser dreifach begründete

141 Siehe dazu die Sitzung des Comité exécutif vom 16.1. 1929, abgedruckt in L'Ere nouvelle vom 17. 1. 1929, S. 1.

142 Vier Abgeordnete wurden ausgeschlossen: Brunet, Gasparin, Guilhaumon, Borel. Vor dem Disziplinarausschuß hatten sich Cuttoli, Graeve und Beluel zu verantworten; vgl. Le Radical vom 27. 1. 1929, S. 1, 3.

143 Zum Protest der Fraktion siehe La Parole vom 29. 1. 1929, S. 1.

144 Ausführlich zur radikalen Doktrin bei Alain, Élements d'une Doctrine radicale, Paris 1925; F. Buisson, La Politique Radicale, Paris 1908.

${ }_{145} \mathrm{La}$ Parole vom 5. 2. 1929, S. 1.

146 Ebenda. 
Protest wurde nicht nur von den Parlamentariern gebilligt, sondern auch von den großen und wichtigen Föderationen im Südwesten Frankreichs. Vor allem auch die einflußreiche Zeitung La Dépêche de Toulouse unterstützte Nogaro in seinem Unterfangen ${ }^{147}$.

Der deutliche Widerstand, der Daladier in seinen Reform- und Disziplinierungsversuchen entgegengebracht wurde, zeigte ihm unmißverständlich, daß der Parti radical nicht zentralistisch geführt werden konnte. Bereits nach dem $\mathrm{Fe}$ bruar 1929 scheint sich die Lage zugunsten der Parlamentarier entwickelt zu haben, denn es wurde kaum mehr von der Abstimmungsdisziplin und der Kontrolle über die Fraktion durch die Parteispitze gesprochen. Jedoch hinterließ diese Kraftprobe bei den radikalsozialistischen Abgeordneten großes Mißtrauen, und der Widerstand gegen Daladier wuchs unterschwellig weiter an. Ein Parteivorsitzender, der es gewagt hatte, gegen die Prinzipien der radikalen Tradition zu verstoßen, schien ihnen an der Spitze des Parti radical ungeeignet.

Daladiers Reformversuche müssen in einen größeren Zusammenhang gestellt werden, um die ganze Dimension dieses politischen Handelns zu begreifen. Hinter dem Konflikt Fraktion versus Daladier verbarg sich ein Generationenkonflikt im Parti radical. Daladier stand an der Spitze der jungen Generation, die sich innerhalb des Parti radical allmählich formierte und sich Jeunesses radicales oder Jeunes Turcs ${ }^{148}$ nannte. Sie waren der Überzeugung, daß die radikalen Konzeptionen, die erfolgreich in der Vorkriegszeit gewirkt hatten, nicht mehr geeignet waren, um die durch den Krieg verursachten Krisenphänomene zu bewältigen. Sie versuchten deshalb, neue, weiterführende, auf dem Fundament der radikalen Doktrin fußende Konzeptionen zu erarbeiten. Diese überwiegend intellektuelle Bewegung innerhalb der radikalsozialistischen Partei diskutierte ihre Ideen in verschiedenen Zeitungen und Zeitschriften ${ }^{149}$. Auch sie gestaltete sich überaus heterogen, was zusätzliche innerparteiliche Spannungen förderte. Es können grundsätzlich aus den verschiedenen Schattierungen der Bewegung zwei Richtungen herausfiltriert werden. Zum einen die junge überzeugte Gruppe um Jacques Kayser, die forderte, daß der Parti radical sich auf seine ursprünglichen Ziele aus der Anfangszeit des Radikalismus besinnen, also einen streng republikanischen Staatsaufbau und soziale Reformen anstreben solle ${ }^{150}$. Zum anderen muß man die

147 La Dépêche de Toulouse vom 27. 1. 1929, S. 1.

148 Zum Phänomen Jeunes Turcs bietet S. Berstein, Parti radical, vol. 2, S. 94-126 einen kurzen Überblick. Eine sehr instruktive zeitgenössische Darstellung lieferte Jacques Kayser, ein führendes Mitglied dieser Bewegung, mit seiner Analyse, die er nach 1932 geschrieben haben muß und die Teil seines Nachlasses bildet; siehe A.N., Papiers Jacques Kayser 465AP/6. Aus zeitgenössischer Sicht auch J. Luchaire, Une génération réaliste, Paris 1929; J. Montigny, La République réaliste, Paris 1927. Spätere Darstellungen von J. Touchard, L'ésprit des années trente: une tentative de renouvellement de la pensée politique française, in: derselbe, Tendances politiques dans la vie française depuis 1789, Paris 1960; Derselbe/J.-L. Loubet del Bayle, Les non-conformistes des années 30, Paris 1969; P. Balmand, Les jeunes intellectuels de l' Esprit des années Trente“: un phénomène de génération?, in: J.-F. Sirinelli (Hg.), Génerations intellectuelles, Cahiers de l'Instiut d'Histoire du Temps présent 6 (Nov. 1987), S. 49-63; J.-F. Sirinelli, „Note sur ,Révolution constructive’: des ,non-conformistes' des années vingt?“, in: Bulletin du Centre d'Histoire de la France Contemporaine 6 (1985); D. Bardonnet, L'Évolution de la structure du parti radical, S. 177-179.

149 Presseorgane dieser Bewegung waren z.B. La République, 1929 gegründet, La Volonté und Notre Temps, 1927 gegründet, und La Voix, welche 1928 ins Leben gerufen wurde.

150 Kayser hatte dieses Ziel folgendermaßen formuliert: „(...) rendre au radicalisme sa raison d'être et de lui restituer le privilège de son originalité."; vgl. S. Berstein, Parti radical, vol. 1, S. 99. 
Gruppe um Joseph Caillaux nennen, die einen kompromißlosen Realismus verlangte, da in ihren Augen die aktuellen Probleme nicht mit den Lösungsmodellen aus der Vorkriegszeit zu lösen waren. In diesem Punkt bestand vielleicht der gravierendste Unterschied zwischen den beiden Hauptrichtungen der Bewegung der Jeunes Turcs. Der gemeinsame Nenner hingegen ließ sich in den beiden Punkten erstens, in dem Willen zur Modernisierung und, zweitens, in der Anpassung der radikalsozialistischen Doktrin an die Zwischenkriegszeit - ausmachen. Hinsichtlich der Wirtschaftspolitik übten die Jeunes Turcs heftige Kritik am Kapitalismus, da er eine „anarchie économique "151 erzeugt habe. Sie propagierten einen sogenannten „dritten Weg“ zwischen Kapitalismus und Kommunismus und setzten sich dafür ein, daß das Individuum in einem vom Staat geschaffenen Rahmen frei agieren kann. Ihre Hauptkritikpunkte am aktuellen politischen System konzentrierten sich vor allem auf zwei Aspekte: 1) auf die Ineffizienz und 2) auf den Formalismus bzw. auf die Trägheit des Systems. Zum einen beanstandeten sie, daß das Parlament zu sehr von den Wählern abhängig sei und somit nicht dem Gemeinwohl dienen könne, da es auf eine Vielzahl von Lokalinteressen Rücksicht nehmen müsse. Zum anderen hielten sie nicht nur die Abhängigkeit der Regierung vom Parlament für reformbedürftig, sondern übten darüber hinaus auch heftig Kritik daran, daß die ohnehin schon schwache Position der Regierung durch die Macht der in ihren Augen verantwortungslosen Bürokratie noch zusätzlich geschwächt werde. Deshalb kamen sie zu dem Ergebnis, daß die Regierung nicht wirklich regiere und das Parlament seine Kontrollfunktion nicht im Namen des Volkes ausübe. Aus diesem Befund resultierte für sie die Forderung nach einer Verfassungsänderung. Die Machtbefugnisse von Regierung, Parlament und Verwaltung sollten sich ändern ${ }^{152}$. Ein weiterer wichtiger Punkt, der innerhalb der Bewegung der Jeunes Turcs für Polarisierung sorgte, war die Koalitionsfrage. Hier trafen zwei Koalitionsmodelle aufeinander. Einerseits gab es eine Gruppe, die sich für die concentration stark machte und mit dem Abgeordneten Dubarry eine Vereinigung der "Realisten“ aller Parteien forderte, jedoch die reaktionären Rechten, die Klerikalen und die Kommunisten ausgeschlossen wissen wollte. Dem stand die Gruppe um Kayser entgegen, die eine Regierung der concentration vehement ablehnte und sich für eine klare Entscheidung zugunsten eines politischen Lagers aussprach, da ihrer Meinung nach die concentration nur zu politischer Handlungsunfähigkeit führe. Nachdem sich 1934 letztlich aber die Befürworter der concentration durchsetzen konnten, glitt die Bewegung der Jeunes Turcs immer mehr nach rechts ab, nur die kleine Gruppe um Jacques Kayser, Pierre Cot und Jean Zay blieb der alten linksgerichteten Tradition des Parti radical treu verbunden.

Die Gruppe um Daladier, die den Parti radical vor allem organisatorisch erneuern wollte, stand politisch für die traditionelle Ausrichtung der Radikalsozialisten und setzte sich für eine Union des gauches ein. Ihr stand in erster Linie die Gruppe um Herriot und die Brüder Sarraut gegenüber, die eine neue Taktik für den Parti

151 Ebenda, S. 106.

$152 \mathrm{Zu}$ den konkreten Reformforderungen hinsichtlich des politischen Systems vgl. Punkt 2 dieses Fallbeispiels. 
radical in Richtung concentration anstrebte. In den Jahren von 1929 bis 1931 befand sich der Parti radical in einem Spannungsfeld, das sich nicht nur aus innerparteilichen, sondern auch aus zwischenparteilichen Faktoren speiste. Unter den innerparteilichen Spannungsmomenten muß das Ringen zwischen den beiden Rivalen Daladier und Herriot bzw. Sarraut genannt werden. Die zwischenparteilichen Einflüsse auf den Parti radical resultierten vor allem aus dem Verhalten der Sozialisten gegenüber den Radikalen. Hinzu traten aber auch die Spaltungsversuche Tardieus ${ }^{153}$, die dieser gezielt gegen den Parti radical richtete. In diesem Koordinatensystem bewegten sich das mühsame Ringen des Parti radical und sein Versuch, aus der Krise herauszufinden.

Obwohl Daladier bestrebt war, den Parti radical mit Hilfe einer Regierung der Union des gauches wieder an die Macht zu bringen, wurde seine Position innerhalb der Partei durch seine Niederlage in der Auseinandersetzung mit der Fraktion geschwächt. Der zunehmende Autoritätsverlust Daladiers hing eng mit den innerparteilichen Spannungen zusammen und wurde ab Mai 1929154 durch eine gezielte Kampagne in der Zeitung La Volonté, die unter der Leitung von Albert Dubarry stand, öffentlich sichtbar. Erstaunlicherweise handelte es sich um dasselbe Presseorgan, das Daladier in den Jahren 1927 bis 1928 unterstützt hatte, um ihn an die Spitze des Parti radical zu bringen.

Durch die starke Position der Fraktion innerhalb der Partei gewannen die Strömungen, die zunehmend die Zukunft des Parti radical in Regierungen der concentration sahen, an Durchsetzungskraft. Obwohl diese Gruppe keineswegs als homogen bezeichnet werden kann - sie setzte sich aus mindestens drei Gruppierungen, deren führende Vertreter Herriot und die Brüder Sarraut waren, zusammen gewann sie politisch an Einfluß. Nach dem Rücktritt Poincarés im Juli 1929 versuchten die Anhänger der concentration innerhalb des Parti radical, im Parlament ihre Kräfte auszuloten. Verschiedene Ansätze dieses radikalsozialistischen Flügels, in eine Regierung der Mitte bzw. der rechten Mitte einzutreten, schlugen fehl, da Daladier und der linke Flügel der Partei dies vereitelten ${ }^{155}$. Nachdem solche Versuche, wieder Regierungsverantwortung zu übernehmen, gescheitert waren, schien sich die Waage immer mehr zugunsten des früheren Parteivorsitzenden Herriot zu neigen. Daladier und sein Flügel hatten stark an Gewicht verloren, und alles deutete darauf hin, daß auf dem Parteitag in Reims im Herbst 1929 ein neuer Vorsitzender gewählt werden würde. Jedoch schadete eine Kampagne, die aus den Reihen der Anhänger der concentration im Parti radical in der Zeitung La Volonté initiiert worden war ${ }^{156}$, dem eigentlichen Ziel und begünstigte letztlich den Flügel der Verfechter der Union des gauches. In dieser Pressekampagne ergriff

${ }_{153}$ Zu Tardieu vgl. J. Jolly, Dictionnaire, vol. 8, S. 3051-3053.

${ }^{154}$ Siehe zur Rolle der Presse hinsichtlich des Richtungskampfes innerhalb des Parti radical und darüber hinaus auch über die Rivalität zwischen Herriot und Daladier um den Parteivorsitz A.N., Notes Jean F7/13192, hier vor allem die Berichte vom 4. 10., 10. 10. und 16. 10. 1929. Außerdem La Volonté vom 23. 5. 1929, S. 1; L'Ere nouvelle vom 23. 5. 1929, S. 1 und La Dépêche de Toulouse vom 24. 5. 1929, S. 1.

155 Vgl. hierzu Le Matin vom 28. 7. 1929, S. 1; La République vom 28. 7. 1929, S. 1; L’Ere nouvelle vom 28. 7. 1929, S. 1. Außerdem auch E. Bonnefous, Histoire politique, vol. 4, S. 361.

156 Im August 1929 scheint der Höhepunkt dieser Auseinandersetzungen erreicht gewesen zu sein; vgl. A.N., Notes Jean F7/12957, Bericht vom 30.7. 1929; A.N., Notes Jean F7/13197, Berichte vom 5. 8. und 6.8. 1929. 
vor allem Jean Montigny157, der als Gefolgsmann Caillaux' galt, das Wort und erklärte, unter welchen Bedingungen der Parti radical bereit war, sich an Regierungen der concentration zu beteiligen: „Le Parti radical-socialiste peut participer à la concentration républicaine à deux conditions, qu'il soit non seulement le pivot, mais l'animateur de cette combinaison; qu'il impose un programme très ferme d'action et qu'il s'assure les principaux ministères. " 158 Schon diese öffentliche Stellungnahme weckte das Mißtrauen des linken radikalsozialistischen Flügels, aber als die Erklärung für die Teilnahme an einer Regierung der concentration noch Unterstützung in der gemäßigten und konservativen Presse und vor allem von seiten des konservativen Innenministers André Tardieu ${ }^{159}$ erhielt, nutzte Daladier den Vorfall, um in seiner Partei gegen die Bestrebungen der Befürworter einer Regierung der concentration vorzugehen. Er warf dem rechten Flügel vor, Tardieu Einfluß auf den Parti radical zu ermöglichen sowie sich in den Dienst seiner Interessen zu stellen und damit letztlich der eigenen Partei zu schaden. Dank der eingetretenen Situation gelang es Daladier, der den linken Flügel geschlossen hinter sich wußte, den Parteivorsitz auf dem Parteitag in Reims von 1929 zu verteidigen. Herriot und Chautemps, die im Vorfeld des Parteitages ebenso als mögliche Kandidaten diskutiert worden waren, verzichteten auf eine Auseinandersetzung mit Daladier, die eine hohe Spaltungsgefahr in sich barg. Durch die offensive Einmischung Tardieus in den Richtungsstreit des Parti radical hat sich die Parteibasis auf dem Parteitag in Reims dezidiert gegen eine Regierung der concentration ausgesprochen und einen entsprechenden Parteitagsbeschluß gefasst ${ }^{160}$. Die Position Daladiers in der Partei schien wieder gefestigt zu sein, nachdem er im Sommer 1929 die Jeunes Turcs hinter sich wußte, die unbedingt an ihm festhielten, da sie hofften, daß er die begonnene Reform des Parti radical auch erfolgreich beenden würde.

Als Daladier von Doumergue im Oktober 1929 einen Auftrag zur Regierungsbildung erhielt, wollte er zusammen mit den Sozialisten ein Kabinett der Union des gauches bilden, was letztlich am Nein des obersten Parteigremiums der Sozialisten scheiterte ${ }^{161}$. Ohne die Sozialisten war eine regierungsfähige Mehrheit im Parlament für ein Bündnis der Union des gauches nicht vorhanden ${ }^{162}$, wie ein wei-

157 Zu Montigny vgl. J. Jolly, Dictionnaire, vol. 7, S. 2506-2507.

158 La Volonté vom 8. 9. 1929, S. 1 und vom 9. 9. 1929, S. 1.

159 Tardieu hatte in einer Rede, die er in Gray hielt, die radikalsozialistischen Abgeordneten aufgefordert, die alten Politikraster zu überwinden, um „proteger la race et developper l'outillage économique“, in A.N., Notes Jean F7/12957, Bericht vom 14.10. 1929, sowie F. Monnet, Réfaire la République. André Tardieu, une dérive réactionnaire (1876-1945), Paris 1993, S. 131-136; S. Berstein, Parti radical, vol. 2, S. 141.

160 Aus dem Parteitagsbeschluß des Parti radical vom Parteitag in Reims vom 24. 10.-27. 10. 1929: „Le parti républicain radical et radical-socialiste (...) repousse toute participation de ses membres ou tout appui de ses membres à une combinaison parlementaire ou gouvernementale dirigée ou soutenue par la droite et ses alliées, et qui n'aurait pour but, de quelque nom qu'on la décore que de prolonger, en y associant des républicains, une formation politique désormais condamnée (...).“; L'Oeuvre vom 25. 10. 1929, S. 4.

161 Auf der Tagung des Conseil national der SFIO, den das oberste Parteigremium CAP einberufen hatte, wurde die Entscheidung der sozialistischen parlamentarischen Gruppe revidiert; vgl. Le Populaire vom 29. 10. 1929, S. 1/2; L'Oeuvre vom 29. 10. 1929, S. 1; L'Ere nouvelle vom 29. 10. 1929, S. 1; La Dépêche de Toulouse vom 29. 10. 1929, S. 1.

162 Radikalsozialisten und Sozialisten hätten allein keine Mehrheit stellen können und waren somit auf kleinere linksrepublikanische Fraktionen bis hin zu parlamentarischen Gruppen der Mitte an- 
terer erfolgloser Versuch Daladiers, mit den Republikanern ein Mitte-LinksBündnis zu formieren, verdeutlichte ${ }^{163}$. Das Verhältnis zwischen dem Parti radical und der SFIO war nach diesem erneut gescheiterten Versuch einer Zusammenarbeit nachhaltig belastet, deshalb waren die Reaktionen in den einzelnen Presseorganen des Parti radical, wie z. B. des Ere Nouvelle, entsprechend deutlich. Albert Milhaud kritisierte das Verhalten der Mehrheit der SFIO als reine Taktik im Hinblick auf die nächsten Wahlen: „Car, somme toute, à quoi servent les partis d'avant-garde si, paralysés, ligotés, ils sont soumis à un formalisme étriqué et désuet? Armée de parade, non pas troupes d'action. Parti de propagande, non pas parti de réalisation. J'entends bien qu'on ne recule que pour préparer une offensive triomphale. J'entends bien qu'on se réserve pour les nouvelles consultations électorales (...).“164

Nach der Absage der SFIO blieben dem Parti radical nur noch zwei Möglichkeiten, um aus der politisch verfahrenen Situation herauszufinden: zum einen definitiv in die Opposition zu gehen und zum anderen Allianzen mit anderen Parteien zu suchen. Da sich der Parti radical seinem Selbstverständnis nach als eine Regierungspartei und nicht als eine Oppositionspartei sah, war es ziemlich naheliegend, daß nach der Absage der Sozialisten der Parti radical mit anderen Parteien zu koalieren versuchte. Daher können die Jahre von Ende 1929 bis Anfang 1932 als ein Lavieren zwischen erzwungener Opposition und den Bemühungen, mit Parteien der Mitte zu regieren, charakterisiert werden.

Stark eingeschränkt war der Parti radical in seinem Handlungsradius auch durch den innerparteilichen Führungskonflikt. Vor diesem Hintergrund müssen die verschiedenen gescheiterten Versuche des Parti radical, unter seiner Führung eine Regierung der concentration zu bilden, betrachtet werden. Nachdem Daladier selbst eine erfolgreiche Regierungsbildung mit Kräften der concentration versagt blieb, mußte er im Interesse seiner Position als Parteivorsitzender darauf achten, daß nicht ein anderes exponiertes Mitglied des Parti radical darin erfolgreich war. Als Clémentel Ende Oktober ${ }^{165}$ einen Auftrag zur Regierungsbildung erhal-

gewiesen. Noch bevor die Entscheidung auf der Tagung des Conseil National der Sozialisten gegen eine Regierungsbeteiligung gefallen war, verkündete die Gruppe der Républicains de gauche, daß sie keine Regierung mit sozialistischer Beteiligung unterstützen werde; vgl. Le Populaire vom 29. 10. 1929, S. 1. Auch die Alliance Démocratique hatte sich in einer gemeinsam verabschiedeten Stellungnahme gegen eine Regierung mit sozialistischer Beteiligung ausgesprochen, weil dies gegen das Wahlergebnis von 1928 sprechen würde; vgl. Le Temps vom 30. 10. 1929, S. 1 .

163 Daladier führte auch Gespräche mit der Gruppe der Gauche radicale. Zu den Sondierungsverhandlungen Daladiers Ende Oktober 1929 siehe Le Populaire vom 29. 10. 1929, S. 3; Le Temps vom 29. 10. 1929, S. 6 und Le Temps vom 30. 10. 1929, S. 1. Außerdem liegt ein ausführlicher Bericht über die Regierungsbildungsverhandlungen Daladiers sowohl mit den Sozialisten als auch mit Briand im Nachlaß Génébrier, zur damaligen Zeit Sekretär Daladiers: Fondation Nationale des Sciences politiques, Nachlaß Génébrier, GE 1, Essai de la constitution d'un ministère Daladier de 25. 10.-30. 10. 1929. Diese Unterlagen sind äußerst aufschlußreich, da Briand während der Verhandlungen mit Daladier ein doppeltes Spiel betrieben hatte, denn er stand gleichzeitig auch in Verbindung mit Laval für eine eventuelle Regierung einer Union républicaine. Als Daladier dies entdeckte, verzichtete er auf eine Regierungsbildung und gab den Regierungsauftrag zurück. Diese Regierungsverhandlungen trugen dazu bei, daß es zwischen Daladier und Briand zu einem polemischen Schlagabtausch kam.

${ }^{164}$ L'Ere nouvelle vom 30. 10. 1929, S. 1. Weitere Äußerungen zum Verhalten der SFIO aus Sicht des Parti radical: ebenda.

$165 \mathrm{Zu}$ den Sondierungsgesprächen Clémentels für eine Regierungsbildung siehe La Dépêche de Toulouse vom 31. 10. 1929, S. 1; vom 1. 11. 1929, S. 1 sowie Le Temps vom 1. 11. 1929, S. 1. 
ten hatte und Chautemps das Schlüsselministerium des Inneren überantworten wollte, wurde dies durch die Intervention des radikalsozialistischen Abgeordneten Montigny 166 vereitelt, der forderte, daß dem Parteivorsitzenden des Parti radical dieses Ministerium angeboten werden müsse. Daladier wurden zwar Ministerposten angetragen, aber nicht das Innenministerium; deshalb lehnte er ab, woraufhin auch die anderen radikalsozialistischen Abgeordneten auf die ihnen angebotenen Ministerämter verzichteten ${ }^{167}$. Innerhalb des Parti radical schloß sich an diese ausgeschlagene Chance eine rege Diskussion und Auseinandersetzung an ${ }^{168}$. Da die Fraktion nach wie vor mit Daladier in Widerspruch stand, quittierte sie seine Entscheidung damit, daß sie anstelle Daladiers Chautemps zu ihrem Fraktionsvorsitzenden wählte ${ }^{169}$. Nachdem Ende Januar 1930 die Sozialisten auf einem Sonderparteitag eine Zusammenarbeit mit anderen Parteien definitiv abgelehnt hatten, mußte Daladier erkennen, daß eine Rückkehr des Parti radical in die Regierungsposition mit Hilfe der Sozialisten nicht möglich war.

Tardieu, der ab Ende November 1929 die Regierungsverantwortung übernommen hatte, bot den Radikalen acht Ministerposten an ${ }^{170}$, in der Hoffnung, damit einen Teil des Parti radical für sein Lager gewinnen zu können und dadurch zugleich die Herausbildung eines bipolaren Parteiensystems zu fördern. Einige Exponenten des rechten Flügels, die die Regierungsfunktion des Parti radical als existentielles Element dieser Partei werteten, gingen auf das Angebot Tardieus ein, jedoch setzte sich Herriot massiv gegen die Annahme der Ministerämter ein ${ }^{171}$, um die Einflußnahme Tardieus auf den Parti radical zu verhindern. Tardieu galt bei den linksrepublikanischen Kräften als Spalter der Radikalen, und sein Verhältnis zu dieser zentralen Partei im französischen Parteiensystem ist als äußerst ambivalent zu bezeichnen.

166 Vgl. dazu S. Berstein, Parti radical, vol. 2, S. 152, aber auch die Erklärung Montignys in Le Temps vom 2. 11. 1929, S. 1/2. Hier erklärte Montigny allerdings nur, daß er selbst einen Ministerposten von Clémentel angeboten bekommen habe, welchen er aber ablehnte, weil er es nicht als angemessen empfand, einer Regierung anzugehören, wenn der Parteivorsitzende keinen Ministerposten angeboten bekommen habe. Clémentel fragte deshalb auch bei Daladier an, ob er in sein Kabinett eintreten wolle.

167 Clémentel hatte Daladier sowohl das Justizministerium wie auch das Kriegsministerium angeboten, jedoch lehnte Daladier beide ab und forderte das Innenministerium. Clémentel teilte ihm mit, daß die Kabinettsmehrheit sich damit nicht einverstanden erklären werde. Nachdem Daladier das Innenministerium nicht erhalten konnte, riet ihm Montigny, zu verzichten. Daraufhin zogen sich auch die anderen radikalsozialistischen Kandidaten aus der Kabinettsbildung zurück. Clémentel gab den Auftrag der Regierungsbildung zurück; vgl. Le Temps vom 2. 11. 1929, S. 1. In der Verzichtserklärung Clémentels wies dieser darauf hin, daß es zu Komplikationen um die Vergabe des Innenministeriums gekommen war; vgl. La Dépêche de Toulouse vom 1. 11. 1929, S. 1.

${ }_{168} \mathrm{Zu}$ den Auseinandersetzungen in der parlamentarischen Gruppe des Parti radical über die Entscheidung Daladiers siehe Le Temps vom 2. 11. 1929, S. 6. Die Diskussion wurde so heftig geführt, daß Daladier drohte, vom Parteivorsitz zurückzutreten, wenn Jacquier seinen Tagesordnungspunkt nicht zurückziehe. Jacquier hatte in seinem Tagesordnungspunkt die Entscheidung der radikalsozialistischen Abgeordneten, die von Clémentel angetragenen Ministerposten nicht zu akzeptieren, stark kritisiert, da sie diese Entscheidung nicht in Rücksprache mit der Partei getroffen hatten.

169 Am 17. 1. 1930 wurde Chautemps zum Vorsitzenden der radikalsozialistischen Fraktion gewählt; vgl. Le Temps vom 18.1. 1930, S.8.

170 La Dépêche de Toulouse vom 2.11. und 3. 11. 1929, jeweils S. 1.

171 Zur ausführlichen und kontroversen Diskussion innerhalb der radikalsozialistischen Fraktion vgl. La Dépêche de Toulouse vom 3. 11. 1929, S. 1. 
Als auch diese Regierungschance des Parti radical ungenutzt blieb, kam es bei den Radikalen zu heftigen Protesten. Diejenigen, die protestierten, wurden, da sie die Einheit des Parti radical gefährdeten, aus der Partei ausgeschlossen ${ }^{172}$. Auf die Bemühungen Tardieus folgten zwischen Februar 1930 und Januar 1931 von seiten des Parti radical nochmals einige Anläufe unter Chautemps eine Regierung der concentration zu bilden, die sich allerdings nicht als längerfristig tragfähig erwiesen ${ }^{173}$. Tardieu jedoch unternahm im Frühjahr 1930 einen weiteren Versuch, um den Parti radical in eine von ihm geführte Regierung einzubinden, aber wiederum versagten sich die Radikalen, da sie um die Einheit der Partei fürchteten. Als Tardieu zur Kenntnis nehmen mußte, daß er mit Regierungsangeboten an den Parti radical sein Ziel nicht erreichen konnte, attackierte er in einer Rede am 1. Juni 1930174 in Dijon den Parti radical. Diese Rede führte dazu, daß innerhalb des Parti radical die einzelnen Führungskämpfe nachließen und wieder das Bemühen um die Einheit der Partei in den Vordergrund trat. Sowohl Daladier als auch Herriot, beide wichtige führende Persönlichkeiten des Parti radical, verteidigten die Partei gegen die Vorwürfe des konservativen Politikers André Tardieu.

Der Parteitag von Grenoble vom 9. bis 12. Oktober 1930175 kann als Wendepunkt für den Parti radical gewertet werden. Durch die Attacken Tardieus und seine vielfachen Versuche, den Parti radical zu spalten, kam es im Parti radical zwischen den Flügeln zu einem neuen Einheitsgefühl. Die verschiedenen gemäBigten Parteiströmungen versuchten vorsichtig, die Partei auf eine Linie zu bringen, um sie für einen Kurs der concentration zu gewinnen. Dieses Unterfangen der Kreise um Herriot, die Brüder Sarraut und Chautemps wurde durch Gaston Bergery konterkariert, der kritisierte, daß die politischen Lösungsvorstellungen der gemäßigten Strömungen im Parti radical letztlich die Akzeptanz eines Rechtsrutsches bedeute und die Reformpolitik, die seit 1927 unter Daladier praktiziert worden war, damit aufgegeben würde.

In Grenoble wurde offensichtlich, daß sich der linke Parteiflügel in der Minderheit befand. An eine Regierung der Union des gauches glaubte fast niemand mehr unter den Radikalsozialisten, vielmehr hatten Verbitterung und Enttäuschung um sich gegriffen. Dies fand besonders darin seinen Niederschlag, daß die Parteibasis der Parteispitze in ihrer Schlußresolution ${ }^{176}$ einen koalitionspolitischen Blanko-

172 Drei radikalsozialistische Abgeordnete, Cortehoux, Lautier und Philippoteaux, reichten ihre Austrittsgesuche ein, da sie sich nicht an das Votum halten wollten. Zu ihren Austrittsgesuchen siehe Le Temps vom 9.11.1929, S. 6.

173 Chautemps bildete am 21. 2. 1930 ein Kabinett, das in der Kammer am 25. 2. 1930 nicht die notwendige Unterstützung fand; vgl. E. Bonnefous, Histoire politique, vol. 5, S. 14-16.

174 Zum Wortlaut der Rede Tardieus vom 1.6. 1930 siehe La Dépêche de Toulouse vom 2.6. 1930, S. 1/2. Tardieu unterstrich in seinem Angriff auf den Parti radical, daß dieser nicht mehr die Schlüsselpartei im französischen Parlament darstelle, sondern sich durch die geringe Anzahl der Abgeordneten nur noch an Regierungen beteiligen, aber keinen Führungsanspruch mehr stellen könne: „Le Parti radical socialiste ne possède ni privilège héréditaire, ni hypothèque légale, ni droit éminent sur ce qu'il appelle volontiers les leviers de commande - par exemple, sur le ministère de l'interiéur. Il n'est plus dans la Chambre actuelle un axe déterminant d'orientation. La mathématique électorale le réduit à n'être qu'un appoint.“

$17527 \mathrm{e}$ Congrès du Parti républicain radical et radical-socialiste tenu à Grenoble, les $9,10,11,12$ octobre 1930, Paris 1930; ebenso L'Oeuvre vom 9. 10.-13. 10. 1930, jeweils S. 1, 3, 4.

176 Zum Wortlaut der Schlußresolution siehe L'Oeuvre vom 13. 10. 1930, S. 1: „(...) nous voulons, une fois encore, proclamer notre résolution de repousser toute alliance avec les droites cléricales, natio- 
scheck ausstellte, der nur eine Zusammenarbeit mit den rechten Kräften und den Klerikalen ausschloß. Die Zukunft des Parti radical wurde nur noch in Regierungen der concentration gesehen. Jedoch scheiterte, wie schon alle früheren Anstrengungen, im Dezember 1930 bzw. im Januar 1931 auch ein weiterer Regierungsversuch in diese Richtung unter Steeg ${ }^{177}$. So blieb bis zum Ende der Legislaturperiode (von Januar 1931 bis April 1932) dem Parti radical nur die Rolle der erzwungenen Opposition übrig, denn eine Teilnahme an den rechten Regierungen, in denen der Parti radical den linken Rand gebildet hätte, konnte in der Partei nicht durchgesetzt werden.

Durch diese aussichtslose und sehr unbefriedigende Situation wurde die Position Daladiers als Parteivorsitzender zunehmend geschwächt, und Herriot befand sich weiter im Aufwind. Auf ihm ruhte die einzige Hoffnung, die mittlerweile dem Parti radical noch verblieben war, die Wahlen mit großem Erfolg zu gewinnen. Die Parteigremien wandten sich immer stärker Herriot zu, dies hing auch damit zusammen, daß Daladier bekannt gab, für den Parteivorsitz nicht mehr zu kandidieren. Herriot, der sich noch 1929 geweigert hatte, wieder für den Parteivorsitz zur Verfügung zu stehen, hatte im Laufe des Jahres 1930 diesbezüglich seine Meinung geändert, da sich auch der Einfluß Chautemps' nach und nach auszubreiten begann. Der Parteitag von 1931, der vom 5. bis 8. November 1931178 stattfand, geriet zum großen Erfolg für Herriot. Er wurde einstimmig zum Parteivorsitzenden gewählt ${ }^{179}$, Daladier erhielt den Titel eines Ehrenpräsidenten. Mit dieser Geste versuchte Herriot, auch den linken Flügel des Parti radical einzubinden ${ }^{180}$. Der Parti radical hatte mit Herriot nun wieder eine Persönlichkeit an seiner Spitze, die die Partei einte und geschlossen in den Wahlkampf von 1932 führte. Der Wahl Herriots folgten einige personelle Veränderungen im Parteisekretariat ${ }^{181}$, und die Bewegung der Jeunes Turcs wurde weitgehend in den Hintergrund gedrängt.

Die machtvolle Position Herriots innerhalb des Parti radical basierte größtenteils auf der neu gewonnenen Stärke in der Auseinandersetzung mit den Sozialisten. Mit der SFIO war es bei Nachwahlen zunehmend zu Konflikten gekommen.

nalistes et conservatrices." Es wurde von einem Delegierten reklamiert, daß die Formulierung, der Parti radical stelle sich gegen jede Allianz mit den rechten Kräften, ungenügend sei, und er forderte den Zusatz „und alle ihre Verbündeten“; ebenda.

177 Zur Regierung Steeg und ihrem Sturz vgl. E. Bonnefous, Histoire politique, vol. 5, S. 49-60; La Dépêche de Toulouse vom 12. 12.-16. 12. 1930, 24. 12. 1930 und 23.1.1931, jeweils S. $1,3$.

178 Zum Parteitag von 1931: 28 e Congrès du Parti républicain radical et radical-socialiste tenu à Paris les 5, 6, 7, 8 novembre 1931, Paris 1931; ebenso L'Oeuvre vom 5. 11.-9. 11. 1931, jeweils S. 1, 3, 4.

179 Zur Wahl Herriots, die auf Vorschlag Daladiers per Akklamation am 6. 11. 1931 stattfand, vgl. La Dépêche de Toulouse vom 7.11. 1931, S. 1/2. Obwohl die Wahl Herriots sehr theatralisch geschildert wird, erfolgte ein kleiner Seitenhieb gegen Caillaux: "L'émotion de l'auditoire atteint à son comble. Celle du nouveau président du parti n'est pas moins intense et M. Caillaux, assis aux tables de la presse, au pied de la tribune, demeure, immobile, le visage crispé."; ebenda, S. 2.

180 Das Hauptcharakteristikum, das den Parteitag von 1931 auszeichnete, war vor allem die demonstrative Geschlossenheit des Parti radical. Siehe dazu auch den Pressespiegel in La Dépêche de Toulouse vom 7.11.1931, S. 3.

181 Nach der Wahl Herriots zum Parteivorsitzenden kam es zu personellen Veränderungen im Parteiapparat: Albert Milhaud übernahm das Generalsekretariat anstelle von Léon Martinaud-Deplat und Roger Colledeboeuf, der persönlicher Sekretär Herriots in Lyon war, wurde stellvertretender Generalsekretär bei der Partei; vgl. S. Berstein, Parti radical, vol. 2, S. 185. 
Bei den Nachwahlen in Narbonne (1929) ${ }^{182}$ wie auch in Bergerac (1930)183 gerieten beide Parteien in eine Konkurrenzsituation, die das Verhältnis zwischen dem $P$ arti radical und der SFIO nachhaltig belastete.

Die zunehmenden Auseinandersetzungen zwischen beiden Parteien fanden ihren Höhepunkt im Konflikt zwischen der SFIO und Herriot bei den Stadtratswahlen in Lyon im Frühjahr $1931^{184}$. Dort kam es zu einer Machtprobe zwischen dem Stadtrat und Herriot, als bei der Benennung der Delegierten für die Nachwahl des verstorbenen Senators der Radikalen, Robert Lacroix, die Sozialisten, die im Stadtrat über die Mehrheit verfügten, nur sozialistische Delegierte auswählten. Herriot trat daraufhin verbittert vom Amt des Bürgermeisters zurück. Bedingt durch Todesfälle und Rücktritte bestand der Stadtrat nur noch aus 25 sozialistischen, 23 radikalsozialistischen und sieben gemäßigten Mitgliedern. Bei den dadurch notwendig werdenden Neuwahlen zeigte sich Herriot kämpferisch. Er trat als Stadtrat im ersten Arrondissement zurück, da dort mit Sicherheit ein radikalsozialistischer Kandidat gewählt wurde, und beschloß, im dritten Arrondissement anzutreten, in dem der dort 1929 gewählte sozialistische Stadtrat verstorben war ${ }^{185}$. Obwohl es sich vordergründig um eine lokale Angelegenheit zu handeln schien ${ }^{186}$, schalteten sich auf beiden Seiten die Parteigremien auf nationaler Ebene ein. Die Wahl wurde für Herriot zum großen Triumph; im ersten Arrondissement konnte sich der radikalsozialistische Kandidat wie erwartet durchsetzen und Herriot behauptete sich im dritten Arrondissement mit großer Stimmenmehrheit und wurde vom Stadtrat wieder zum Bügergermeister gewählt ${ }^{187}$. Dieser Wahlausgang hatte in verschiedener Hinsicht seine Bedeutung und Wirkung. Zum einen wurde er von den Radikalsozialisten als Revanche für die Niederlage gegen die Sozialisten in Bergerac gewertet. Zum anderen unterstrich er sehr anschaulich, daß der Radikalismus wieder in der Lage war, sich gegen den Sozialismus bei den Wählern zu behaupten, und das traditionelle Verhältnis zwischen den beiden Parteien wie-

182 Obwohl Blum als sicherer Kandidat galt, stellte die radikalsozialistische Föderation einen eigenen Kandidaten auf, und trat damit in Konkurrenz zu den Sozialisten. Erstaunlicherweise verzichteten die konservativen Kräfte auf einen eigenen Bewerber und unterstützten den Radikalsozialisten. Diese Aktion bot Anlaß zu heftigen Diskussionen zwischen dem Parti radical und der SFIO im Hinblick auf ihr Verhältnis zueinander. Zur Interpretation Blums siehe Le Populaire vom 21. bis 23. und vom 25. bis 27.4. 1929, jeweils S. 1 .

183 Vgl. dazu Punkt 1 dieses Prozeßbeispiels. Zur Bewertung des Wahlergebnisses innerhalb der verschiedenen Flügel des Parti radical vgl. S. Berstein, Parti radical, vol. 2, S. 176-179.

184 Zum genauen Hintergrund der Situation und der allgemeinen Verwunderung über die Kampfansage Herriots, der sich im ersten Arrondissement zurückzog und im dritten Arrondissement zur Wahl antrat, obwohl dieses als sozialistische Hochburg galt, siehe La Dépêche de Toulouse vom 6. 4. 1931, S. 2: „La décision de M. Herriot de quitter son fief du premier arrondissement pour aller porter le combat au coeur de la Guillotière, en plein terrain ouvrier et socialiste, a produit une certaine sensation."

$185 \mathrm{Vgl}$. S. Berstein, Edourd Herriot ou la République en personne, S. $173 \mathrm{f}$.

186 Herriot wies jegliche Verantwortung für die nationale Bedeutung dieser lokalen Angelegenheit von sich: „Je fais remarquer, d'ailleurs, que ce sont mes adversaires qui ont donné un caractère politique à une élection que j'aurais voulu maintenir sur le terrain strictement municipal."; vgl. La Dépêche de Toulouse vom 10. 4.1931, S. 1/2.

187 Die Wahl fand am 19.4. 1931 statt. Herriot konnte mit großem Abstand 8881 Stimmen auf sich vereinen gegenüber dem gemäßigten Kandidaten, der 2236 Stimmen erhielt, und dem sozialistischen Vertreter, der nur 1923 Voten erringen konnte. Zum Wahlergebnis vgl. La Dépêche de Toulouse vom 20. 4. 1931, S. 1 und auch S. Berstein, Parti radical, vol. 2, S. 180. 
der hergestellt war, nachdem bei den Stadtratswahlen von 1929188 die Sozialisten den Radikalen hohe Stimmenverluste zugefügt hatten. Yvon Delbos drückte am treffendsten aus, welchen Stellenwert die Wahl von 1931 für den Parti radical hatte: "C'est le radicalisme qui a été plébiscité à Lyon en la personne de son chef." 189 Diese Wertung erfaßte die Bedeutung des Wahlerfolges für den Parti radical einerseits im Hinblick auf das Verhältnis zu den anderen Parteien, denn Herriot gelang mit diesem Ergebnis sowohl ein Erfolg gegenüber der SFIO wie auch gegenüber den Gemäßigten. Zugleich entschied Herriot mit seinem Triumph wie selbstverständlich den Kampf um den Parteivorsitz für sich, und es gelang $\mathrm{ihm}$, aus dem Parti radical wieder eine geschlossene Partei zu formieren. Die weitreichendsten Konsequenzen aus dieser Stadtratswahl von 1931 zog die Zeitung L'Ere nouvelle, die beide Aspekte zu interpretieren verstand: „L'élection de Lyon nous a donné une tactique et a montré notre chef. Elle a d'abord prouvé qu'en forcant les socialistes à déployer leur drapeau, à dévoiler leur véritable programme, les radicaux ralliaient aisément la grande majorité des voix républicaines (...). Trop longtemps, le parti collectiviste a pu se targuer de succès électoraux qui ne lui appartenaient pas. (...) Le radicalisme doit être défendu et représenté par les radicaux eux-mêmes. Ils n'ont pas besoin de porte-parole, encore moins de porte-drapeau emprunté aux partis voisins. Il appartient à Edouard Herriot qui a fait triompher cette thèse dans des circonstances mémorables de conduire le parti dans la voie où il doit désormais s'engager. A la verité, c'est la bataille électorale de 1932 qui vient non seulement de commencer, mais de se définir. ${ }^{\text {"190 }}$

Neben der angeführten Konkurrenzsituation bei verschiedenen Nachwahlen zwischen dem Parti radical und der SFIO entzweite auch die Wahl des Staatspräsidenten die beiden Parteien. Im ersten Wahlgang traten Briand und Doumer ${ }^{191}$ gegeneinander an. Innerhalb des Parti radical hatten sich zu dieser Frage unterschiedliche Lager gebildet. Der Großteil des Parti radical unterstützte zusammen mit den anderen linksrepublikanischen Kräften Briand und nicht Doumer, den radikalsozialistischen Senator, der innerhalb der Partei als zu weit rechtsstehend und als Verbünderter des rechten Louis Marin ${ }^{192}$ galt. Als jedoch Briand im ersten Wahlgang gegen Doumer unterlag ${ }^{193}$, zog er seine Kandidatur zurück. Die Sozialisten baten die Radikalen, im zweiten Wahlgang gemeinsam mit ihnen zu stimmen. Sie unterstützten jedoch nicht Doumer, sondern präsentierten mit Pierre Marraud ${ }^{194}$ einen neuen Kandidaten, der aber nur 334 Stimmen von 883 auf sich vereinen konnte. Doumer behauptete sich schließlich mit 504 Stimmen und übernahm das Amt des Staatspräsidenten ${ }^{195}$. Die Sozialisten gaben vor allem den Radi-

$188 \mathrm{Zu}$ den Stadtratswahlen vom Mai 1929 siehe Le Radical vom 12. 5. und 19. 5. 1929, jeweils S. 1, und in Bezugnahme dazu, La Dépêche de Toulouse vom 30. 3. 1931, S. 1, 3.

184 La Dépêche de Toulouse vom 21. 4. 1931, S. 1.

190 L'Ere Nouvelle vom 21. 4. 1931, S. 1.

191 Zu Paul Doumer vgl. J. Jolly, Dictionnaire, vol. 4, S. 1473-1476.

$192 \mathrm{Zu}$ Louis Marin vgl. ebenda, vol. 7, S. 2371-2373.

193 Doumer konnte im ersten Wahlgang 442 Stimmen auf sich vereinen, während Briand nur 401 Stimmen erzielte. Zum Abstimmungsergebnis im ersten und zweiten Wahlgang siehe Le Temps vom 15. 5. 1931, S. 1.

${ }^{194} \mathrm{Zu}$ Pierre Marraud, Senator aus dem Département Lot-et-Garonne, siehe J. Jolly, Dictionnaire, vol. 7, S. 2379-2380.

${ }^{195}$ Zum Wahlergebnis im zweiten Wahlgang siehe Le Temps vom 15. 5. 1931, S. 1. 
kalsozialisten für die Niederlage Briands im ersten Wahlgang die Schuld, da Briand nicht alle Stimmen der Gruppen erhalten hatte, die sich im Vorfeld der Wahl für ihn ausgesprochen hatten ${ }^{196}$. Blum unterstellte Herriot, daß er gegen Briand gearbeitet hätte, um die Basis für eine Mehrheit der concentration mit Tardieu vorzubereiten ${ }^{197}$.

Alle diese genannten Faktoren trugen dazu bei, daß das Verhältnis zwischen SFIO und Parti radical sich ziemlich abkühlte und ein gemeinsames Agieren bei den Wahlen von 1932 alles andere als erstrebenswert schien. Vor allem aus den Erfahrungen der Lyoner Nachwahl hatte Herriot sein Konzept für die Parlamentswahlen von 1932 entwickelt. Es kristallisierte sich immer deutlicher heraus, daß der Parti radical ohne Bündnispartner antreten würde, um damit vor allem seine Unabhängigkeit demonstrieren und bewahren zu können.

\section{Wahlkampf und Wahlsieg der Union des gauches 1932}

\section{Wabltaktik und Wablkampf der SFIO}

Wie im vorhergehenden Kapitel bereits dargelegt, hatte sich das Verhältnis zwischen dem Parti radical und der SFIO in den Jahren 1927 bis 1932 besonders aus zwei Gründen abgekühlt: Zum einen wegen der unterschiedlichen Enttäuschungen beider Parteien, die aus der Zusammenarbeit im Rahmen des Cartel des gauches resultierten, und zum anderen wegen der zunehmenden Konkurrenz, zu der es zwischen beiden Parteien auf dem linken Parteienspektrum im Kampf um die Wählergunst gekommen war. So zeichnete sich bereits im Vorfeld des Wahljahres $1932 \mathrm{ab}$, daß beide Parteien ohne gemeinsame Wahlkoalition zu den Wahlen vom 1. bzw. 8. Mai 1932 anzutreten beabsichtigten. Die Sozialisten setzten sich mit ihrem Wahlprogramm und ihrer Wahltaktik auf dem außerordentlichen Parteitag am 30./31. Januar 1932 auseinander. Auf dem vorausgegangenen ordentlichen Parteitag der SFIO vom 24. bis 27. Mai 1931, der sich hauptsächlich mit der Position der sozialistischen Partei in der Frage der Landesverteidigung beschäftigt hatte, hatte Blum das Thema Wahlen von 1932 lediglich beiläufig angeschnitten, als er äußerte, daß er eine gemeinsame Front der rechten und nationalen Parteien gegen die Sozialisten bei den Wahlen von 1932 vermute ${ }^{198}$. Er selbst ging von einem großen Erfolg der SFIO bei den bevorstehenden Wahlen aus, den er größtenteils nach dem positiven Abschneiden der Sozialisten bei Nachwahlen und der dezidiert geführten Oppositionspolitik der SFIO in der Zeit der Kabinette Tar-

196 Blum warf Herriot vor, daß er mit seiner Rede zur Außenpolitik Briand kritisiert und damit die Chancen Briands gemindert habe. Vgl. dazu die Artikel Blums, in denen er seine Vorwürfe gegenüber Herriot ausführte, in Le Populaire vom 14. 5., 15. 5., 16. 5., 18. 5., 20. 5. 1931, jeweils S. 1. Blum hatte angeregt, Briand als Kandidat um das Staatspräsidentenamt zu unterstützen, da er in Frankreich als Mann des Friedens galt; vgl. Le Temps vom 13. 5. 1931, S. 1.

197 Blum in Le Populaire vom 16. 5. 1931, S.1. Vgl. dazu auch La Dépêche de Toulouse vom 18. 5. 1931 und 19. 5. 1931, jeweils S. 1, wo Herriot ausführlich die Vorwürfe Blums zurückwies. Dieser hatte Herriot vorgehalten, daß er durch seine Intervention in der Debatte um den Anschluß den Elan des Parti radical geschwächt und damit der Kandidatur Briand geschadet hätte. Vgl. dazu auch den offenen Brief Herriots an Blum in La Dépêche de Toulouse vom 19.5. 1931, S. 1.

198 28e Congrès National à Tours de 24.-27. 5. 1931, Paris 1931, S. $163 \mathrm{ff}$. 
dieu-Laval erwarten zu dürfen glaubte. Léon Blum hielt diese Ausgangsposition der Sozialisten für den Wahlkampf 1932 für äußerst vorteilhaft und erhoffte sich zum einen, aus der Oppositionsrolle eine wirksame Wahlpropaganda entfalten zu können, und zum anderen, die Einheit der sozialistischen Partei stärken zu können ${ }^{199}$.

Im Vorfeld des Parteitages wurde ein Ausschuß bestimmt ${ }^{200}$, der die zur Diskussion und zur Verabschiedung stehenden Texte vorbereitete. Um ein innerparteiliches Gleichgewicht zwischen den verschiedenen Parteiströmungen zu gewährleisten, war dieser Ausschuß mit Vertretern der verschiedenen Richtungen wie Renaudel, Auriol, Séverac, Zyromski und Blum besetzt worden; wobei Blum eine besondere Rolle zukam, da ihm die Ausarbeitung der Wahlplattform übertragen wurde 201 .

Blum erklärte zu Beginn seiner Ausführungen über die Wahlplattform, daß sie sich sowohl vom Aktionsprogramm von 1919 als auch vom detaillierten Reformprogramm von 1928 unterscheide, denn sie konzentriere sich auf die wesentlichen Punkte der Krise, die die Bevölkerung beschäftige. Er betonte sehr propagandistisch, daß diese Plattform vor allem dem sozialistischem Gedankengut und dem Ziel, die Grundlagen für die Ablösung des kapitalistischen Systems durch das sozialistische zu schaffen, Rechnung trage. Folgende Aspekte beinhaltete die Wahlplattform: Der erste Punkt behandelte die Überwindung der kapitalistischen Krise durch das sozialistische System ${ }^{202}$. Der zweite große Themenaspekt wurde unter der Formel „Der Kampf gegen den Krieg und der Kampf für den Frieden“ zusammengefaßt. Blum unterstrich im Hinblick auf die Genfer Konferenz, daß ein dauerhafter Friede nur durch die beiden Prinzipien kollektive Sicherheit durch obligatorische Schiedsgerichtsbarkeit und Abrüstung erreicht werden könne.

Der dritte Aspekt beinhaltete die Einführung der 40-Stundenwoche bei gleichem Lohn und die Einführung einer Arbeitslosenversicherung und kritisierte vor allem das kapitalistische System, das eine hohe Arbeitslosigkeit verursache, die es mit eigenen Mitteln nicht mehr zu verringern vermöge203. Die Wahlplattform rundete Blum mit der abschließenden Forderung nach der Einheitsschule und dem Verhältniswahlrecht ab. Blum unterstrich mit großem Optimismus, daß die aktuelle Situation Frankreichs der sozialistischen Kritik am Kapitalismus Recht gegeben habe und der Sozialismus der einzige Ausweg aus der Krise sei204.

Neben den Wahlthemen spielte auf dem außerordentlichen Parteitag auch die Wahltaktik eine zentrale Rolle. Die einstimmig am 31. Januar 1932 verabschiedete Resolution zur Wahltaktik enthielt für den ersten Wahlgang die Bestimmung, daß die sozialistische Partei in allen Wahlkreisen Kandidaten aufstellen werde ${ }^{205}$. Für

199 Siche hierzu L'Oeuvre de Léon Blum, Bd. III/2, Paris 1972, S. 377.

200 Vgl. Le Populaire vom 18. 1. 1932, S. 1, sowie auch Le Populaire vom 31. 1. 1932, S. 1.

201 Le Populaire vom 18. 1. 1932, S. 1; Le Populaire vom 31. 1. 1932, S. 1, sowie das Parteitagsprotokoll: 29c Congrès National à Paris de 29. 5.-1. 6. 1932, Paris 1932, S. 27.

202 „Le premier article de la plate-forme électorale, c'est en effet le socialisme lui-même (...) Ce qu'on trouvera dans le rapport, ce sont donc des mesures pour déterminer notre position à l'intérieur du cadre capitaliste et pour soulager autant que possible les souffrances et les misères;" vgl. Le Populaire vom 31.1.1932, S. 1.

${ }^{203}$ Le Populaire vom 31. 1. 1932, S. 2.

$20+$ Ebenda.

205 Falls die Föderation sich dazu mangels finanzieller Mittel außer Stande sah, mußte dies umgehend 
den zweiten Wahlgang wurde den Föderationen die Richtlinie an die Hand gegeben, den eigenen Kandidaten zugunsten desjenigen Kandidaten zurückzuziehen, der die meisten Aussichten habe, den der „Reaktion“ zu schlagen ${ }^{206}$. Es wurde auBerdem beschlossen, die definitive Gestaltung und Ausarbeitung der Wahlplattform und des Wahlprogramms einer Kommission anzuvertrauen. Auriol legte die Vorschläge der Resolutionskommission dar, die sechs gesonderte Punkte ${ }^{207}$ für die Wahlplattform vorsah, zudem galt das Wahlprogramm von 1928 als Grundlage.

Die Sozialisten begannen ihren Wahlkampf mit einer Veranstaltung Léon Blums in Montbéliard am 13. März 1932208. Ihr Wahlkampf 1932 fußte in erster Linie auf dem Hauptargument, daß die anhaltende Weltwirtschaftskrise das Ende des kapitalistischen Wirtschafts- und Gesellschaftssystems der bürgerlichen Parteien einläute. Damit grenzte sich die SFIO gegen den von Tardieu errichteten Mitte-Rechts-Wahlblock ${ }^{209}$ entschieden ab.

In einem Wahlaufruf der Partei, den diese am 1. April 1932210 in der Parteizeitung Le Populaire veröffentlichte, werden alle wichtigen Elemente der Wahlpropaganda der SFIO deutlich. Bereits in der Einführung präsentierte sich die SFIO entschieden als Anwältin und Vertreterin der arbeitenden Bevölkerung, worunter sie verstand: „(...) tous ceux que le capitalisme exploite, opprime ou dépouille et que le socialisme libérera. “211 Vor allem betonte der sozialistische Wahlaufruf, daß die Konsequenzen der Wirtschafts- und Sozialkrise verdeutlichen würden, daß die Zeit für die Umsetzung der sozialistischen Programmatik gekommen sei. Die Sozialisten kritisierten den Antagonismus zwischen fortgeschrittener wirtschaftlicher und gesellschaftlicher Entwicklung und gleichzeitiger hoher Arbeitslosigkeit. Das Feindbild war wie in allen bisherigen Wahlkämpfen auch dieses Mal eindeutig festgelegt; die Sozialisten bekämpften vor allem die „Reaktion“. Auf dem Banner der „République sociale“, für die sich die Sozialisten einsetzten und die sie als die wahre Republik bezeichneten, fanden sich vor allem folgende Schlagwörter: Herstellung des Friedens, Aussöhnung der Völker und Bekämpfung der nationalistischen Parteien. Bezeichnenderweise führten die Sozialisten ihren Wahlkampf auch auf der Basis der republikanischen Kultur, instrumentalisierten für sich also den republikanischen Mythos.

dem obersten Kontrollorgan CAP gemeldet werden, um eine gemeinsame Entscheidung treffen zu können; vgl. Le Populaire vom 1.2.1932, S. 1.

206 Die Resolution zur Wahltaktik, die von Bracke verfaßt wurde, ist abgedruckt in Le Populaire vom 1.2. 1932, S. 1.

207 Bei den sechs Basispunkten handelte es sich um folgende: „1) Lutte contre la guerre: désarmement général; organisation politique et économique internationale. 2) Lutte contre l'insécurité du travail: semaine de 40 heures; Contrôle ouvrier; assurance-chômage; assurance contre les risques agricoles. 3) Lutte contre l'anarchie de la production nationale: Offices publics agricoles; nationalisation (assurances, mines, chemin de fer, pétroles). 4) Lutte contre la spéculation capitaliste: Organisation du crédit; protection de l'épargne, controle des banques. 5) Lutte contre l'ignorance: Egalité des enfants devant l'instruction; laicité et statut unique de l'éducation nationale. 6) Lutte contre l'iniquité politique: Représentation proportionelle; vote des femmes“; vgl. Le Populaire vom 1.2. 1932, S. 1.

208 Zum Wahlkampfauftakt siehe Le Populaire vom 14. 3. 1932, S. 2.

209 Vgl. dazu vor allem die vieldiskutierte Rede Tardieus vom 6. 4. 1932 in Bullier, die sich vor allem als Kernstück einer antisozialistischen Kampagne verstand, in L'Oeuvre vom 7. 4. 1932, S. 1, 4. Die Antwort Blums auf diese Rede Tardieus ist abgedruckt in Le Populaire vom 8. 4. 1932, S. 1.

210 Le Populaire vom 1. 4. 1932, S. 1: „Aux travailleurs de France!“

211 Ebenda. 
Der Wahlkampf von 1932 war von Beginn an von zwei Gegenpolen dominiert: auf der einen Seite das konservative Lager unter Tardieu, das vor allem den Parti radical für sich zu gewinnen suchte, und auf der anderen Seite die SFIO, die Tardieu durch einen antisozialistischen Block zu isolieren gedachte.

Eine weitere wichtige Wahlkampfversammlung stellte die Rede von Léon Blum in Narbonne vom 10. April $1932^{212}$ dar, in der er mit der aktuellen Mehrheit im Parlament abrechnete und gleichzeitig den sozialistischen Wahlsieg propagierte. Léon Blum betrachtete seine Ausführungen als Antwort auf die Wahlrede Tardieus in Bullier vom 6. April 1932, in der dieser eine positive Regierungsbilanz vorgelegt hatte. Zunächst übte er Kritik an der Finanzpolitik der Regierung Tardieu, dann widersprach er der Erfolgsbilanz Tardieus, der für sein Kabinett die Stabilisierung der Finanzen und der Währung beansprucht hatte. Blum führte das Verdienst der Stabilisierungsmaßnahmen auf die Regierung Poincaré 1928 zurück, die Tardieu, so Blum, nur fortgeführt hatte. Außerdem zweifelte Blum an der Authentizität der Stabilisierung, die stark auf finanztechnische Manöver zurückzuführen sei, die nun wiederum den Geldwert in Gefahr bringen konnten. Als weiteren Kritikpunkt sprach er die Landwirtschaftspolitik der Regierung an, der er vorwarf, daß sie die Preise in der Landwirtschaft nur habe aufrecht erhalten können, "qu'en instituant une taxation uniforme qui ne tenait aucun compte des prix de revient." 213

Auch die Außenpolitik der Regierungen Laval-Tardieu wurde einer ausführlichen Kritik unterzogen. Blum prangerte den Sturz Briands durch die aktuelle Mehrheit im Parlament an und verwies darauf, daß die erfolgreiche Außenpolitik Frankreichs größtenteils auf Briand zurückgehe, dieser aber letztlich dafür bekämpft worden sei. In seine außenpolitische Beurteilung bezog er auch die Konferenz von Genf und die Vorverhandlungen von London mit ein. Bezüglich der Konferenz von Genf erhob Blum gegen die Haltung der Regierung Tardieu schwere Vorwürfe, die er bereits seit längerem in verschiedenen Artikeln zum Ausdruck gebracht hatte ${ }^{214}$. Jedoch räumte er in Hinblick auf die Vorgespräche in London, die gescheitert waren, ein, daß Tardieu hier nur eine Teilschuld trage; er lastete ihm jedoch an, sich nicht ernsthaft im Sinne Europas eingesetzt zu haben. Seine inhaltliche Kritik an der Politik der Kabinette Laval-Tardieu schloß Blum mit dem Vorwurf, daß diese nicht frühzeitig die schwerwiegenden Folgen der

212 Ausführlicher Bericht zur Rede Blums in Narbonne vom 10.4. 1932 in Le Populaire vom 11.4. 1932, S. $1 / 2$.

213 Le Populaire vom 11. 4. 1932, S. 2.

214 Blum setzte sich mit den Abrüstungsvorstellungen Tardieus in mehreren Leitartikeln sehr kritisch auseinander; siehe Le Populaire vom 1.3. 1932, S. 1; Le Populaire vom 5. 3. 1932, S. 1; Le Populaire vom 5. 4. 1932, S. 1; Le Populaire vom 13. 4. 1932, S. 1; Le Populaire vom 15. 4. 1932, S. 1; Le Populaire vom 24. 4. 1932, S. 1. Siehe dazu aber auch L'Oeuvre de Léon Blum, Bd. III/2, S. 364376: „On voit comment M. Tardieu se joue des mots et des choses. Si les engins dits offensifs étaient simultanément remis à la Société des Nations et interdits aux nations, si l'internationalisation des armements visés avait pour corollaire immédiat leur suppression en tant qu'armements nationaux, alors oui, nous pourrions admettre le plan Tardieu et nous y souscririons avec joie. Mais ce n'est pas cela, c'est même tout le contraire. On ne les supprime pas, on les garde, on ne s'engage à les remettre à la Société des Nations un jour ou l'autre, un jour futur et incertain, que pour pouvoir les garder aujourd'hui. A la faveur de cet engagement indéterminé, on s'efforce de consolider le statu quo. Nous pouvons l'affirmer et le répéter sans crainte d'injustice. L'internationalisation ainsi entendue n'est qu'une manoeuvre détournée pour s'opposer à la réduction.“; ebenda, S. 376 . 
Weltwirtschaftskrise für Frankreich erkannt hätten. Weiter bemängelte er, daß die führenden Regierungsmitglieder ohne Partei und ohne politisches Programm ihren politischen Geschäften nachgingen und sich der konservativen Parteien nur bedienten, die wiederum nur eine temporäre Zusammenarbeit suchten, um schließlich stark genug zu sein, um mit ihren eigenen Vertretern zu regieren ${ }^{215}$. Im Kernstück seiner Rede ging Blum auf die Haltung der Sozialisten zu den anderen Parteien nach den Wahlen ein, vor allem auf die fundamentale Differenz zwischen Sozialisten und Kommunisten: "J'ai souvent appelé l'attention de nos camerades sur une distinction à mes yeux capitale, celle qu'il faut faire entre la conquête révolutionnaire du pouvoir et l'exercise de ce pouvoir dans le cadre des institutions existantes. Il est nécessaire d'appler sur cette distinction l'attention de l'opinion publique tout entière. Nous pensons, nous socialistes, que la transformation complète du régime implique la conquête totale du pouvoir politique. Mais nous pensons aussi, que même ayant conquis ce pouvoir, ayant détruit et reconstruit nous n'aurons rien fait si certaines conditions économique ne sont pas rempliées, et c'est ce qui nous distingué des bolchevistes ${ }^{216}$."

Zum Thema Koalitions- oder Unterstützungspolitik nach den Wahlen betonte Blum, daß dies nur auf einem eigenen Parteitag der Sozialisten definitiv bestimmt werden könne, jedoch nannte er bereits die conditio sine qua non für eine Regierungsbeteiligung: 1) Sofortige Reduktion der Militärausgaben; 2) ein nationales Versicherungssystem, das sowohl die Arbeitslosigkeit als auch die Berufsrisiken der Arbeiter und Bauern umfassen sollte; 3) Verstaatlichung der Privatversicherungen und der Eisenbahn ${ }^{217}$. Abschließend wies Blum auf eine Übereinstimmung in einigen der oben genannten Punkte mit dem Parti radical hin.

Kurz vor den Wahlterminen am 1. Mai und am 8. Mai 1932 spitzten sich die Wahlkampfdebatten zu. Nach den Angriffen der Regierungsparteien ${ }^{218}$ auf die Opposition und vor allem auf die Sozialisten setzte Blum in Pertuis zu einem gewichtigen Gegenangriff an. Zunächst warf er dem nationalistischen Block starke Heterogenität und mangelnde Absprache vor ${ }^{219}$, denn die Reden von Tardieu in Bullier und die Rede von Reynaud in Rouen offenbarten deutliche Unterschiede. Vor allem die Einladung Tardieus an die Radikalsozialisten, in eine Regierung der concentration einzutreten, stieße bei den nationalistischen Parteien auf sehr unterschiedliche Beurteilung. Außerdem kritisierte Blum die Wahlpropaganda des rechten Wahlblocks, weil dieser versucht hatte, den Wählern mit Hinweisen auf das finanzpolitische Scheitern des Cartel des gauches von 1926 von einer Wahl linker Parteien abzuraten; doch die Ausgangssituation von 1926 sei nicht mit der von 1932 zu vergleichen. Die Rechte prophezeie, um bei den Wählern Angst zu schüren, so Blum weiter, besonders im Falle eines großen Wahlerfolges der Sozialisten

215 Le Populaire vom 11. 4. 1932, S. $1 / 2$.

216 Ebenda, S. 2.

217 Ebenda.

218 Vor allem die Reden von Tardicu und Reynaud hatten starke antisozialistische Akzente gesetzt. Zur Rede Tardicus in Bullier vgl. L'Oeuvre vom 7.4. 1932, S. 1, 4 und zur Rede Reynauds in Rouen vgl. L'Oeuvre vom 15. 4. 1932, S. 4.

219 "Cet orchestre, je le crains, aboutira à quelque cacophonie car entre la petite flute de M. Paul Reynaud et le cuivre éclatant de M. Tardieu, l'accord n'est pas parfait.“; Le Populaire vom 18. 4. 1932, S. 1. 
einen drastischen Währungsverfall des Franc220. Léon Blum sprach nochmals indirekt von einer gewissen Übereinstimmung zwischen den Sozialisten und den Radikalen. Geschickt beendete der führende Sozialist seine Wahlrede mit dem wichtigsten Stilmittel der politischen Kultur Frankreichs; er reklamierte den „wahren Geist der Republik“ für die sozialistische Partei: „La France ne seraitelle plus le pays des journées de 1789 , de 1792 , de juillet 1830 , de 1871 ? (...) Il y a trop des républicains qui ont oublié les origines révolutionnaires de la République. Ils ont peur maintenant du grand souffle révolutionnaire qui l'animait à ses origines. Le véritable ésprit républicain est en nous." 221

Der Wahlkampf zwischen dem rechten Block und den Sozialisten strebte unmittelbar vor dem ersten Wahlgang am 1. Mai 1932 in einer Rede Tardieus in Belfort seinem Höhepunkt entgegen. Tardieu forderte dezidiert den Parti radical auf, sich dem antisozialistischen Block anzuschließen. In seinen Ausführungen konzentrierte sich Tardieu darauf, dem Parti radical die Vorzüge einer Koalition mit dem Rechtsblock aufzuzeigen, dabei betonte er den Konsens in innen- wie auch außenpolitischen Problemfeldern und verwies auf die positiven Bilanzen der radikalsozialistischen Politik, solange sie im Bündnis mit der Union nationale, wie in den Jahren 1919 bis 1924 und 1926 bis 1928, stand. In Kontrast dazu setzte er die negative Bilanz der Politik des Cartel des gauches. Die Sozialisten grenzte er klar aus und bezeichnete sie als "hommes de l'illégalité, du collectivisme et de l'Internationalisme?" 222 Obwohl seine Rede ganz darauf ausgerichtet war, kurz vor den Wahlen die Radikalen für seinen Wahlblock zu gewinnen, kritisierte er vehement die angekündigte lose Koalition der Radikalsozialisten mit den Sozialisten im zweiten Wahlgang, die er als eine Neuauflage des Cartels etikettierte, auch wenn die beiden "Koalitionsparteien“ diese Zusammenarbeit als "discipline républicaine" deklarierten ${ }^{223}$. Tardieu beendete seine Rede mit einem propagandistischen Schlußappell an den Parti radical: "Contre le cartel, sous toutes ses formes, telle est la régie qui ne trompe pas. Car, dans le cartel, le socialiste est maitre, le radical prisonnier." 224

Obwohl Herriot sich in seiner letzten Rede vor den Wahlen gegen das Angebot Tardieus mit folgenden Worten wandte: „Démocrates que nous sommes, nous n'accepterons pas d'être contre le socialisme, même en échange d'une copieuse pitance, des chiens de garde de la réaction “225, führte Blum den Wählern in seinem Leitartikel „La Volonté du pays“226 deutlich vor Augen, daß die Radikalsozialisten in diesem Wahlkampf keine Cartelkoalition eingehen wollten und nach den Wahlen, falls sie diese gewinnen sollten, sicherlich versuchen würden, eine Koalition der concentration, deren Mittelpunkt der Parti radical sein würde, anzustreben. Ein weiterer Hinweis für die von den Radikalen angestrebte Lösung ging, laut Blum, auch aus den Äußerungen Herriots in kurz vor der Wahl gegebenen In-

220 Vgl. hierzu die Rede von Tardieu in Giromagny und die Rede Reynauds in Rouen vom 14. 4. 1932, abgedruckt in Le Populaire vom 18. 4. 1932, S. $1 / 2$.

221 Le Populaire vom 18. 4. 1932, S. 2.

222 Le Populaire vom 29. 4. 1932, S. 3.

223 Ebenda.

224 Ebenda.

${ }^{225}$ Le Populaire vom 30. 4. 1932, S. 1.

226 Ebenda. 
terviews hervor, in denen Herriot von seinen Erfahrungen von 1924 und den daraus gezogenen Konsequenzen sprach: „La politique de soutien est une épreuve à laquelle on ne s'expose pas deux fois. (...) Il y a des méchants socialistes. (...) Il faudrait une majorité de quatre cents voix pour soutenir un gouvernement fort (...)."227 Aus diesem Grund forderte er nochmals nachhaltig, jede Stimme für die Sozialisten abzugeben, da nur ein solches Votum eine Neuerung garantieren würde, denn eine Regierung der concentration unter Führung der Radikalen brächte letztlich keine grundlegenden Veränderungen für Frankreich.

Aus dem auf die Zukunft gerichteten Blickwinkel Blums zeigte sich die klare Abgrenzung zwischen den beiden wichtigsten Parteien auf dem linksrepublikanischen Parteienspektrum und das Bemühen um jede Wählerstimme für die eigene Partei. Daraus geht ebenso eindeutig das Konkurrenzverhalten zwischen den beiden politischen Kräften in diesem Wahlkampf hervor. Im Schlußwahlaufruf der SFIO vom 30. April 1932 faßten die Sozialisten sehr präzise die Prioritäten ihres politischen Programms zusammen. An erster Stelle setzten sie sich für die Sicherung des Friedens ein und präsentierten gleichzeitig die Maßnahmen, die ihn ihrer Meinung nach garantierten. Die Friedenssicherung in Europa basierte in sozialistischer Sicht auf zwei großen Säulen: zum einen auf einer gleichzeitigen und kontrollierten Abrüstung und zum anderen auf der Organisation einer internationalen wirtschaftlichen Zusammenarbeit. An zweiter Stelle folgten sozialpolitische Forderungen, wie die Ablehnung sinkender Löhne, die Einführung einer Arbeitslosenversicherung und die 40-Stundenwoche. An dritter Position führte die SFIO wirtschaftspolitische Maßnahmen an, wie die Schaffung internationaler Einrichtungen, die die Märkte für Grundnahrungsmittel koordinieren sollten, oder die Verstaatlichung z. B. der Eisenbahn und der Versicherungen. Auf dem Feld der Finanzpolitik erstrebte die SFIO die Kontrolle der Banken und der Börse. Den Abschluß bildete eines der wichtigsten Elemente aus dem republikanischen Kanon, die Einheitsschule bzw. das Recht auf gleiche Bildungschancen für alle Schichten der Bevölkerung sowie die Forderung nach dem Verhältniswahlrecht, das eine gerechtere Umsetzung des Wählerwillens mit sich bringe ${ }^{228}$.

\section{Wabltaktik und Wablkampf beim Parti radical}

Nach den Erfolgen des Parti radical bei den Stadtratswahlen in Lyon und den Kantonatswahlen, beide 1931, war die Einheit und das Selbstbewußtsein der Partei nach den kritischen Jahren zwischen 1927 und 1931 wieder gestärkt worden. Auf dem Parteitag vom 5. bis 8. November 1931 legte der Parti radical sein Wahlprogramm fest; hinsichtlich der Wahltaktik wurde einstimmig beschlossen, keine Wahlallianzen zu schließen, sondern auf die Unabhängigkeit der Partei zu achten 229. Dieses Ergebnis war noch zu Beginn des Parteitages nicht unbedingt zu erwarten gewesen, da die Bündnisfrage durchaus kontrovers diskutiert worden ist.

227 Dieses Zitat stammte aus einem Interview, das Herriot den Zeitungen Le Matin und La Volonté gegeben hatte; zitiert nach Le Populaire vom 30. 4. 1932, S. 1.

${ }_{228}$ Zum Wortlaut des Wahlaufrufes siehe Le Populaire vom 30. 4. 1932, S. 1.

229 Bereits bei der Eröffnung des Parteitages wurde auf die Bedeutung der Unabhängigkeit der Partei im Wahlkampf von 1932 hingewiesen; vgl. L'Oeuvre vom 3. 11. 1931, S. 1. 
Mitglieder des rechten Parteiflügels favorisierten ein Wahlbündnis mit Parteien der Mitte bzw. der rechten Mitte, der sogenannten concentration, und Teile des linken Flügels hofften auf eine Wahlallianz der Cartelparteien ${ }^{230}$. Es zeichnete sich jedoch gleichzeitig ab, daß die Radikalen weder für die eine noch für die andere Bündnisoption geeignete Partner finden konnten. In diesem Zusammenhang wurde auch die Ankündigung Blums gegenüber dem Parti radical zitiert: „Aux prochaines élections, pas de convention préliminaire avec les autres partis! Pas de ,contrat'! Pas de ,cartel'!“231 Diese Äußerung nutzten die Radikalen, um ihre Handlungsfreiheit nicht selbst mit Bündnissen und Kompromissen bei den Wahlen einzuschränken. Immerhin schloß sich der Parti radical der Devise der Sozialisten an: „Battre la réaction“. Im Laufe des Parteitages wurde trotz allem Selbstbewußtsein von einigen Rednern dennoch immer wieder die Bündnisfrage aufgeworfen. So plädierten z.B. Kayser und Bergery ${ }^{232}$, beide Vertreter des linken Flügels des Parti radical, für eine Allianz mit Parteien der politischen Linken. Chautemps hingegen wies daraufhin, daß die Bündnisunabhängigkeit für den Parti radical eine wichtige Prämisse für die Wahlen von 1932 darstelle. Vor allem aber, so Chautemps weiter, sei es von entscheidender Bedeutung, ein glaubwürdiges Programm auszuarbeiten ${ }^{233}$. Er schloß seine Ausführungen mit einem ersten Programmvorschlag, der einstimmig angenommen wurde: So wurde das Programm von 1928 zur Grundlage des Wahlprogramms von 1932 erklärt. Als weitere Elemente wurden die Verteidigung des Laizismus und der bisher errungenen sozialen Fortschritte genannt. Daran schloß sich die Forderung nach Sofortmaßnahmen zur Überwindung der Wirtschaftskrise und zur Organisation des Friedens an. Außerdem wurden für die Wahlen von 1932 ein faires Verhalten im Sinne der Demokratie sowie das Festhalten und die Praktizierung der "discipline électorale“ angekündigt.

Der Wille der Partei zur Einigkeit zeigte sich zunächst, trotz der unterschiedlichen Positionen der Redner, in der einstimmigen Wahl Herriots zum Parteivorsitzenden ${ }^{234}$. Wie bereits in der unmittelbaren Zeit nach dem Ersten Weltkrieg, gelang es Herriot auch 1931 wieder, die verschiedenen Flügel innerhalb des Parti radical unter seiner Führung zusammenzuführen. Herriot verstand es, den Parti radical auf diese Einheit und Disziplin am letzten Parteitag einzuschwören, die besonders für seine Partei, - deren starke Heterogenität gleichzeitig ihre Stärke und Schwäche verkörperte - von enormer Wichtigkeit war. Er verwies auf die Erfolge, die die Partei bisher erreichen konnte, die aber immer unter der Voraussetzung, daß sie ihre Einheit wahrte, zustande gekommen waren. Herriot beanspruchte für den Parti radical, die modernste und progressivste von allen demokratischen Parteien zu sein, und verband solchen Anspruch mit der Aufforderung, im künftigen Wahlkampf von 1932 vereint und diszipliniert zusammenzuarbeiten, um erfolgreich aus den Wahlen hervorzugehen: „Vous n'oublierez pas que la meilleure façon de faciliter le deuxième tour, c'est de réussir, si possible au pre-

$230 \mathrm{Vgl}$. L'Oeuvre vom 6. 11. 1931, S. 1.

231 Ebenda.

232 Zu den Ausführungen der obengenannten Redner siehe L'Oeuvre vom 6. 11. 1931, S. 4.

${ }^{233}$ Ebenda.

234 L'Oeuvre vom 7. 11. 1931, S. 1. 
mier où du moins, d'y prendre la meilleure position. Nous travaillerons tous ensemble, unis comme une famille qui s'aime. " 235 Zugleich unterstrich diese Vorgabe jedoch auch die Entschlossenheit, an der Unabhängigkeit des Parti radical bei den Wahlen von 1932 festzuhalten.

Trotz der betonten Abgrenzung zu anderen Parteien fällt auf, daß der Parti radical in einigen Punkten seines Wahlprogramms den Positionen der SFIO sehr nahe stand. Vergleicht man beide Wahlprogramme miteinander, kann man durchaus eine größere Konsensfähigkeit feststellen. Dies erklärt einerseits auch, warum beide Parteien sich voneinander abzugrenzen versuchten, denn sie mußten Profil gewinnen, um Wähler zu überzeugen. Wie bei den Sozialisten spielte auch bei den Radikalen die Abrüstungsdiskussion eine entscheidende Rolle. Auch sie befürworteten langfristig eine Abrüstung im internationalen Rahmen ${ }^{236}$ und, damit verbunden, auch eine schrittweise Reduzierung der Militärausgaben. Sie wiesen hier die Kritik der Sozialisten zurück, die den Radikalen vorwarfen, daß sie Krediten für das Militär und Grenzbefestigungsanlagen zugestimmt hatten. Denn eine vernünftige Lösung in der Abrüstungsdebatte könne nur durch sukzessive Maßnahmen erfolgen. Im Zusammenhang mit der Abrüstungsdiskussion sprach sich der Parti radical auch für eine Annäherung und Aussöhnung mit Deutschland aus. In diese Überlegungen schlossen die Radikalsozialisten sogar einen eventuellen Spielraum für Revisionsmöglichkeiten des Versailler Vertrages zugunsten Deutschlands ein.

Auch auf dem außenpolitischen Sektor erwiesen sich die politischen Positionen des Parti radical als weitgehend kompatibel mit denen der Sozialisten. Auch die Radikalsozialisten hielten den Erhalt eines dauerhaften Friedens trotz der immer stärker werdenden Wirtschaftskrise nur auf der Grundlage internationaler Maßnahmen und im Rahmen internationaler Abkommen für möglich. Deshalb forderten sie eine französisch-deutsche Zusammenarbeit, eine europäische Kooperation und schließlich eine weltweite Verständigung. Diese außenpolitische Zusammenarbeit sollte auch eine international geregelte Wirtschaftspolitik umfassen, der die Aufgabe zugedacht war: „(...) à regler par voie d'ententes de plus en plus larges les conditions de la production, de la circulation et de la distribution des richesses. “237

Die Außenpolitik der Regierung Laval-Tardieu wurde als wenig erfolgreich kritisiert, und in Kontrast ${ }^{238}$ dazu setzte der Parti radical auf sein eigenes bisher bewährtes Konzept „arbitrage, sécurité, désarmement“239, das auf Herriot zurückging. Die Radikalen unterließen es auch nicht, auf die erfolgreiche Umsetzung des Locarnovertrages und des Briand-Kellog-Planes zu verweisen. Außerdem betonten die Radikalen die Wichtigkeit des Völkerbundes, der auf die Idee einer ihrer großen Autoritäten, Léon Bourgeois zurückging. Konsensfähigkeit zwischen beiden Parteien lag auch in der Kulturpolitik vor; sowohl die Radikalsozialisten wie die Sozialisten forderten die Einheitsschule.

${ }^{235}$ L'Oeuvre vom 9. 11. 1931, S. 4.

236 Pierre Cot betonte die Notwendigkeit eines sinnvollen Verhältnisses zwischen Abrüstung und dem Prinzip der internationalen Sicherheit; vgl. L'Oeuvre vom 8. 11. 1931, S. 4.

237 L'Oeuvre vom 9. 11. 1931, S. 1.

238 „Le parti radical et radical-socialiste ne s'est jamais contenté de reprouver en paroles les excitations nationalistes et le défaitisme de la paix.“; L'Oeuvre vom 9. 11. 1931, S. 1.

239 Ebenda. 
Schließlich wurde die Finanzpolitik der Regierungen seit 1928 vom Parti radical heftig kritisiert, da das Haushaltsdefizit seit 1928 stetig gestiegen war. Erneute Steuererhöhungen zur Regulierung des Haushalts lehnten die Radikalsozialisten entschieden ab. Vielmehr schlugen sie als Gegenmaßnahmen vor, die vorhandenen Steuergelder effektiver zu nutzen und die Militärausgaben zu reduzieren. Auf dem sozialpolitischen Sektor forderte der Parti radical die Bekämpfung der Arbeitslosigkeit und die soziale Absicherung der Arbeitnehmer240.

Die führenden radikalsozialistischen Politiker Herriot, die Brüder Albert und Maurice Sarraut, Caillaux und auch Chautemps konzentrierten sich während des Wahlkampfes auf die Bewältigung der Wirtschaftskrise in Frankreich, indem sie vehement daraufhin wiesen, daß die bisherige Wirtschaftspolitik des "laisserfaire“ durch eine „économie ordonnée“ ersetzt werden müsse241. Als unerläßliche Voraussetzung für den wirtschaftlichen Aufschwung Frankreichs forderten die radikalsozialistischen Vertreter zunächst die Wiederherstellung des budgetären Gleichgewichts. Die Überwindung der Weltwirtschaftskrise konnte ihrer Meinung nach nur im internationalen Rahmen gefunden werden, was wiederum eine Völkerverständigung begünstigen würde, die es Frankreich gleichzeitig erlauben würde, die Friedenspolitik Aristide Briands fortzusetzen.

In erstaunlichem Kontrast dazu standen jedoch die Themen der professions de foi der einzelnen radikalsozialistischen Kandidaten, in denen andere Sachthemen dominierten. Trotz der nationalen Auswirkungen der Weltwirtschaftskrise spielte diese in den professions de foi eine untergeordnete Rolle, z.B. fand sie bei 48 von 157 Kandidaten, wenn überhaupt, nur eine beiläufige Erwähnung. Fast nur in den Wahlaussagen der radikalsozialistischen Vertreter, die als Finanzexperten galten, wie z.B. Bertrand Nogaro, Georges Bonnet und Yvon Delbos ${ }^{242}$, wurde auf die Wirtschaftskrise eingegangen. Auffallend ist, daß auch 1932 der Großteil der radikalsozialistischen Kandidaten auf die traditionellen Themen der radikalen Doktrin zurückgriff und damit erfolgreich die Wahl bestritt. Folgende politische Ziele wurden häufig in den Wahlaufrufen der verschiedenen radikalsozialistischen Kandidaten genannt: 1) Die Verteidigung des Laizismus, 2) die Entwicklung der Einheitsschule, 3) der Widerstand gegen „Reaktion" und „Revolution“. Die Traditionalisten hatten mit der Entscheidung, sich auf diese Themen zu konzentrieren, mehr Erfolg als die Jeunes Turcs, die sich mit ihrer Wahlpropaganda in ihren Presseorganen gegenüber den Traditionalisten abgegrenzt hatten ${ }^{243}$.

240 Zum vorläufigen Wahlprogramm des Parti radical auf dem Parteitag von 1931 siehe L'Oeuvre vom 9.11. 1931, S. 4 .

${ }^{241} \mathrm{Zu}$ den Äußerungen Caillaux' in Bezug auf die Weltwirtschaftskrise vgl. La Dépêche de Toulouse vom 26. 4. 1932, S. 1. Zu den Vorstellungen Maurice Sarrauts siehe La Dépêche de Toulouse vom 29. 4. 1932, S. 1 .

${ }^{242}$ S. Berstein, Parti radical, vol. 2, S. 200.

${ }^{243}$ Z.B. hatten sich die Jeunes Turcs seit 1926 für eine Verfassungsreform stark gemacht, die jedoch in den offiziellen Wahlaussagen keinerlei Erwähnung fand. Bei ihren Überlegungen zur Verfassungsreform konzentrierten sich die Jeunes Turcs auf folgende Punkte: Stärkung der Exekutive durch Vergrößerung der Machtbefugnisse des Ministerpräsidenten; Abschaffung des Staatspräsidentenamtes; außerdem Abschaffung des Senats, an dessen Stelle die Einrichtung einer Chambre des départements, die sich einmal im Jahr zum Austausch und zur Beratung von lokalen Interessen treffen sollte, über deren Vorschläge dann die Chambre des députés entscheiden sollte. Damit wollten die Jeunes Turcs die Diskussion lokaler Probleme in den Parlamentsdebatten vermeiden. Vgl. zum Reformprogramm der Jeunes Turcs allgemein S. Berstein, Parti radical, vol. 2, S. 94-126. 
Vergleicht man die Wahl von 1932 mit der von 1924, treten einige Unterschiede deutlich zutage. Trafen 1924 noch zwei Lager - das Cartel des gauches und der Bloc national - aufeinander, so begegneten sich 1932 auf der einen Seite ein geschlossener Block, den Tardieu selbst als antisozialistisch ${ }^{244}$ bezeichnete, und auf der anderen Seite ein linksrepublikanisches Lager, das aus drei größeren Parteien bestand, von denen jede einen unabhängigen Wahlkampf führte. Die wichtigste Partei der Dritten Republik, der Parti radical, fand sich in diesem Wahlkampf von zwei Seiten umworben, sowohl vom konservativen Lager unter der Führung Tardieus ${ }^{245}$ wie auch von den Sozialisten ${ }^{246}$.

Auf beide Angebote reagierte der Parteivorsitzende des Parti radical während des Wahlkampfes. Zunächst nahm Herriot in seiner Wahlrede in Lyon am 12. April $1932^{247}$ Stellung zu den Appellen Tardieus, der in Bullier den Parti radical aufgefordert hatte, mit den rechten politischen Kräften ein Bündnis einzugehen. Herriot verwies gleich zu Beginn seiner Antwort darauf, daß die Zusammenarbeit mit der Union nationale unter Poincaré von beiden Seiten klar als eine temporäre Allianz definiert worden war, deren Aufgabe es gewesen sei, die Finanzen und die Währung Frankreichs zu stabilisieren ${ }^{248}$. Des weiteren unterstrich Herriot, daß die Erfahrung seit 1928 gezeigt habe, daß das Cartel des Droites immer mehr versucht habe, das politische System Frankreichs zu verändern, zuletzt durch eine massive Wahlrechtsänderung ${ }^{249}$, die vor allem gegen die linksrepublikanischen demokratischen Parteien gerichtet gewesen sei250. Obwohl Herriot betonte, daß die linksrepublikanischen Parteien in diesem Wahlkampf auf ihre Unabhängigkeit bedacht seien, hob er die Erfolge der Außenpolitik des Linksbündnisses von 1924 bis 1926 hervor, die bis 1928 fortgeführt worden sei. Dagegen setzte er die Außenpolitik der Regierungen Tardieu-Laval, die Frankreich erneut in eine Sackgasse manövriert habe. In seine Kritik schloß er noch weitere Politikfelder wie die Wirtschafts- und Sozialpolitik mit ein, um schließlich eine Ablösung der rechten Regierungen zu fordern. Er beendete seine Rede mit der Aufforderung an den Wähler, mit seinem Votum eine republikanische Politik à la Waldeck-Rousseau zu ermöglichen: „A une heure plus agitée d'apparence, mais non moins redoutable, un Waldeck-Rousseau assembla dans un même gouvernement tous ceux qui placent, au-dessous de tout autre but, la défense et le développement des idées républicaines. Tout l'ensemble de la politique en est d'un seul coup rehaussé." 251 Auch hier wird, wie bereits im Wahlkampf von 1924, der die erfolgrei-

${ }^{244} \mathrm{Vgl}$. hierzu die Rede Tardieus in Bullier vom 11.4. 1932, auf die weiter oben bereits verwiesen worden ist.

$245 \mathrm{Vgl}$. Ebenda.

${ }_{246}$ Vgl. das Angebot Blums an den Parti radical in seiner Rede von Narbonne vom 10. 4. 1932, abgedruckt in Le Populaire vom 11. 4. 1932, S. 1/2.

$247 \mathrm{Vgl}$. zur Rede Herriots am 12. 4. 1932 in Lyon: L'Oeuvre vom 13. 4. 1932, S. 1.

248 Ebenda.

${ }^{249}$ Zum Vorschlag der Wahlrechtsänderung der Rechten vgl. L'Oeuvre vom 13. 2. 1932, S. 1, 4: „Suppression du deuxième tour dans tous les cas où le candidat arrivé en tête réunira le quart au moins du nombre des électeurs inscrits, suffrage et éligibilité des femmes, institution du vote obligatoire avec sanctions, et création d'un $613^{e}$ siège de député, à Sédan: tel a été le bilan de ce débat épique commencé la nuit précédente à une heure du matin, et qui ne devait se terminer hier qu'au début de l'après-midi."; hier S. 1.

250 L'Oeuvre vom 13. 4. 1932, S. 1.

251 L'Oeuvre vom 13. 4. 1932, S. 4. 
che Politik des Parti radical in der Zeit der Dritten Republik vor dem Ersten Weltkrieg glorifiziert hatte, als Modell der Zukunft gepriesen. Besondere Aufmerksamkeit muß auf den gesamten letzten Abschnitt der Wahlrede Herriots gelegt werden, denn hier entfaltete der Vorsitzende des Parti radical eine für die republikanische Kultur Frankreichs typische Rhetorik. Gleichzeitig grenzte er die republikanischen Parteien der Linken deutlich vom Cartel des Droites unter TardieuLaval ab: „Personnellement, je crois de tout mon esprit, - et c'est la conclusion logique de mon exposé - , que la République, libérée du contrôle des droites, aura besoin d'un gouvernement fort, appuyé sur tous les vrais laïques, sur tous les vrais pacifistes, non seulement pour la redresser à l'intérieur, mais pour défendre avec autorité, dans des organisations internationales dont on a laissé menancer le prestige, une paix actuellement si fragile." 252

Der Parti radical verfolgte, wie im Wahlkampf von 1924, als erstes Ziel die Ablösung der konservativen Regierung. Herriot beanspruchte zugleich die Führungsrolle Frankreichs in dem auf internationaler Ebene geführten Kampf um den Erhalt des Friedens: „Je m'adresse à tous ceux pour qui la République est une réalité vivante, un régime de justice et de fraternité, à ceux qui veulent voir notre pays entrainer les autres peuples dans les voies de la paix, à ceux qui ont décidé d'en finir avec le cartel des droites, pour revenir aux politiques auxquelles nous avons du, progrès et de tranquillité. Et je salue avec confiance l'éclatante victoire qui nous permettra dans la Chambre prochaine, de confier les destinées de la République, non pas à une majorité hétérogène et équivoque, mais à une large majorité de vrais républicains!" 253

In einer weiteren Wahlrede Herriots am 23. April 1932, die ebenfalls als Antwort auf Tardieus Wahläußerungen gewertet werden kann, wurde der Vorsitzende des Parti radical noch deutlicher. Hier kritisierte er nochmals vehement die Politik des Cartel des Droites und unterstrich, daß dieses Cartel nicht nur um ein Vielfaches heterogener sei als das Cartel der Linksparteien, sondern auch weitaus mehr Divergenzen aufweise als der Parti radical in der Zusammenarbeit mit der SFIO. Insbesondere griff er den Nationalismus und den Klerikalismus des Cartel des Droites an ${ }^{254}$. Auch diese Rede beendete Herriot mit dem Aufruf, für die republikanische Partei zu votieren: „Reconstituons ce grand parti républicain qui a donné au pays tant d'années heureuses et fécondes: c'est pour cette oeuvre que nous luttons!“ 255

Herriot vermied jegliche Stellungnahme zu den Forderungen Léon Blums, die dieser in seiner Rede in Narbonne vom 10. April 1932 an die Radikalsozialisten im Hinblick auf ein Bündnis nach den Wahlen gestellt hatte. Vielmehr konzentrierte sich Herriot ganz auf seine Wahlkampfstrategie, die, abgesehen von der Tatsache, daß die Radikalsozialisten 1932 ihre Unabhängigkeit betonten, derjenigen von 1924 inhaltlich weitgehend ähnelte. Besonders gegen Ende des Wahlkampfes, d.h. in den letzten zwei Aprilwochen, räumte Herriot in seinen Wahlaufrufen trotz der Weltwirtschaftskrise dem Festhalten am Laizismus und der Betonung der außen-

\footnotetext{
252 Ebenda.

253 Ebenda.

254 L'Oeuvre vom 24. 4. 1932, S. 4.

255 Ebenda.
} 
politischen Erfolge der Regierung des Cartel des gauches unter seiner Führung oberste Priorität ein. So unterstrich Herriot in einer Wahlrede in Avignon am 24. April 1932, daß die Wähler in Frankreich den Parti radical, die große Partei der Mitte, stärken sollten, damit nicht, wie in Deutschland oder England, die großen liberalen Parteien jeglichen politischen Einfluß verlören 256.

Im Vergleich zu den früheren Wahlen in der Zwischenkriegszeit fällt 1932 ein weiterer Unterschied auf: Nach dem ersten Wahlgang am 1. Mai 1932 beschloß das oberste Parteigremium des Parti radical, das Comité exécutif, am 3. Mai 1932257, daß die einzelnen Föderationen für den zweiten Wahlgang selbst bestimmen sollten, mit wem sie eine Allianz eingehen wollten, um die Kandidaten der „Reaktion“ zu verhindern. Gleichzeitig wurde jedoch betont, daß diese Allianz keinen Einfluß auf das Wahlprogramm der jeweiligen Partner ausübe, hier also weiterhin völlige Unabhängigkeit gewährt bleiben müsse. Des weiteren wurden jegliche Hinweise über Koalitionsaussagen nach den Wahlen untersagt, d.h. ein eventuelles Wahlbündnis mußte strikt von einer eventuellen Regierungsmehrheit getrennt werden ${ }^{258}$. Herriot exponierte sich in einer Presseerklärung dergestalt, daß er den Sozialisten mitteilen ließ, daß er eine Kooperation wie 1924, wo sich die Sozialisten nur zu einer Regierungsunterstützung bereit erklärt hatten, nicht mehr akzeptieren werde ${ }^{259}$. Herriot, der sich nach dem ersten Wahlgang ganz als Integrationsfigur der linksrepublikanischen Parteien präsentierte und damit als Gegenspieler zu Tardieu, dem Führer der Rechten, auftrat, verkündete während der Sitzung des Comité exécutif des Parti radical am 3. Mai 1932 der Presse, daß er eine Regierungsbildung à la Waldeck-Rousseau anstrebe, also eine breit angelegte Mitte-links-Regierung, die über eine stabile Mehrheit verfügen sollte260. Befragt hinsichtlich der Sozialisten, gab sich Herriot äußerst zurückhaltend und wich einer direkten Antwort aus: „Demandez plutôt aux socialistes, ce qu'il feront à notre égard, dirigez de leur côté vos investigations." ${ }^{261}$ In dieselbe Richtung wies auch ein Kommentar von Jean Piot, der ebenfalls unterstrich, daß sich im zweiten Wahlgang eine spontane Allianz der Union des gauches gebildet habe, um dem Cartel des Droites begegnen zu können. Jedoch hielt auch er strikt daran fest, daß damit keine programmatischen Konzessionen verbunden seien, vielmehr stehe diese spontane Union auf dem Fundament der Politik Aristide Briands: „(...) c'est une union (...) entre les partisans d'une large politique d'entente et de paix. Et

256 „Notre parti est au centre des institutions républicaines. Ne commettons pas la faute de le laisser disparaître, comme en Angleterre le parti libéral, et en Allemagne le parti démocrate. La France ait appel à toutes les formes de la raison républicaine. Nous sommes, nous, sociaux et nationaux, et je crois que le plus grand parti est celui qui couvre le mieux les intérêts les plus étendus du pays."; L'Oeuvre vom 25.4. 1932, S. 4.

257 Zum Wortlaut der Resolution des Comité exécutif des Parti radical siehe Le Populaire vom 4. 5. 1932, S. 1.

${ }^{258}$ Text der Resolution bezüglich der nächsten Mehrheits- bzw. Regierungsbildung in Le Populaire vom 4. 5. 1932, S. 1.

259 La Dépêche de Toulouse vom 4. 5. 1932, S. 1/2 sowie L'Oeuvre vom 7. 5. 1932, S. 1/2.

260 „Pour ma part, je rêve d'un gouvernement large, solide, stable, qui n'ait pas à defendre chaque jour son existence, - un gouvernement à la Waldeck-Rousseau.“; L'Oeuvre vom 4. 5. 1932, S. 1.

261 Ebenda. 
c'est le nom, c'est le souvenir, c'est la pensée d'Aristide Briand qui président à cette union." 262

Ein weiterer wichtiger Aspekt, der bei der Analyse des radikalsozialistischen Wahlkampfes von 1932 auffällt, betrifft die Entscheidung des Parti radical, nur in den Wahlkreisen anzutreten, in denen die Partei seit Jahren gut vertreten war, d.h. die Kräfte gezielt einzusetzen und nicht in allen Départements Kandidaten aufzustellen. Dies führte dazu, daß der Parti radical 1932 nur mit 366 Kandidaten im Vergleich zu 383 im Jahr 1928 antrat ${ }^{263}$. Die Koordination der Wahl lag in den Händen des Parteisekretärs Albert Milhaud264. Auch dies war im Vergleich zu 1924 eine Neuerung. Das Amt des Parteisekretärs war erst im Laufe der zwanziger Jahre im Parti radical eingeführt worden ${ }^{265}$. Das stärkte die Parteiorganisation und den Zentralismus in der Partei.

\section{Wablergebnis von 1932: Sieg der Linkskräfte}

Die Wahlkampfstrategie der Radikalen erwies sich als erfolgreich. Bereits im ersten Wahlgang vom 1. Mai 1932 kristallisierte sich ein eindeutiger Sieg der linksrepublikanischen Parteien heraus. Die meisten Mandate konnte der Parti radical mit 63 gewählten Deputierten erringen, gefolgt von den Sozialisten mit 41 Mandaten 266. Die führenden Persönlichkeiten des Parti radical wie Herriot, Daladier, Chautemps, Delbos, Bonnet, Berthod, Malvy, Marchandeau und Pierre Cot ${ }^{267}$ konnten bereits im ersten Wahlgang ihr Mandat für das Parlament erringen. Ein Blick auf die Wahlkarte zeigt, daß die Radikalsozialisten in den Départements ihre größten Erfolge verbuchen konnten, wo sie bereits seit Jahren solide Strukturen aufgebaut hatten, wie z. B. im Südosten, im südwestlichen Teil des Zentralmassivs, im Rhônetal und in den Zentren des Westens. Der Parti radical konnte überdies im Osten Gebiete zurückgewinnen, die er 1928 verloren hatte, wie z.B. in HauteSaône, Doubs, Jura und Belfort. Aber es gelang ihm auch, an der Peripherie des Pariser Beckens, wie z.B. in Loiret, Eure-et-Loire, Eure, Seine-Inférieure, Oise, Marne und Haute-Marne Erfolge zu erzielen. Dagegen waren die Radikalsozialisten in einigen Gebieten, wie bereits 1928, weniger erfolgreich. Das war z.B. im Westen der Fall, besonders im Finistère, in les Côtes-du-Nord, im Morbihan, im Norden, im Osten und im Nordosten, sowie in der Hauptstadt und dem unmittelbaren Umland. In folgenden Départements war der Parti radical gar nicht vertreten: Alpes-Maritimes, Bouches-du-Rhône, Korsika, l'Hérault, Pyrénées-Orientales. Im Zentrum Frankreichs gehörten le Cantal, die Corrèze und die Dordogne zu den erfolgreichen Wahlkreisen des Parti radical. Dafür traten die Radikalsozialisten in Haute-Vienne nicht mehr zur Wahl an; in Le Puy-de-Dome, in La

${ }^{262}$ Siehe den Artikel von Jean Piot in L'Oeuvre vom 4. 5. 1932, S. 1.

263 Vgl. S. Berstein, Parti radical, vol. 2, S. 203.

${ }^{264} \mathrm{Zu}$ Albert Milhaud siehe J. Jolly, Dictionnaire, vol. 7, S. 2461/2462.

${ }^{265}$ Die Errichtung des Posten eines Parteisekretärs wurde auch schon in der organisatorischen Reformphase des Parti radical unter Daladier ab 1927 diskutiert, vgl. dazu die Zeit Daladiers als Vorsitzender des Parti radical und seine Organisationsversuche in den Jahren 1927-1930 in Kapitel 1 dieses zweiten Prozeßbeispiels.

266 Zum Wahlergebnis aus dem ersten und zweiten Wahlgang siehe L'Oeuvre vom 9. 5. 1932, S. 1.

${ }^{267}$ Vgl. S. Berstein, Parti radical, vol. 2, S. 206. 
Creuse, in Le Cher, in L'Indre mußten die Radikalsozialisten spektakuläre Einbußen in Kauf nehmen. Im Südwesten sah die Wahlbilanz folgendermaßen aus: Die Radikalsozialisten schnitten äußerst erfolgreich in Landes, in Le Gers, in Les Hautes-Pyrénées, Le Tarn-et-Garonne ab, während sie in Le Lot, Le Tarn und Le Lot-et-Garonne Verluste zu verzeichnen hatten. Abschließend läßt sich summarisch dasselbe Phänomen wie bei den Wahlen von 1928 feststellen: Die radikalsozialistischen Wahlerfolge konnten vor allem in Gebieten errungen werden, die besonders von ländlichen Strukturen dominiert waren, in denen der Kleinbesitz überwog oder die katholische Kirche nur geringen Einfluß besaß268. Auf einen kurzen Nenner gebracht: Der Parti radical konnte in den Kleinstädten, in denen die lokalen Notablen eine gewichtige Rolle spielten, die größten Erfolge verbuchen.

Im zweiten Wahlgang gewannen die Radikalsozialisten mit Hilfe der „discipline républicaine" nochmals 67 Mandate dazu und zogen somit als stärkste Fraktion mit insgesamt 162 Abgeordneten in die neu gewählte Deputiertenkammer ein. Der Parti radical galt eindeutig als der große Wahlsieger, wenngleich auch die Sozialisten im Vergleich zu 1928 Mandate dazugewinnen konnten. Die SFIO errang im ersten Wahlgang 41 Abgeordnetensitze und im zweiten kam sie auf weitere 89 Mandate, womit sie insgesamt 130 Parlamentssitze auf sich vereinen konnte und damit zweitstärkste Fraktion wurde ${ }^{269}$. Bereits nach dem ersten Wahlgang feierte der linke Flügel der SFIO. Paul Faure überschrieb einen Leitartikel im Populaire vom 3. Mai 1932270 mit: „Vive le Socialisme.“ Im Vergleich zum ersten Wahlgang von 1928 konnten die Sozialisten sich von 15 Mandaten auf 41 Mandate steigern. In der Wahlpropaganda zwischen dem ersten und zweiten Wahlgang beschwor man den Sieg der sozialistischen Partei. Am 9. Mai 1932, also nach dem zweiten Wahlgang, titelte Le Populaire: „Victoire, confirmée et élargie!“

Am 10. Mai 1932 widmete sich Léon Blum ausführlich im Leitartikel des Populaire dem sozialistischen Erfolg bei den Wahlen, wobei er besonders den zu verzeichnenden Stimmenzuwachs der SFIO im Vergleich zu 1928 hervorhob. Die Sozialisten fuhren besonders erfolgreiche Wahlergebnisse vor allem im zweiten Wahlgang in folgenden Départements ein: in Nord von 24 Sitzen neun; in Somme von sieben Sitzen drei; in Aisne von sieben Sitzen drei; in Loir-et-Cher von vier Sitzen drei; in Saône-et-Loire von acht Sitzen vier; in Haute Vienne von fünf Sitzen drei; in Allier von sechs Sitzen fünf; in Creuse von vier Sitzen drei; in Gironde von 13 Sitzen sieben; in Isère von acht Sitzen vier; in Drôme von vier Sitzen drei; in Basses-Alpes von drei Sitzen zwei; in Var von fünf Sitzen drei; in Bouches-duRhône von elf Sitzen sieben; in Herault von sieben Sitzen vier und in Pyrénéesles-Or von drei Sitzen alle drei. Es zeichnet sich hier ganz deutlich für die Sozialisten ein Schwerpunkt im Süden Frankreichs ab271.

Obwohl die Sozialisten einen Stimmengewinn und damit eine Erhöhung ihrer

268 Vgl. hier vor allem die Graphiken in ebenda, S. 205.

${ }^{269} \mathrm{Zu}$ den errungenen Mandatszahlen der einzelnen Parteien siehe L'Oeuvre vom 9. 5. 1932, S. 1. Für den ersten Wahlgang vom 1. 5. 1932 siehe Le Populaire vom 3. 5. 1932, S. 1.

270 "Vive le Socialisme" von Paul Faure in Le Populaire vom 3. 5. 1932, S. 1.

271 Zum Wahlergebnis von 1932 siehe Le Temps vom 10. 5. 1932, S. 3-7. 
Mandate von $112^{272}$ auf 130 erringen konnten, war Léon Blum vom Wahlergebnis enttäuscht. Nach Meinung Blums hätten die Sozialisten noch bessere Wahlergebnisse erzielen können. Er machte für das nicht optimale Ergebnis besonders zwei Faktoren verantwortlich: zum einen die massive antisozialistische Propaganda des konservativen Blocks unter Tardieu ${ }^{273}$ und zum anderen die Kommunisten und ihre Wahltaktik, die ihre Kandidaten im zweiten Wahlgang nicht zurückgezogen und damit nach Schätzung Blums die SFIO um mindestens 13 Mandate gebracht hatten ${ }^{274}$; davon profitierte hauptsächlich der Parti radical. Für die Kommunisten selbst war das Wahlergebnis noch unbefriedigender, da sie im Vergleich zu den Wahlen von 1928275 starke Stimmeneinbußen hinnehmen mußten und statt $13 \mathrm{Ab}$ geordnete nur noch zehn in das Parlament entsenden konnten. Trotz der bis zuletzt sehr kämpferischen Wahlpropaganda gegen den Linksblock ging das linke Parteienspektrum klar als Sieger der Wahlen von 1932 hervor. Der rechte Block unter Tardieu war eindeutig unterlegen, wie dies sehr anschaulich aus folgender Wahlstatistik von 1932 hervorgeht:

\begin{tabular}{lrrcr}
\hline Gruppe & 1928 & 1932 & Gewinne & Verluste \\
\hline S.F.I.O. & 101 & 130 & 29 & \\
Radicaux-socialistes & 122 & 162 & 40 & \\
Républicains-socialistes et socialistes français & 26 & 31 & 40 & \\
Radicaux indépendants et indépendants de gauche & 34 & 32 & & 2 \\
Tardieussards & 176 & 116 & & 58 \\
U.R.D. & 102 & 82 & & 20 \\
Démocrates populaires & 19 & 18 & & \\
Conservateurs & 10 & 10 & & \\
Autonomistes & 4 & 5 & & 3 \\
Communistes & 13 & 10 & & \\
Communistes dissidents & 1 & 8 & 2 & \\
Pupistes & & 2 & 2 & \\
Non classés & 608 & 608 & 120 & 83 \\
\hline Insgesamt & & & & \\
\hline
\end{tabular}

Die neue Mehrheit im Parlament, die sich aus den politischen Kräften der Linken zusammensetzte, kam auf eine solide Anzahl von 325 Abgeordneten, während die Wahlverlierer - die politische Rechte - nur noch 258 Parlamentssitze erringen konnte.

272 Am Ende der Legislaturperiode 1928-1932 zählten die Sozialisten 112 Mandate; vgl. dazu Le Temps vom 29. 4. 1932, S. 6.

273 Blum in seinem Leitartikel "Les succès du Socialisme“ in Le Populaire vom 10. 5. 1932, S. 1.

274 Ebenda: „(..) cette tactique communiste du second tour qui prend vraiment, à la longue, le caractère d'une sorte d'aberration maniaque. (...) le maintien communiste nous a frustrées, nous socialistes, d'au moins treize grains supplémentaires."

275 Immerhin war es der kommunistischen Partei im ersten Wahlgang von 1928 noch gelungen, 1,1 Millionen Stimmen zu erringen. Im Gegensatz dazu fiel das Ergebnis für die Kommunisten im ersten Wahlgang von 1932 wesentlich schwächer aus, sie mußten sich mit 790000 Stimmen begnügen; vgl. Le Populaire vom 3. 5. 1932, S. 1, und G. Ziebura, Blum, S. 427. 
Der französische Wähler hatte mit diesem Votum die Regierung Tardieu-Laval abgewählt. Verständlicherweise suchte die abgewählte parlamentarische Mehrheit nach Erklärungsgründen für dieses Wahldesaster. Insgesamt verloren die Kräfte der politischen Rechten bzw. rechten Mitte gegenüber der Wahl von 1928101 Wahlkreise. Wie sich diese Verluste im einzelnen auf die politischen Gruppierungen der alten Mehrheit Tardieu-Laval verteilten, wird in der folgenden Tabelle deutlich:

\begin{tabular}{lc}
\hline Politische Gruppierung & verlorene Wahlkreise \\
\hline U.R.D. & 21 \\
Républicains Indépendants & 4 \\
Démocrates Populaires & 2 \\
Action Démocratique et Socialiste & 10 \\
Républicains de Gauche & 29 \\
Gauche radicale & 18 \\
Gauche socialiste et radicale & 6 \\
Indépendants de Gauche & 4 \\
Républicains socialistes & 2 \\
Aucun groupe & 5 \\
\hline
\end{tabular}

In einer Wahlstudie, die sich im Nachlaß Tardieu276 befindet, werden zur Erklärung der Wahlniederlage der alten Mehrheit fünf Faktoren angeführt. Als wichtigster Faktor wird die Zunahme der Wahlbeteiligung genannt, die ungefähr dem Gewinn des Stimmenanteils der linken politischen Kräfte entsprach. Im ersten Wahlgang konnten die Linkskräfte zwölf Prozent der Wählerstimmen im Vergleich zu den Wahlen von 1928 dazugewinnen, während die Stimmenanzahl für die rechten Kräfte konstant blieb. Dieser Stimmenzuwachs von zwölf Prozent entsprach einem Gewinn an Parlamentssitzen von 30 Prozent für die linken Kräfte. Neben diesem Hauptfaktor fielen aber noch weitere kleinere Komponenten ins Gewicht. So wird in der Wahlanalyse als zweiter Punkt das Verhalten der kommunistischen Partei im zweiten Wahlgang genannt. Immerhin brachte bei den Wahlen von 1928 das Festhalten der Kommunisten an ihrem Kandidaten im zweiten Wahlgang für die rechte Mehrheit einen Gewinn von 30 Mandaten im Parlament. Obwohl die Kommunisten auch 1932 an ihrem Kandidaten im zweiten Wahlgang festhielten, hatte dies weniger gravierende Konsequenzen als 1928, denn die Kommunisten mußten 1932 im Vergleich zu 1928 größere Stimmeneinbußen (ca. 30 Prozent) hinnehmen, was bedeutete, daß weniger kommunistische Kandidaten in den zweiten Wahlgang gingen. Außerdem profitierten 1932 mehr die Linksparteien von den abtrünnigen Stimmen der Kommunisten als 1928, wo überwiegend die rechten Parteien daraus Nutzen zogen. Jedoch kam in einigen Wahlkreisen auch dem kommunistischen Kandidaten die Politik des désistement der Linksparteien ${ }^{277}$ zugute; so konnte sich dieser dann erfolgreich gegen den

276 Der umfangreiche Nachlaß Tardieu $324 \mathrm{AP}$ ist in den Archives Nationales Paris einzusehen. Die oben genannte Wahlstudie „Note sur les sièges perdus par la majorité aux élections de 1932“ liegt in $324 \mathrm{AP} / 52$.

277 Die erfolgreiche Kandidatur eines Kommunisten gegen einen gemäßigten Kandidaten dank des 
Gegner aus den Reihen der gemäßigten Parteien behaupten. Ein weiterer Aspekt, der zur Erklärung der Wahlniederlage des konservativen Lagers herangezogen wurde, galt dem Faktum, daß das sogenannte Linkskartell 1932 in mehr Wahlkreisen als 1928 vertreten war. Ein vierter Punkt ging auf die mangelnde Einhaltung der "discipline républicaine" bei den rechten Parteien zurück; davon konnte oft ein Kandidat der linken politischen Kräfte profitieren. Im umgekehrten Falle war es aber auch dazu gekommen, daß gerade durch das désistement einer Partei der rechten Kräfte sich ein Kandidat der linken Parteien behaupten konnte. Sehr aufschlußreich ist eine Tabelle, die am Ende der oben genannten Wahlstudie aufgeführt wurde. Aus ihr geht deutlich hervor, aufgrund welcher Faktoren die einzelnen Parteien der alten rechten Mehrheit Stimmkreise verloren haben.

Gründe für die Sitzverluste der früberen Regierungsmehrbeit

1. Grund 2. Grund 3. Grund 4. Grund 5. Grund Gesamt

\begin{tabular}{lrrrrrr}
\hline U.R.D & 11 & 7 & 1 & 1 & 1 & 21 \\
Républicains Indépendants & 3 & - & 1 & - & & 4 \\
Démocrate populaire & - & 2 & - & - & - & 2 \\
Action Démocratique et Sociale & 2 & 3 & 5 & - & - & 10 \\
Républicains de gauche & 15 & 9 & 3 & 2 & - & 29 \\
Gauche radicale & 8 & 7 & 2 & - & 1 & 18 \\
Gauche sociale et radicale & 3 & 1 & - & 1 & 1 & 6 \\
Indépendants de gauche & 1 & 2 & 1 & - & - & 4 \\
Républicains sociales & - & 2 & - & - & - & 2 \\
Aucun groupe & 4 & 1 & - & - & - & 5 \\
\hline Insgesamt & 47 & 34 & 13 & 4 & 3 & 101 \\
\hline
\end{tabular}

1. Grund: Verschiebung nach links

2. Grund: Aktionen der Kommunisten

3. Grund: Cartel, wo es 1928 keine Rolle spielte

4. Grund: Aus Mangel an Disziplin

5. Grund: Désistement einer Partei, die der Mehrheit angehörte, zugunsten einer gegnerischen Partei

Vor allem der Union républicaine démocratique und der Républicains de gauche schadete der allgemeine Linksrutsch bei den Wahlen von 1932; beide Parteien verloren die meisten Sitze. Interessanterweise liegt dieser Wahlanalyse auch eine Einschätzung über die Regierungsfähigkeit der neuen Mehrheit im Parlament bzw. über deren Grenzen und Schwächen bei. In dieser Kurzanalyse wird von den „angeborenen" Schwächen einer Cartelregierung gesprochen, die aus konservativer Sicht vier Faktoren umfaßte. 1) Die religiöse Frage; 2) die Wirtschaft- und Finanzpolitik; 3) die Frage der Sicherheit und des nationalen Prestiges; 4) das Problem mit den Kommunisten. Bei Punkt eins ging die neue Minderheit davon aus, daß Herriot in einer erneuten Regierung nicht mehr wie 1924 den gravierenden Fehler

désistements der Linksparteien kam z. B. in den Départements Seine, Seine-et-Oise und im Norden zustande; vgl. die Wahlstudie in A.N. Nachlaß Tardieu 324 AP/52. 
begehen würde, die Religionsfrage für Elsaß-Lothringen zu klären, was beinahe zu einem neuen Kulturkampf geführt hätte. Die Opposition hielt es für wahrscheinlich, daß sich die Cartelregierung, so die Studie, im kulturpolitischen Sektor dieses Mal nur auf die weitere Förderung der Einheitsschule konzentrieren würde. Die politische Rechte schätzte in puncto Finanz- und Wirtschaftspolitik, daß Herriot sein Augenmerk besonders auf diesen kritischen Politikbereich lenken würde. Man attestierte ihm eine bessere finanzielle Ausgangposition als 1924 und vermutete, daß er eine erneute Kapitalflucht ins Ausland durch eine günstige Steuerpolitik zu unterbinden versuchen werde. Den dritten Aspekt, also die Frage nach den nationalen Interessen, hielt die Opposition für den neuralgischen Punkt der Cartelregierung. Beide Parteien, d.h. sowohl die Radikalsozialisten als auch die Sozialisten, würden zwar nicht leichtfertig die nationalen Interessen opfern, aber dennoch enthielten ihre Doktrinen kaum Anhaltspunkte, um sich den ausländischen Forderungen vehement entgegenzustellen. Als letzter eventueller Schwachpunkt wurde das Problem der Sozialisten mit den Kommunisten angeführt, die sicherlich eine Regierungsbeteiligung oder -unterstützung der Sozialisten mit ständigen Attacken begleiten würden. Dies könnte zur Folge haben, daß die Sozialisten gezwungen seien, den Aktionen der Kommunisten mit einer gewissen Toleranz zu begegnen. Das Strategiepapier schloß mit der Empfehlung an die neue Minderheit, sich auf Punkt drei zu konzentrieren, da er für die künftige Regierung wohl den größten Schwachpunkt darstellen dürfte. Hier sah man eine Möglichkeit, um die Mehrheit des Linksblocks aufzubrechen, riet allerdings angesichts der Friedenssehnsucht des französischen Volkes zu einem taktisch klugen Vorgehen: „Mais la partie est délicate, parce qu'il faut éviter de paraître emboiter le pas de Marin et des nationalistes, de heurter Briand et d'éveiller la défiance du peuple qui veut la paix. Le peuple est pacifiste, mais en même temps germanophobe, anglophobe (depuis La Haye), soucieux de l'indépendance et du prestige national. Laisser à Marin et à Maginot les protestations contre l'évacuation de la Rhénanie et, en général, contre la politique franco-allemande de Briand.“"278

\section{Regierungsverhandlungen zwischen SFIO und Parti radical}

Nachdem der Parti radical aus den Wahlen als stärkste Partei hervorgegangen war, betraute Staatspräsident Lebrun Herriot mit der Regierungsbildung. Besonderes Interesse wurde nun den Regierungsverhandlungen entgegengebracht. Obwohl die sozialistische Partei die zweitstärkste politische Kraft im Parlament darstellte, verhielt sich Herriot der SFIO gegenüber - wie bereits im Wahlkampf - sehr reserviert. Das Verhältnis zwischen diesen beiden linksrepublikanischen Parteien hatte sich im Vergleich zu 1924 entscheidend verändert. Herriot, der sich in seiner Wahltaktik durch das sehr gute Wahlergebnis seiner Partei bestätigt sah, versuchte auch in der Phase der Regierungsbildung, an seinem Unabhängigkeitskurs gegenüber den Sozialisten festzuhalten. Sein Streben galt einer Regierungsbildung in Richtung concentration. Ihm schien eine Unterstützungspolitik der SFIO vollauf 
zu genügen. Jedoch erregte dies den Protest des mittlerweile kleiner gewordenen linken Flügels des Parti radical, als deren Sprecher Gaston Bergery auftrat.

Auch in der SFIO entbrannte erneut ein Zweikampf zwischen dem rechten und linken Flügel um die Frage der Regierungsbeteiligung bzw. um die Unterstützungspolitik. Aber die Abkühlung der Beziehungen zwischen beiden Parteien hatte sich nicht nur durch den getrennten Wahlkampf verstärkt, sondern wurde noch weiter vertieft durch die unterschiedliche Haltung beider Parteien bei der Wahl Lebruns ${ }^{279}$ Anfang Mai 1932 zum Staatspräsidenten 280 . Zunächst hatte sich Paul Painlevé am 9. Mai 1932 als Gegenkandidat zur Verfügung gestellt, er zog aber seine Kandidatur noch am selben Tag zurück ${ }^{281}$. Die SFIO versagte Lebrun ihre Stimmen und gab in einer Erklärung bekannt, daß sie die Kandidatur Paul Faures unterstützen werde. Sie führte für ihre Haltung zwei Gründe an: Zum einen wollten die Sozialisten damit ihrem Protest Ausdruck verleihen, denn sie waren nicht einverstanden, daß die beiden Kammern der alten Legislaturperiode, also die alten Mehrheiten ${ }^{282}$, die Wahl des Staatspräsidenten vornahmen. Zum anderen verstanden sie ihr Votum für Paul Faure als Zeichen der Solidarität, da dessen Wahlsieg in seinem Wahlkreis Creusot von der Gegenseite durch Korruptionszahlungen verhindert worden sei ${ }^{283}$. Der Parti radical beschloß unmittelbar vor der Wahl des neuen Staatspräsidenten, seinen Mitgliedern das Votum freizustellen ${ }^{284}$. Die überwiegende Mehrheit des Parti radical stimmte für Lebrun ${ }^{285}$.

Schon 1931 war es zu unterschiedlichen Haltungen des Parti radical und der SFIO in der Frage der Staatspräsidentenwahl gekommen. Blum lastete bereits damals Herriot und dem Parti radical das Scheitern Briands bei der Wahl um das Staatspräsidentenamt an ${ }^{286}$. Nach dem Wahlsieg bereiteten sich beide Parteien auf ihre zukünftige Taktik im Parlament vor. Die SFIO diskutierte auf ihrem Parteitag vom 29. Mai bis 1. Juni 1932 ihre Position in der Frage der Regierungsbeteiligung, die erneut sehr unterschiedlich ausfiel. Auch vor diesem Parteitag äußerten sich

279 Albert Lebrun war der Präsident der zweiten Kammer, des Senats. Zur Person Lebruns siehe J. Jolly, Dictionnaire, vol. 6, S. 2185/2186.

280 Doumer, der bisherige Präsident der Republik, war am 7.5. 1932 im Palais Rothschild durch den Russen Gorgulov ermordet worden; vgl. Le Temps vom 8. 5. 1932, S. 1, 3; L'Oeuvre vom 8. 5. 1932, S. 1-2.

281 Vgl. zur Bereitschaft Painlevés, für das Amt des Staatspräsidenten zu kandidieren, Le Temps vom 10.5. 1932, S. 8. Painlevé zog aber bereits am 10.5. 1932 seine Kandidatur zurück, da er in den größten Fraktionen nur von einzelnen Personen Unterstützung signalisiert bekommen hatte. Vgl. zur Rücknahme der Kandidatur Painlevés Le Temps vom 11. 5. 1932, S. 1: „Un grand nombre des députés, désireux de prévenir tout désaccord éventuel entre le président élu par l'Assemblée sortante et la Chambre nouvelle, dont la composition politique est très differente, avaient instamment demandé à $M$. Painlevé d'accepter la candidature à la République pour faciliter la transition entre les deux Chambres. Cette préoccupation ne paraissant point partagée par des nombreux républicains de la haute Assemblée, soucieux surtout d'éviter une dualité de candidature, M. Painlevé a fait savoir ce soir à ses amis qu'il ne serait pas candidat."

282 Die alte Legislaturperiode endete offiziell erst am 1. 7. 1932.

${ }^{283}$ Zur Erklärung der SFIO siehe Le Temps vom 11. 5. 1932, S. 8.

284 Zur Resolution des Parti radical siehe ebenda.

${ }^{285}$ Lebrun konnte die absolute Mehrheit mit 633 Stimmen erlangen, Paul Faure erhielt 114, Painlevé zwölf, Cachin acht Stimmen und verschiedene andere Kandidaten konnten zehn Stimmen auf sich vereinen. Zum Abstimmungsergebnis siehe Le Temps vom 12. 5. 1932, S. 1.

$286 \mathrm{Vgl}$. hier vor allem die Leitartikel von Léon Blum gegen Herriot in Le Populaire vom 14.-16. 5., vom 18. 5. und vom 20.5.1931, jeweils S. 1 . 
die beiden Flügel der SFIO in der Parteipresse zu dieser stets kontrovers diskutierten Frage, die besonders 1932 ein großes Spaltungspotential in sich barg.

\section{Die Diskussion um die Regierungsbeteiligung in der SFIO auf dem Parteitag vom 29. Mai bis 1. Juni 1932}

Betrachtet man die Wochen nach der Wahl von 1932, wird deutlich, daß mehr taktische als inhaltliche Gründe die Politik der beiden Linksparteien lenkten.

Vor Beginn des sozialistischen Parteitages stellte Blum über die zukünftige Regierungsmehrheit zwei alternative Überlegungen im sozialistischen Presseorgan Le Populaire an ${ }^{287}$. Blum sah zum einen eine Regierungsmöglichkeit der concentration, der er rein rechnerisch durchaus eine Grundlage bescheinigte; hingegen hielt er sie inhaltlich für äußerst problematisch, da sie vor allem gegen den Wählerwillen verstoßen würde. Blum sah aber für diese Entwicklung deutliche Anzeichen gegeben ${ }^{288}$. Z.B. deutete für ihn die Wahl Lebruns mit Hilfe der radikalsozialistischen Stimmen zum Staatspräsidenten in diese Richtung, denn Blum hielt Lebrun für einen der konservativsten Staatspräsidenten, den die Dritte Republik seit Casimir Périer und Felix Faure hatte ${ }^{289}$. Er führte weiter die Haltung der politischen Kräfte der Rechten bis rechten Mitte in der Presse an, die mit allen Mitteln versuchten, den Parti radical von den Sozialisten fernzuhalten, indem sie eindringlich an die Jahre der Zusammenarbeit von 1924/1925 erinnerten und vor einer Neuauflage warnten. Blum hielt eine Rechtskoalition für möglich, verurteilte sie aber gleichzeitig sehr scharf. Denn einerseits sei eine Koalition des Parti radical mit der besiegten alten Mehrheit Tardieu-Laval äußerst unmoralisch. Und zweitens berge seiner Meinung nach diese Mehrheit eine viel zu große Heterogenität in sich, die letztlich zu politischer Ohnmacht und Stagnation führen müsse ${ }^{290}$. Als zweite Möglichkeit führte Blum eine Zusammenarbeit zwischen dem Parti radical und den Sozialisten in Form eines Cartel des gauches an. Diese Option hielt er aus zwei Gründen für die glaubwürdigere. Einerseits entsprach sie klar dem Wahlergebnis und damit dem Wählerwillen, andererseits stand eine Regierung des Cartel des gauches 1932 zahlenmäßig auf einer wesentlich solideren Grundlage als 1924291. Allerdings glaubte Blum, daß Herriot sich aus taktischen Gründen für eine Regierung des Cartel des gauches nur unter der Voraussetzung entscheiden würde, daß die SFIO Regierungsverantwortung übernehme. Sollten sich die Sozialisten auch dieses Mal einer Regierungsverantwortung entziehen, konnte Herriot sich der ersten Option, also einer Regierung der concentration, ohne weiteres zuwenden, denn die Verantwortung für das Nichtzustandekommen einer Regierung des Cartel des gauches konnte dann den Sozialisten zugeschrieben werden. Dies würde der SFIO vor allem bei den Wählern langfristig gesehen schaden.

\footnotetext{
287 Z.B. legte Blum in seinen Artikeln vom 14. 5., 15. 5. und 16. 5. 1932 im Populaire seine Überlegungen über die zukünftige Rolle der SFIO unter einer Regierung Herriot dar.

288 Vgl. Blum in Le Populaire vom 14. 5. 1932, S. 1: „La concentration? Sans nous!“

289 Blum in Le Populaire vom 12.5. 1932, S. 1.

290 Blum in Le Populaire vom 13. 5., 15. 5. und 16. 5. 1932, jeweils S. 1.

291 Die Regierung des Cartel des gauches unter der Führung Herriots von 1924 hatte stimmenmäßig nur eine knappe Mehrheit im Parlament.
} 
Blum, der diese Möglichkeit bereits im Vorfeld der Wahlen von 1932 in Erwägung gezogen hatte, nahm in der weiteren Argumentation wieder Bezug auf seine Wahlrede in Narbonne vom April 1932, in der er bereits eine Regierungskoalition zwischen den Sozialisten und dem Parti radical in Aussicht gestellt hatte, jedoch nicht ohne deutlich zu betonen, daß es sich hierbei lediglich um eine "participation sous condition " handeln könne. Er legte in einem weiteren Schritt dar, was er mit einer "bedingten Beteiligung" intendierte: konkret bedeutete das die Aufnahme wichtiger sozialistischer Wahlforderungen in das Regierungsprogramm eines Kabinetts des Cartel des gauches. Diese conditio sine qua non erfüllte für den führenden sozialistischen Sprecher zwei Funktionen: Einmal fungierte sie als taktisches Mittel für die parteiinterne Diskussion zwischen dem linken und rechten Flügel und zum anderen versuchte Blum damit, auch die Wählerschaft der SFIO weiterhin an die Partei zu binden, vor allem im Hinblick auf die zu erwartenden Attacken gegen die Sozialisten von seiten der Kommunisten.

Erstaunlich couragiert äußerte sich Léon Blum zur Frage der Regierungsbeteiligung auch in einem weiteren Leitartikel vom 16. Mai 1932292, in dem er mehr oder weniger offen für eine Regierungsbeteiligung warb, ohne dabei aber das Prinzip der innerparteilichen Demokratie zu verletzen293. Mit seinen Ausführungen versuchte Blum in erster Linie zu erläutern, warum sich 1932 die Frage der Regierungsbereitschaft für die Sozialisten in einem anderen Licht darstelle als in den Jahren davor. Und in zweiter Linie, warum die Partei dieses Mal zu einer bejahenden Antwort finden sollte294. Das Mitwirken an einer radikalsozialistischen Regierung würde den Sozialisten die Möglichkeit der Umsetzung ihres Programmes und ihrer Reformforderungen geben. Außerdem stellte Léon Blum im Vorfeld des Parteitages eine gewisse Übereinstimmung bei allen Strömungen innerhalb der SFIO fest ${ }^{295}$, dieses Mal ein Angebot der radikalsozialistischen Partei nicht abzulehnen. Gleichzeitig sicherte er der SFIO den Rückzug, indem er betonte, daß ihre Antwort eindeutig davon abhänge, zu welchen inhaltlichen Konzessionen sich die Radikalsozialisten bereit zeigten. $\mathrm{Zu}$ diesem $\mathrm{Zweck}$ führte Blum nochmals drei essentielle Programmpunkte an, die als Ausgangsposition für eine Einigung zwischen Parti radical und SFIO dienen sollten: 1) eine sofortige und deutliche Reduzierung der Militärkredite; 2) ein nationales Versicherungssystem, das die Risiken der Arbeitslosigkeit und der Bauern miteinbeziehen sollte; 3) eine Verstaatlichung der privaten Versicherungsmonopole und der Eisenbahn ${ }^{296}$. Die Auswahl dieser drei Punkte begründete Blum mit der Konsensfähigkeit zwischen beiden Parteien: „J'avais été guidé par un double souci: puiser dans les programmes communs des radicaux et des socialistes, car chacune de ces trois

292 Le Populaire vom 16. 5. 1932, S. 1: „Les conditions minima“.

293 Blum betonte ausdrücklich, daß alle Meinungen, die im Vorfeld des Parteitages geäußert würden, persönlicher Natur seien, und nur die Beschlüsse des Parteitages bindende Kraft besäßen; vgl. ebenda.

${ }^{294}$ Ebenda: „Toute la question est de savoir si les mêmes considérations de faits qui, jusqu’à présent, avaient incliné la majorité du Parti à une négative immédiate, doivent le conduire aujourd'hui, et pour la première fois, à la position contraire."

295 Ebenda: „Si l'on va jusqu'au fond des choses, Paul Faure et Zyromski ont tenu à peu près le même langage que Renaudel et que Déat. C'est ce qui permet de présager la résolution du Parti avant que ses Congrès fédéraux et son Congrès national aient statué."

${ }^{296}$ Ebenda. 
mesures s'appuie sur les décisions les plus récentes ou sur les traditions les plus anciennes du Parti radical (...)." 297

Auf dem kommenden Parteitag sollten die Punkte, so Blum, die unbedingt in ein Regierungsprogramm aufzunehmen waren, festgelegt werden, wobei die von ihm bereits in seiner Rede von Narbonne erwähnten fünf Forderungen als Grundlage zu dienen hätten ${ }^{298}$.

Vergegenwärtigt man sich die Diskussion der SFIO um die Frage der Regierungsbeteiligung oder -unterstützung nach dem Wahlerfolg von 1924, fällt eine gravierende Differenz zu 1932 auf. Herriot bemühte sich damals sehr um die Beteiligung der Sozialisten an seiner zukünftigen Regierung; es sei hier nur an die verschiedenen Briefe Herriots an Blum ${ }^{299}$ erinnert, die nicht nur taktischen Charakter besaßen. 1932 verhielten sich die Radikalsozialisten in dieser Frage wesentlich reservierter und warteten zunächst einmal das Ergebnis des sozialistischen Parteitages $a b^{300}$. Im Gegensatz zu Blum, der angesichts der nicht ausgeräumten Bedenken gegen eine Koalitionspolitik den Parti radical sehr umwarb, zeigte Renaudel durch seine Äußerungen, daß er die Lage durchaus realistischer einschätzte. In einem Schreiben an Kautsky vom 13. Mai 1932 erläuterte Renaudel 301 dem greisen SPD-Partei-Theoretiker Chancen und Hindernisse einer Regierungskoalition mit den Radikalen. Er betrachtete die Koalitionsfrage von beiden Seiten und attestierte zunächst den Sozialisten, daß diese endlich bereit seien, einer Regierungsbeteiligung auf dem bevorstehenden Parteitag zuzustimmen. Zur Untermauerung dieser Prognose stützte sich Renaudel auf ein Gespräch mit führenden Sozialisten wie Blum, Bracke und Auriol. Jedoch stellte er weiter in seiner Analyse fest, daß sich das Interesse der Radikalsozialisten gegenüber den Sozialisten als Bündnispartner verändert habe. Noch vor drei Jahren, als Daladier den Sozialisten im Oktober 1929 eine Regierungsbeteiligung anbot und diese gezwungenermaßen ihre ursprüngliche Zusage revidieren mußten ${ }^{302}$, war der Parti radical im Vergleich zu 1932 ernsthaft an der SFIO interessiert. Jetzt hingegen seien die Radikalsozialisten nicht mehr an einem sozialistischen Bündnispartner interessiert ${ }^{303}$. Renaudel kam mit dieser Einschätzung der radikalsozialistischen Haltung der Wirklichkeit sehr nahe, wie die Ereignisse der Folgezeit bestätigen sollten.

Wie üblich hielten die verschiedenen Föderationen der SFIO im Vorfeld des nationalen Parteitages jeweils ihren kleinen Parteitag ab. Bereits hier zeigte sich deutlich, daß innerhalb der sozialistischen Partei die von Blum kreierte Formel "participation conditionnée“ Akzeptanz fand ${ }^{304}$. Die Mehrheit der verschiedenen Föderationen stimmte für eine Regierungsbeteiligung der Sozialisten, aber nur

\footnotetext{
297 Ebenda.

${ }_{298}$ Vgl. dazu Le Populaire vom 11. 4. 1932, S. 1 und vom 16. 4. 1932, S. 1.

299 Vgl. dazu Prozeßbeispiel I, Kapitel 5 dieser Studie.

300 Siehe dazu L'Oeuvre vom 12. 5. 1932, S. 1; aber auch bereits die Äußerungen Herriots in L'Oeuvre vom 7. 5. 1932, S. $1 / 2$.

301 G. Ziebura, Blum, S. 429/430.

302 Vgl. dazu Kapitel 1 des zweiten Prozeßbeispieles dieser Studie.

303 Ebenda.

${ }^{304}$ Im Populaire wurden die Resolutionen der verschiedenen Föderationen, die diese jeweils auf ihrem Parteitag verabschiedeten, publiziert; vgl. Le Populaire vom 20.-26. 5. 1932. Z.B. sprachen sich die Föderationen Haute-Loire, Marne, Pas-de-Calais für eine „bedingte“ Beteiligung der Sozialisten an einer radikalsozialistischen Regierung aus; vgl. Le Populaire vom 26. 5. 1932, S. 6.
} 
unter der Bedingung, daß die Programmpunkte der SFIO in das Regierungsprogramm mitaufgenommen wurden.

Auf dem nationalen Parteitag kam es, wie sich im Vorfeld in Artikeln von einzelnen prominenten Vertretern der zwei Flügel abgezeichnet hatte, dennoch wieder zu einer kontroversen Diskussion, wenngleich diesmal die Befürworter einer Regierungsbeteiligung in der Mehrheit zu sein schienen. Der linke Flügel, für den vor allem Zyromski ${ }^{305}$ sprach, setzte sich deutlich von dem gefundenen Kompromiß einer Regierungsbeteiligung unter Einhaltung bestimmter Bedingungen ab. Er formulierte in einem Artikel am 20. Mai 1932 im Populaire, daß auf dem bevorstehenden nationalen Parteitag nicht über die Konditionen einer Regierungsbeteiligung diskutiert werden müsse, sondern vielmehr eine Grundsatzdiskussion über diese Frage zu führen sei. So bekannte Zyromski gleich zu Beginn seines Artikels, daß er eine kleine Gruppe innerhalb der Partei vertrete, die generell gegen eine Regierungsbeteiligung eintrete, "parce que nous jugeons cette méthode d'action éliminée naturellement par l'évolution du capitalisme et ses répercussions sur les formations politiques de la bourgeoisie" 306 . Falls die SFIO diese Frage dennoch positiv beantworten sollte, dann dürfe das freilich nur unter der Bedingung einer genauen Festlegung der geforderten Programmpunkte geschehen, die sie als unverzichtbar für eine Zusammenarbeit mit den Radikalsozialisten hielt.

Aus den weiteren Ausführungen wird deutlich, daß Zyromski umfassende Reformen in Zusammenarbeit mit dem Parti radical für unwahrscheinlich hielt, weil die sozialistischen Änderungsvorschläge nicht mit der Doktrin der Radikalsozialisten vereinbar seien. Um seiner Argumentation nachhaltig Ausdruck zu verleihen, berief sich Zyromski auf die große sozialistische Autorität Jean Jaurès, der ebenfalls vor und nach den Wahlen von 1914 die sozialistische Partei vor einer Wiederbelebung des „Bloc des gauches“ bzw. vor einer Regierungskoalition gewarnt hatte ${ }^{307}$. Zyromski befürchtete, daß eine Zusammenarbeit mit den bürgerlichen Parteien letztlich zu einer Aufweichung der geforderten Programmpunkte führen müsse und die Kooperation daher keine ausreichende Sicherheit für die Durchsetzung sozialistischer Politik darstellen würde ${ }^{308}$. Mit einem längeren Zitat aus einer 1926 in Bellevilloise gehaltenen Rede von Léon Blum versuchte Zyromski seine Position zu untermauern und gleichzeitig Blum an seine frühere Einschätzung hinsichtlich der Regierungsbeteiligung und die daraus resultierenden Konsequenzen für die SFIO zu erinnern: „Une fois l'idée de la participation admise, une fois le principe admis avec les conditions le plus sincèrement, (...) je vous le dis, vous ne pourrez pas vous en tenir à ces conditions. " 309

Noch deutlicher formulierte Paul Faure, der ebenfalls den linken Flügel der SFIO vertrat, unmittelbar vor dem nationalen Parteitag seine Ablehnung einer Zusammenarbeit mit dem Parti radical in seinem Leitartikel „La question préala-

305 Zyromski meldete sich bereits am 13.5.1932 im Populaire sehr selbstbewußt für den linken Flügel der SFIO zu Wort, wo er zunächst auf den Wahlerfolg der SFIO verwies, den sie eigenständig erarbeitet hatte und der deutliche Akzente setzte. Im Vergleich zu 1924 müßten die Forderungen der SFIO, so Zyromski, deutlich formuliert werden; vgl. Le Populaire vom 13. 5. 1932, S. 6.

306 Zyromski in Le Populaire vom 20. 5. 1932, S. 6.

307 Ebenda.

${ }^{308}$ Ebenda.

${ }^{309}$ Ebenda. 
ble et le silence des radicaux “310. Faure hielt es für unrealistisch, daß der Parti radical die sozialistischen Konditionen akzeptiere, denn er sah keine inhaltliche Konsensfähigkeit in den großen Themen der Außen- und Innenpolitik; vielmehr stellte er Painlevé und Herriot in eine Reihe mit Poincaré und Tardieu311. Der beste Beweis für seine Prognose war in seinen Augen, daß Herriot sich in Schweigen hüllte, obwohl Léon Blum bereits in Narbonne, also noch vor den Wahlen, die Koalitionsbereitschaft der Sozialisten angedeutet hatte. Auch die verschiedenen Äußerungen Blums in seinen Leitartikeln in den Wochen nach der Wahl, in denen er erneut Regierungsbereitschaft signalisierte, blieben von radikalsozialistischer Seite unbeantwortet ${ }^{312}$.

Der rechte Flügel hingegen fand, daß die Konditionen weitgehend in den Hintergrund zu treten hätten, denn für ihn lag der Schwerpunkt in der Regierungsbeteiligung selbst. Er sah in den Konditionen eher eine Behinderung für eine Koalition mit dem Parti radical. Seiner Meinung nach war es wesentlich wichtiger, eine Übereinstimmung in den allgemeinen politischen Grundsätzen zu finden, als einen Konsens in spezifischen Programmpunkten zu verhandeln. Deshalb plädierte er dafür, sich mit den Radikalsozialisten über einige Maßnahmen, die umgehend realisiert werden sollten, zu einigen ${ }^{313}$.

Wie bereits aus den Diskussionen im Vorfeld des Parteitages hervorging, lagen zwischen den Vorstellungen des rechten und denen des linken Flügels, die in den verschiedenen Beiträgen vorgebracht wurden, deutliche Unterschiede. Blum versuchte auch auf diesem Parteitag, die bewährte Rolle des Vermittlers zu übernehmen und reichte einen Resolutionsantrag ein, der beide Positionen abschwächte, um auf dem kleinsten gemeinsamen Nenner eine Einigung zu erzielen. Er kritisierte den Antrag des rechten Flügels ${ }^{314}$, denn eine Übereinstimmung bzw. Ausarbeitung von Sofortmaßnahmen zur Lösung der Wirtschaftskrise reiche als Grundlage für eine Zusammenarbeit mit den Radikalsozialisten nicht aus. Darüber hinaus lehnte er Vorverhandlungen mit dem Parti radical ab und hielt sehr strikt an den Konditionen fest, die lediglich in Detailfragen modifiziert werden könnten. Dem Resolutionsantrag 315 des linken Flügels hielt er entgegen, daß der Parti radical sich wohl kaum auf Programmpunkte, die sich weitgehend mit dem sozialistischen Programm deckten und damit einer Regierung unter sozialistischer Führung entsprächen, festlegen lassen würde. Daher müßten die programmatischen

310 Le Populaire vom 24. 5. 1932, S. 1.

311 Ebenda: „Les chefs radicaux sont connus. Ils ont occupé les plus hautes fonctions gouvernementales. En politique extérieure, de Painlevé à Herriot, ils ont été aussi nationalistes que Tardieu et Poincaré. En politique intérieure, ils ont été hésitants, timides ou capitulards."

312 Ebenda.

${ }^{313}$ Le Populaire vom 17. 5. 1932, S. $1 / 2$.

314 Vgl. dazu den Resolutionsantrag der Föderation der Haute-Garonne in Le Populaire vom 30. 5. 1932, S. 6. In diesem Antrag wird vor allem auf die aktuelle politische Situation rekurriert, die eine Beteiligung der SFIO an der Regierung unausweichlich mache: „(..) dans l'état présente de la France et de l'Europe, le Parti socialiste ne peut opposer aux offres de collaboration gouvernementale qui pourraient lui êtres faites, une fin de non recevoir systématique, et qu'au contraire, il y a licu pour lui de tout entendre et de tout examiner en vue de réaliser les mesures que l'état de la France et du monde impose impérieusement et les réformes essentielles attendues par la classe ouvrière et paysanne de France."

315 Le Populaire vom 31. 5. 1932, S. 3; ebenso das Parteitagsprotokoll der SFIO von 1932: 30e Congrès National, 14.-17. 7. 1933 à Paris, Paris 1933, S. 11/12. 
Bedingungen so ausgewählt und formuliert werden, daß sie mit dem Parteiprogramm des Parti radical vereinbar seien. Außerdem merkte er noch an, daß sich bei Ablehnung der sozialistischen Forderungen durch den Parti radical die SFIO immer noch auf die Position der Unterstützungspolitik zurückziehen könne.

In seinem Resolutionsantrag wird deutlich, daß Blum dem linken Parteiflügel näher stand als den rechten Befürwortern einer Regierungsbeteiligung. Besonders im Resolutionsausschuß 316 fanden zähe Debatten statt, vor allem zwischen Renaudel und Blum. Die Auseinandersetzung zwischen den beiden Hauptkontrahenten der SFIO entzündete sich an der vehementen Forderung Renaudels, daß der Punkt - Verhandlungsgespräche mit dem Parti radical zu führen -, in die Schlußresolution aufgenommen werden müsse ${ }^{317}$. Zur Fixierung der Konditionen mußte sogar eine Unterkommission im Resolutionsausschuß eingerichtet werden, der Blum, Auriol, Lafont, Lebas, Renaudel und Zyromski angehörten. Der Text der Schlußresolution ${ }^{318}$ wurde fast ohne größere Korrekturen verabschiedet. Nur der Zusatz von Renaudel bezüglich der Verhandlungen mit dem Parti radical wurde im Resolutionsausschuß knapp mit 21 zu 18 Stimmen abgelehnt. Blum versuchte die Bedeutung des von Renaudel geforderten Zusatzes herunterzuspielen, da er lediglich eine Nuance im weiteren Procedere darstelle, jedoch widersprach Renaudel Blum heftig und hielt ihm vor, daß er in Wirklichkeit nur versuche, eine sozialistische Regierungsbeteiligung $\mathrm{zu}$ vereiteln ${ }^{319}$. In der Vollversammlung wurde die von der Kommission ausgearbeitete Resolution fast einstimmig angenommen, Renaudel hatte seine Zusatzforderung zurückgenommen. Die Konditionen, die fast einheitlich vom Parteitag akzeptiert worden sind, wurden in den "Cahiers de Huyghens" ${ }^{320}$ zusammengefaßt und bestanden aus neun Punkten: 1) Sicherung des Friedens mit Hilfe eines Schiedssystems und Reduzierung der Militärausgaben auf den Stand von 1928; 2) Verbot des Waffenhandels; 3) Herstellung des budgetären Gleichgewichts, aber ohne Deflationspolitik; 4) Schutz der Spareinlagen und Bankenkontrolle; 5) Schaffung öffentlicher Einrichtungen für Dünger und Weizen; 6) Verstaatlichung der Eisenbahn; 7) Bildung eines nationalen Versicherungssystems; 8) Einführung der 40-Stundenwoche bei gleichbleibendem Lohn; 9) Eine allgemeine politische Amnestie321.

Diese detaillierten Forderungen zeigen deutlich, daß die Vorstellungen des linken Parteiflügels ganz wesentlich in die Schlußresolution eingeflossen waren. Bei

316 Der Resolutionsausschuß setzte sich aus folgenden Mitgliedern zusammen: Blum, Auriol, Masquère, Montel, Lagorgette, Longuet, Monnet, Compère-Morel, Marx Dormoy, Gendre, Léon Bon, Sixte-Quenin, Sonal, Bracke, Lebas, Laurent, Salengro, Paul Faure, Séverac, Zyromski, Graziani, Marceau Pivert, Farinet, Mahler, Louis Lévy, Alleaume, Renaudel, Marquet, Evrard, Déat, Varenne, Rurère, Lafont, Perrin, Frossard, Jules Moch, Hauck, Cayrel, Félix, Groussier, Grumbach. Zusätzliche Mitglieder (Suppléants): Hudelle, Nermond, Forgues, Melis, Emile Kahn, Auray, Maillet, Brenot; vgl. Le Populaire vom 31. 5. 1932, S. 3.

317 Renaudel betonte die Wichtigkeit der Gespräche mit den Vertretern des Parti radical: „Nous estimons que la question des conversations est essentielle. Et je vous signale que ce que vous semblie? craindre tout à l'heure va se réaliser. Si votre procédure est employée, le jugement de l'opinion publique se retournera contre vous."; vgl. Le Populaire vom 31. 5. 1932, S. 3.

${ }_{318}$ Zum Textlaut der Schlußresolution siehe Le Populaire vom 1.6. 1932, S. 1.

319 Vgl. dazu Anmerkung 316.

320 Diese Bezeichnung kommt vom Namen des Gebäudes, in dem der Parteitag der SFIO abgehalten wurde.

321 Le Populaire vom 1.6. 1932, S. 1. 
den genannten Punkten handelte es sich nicht nur um konsensfähige Themen, sondern um Forderungen, die dem sozialistischen Kanon entnommen worden waren 322 . Damit schien ein Konsens mit dem Parti radical nur relativ schwer erreichbar zu sein. Noch während des sozialistischen Parteitages am 31. Mai 1932 überbrachte eine Delegation ${ }^{323}$ der SFIO dem zukünftigen Regierungschef Herriot ein Koalitionsangebot inklusive der formulierten Forderungen für eine Regierungsbeteiligung. Außerdem lag den Unterlagen ein von Paul Faure unterzeichnetes Begleitschreiben bei, indem dieser äußerst vorsichtig und zurückhaltend die Aufgabe der sozialistischen Delegation darlegte: „J'ai l'honneur de vous faire connaître également que le Congrès $a$, dès à present, désigné la délégation qui sera chargée - au cas où le Parti que vous présiderez en exprimerait le désir - d'entrer en contact avec vous. “324 Im Vergleich zu 1924 erstaunt das Vorgehen der SFIO in zweierlei Hinsicht. Zum einen, daß die sozialistische Partei in Eigeninitiative handelte, denn der Parti radical hatte der SFIO dieses Mal kein Koalitionsangebot unterbreitet. Zum anderen war auffallend, daß die Sozialisten, obwohl sie sich dem Parti radical anboten, weitreichende Forderungen stellten, die für den Parti radical kaum akzeptabel waren. Es drängt sich dabei der Gedanke auf, daß der linke Flügel der SFIO, der sich hatte durchsetzen können, unter rein taktischen Gesichtspunkten handelte. Auf seiten des Parti radical, der durch Herriot, Caillaux, Maurice Sarraut und René Renoult ${ }^{325}$ repräsentiert war, begegnete man der sozialistischen Delegation sehr zurückhaltend. Herriot nahm lediglich das von den Sozialisten ausgearbeitete Angebot in Empfang und versprach eine schriftliche Antwort des Comité exécutif der radikalsozialistischen Partei ${ }^{326}$. Das weitere Vorgehen des Parti radical war ebenso von taktischen Überlegungen geprägt wie das der Sozialisten und verriet zugleich, daß der Parti radical unter der Führung Herriots 1932 im Gegensatz zu 1924 eine Regierungsbeteiligung der Sozialisten nicht wünschte. Herriot, der die Antwort auf das sozialistische Angebot verfaßte, ließ diese vom Comité exécutif absegnen und reichte sie noch am selben Abend gegen $23 \mathrm{Uhr}$ an die Presse weiter. Mit dieser Vorgehensweise signalisierte der zukünftige Regierungschef, daß er keinerlei Verhandlungen mit den Sozialisten einzugehen gewillt war. Die Formulierung der Antwort verriet außerdem, daß diese nicht nur eine vorübergehende Absage darstellte, sondern, daß es sich dabei um eine prinzipielle und langfristige Entscheidung handelte. Höflicherweise attestierte Herriot den Sozialisten eine loyale Zusammenarbeit in den Jahren 1924/25,

322 Zur Rechtfertigung dieser Themenauswahl siehe Blum in Le Populaire vom 5.6.-7.6. und vom 9. 6.-12. 6. 1932, jeweils S. 1 .

${ }^{323}$ Die Delegation der SFIO setzte sich aus den Mitgliedern Blum, Auriol, Renaudel und Lebas zusammen; vgl. Le Populaire vom 1.6. 1932, S. 1, sowie den 29 e Congrès National in Paris 29. 5.1.6. 1932, C.R.ST., Paris 1932, S. 37. Außerdem siehe auch den Bericht von Léon Blum in Le Populaire vom 5. 6. 1932, S. 1 und derselbe, Les radicaux et nous 1932-1934, Paris 1934, S. 13-22.

${ }_{324}$ Abdruck dieses Begleitbriefes von Paul Faure in Le Populaire vom 1.6. 1932, S. 1; außerdem auch $30^{\circ}$ Congrès National in Paris 14. 7.-17. 7. 1932, C.R.ST., Paris 1933, S. 12.

325 Le Populaire vom 1. 6. 1932, S. 1: „Le Parti radical n'accepte aucun des points du, Cahier socialiste."

326 Nüchterne Schilderung dieser Begegnung zwischen der sozialistischen und der radikalsozialistischen Delegation in Le Populaire vom 1.6. 1932, S. 1; außerdem auch in L'Oeuvre vom 1. 6. 1932, S. 1/2. Sehr eindrücklich schildert auch Herriot diese Begegnung in seinen Memoiren: Derselbe, Jadis, S. 298 f. 
bevor er ihnen mitteilte, daß er eine Kooperation auf der Grundlage eines gemeinsamen Mindestprogramms ablehne. Vor allem betonte der Vorsitzende des Parti radical, daß er zwar die Doktrin der Sozialisten respektiere, aber umgekehrt nicht nur das Recht, sondern die Pflicht habe, die traditionelle radikalsozialistische Doktrin zu verteidigen. Darüber hinausgehend unterstrich er, daß der Parti radical seinen Mitgliedern immer die Freiheit gewährt habe, gegebenenfalls Regierungen unter ihrer Verantwortung zu bilden, die jedoch inhaltlich im Rahmen der radikalsozialistischen Doktrin zu verorten sein müßten.

In einem zweiten Schritt setzte sich Herriot inhaltlich mit den von den Sozialisten gestellten Konditionen auseinander, wobei er die einzelnen Punkte sehr differenziert behandelte. Zunächst äußerte er sich zu den Programmpunkten, für die durchaus eine gewisse Übereinstimmung zwischen dem Parti radical und den Sozialisten bestand. Konsensmöglichkeiten sah er in den Forderungen, die die Schiedsgerichtsbarkeit und den Schutz der Sparguthaben betrafen, gegeben ${ }^{327}$. Er ließ es sicht nicht nehmen, rigoros darauf zu verweisen, daß der Parti radical die Aufnahme des Prinzips der internationalen Schiedsgerichtsbarkeit in die Protokolle der Londoner Konferenz veranlasst habe.

Einige Punkte überging er mit Stillschweigen, wie z.B. die Forderung nach einer allgemeinen politischen Amnestie oder die Schaffung einer staatlichen Behörde für Dünger und Weizen. Andere Forderungen, wie z.B. die Reduzierung der militärischen Ausgaben, die Einführung der 40-Stundenwoche oder aber die Verstaatlichung der Versicherungen und der Eisenbahnen qualifizierte er als nicht realisierbar ab ${ }^{328}$. Herriot schloß seine Antwort an die SFIO mit der Feststellung, daß es in seinen Augen zunächst drei Probleme zu lösen galt: 1) Die Wiederherstellung des budgetären Gleichgewichts; 2) die Verhandlungen in Lausanne und Genf, d.h. die Reparations- und Abrüstungsfrage; 3) die Sicherung des Friedens. Herriot appellierte an alle demokratischen und republikanischen politischen Kräfte, sich mit den Radikalsozialisten zu vereinen, um die oben genannten Probleme gemeinsam zu lösen. In diesem Rahmen sei auch der Parti radical bereit, mit den Sozialisten zusammenzuarbeiten: „C'est pour cette oeuvre que nous sommes prêts à travailler au Gouvernement avec le Parti socialiste.“329

Trotz dieser versöhnlichen Abschlußformel konnte er die SFIO nicht darüber hinwegtäuschen, daß er nicht, wie 1924, an einer Zusammenarbeit interessiert war. Diese Absage wurde auf dem Parteitag der Sozialisten von Léon Blum, Renaudel und Zyromski kommentiert. Blum hielt fest, bei welchen Themen Konsens bzw. Dissens zwischen beiden Parteien herrsche ${ }^{330}$. Daran schloß er die Klage an, daß die Mitglieder der SFIO am meisten darüber enttäuscht seien, daß Herriot sich

327 Zum Text des Antwortschreibens Herriots an die sozialistische Partei siehe L'Oeuvre vom 4. 6. 1932, S. 4; Le Populaire vom 4. 6. 1932, S. 3.

${ }_{328},(.$.$) je me place sur le terrrain des réalités et des faits. Je cherche ce qui est possible et ce qui ne$ l'est pas. Je pense et je dis que le prochain gouvernement va se trouver saisi à la gorge par des difficultés qui ne lui permettront pas de se contenter de solutions dont le moins que l'on puisse dire, c'est qu'elles sont à longues échéances." Ebenda.

329 Ebenda.

330 Le Populaire vom 2. 6. 1932, S. 2. Konsens sah Blum bei Themen wie der Friedenssicherung, der obligatorischen internationalen Schiedsgerichtsbarkeit und der Bankenkontrolle. Dissens lösten Problemfelder wie die Reduzierung der Militärausgaben aus, die privaten Waffenproduktionsstätten und die Methoden zur Bewältigung der Wirtschaftskrise. 
mit keinem Wort zu den zentralen Themen des sozialistischen Parteitages geäußert, ja nicht einmal erwähnt habe, daß sich die SFIO durch ihr erfolgreiches Abschneiden bei der Wahl und der damit ausgedrückten Wählerentscheidung verpflichtet sah, diesem Ergebnis Rechnung zu tragen, und sich zur Übernahme der Regierungsverantwortung bereit zu erklären. Renaudel verfaßte eine Schlußresolution ${ }^{331}$, in der er nüchtern feststellte, daß die Gespräche mit den Radikalsozialisten durch deren Antwort beendet seien. Der Antrag wurde einstimmig vom Parteitag angenommen und Zyromski kommentierte diesen Akt mit den Worten: „La preuve expérimentale est faite !" 332

Der sozialistische Parteitag endete mit einem Appell an das Land, der von einer paritätisch besetzten Kommission verfaßt wurde ${ }^{333}$. Darin feierte die SFIO nochmals ihren Wahlerfolg von 1932. Der hatte für die SFIO nicht nur dadurch besondere Bedeutung, daß er für die Sozialisten das bisher beste Wahlergebnis in der Zwischenkriegszeit darstellte, sondern auch durch die Bedingungen, unter denen er erzielt werden konnte. Denn 1932 hatte sich die SFIO gegen zwei Seiten zur Wehr setzen müssen. Zum einen war sie der antisozialistischen Propaganda der rechten politischen Kräfte unter der Führung Tardieus ausgesetzt gewesen und zum anderen auf der linken Seite von den Kommunisten schwer attackiert worden. Die sozialistische Partei selbst sah sich in einer Vorkämpferrolle: „Le Parti socialiste a rempli efficacement dans cette lutte difficile son rôle d'animateur du prolétariat et de la démocratie contre la misère économique et pour la sauvegarde de la paix." 334 Ferner versuchten die Sozialisten in ihrer Erklärung, den Radikalsozialisten mangelndes Interesse an einer gemeinsamen Zusammenarbeit anzulasten $^{335}$. Dieser Punkt war insofern wichtig, als damit späteren Schuldzuweisungen von seiten der Radikalsozialisten vorgebeugt werden sollte. Auch die Sozialisten hatten aus den Erfahrungen von 1924/1925 ihre Lehren gezogen. Im dritten Abschnitt skizzierte die SFIO, wie sie sich unter den jetzigen Bedingungen in der neuen Legislaturperiode verhalten wolle, und erklärte, daß dabei für sie einzig und allein das sozialistische Programm, das der Parteitag verabschiedet hatte, Verbindlichkeit besitzen würde.

\section{Das Ringen innerbalb des Parti radical um den Regierungspartner}

Die Radikalsozialisten verschoben ihre ursprünglich für den 18. Mai 1932 vorgesehene Sitzung des Comité exécutif, auf der über Regierungskoalitionen gesprochen werden sollte, auf den 31. Mai 1932, um zunächst die Entscheidung des Parteitages der SFIO abzuwarten ${ }^{336}$. Innerhalb des Parti radical war es über die Frage

331 Zum Wortlaut der von Renaudel eingereichten und einstimmig vom Parteitag verabschiedeten Schlußresolution siehe Le Populaire vom 2. 6. 1932, S. 2.

332 Ebenda.

333 Der Kommission gehörten Vertreter des rechten und linken Parteiflügels an: Auriol, Déat, Faure und Zyromski.

334 Zum Wortlaut des sozialistischen Appells siehe Le Populaire vom 2. 6. 1932, S. 1.

335, „(...) la réponse du Parti radical rendait impossible l'accord sur les nécessités immédiates d'une action gouvernementale commune susceptible d'apporter à ces problèmes urgents les solutions espérés par les travailleurs et démocrates de ce pays."; ebenda.

${ }_{336}$ Vgl. dazu L'Oeuvre vom 12. 5. 1932, S. 1. In dem Artikel „Ne jouons pas à cache-cache“ wird diese 
der Regierungsbildung und die dabei anzuwendende Taktik zu einer Diskussion gekommen. Obwohl der Großteil des Parti radical geschlossen hinter Herriot und seinem Handeln nach dem Wahlsieg von 1932 stand, erhob sich von seiten des mittlerweile relativ klein gewordenen linken Flügels, der seinen Sprecher in Gaston Bergery gefunden hatte, Kritik an der Taktik Herriots, der die Initiative für eine Regierungsbeteiligung den Sozialisten überließ. Bergery wandte sich gegen diese Vorgehensweise, da sie offensichtlich eine Entscheidung gegen eine Zusammenarbeit mit den Sozialisten impliziere. Er unterstellte der Mehrheit des Parti radical, die er als Anhänger der concentration bezeichnete, daß sie die Forderung der Sozialisten abwarten wollte, weil sie hoffte, daß diese so ausfallen würde, daß sie für den Parti radical nicht akzeptabel sei. Bergery hingegen versuchte eine andere Vorgehensart nahezulegen, denn er vertrat die These, daß die Allianzen, die im zweiten Wahlgang praktiziert worden waren, auch auf der parlamentarischen bzw. der Regierungsebene fortgesetzt werden sollten ${ }^{337}$. Er sprach sich für ein Regierungsbündnis mit den Sozialisten aus. Deshalb schlug er vor, der SFIO ein Programm zu unterbreiten und sie auf solcher Grundlage zur Zusammenarbeit aufzufordern. Bergery verfaßte ein Programm, das er vom linken Parteiflügel unterzeichnen ließ. Es enthielt nur Punkte, die dem Programm des Parti radical entsprachen, wie 1) gleichzeitige und kontrollierte Abrüstung; 2) obligatorische internationale Schiedsgerichtsbarkeit; 3) Liquidierung der interalliierten Schulden; 4) internationale Organisation der Produktion und des Verkaufs von Gütern, die einer gemeinsamen Wirtschaft angehören; 5) Verbot der Herstellung und des privaten Handels mit Waffen; 6) Wiederherstellung des budgetären Gleichgewichts durch Einsparungen bei den Militärausgaben und eine Neuorganisation des Transportwesens; 7) ein Arbeitsbeschaffungsprogramm gegen Arbeitslosigkeit; 8) eine industrielle Organisation der öffentlichen Dienstleistungsunternehmen und der Monopole unter der Kontrolle und zum Vorteil der Nation, Schutz der Sparguthaben; 9) Unterbindung der Steuerhinterziehung 338 . Vergleicht man die Punkte mit denen, die die Sozialisten als Basisprogramm den Radikalen am 31. Mai 1932 überbringen ließen, sind große Übereinstimmungen zu erkennen. Bergery forderte Herriot deshalb auf, sein ausgearbeitetes Mindestprogramm den Sozialisten mit einem Angebot zur Regierungsbeteiligung zukommen zu lassen. Herriot wies dies vehement zurück und forderte absolute Handlungsfreiheit ein. Deshalb bestand er darauf, das Ergebnis des sozialistischen Parteitages abzuwarten. Wie sehr sich das Gewicht innerhalb des Parti radical auf den rechten Flügel verlagert hatte, wurde auch durch die Reaktionen in L'Oeuvre und L'Ere nouvelle deutlich, die noch in den zwanziger Jahren eindeutig auf dem linken Flügel der Partei zu verorten waren, die aber 1932 beide Herriot darin unterstützten, sich alle Möglichkeiten in der Wahl des Regierungspartners offen zu lassen. Sie kritisierten deshalb den Vorstoß Bergerys heftig, weil er eine Einengung der Entscheidungsfreiheit des Parti radical darstellte ${ }^{339}$.

Terminverschicbung gerechtfertigt, da Blum diese Terminänderung in einem Artikel kritisiert hatte.

337 Bergery im Comité exécutif am 31. 5. 1932; vgl. Le Populaire vom 1. 6. 1932, S. 1/2.

338 L'Oeuvre vom 1. 6. 1932, S. 1, 4. Außerdem auch S. Berstein, Parti radical, vol. 2, S. 212.

339 L'Oeuvre vom 1. 6. 1932, S. 4; L'Ere nouvelle vom 1. 6. 1932, S. 2. 
Untersucht man im Vorfeld des sozialistischen Parteitages die verschiedenen Presseorgane des Parti radical, wie z. B. L'Oeuvre, L'Ere Nouvelle oder La Dépêche de Toulouse, fällt auf, daß abgesehen von Bergery, der nur durch den radikalsozialistischen Abgeordneten François-Albert Unterstützung fand ${ }^{340}$, einheitlich die Meinung vorherrschte, die Sozialisten seien nicht ernsthaft an einer Regierungsbeteiligung interessiert ${ }^{341}$. Aus den verschiedenen Artikeln geht klar hervor, $\mathrm{da} ß$ im Parti radical eindeutig eine Präferenz für eine Regierung der concentration unter radikalsozialistischer Führung herrschte. Argumente, die in den Wochen zwischen dem zweiten Wahlgang (8. Mai 1932) und dem 31. Mai 1932 in radikalsozialistischen Presseorganen angeführt wurden, konzentrierten sich auf drei Aspekte: In erster Linie wurde stets betont, daß der Parti radical als der große Wahlsieger zu betrachten sei; dabei wurde vor allem unterstrichen, daß diesem Ergebnis besondere Bedeutung zukomme, da die Partei ohne Bündnispartner im Wahlkampf angetreten sei. Daraus schloss man, daß mit diesem allein errungenen Wahlsieg dem Parti radical auch die Freiheit in der Wahl des Regierungspartners zustehe. Überwiegend begegnete der Parti radical den Sozialisten als Bündnispartner sehr misstrauisch, stets wurde auf Erfahrungen aus der Vergangenheit verwiesen. Trotz der Äußerungen von sozialistischer Seite, dieses Mal Regierungsverantwortung übernehmen zu wollen, schien dies beim Parti radical mit großer Skepsis aufgenommen worden zu sein, wie aus den Einschätzungen der Reden Blums hervorgeht: „Faut-il en conclure que M. Léon Blum est, positivement, partisan de la collaboration des gauches ou, comme on dit, de la ,participation'? Il s'en défendait, le 10 avril, à Narbonne, en ces termes: ,Il y en a parmi nous qui souhaitent cette épreuve pour le parti: il y en a qui la redoutent. Je suis parmi ceux qui la redoutent.' 'Sur cette prévention à l'égard d'une éventuelle ,participation'. M. Léon Blum serait-il revenu? Son article d'hier ne nous le dit pas. N'est-ce pas, cependant, toute la question?" "342 Außerdem wurde deutlich darauf verwiesen, daß ein Regierungsbündnis mit den Sozialisten, wenn überhaupt, dann nur unter der Prämisse in Frage kommen könne, daß der Parti radical den Sozialisten ein Mindestprogramm als Grundlage für eine Regierungsallianz vorlegen würde, dem diese zustimmen müssten. Denn die Rollenverteilung in einem Bündnis mit den Sozialisten war offensichtlich, die SFIO galt bestenfalls als Juniorpartner und hatte daher von sich aus keine Bedingungen zu stellen ${ }^{343}$.

Ein weiteres Argument, das häufig in diesen Wochen angeführt worden ist, betraf das Selbstverständnis des Parti radical; die Zufriedenheit darüber, daß der Parti radical durch den Wahlsieg wieder tonangebende Regierungspartei geworden war und nicht länger in der ungeliebten Rolle einer Oppositionspartei verharren mußte ${ }^{344}$. Diese Feststellung präjudizierte in einer gewissen Weise auch eine

${ }^{3+0} \mathrm{Zu}$ François-Albert siehe J. Jolly, Dictionnaire, vol. 1, S. 350.

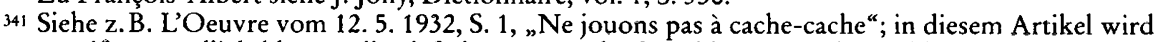
unmißverständlich klargestellt, daß der Parti radical unabhängig in die Wahl gegangen war und siegte, deshalb könne er sich nun auch unabhängig für einen Regierungspartner entscheiden. Außerdem verwies der Artikel darauf, daß die Sozialisten keine ernsthaften Regierungsambitionen hätten.

${ }^{342}$ L'Oeuvre vom 12. 5. 1932, S. 1.

${ }^{343}$ L'Oeuvre vom 15. 5. 1932, S. 1.

${ }^{344}$ L'Oeuvre vom 21. 5. 1932, S. 1. 
Präferenz für ein Regierungsbündnis in Richtung concentration und gegen eine Regierungsallianz mit den Sozialisten, da die SFIO klar als eine Partei der Opposition galt ${ }^{345}$.

Auffallend ist, daß der Parti radical sehr genau die Diskussion innerhalb der SFIO verfolgte und zur Kenntnis nahm, daß die sozialistische Partei keineswegs geschlossen die Regierungsbeteiligung bejahte, sondern diese nach wie vor sehr unterschiedlich beurteilte 346 . Auf jeden Fall wollte der Parti radical abwarten, welche Tendenz sich innerhalb der SFIO auf dem Parteitag durchsetzen konnte.

Neben der Frage des Bündnispartners mußten parteiintern auch die dringlichsten Themen der zukünftigen Regierung geklärt werden. Hier kristallisierten sich für Herriot zwei zentrale Themen heraus: zum einen die Lösung der Finanzkrise und zum anderen die Frage der Außenpolitik ${ }^{347}$. Ein interessantes Licht auf den Zusammenhang beider Problemfelder wirft ein Artikel, der am 31. Mai 1932 in L'Oeuvre erschien und der ankündigte, daß Herriot abends bekannt geben werde, welche Entscheidung er in der Frage der Regierungsbildung getroffen habe. Darin wurde darauf hingewiesen, daß das zentrale Thema an diesem Tag in den Gängen des Palais Bourbon nicht die eventuelle Regierungsbeteiligung der Sozialisten, sondern vielmehr der Rücktritt des deutschen Reichskanzlers Brüning war, durch den sich die außenpolitische Konstellation schlagartig ändern konnte. Außerdem appellierte die rechte Mitte unter der Führung Flandins an das Parlament, die zukünftige Regierung Herriot zu unterstützen ${ }^{348}$, damit sie die nächsten außenpolitischen Aufgaben in Lausanne und Genf für Frankreich erfolgreich verhandeln könne.

Für den 31. Mai 1932 wurde eine Zusammenkunft des Comité exécutif angesetzt, in der Herriot seine Entscheidung zur Regierungsbildung bekannt gab. Während dieser Sitzung meldete sich auch der linke Parteiflügel unter Bergery nochmals zu Wort. Bergerys Handeln folgte einer Doppelstrategie. Zunächst stellte er fest, daß die linken Kräfte im Parlament zum ersten Mal in der Zwischenkriegszeit über eine starke Mehrheit verfügen, die es ihnen erlauben würde, allein auf dieser Basis zu regieren, ohne auf zusätzliche Kräfte aus der Mitte angewiesen zu sein. Er erklärte den Wahlsieg der linken Kräfte in erster Linie als Ergebnis ihrer vierjährigen Oppositionspolitik gegen eine rechte Regierung und in zweiter Linie als ein Zeichen der Disziplin der linken Kräfte im zweiten Wahlgang. Er setzte sich deshalb dafür ein, daß dieses Zusammenwirken der politischen Linken auch im Parlament und in der Regierung fortgesetzt werde. Eine Unterstützungspolitik der Sozialisten auf parlamentarischer Ebene hielt er für nicht ausreichend, vielmehr forderte er eine Regierungskoalition mit der SFIO. Allerdings räumte Bergery ein, daß sich beide Seiten, d.h. sowohl der Parti radical als auch die SFIO,

345 Ebenda: „(...) il s'agit maintenant de constituer, non pas une majorité d'opposition - ce qui serait un singulier paradoxe - mais une majorité de gouvernement.“

346 L'Oeuvre vom 28. 5. 1932, S. 1; und auch vom 31. 5. 1932, S. 1/2.

$3+7$ L'Oeuvre vom 21. 5. 1932, S. 1.

${ }^{348}$ L'Oeuvre vom 31. 5. 1932, S. 1: Flandin führte wörtlich aus „Je souhaite de tout coeur, que les républicaines de gauche votent dès la déclaration ministérielle pour le cabinet Herriot. Car il faut lui permettre de représenter la France avec autorité dans les négociations extérieures difficiles qu'il doit mener non pas au nom d'un parti, mais au nom du pays.“ 
dafür nicht sonderlich in den vergangenen Wochen eingesetzt hätten. Auch er lehnte Forderungen von seiten der SFIO ab, regte aber an, Verhandlungen mit den Sozialisten zu führen. Bergery plädierte auch aus taktischen Gründen für dieses Vorgehen, denn für den Fall, daß die Zusammenarbeit mit den Sozialisten scheitern sollte, könnte das nicht den Radikalsozialisten angelastet werden. Außerdem betonte er auch, warum er diese Bemühungen für so wichtig hielt: weil die Partei, die die Verantwortung für das Scheitern eines Linksbündnisses trage, bei den nächsten Wahlen mit starken Einbußen rechnen müsse $\mathrm{e}^{349}$.

Herriot widersprach den Einwänden Bergerys entschieden, indem er eindringlich darauf verwies, daß die Situation von 1932 nicht mit der von 1924 zu vergleichen sei. 1924 habe ein gemeinsamer Wahlkampf des Cartel des gauches stattgefunden, daher schien es nach dem gemeinsamen Wahlsieg nur folgerichtig, auch gemeinsam die Regierungsverantwortung zu übernehmen. Aus diesem Grund leitete sich auch 1924 die Aufforderung des Parti radical gegenüber der SFIO für eine Regierungsbeteiligung ab. 1932 stellte sich diesbezüglich eine ganz andere Situation dar. Herriot betonte, die Linksparteien hätten einen getrennten Wahlkampf geführt, daher ergebe sich für ihn keine zwingende Zusammenarbeit. Er räumte aber ein, daß er eine Unterstützungspolitik der SFIO begrüßen würde 350 .

Trotz all der freundlichen Rhetorik blieb nicht verborgen, daß Herriot nicht gewillt war, mit den Sozialisten zu regieren. Das wirft die Frage nach den Gründen Herriots auf. Sicherlich spielten verschiedene Faktoren, wie die Erfahrungen von 1924/25 und die Auseinandersetzungen in Lyon von 1931, eine Rolle. Eine weitere Erklärungsmöglichkeit findet sich in den Memoiren von Herriot, in denen er selbst zugibt, daß er sich gegen den offensichtlichen Wunsch der Sozialisten, ihnen ein Regierungsangebot zu machen, stellte. Er lehnte dies ab, weil damit für den Parti radical die Gefahr verbunden war, die Entscheidung der Sozialisten mitverantworten zu müssen ${ }^{351}$. Herriot konnte sich mit diesem Argument in seiner Partei bzw. im Comité exécutif durchsetzen ${ }^{352}$ und so wurde beschlossen, eine definitive Entscheidung in der Frage der Regierungsbildung erst am 31. Mai 1932 zu treffen ${ }^{353}$. In den Memoiren Herriots wird außerdem deutlich, daß er in den Tagen zwischen dem 20. und dem 31. Mai 1932 sehr eng mit seinem früheren Gegner Caillaux zusammenarbeitete, der ihn auch bei der Abfassung seines Antwortschreibens an die Sozialisten beriet. Herriot zeigt ferner in den Ausführungen seiner Memoiren, daß ihn in den damaligen Tagen die Frage des Koalitionspartners weniger intensiv beschäftigte als die Themen seiner künftigen Regierung.

Herriot richtete seine Aufmerksamkeit erstens auf die innenpolitischen Probleme in Deutschland und damit verbunden auf die endgültige Klärung der Reparationsfrage, die auf der Konferenz in Lausanne zu verhandeln war, und zweitens auf die Finanzkrise in Frankreich. Vor allem die Wiederherstellung eines ausgegli-

${ }^{349}$ L'Oeuvre vom 1.6. 1932, S. 1.

350 L'Oeuvre vom 1.6. 1932, S. 4; Lc Quotidien vom 1.6. 1932, S. 2.

351 E. Herriot, Jadis, S. 292.

352 Nur zwei Mitglieder stimmten nicht für Herriots Vorschlag; vgl. ebenda.

353 Ebenda. 
chenen Staatshaushaltes wurde von der neuen Regierung erwartet ${ }^{354}$. Herriot schilderte in seinen Memoiren die Vorgänge bei der Sitzung des Comité exécutif am 31. Mai 1932 und betonte besonders, daß der Parti radical geschlossen gegen eine Regierungsbeteiligung der SFIO votierte. Er erwähnte zwar dabei auch kurz den Versuch Bergerys, sich für eine Zusammenarbeit mit den Sozialisten einzusetzen, dem er jeodoch keine Bedeutung beimaß, da er innerhalb des Parti radical nur auf Ablehnung stieß355.

\section{Die Regierung Herriot (3. Juni bis 14. Dezember 1932) und ihr Versuch einer Politik der Mitte}

Herriot konzentrierte sich zwischen dem 2. und 4. Juni 1932 auf die Bildung seiner Regierung. Von 18 Ministern gehörten $13 \mathrm{dem}$ Parti radical an, die übrigen fünf Minister, Painlevé und de Monzie (beide Républicains-socialistes), Paul-Boncour (Socialiste-indépendant), Germain-Martin (Gauche radicale) und Georges Leygues (Républicain de gauche), kamen aus anderen Parteien der linken Mitte. Von elf Unterstaatssekretären stellte die radikalsozialistische Partei 356 acht; die übrigen drei wurden von der Gauche radicale und den Indépendants de gauche gestellt. In seinen Memoiren bemerkte Herriot über seine Erfahrung bei der Regierungsbildung: "J'observe, à cette occasion, que les hommes se montrent d'autant plus exigeants qu'ils sont plus médiocres. Un homme de valeur dit: ,Prenezmoi ou ne me prenez pas; je suis à votre service. En tout cas, placez-moi où vous voudrez'." 357

Herriot selbst übernahm wie bereits 1924 neben dem Amt des Ministerpräsidenten auch das des Außenministers und widmete sich in diesen Tagen verstärkt den Vorbereitungen für die Konferenzen von Lausanne und Genf 358 .

Herriot setzte seinen eingeschlagenen Kurs, den Parti radical mehr in die Mitte zu führen, auch bei der Regierungsbildung fort. Innerhalb des Parti radical berücksichtigte er bei der Wahl seiner Kabinettsmitglieder Persönlichkeiten des rechten Flügels, der linke Parteiflügel erhielt keinen Ministerposten. Diese Vorgehensweise Herriots zog bereits in den Wochen nach seinem Regierungsantritt innerparteilich folgenschwere Konsequenzen nach sich, denn der linke Flügel unter Bergery entwickelte sich immer mehr zur innerparteilichen Opposition im Parti radical.

${ }^{354}$ E. Herriot, Jadis, S. 293/294; S. 290-292 und besonders in seiner Antwort auf das sozialistische Angebot vom 31. 5. 1932, ebenfalls in seinen Memoiren: Derselbe, Jadis, S. 301/302.

355 E. Herriot, Jadis, S. 302: „Le soir de ce même 31 mai, le Comité exécutif entendit d'abord un discours de M. Bergery. Mais le député de Seine-et-Oise se heurta, dès le début, à une vive hostilité de l'assemblée, ce qui l'amena à modérer beaucoup ses conclusions et donna à sa démonstration un caractère assez obscur."

356 Zur Regierungszusammensetzung siehe Le Quotidien vom 4.6. 1932, S. 1 und Le Temps vom 5. 6. 1932, S. 3.

357 Herriot, Jadis, S. 306.

358 In seinen Memoiren berichtet Herriot, daß die englische Führung den englischen Staatssekretär beauftragt habe, durch den französischen Botschafter in London vor der Konferenz von Lausanne ein Treffen zwischen Herriot und MacDonald zu arrangieren; vgl. E. Herriot, Jadis, S. 306. 
Herriot stellte in den Mittelpunkt seiner Regierungserklärung 359 - wie nicht anders zu erwarten war - zwei zentrale Themen: die Überwindung der Finanz- und Wirtschaftskrise sowie die Lösung der Reparationsfrage und Friedenssicherung im internationalen Rahmen. Der Ministerpräsident wollte die Finanzkrise mit Hilfe einer Deflationspolitik in den Griff bekommen. In der Reparationsfrage verteidigte er ganz entschieden die Ansprüche Frankreichs: „En ce qui concerne les réparations, la France ne peut laisser contester des droits qui résultent, non seulement de traités mais d'accords contractuels protégés par l'honneur des signatures (...). “ 360 Diese beiden Hauptaspekte der Regierungserklärung Herriots zeigten deutlich, daß Herriot einen Mittelkurs anstrebte und dementsprechend auch sein Kabinett formiert hatte.

Neben diesen vorrangigen Aufgaben ließ Herriot auch traditionelle Themen des radikalsozialistischen Kanons nicht außer acht, wie z.B. die republikanische Erziehung, die den Anspruch einschloss, allen gleichermaßen den Zugang zur Bildung zu ermöglichen, sowie die Betonung und das Festhalten am Laizismus. Jedoch schien Herriot in diesem Punkt Lehren aus seiner Regierung von 1924/25 gezogen zu haben, da er dieses Thema wesentlich vorsichtiger behandelte ${ }^{361}$. Die Regierungserklärung Herriots war geprägt von einer Verbindung aus linksrepublikanischer Rhetorik und rechtsrepublikanischer Außen- und Finanzpolitik. Mit solcher Bandbreite versuchte sich Herriot, eine Mehrheit zu verschaffen, in die er die politischen Kräfte von der linken bis zur rechten Mitte einzubeziehen hoffte.

Nach der Regierungserklärung fanden sich die verschiedenen Gruppen der politischen Kräfte im Parlament zu Beratungen über die Diskussion um die Regierungserklärung und über ihr Abstimmungsverhalten zusammen. Interessanterweise schien die von Herriot beschworene Einheit innerhalb der Fraktion nicht vorhanden zu sein, denn es kam in der parlamentarischen Gruppe des Parti radical zu einer heftigen Diskussion über die Regierungsbildung und -erklärung Herriots. Es kristallisierten sich drei verschiedene Positionen heraus. Ein Teil der Abgeordneten, für die Nogaro sprach, wollte einen Tagesordnungspunkt verabschieden, der kritisierte, daß bei der Bildung der Regierung der Wählerwille nicht vollständig Berücksichtigung gefunden habe. Damit wurde auch auf die unterlassenen Verhandlungen mit den Sozialisten angespielt ${ }^{362}$. Den Einwand Nogaros wies ein größerer Teil unter Archimbaud unter heftigem Protest zurück, da er als ein indirekter Angriff auf Herriot und auf die Kollegen, die sich bereit erklärt hatten, in die Regierung einzutreten, gewertet werden mußte ${ }^{363}$. Zu diesen beiden extremen Positionen trat noch ein dritter Antrag hinzu, den André Hesse vortrug und der vermittelnd wirken sollte. Hesse sprach der Regierung das Vertrauen aus und un-

${ }^{359}$ Zum Wortlaut der Regierungserklärung Herriots vom 7.6. 1932 siehe Le Temps vom 8. 6. 1932, S. 8.

360 Ebenda.

361 Ebenda: „Fidèles à une doctrine de laïcité qui ne s'inspire d'aucune intention agressive mais garantit la liberté personnelle et la fraternité nationale."

362 Bericht über die Sitzung der parlamentarischen Gruppe des Parti radical in Le Temps vom 3.6. 1932, S. 6.

363 Ebenda. 
terstützte die Regierungserklärung ${ }^{364}$. Die beiden anderen Abgeordneten zogen ihre Anträge zurück. Letztlich einigte sich die parlamentarische Gruppe des Parti radical auf den Antrag von Hesse.

Eine rege Diskussion entspann sich auch in der sozialistischen Gruppe, wo man sich schließlich auch auf eine Mittelposition einigte. Die sozialistischen Abgeordneten verabschiedeten eine Resolution, in der sie der Regierung ihre Unterstützung zusagten, weil sie damit dem Wählerwillen, der sich bei den Wahlen für eine republikanische Mehrheit ausgesprochen hatte, Rechnung tragen wollten ${ }^{365}$. Gleichzeitig bestimmte die sozialistische Gruppe Léon Blum zu ihrem Sprecher für die Debatte über die Regierungserklärung. Darüber hinaus ernannte sie eine Delegation, bestehend aus Blum, Auriol, Lebas, Déat und Marquet, die mit der parlamentarischen Gruppe des Parti radical über eine gemeinsame Resolution beider Gruppen verhandeln sollte. Immerhin zeigte das Verhalten der SFIO, daß sie trotz der Absage des Parti radical gewillt war, die Regierung Herriot politisch zu unterstützen. Ganz auf dieser Linie gestaltete sich auch der Redebeitrag Blums in der Aussprache über die Regierungserklärung. Blum betonte zunächst den Konsens zwischen den Sozialisten und dem Parti radical in der Ablehnung der „alten Mehrheit“ unter Tardieu im Parlament. In einem zweiten Schritt unterstrich er seine Hoffnung, daß die Regierung Herriot ihren Wahlsieg politisch umzusetzen verstehen werde. Abschließend räumte er ein, daß es durchaus Divergenzen in verschiedenen Politikfeldern zwischen dem Kabinett Herriot und der SFIO gebe 366 .

Die Regierung Herriot wurde bei der Abstimmung im Parlament mit $384 \mathrm{zu}$ 115 Stimmen im Amt bestätigt. Das Abstimmungsergebnis zeigt, daß die linksrepublikanischen Kräfte weitgehend einheitlich für die Regierung gestimmt hatten; die politische Mitte enthielt sich und die rechten Kräfte lehnten die Regierung $a b^{367}$. Herriots Absicht, für seine Regierung einen breiten Rückhalt in der Mitte und in der rechten Mitte anzustreben, war gescheitert. Hingegen unterstützten ihn die linken Parlamentsgruppen, obwohl er bei der Regierungsbildung keinen ihrer Repräsentanten berücksichtigt hatte. Dieses Dilemma Herriots, eine Politik der Mitte praktizieren zu wollen, dabei aber auf die Unterstützung der linken Kräfte angewiesen zu sein, trat nicht nur gleich zu Beginn seiner Regierung auf, sondern sollte letztlich seine gesamte Regierungszeit prägen.

Das Abstimmungsergebnis ${ }^{368}$ für die Regierung Herriot setzte sich folgendermaßen zusammen:

\footnotetext{
364 Ebenda.

365 Zum Wortlaut der sozialistischen Resolution siehe Le Temps vom 3. 6. 1932, S. 6.

366 Zur Regierungsdebatte und dem Beitrag Blums siche Le Temps vom 9.6. 1932, S. 3.

${ }_{367}$ Tardieu, der in der Regierungsdebatte Herriot angriff, indem er einerseits cine Abhängigkeit der Regierung von den Sozialisten unterstellte und andererseits Herriot mit der Frage zu diskreditieren versuchte, ob er sich nun für die Abrüstungsvorstellungen der SFIO einsetzen oder weiterhin am Primat der Sicherheitspolitik festhalten werde, stimmte gegen die Regierung Herriot; vgl. Le Temps vom 9. 6. 1932, S. 3/4.

368 Le Temps vom 9.6. 1932, S. 4.
} 


\begin{tabular}{rlrccc}
\hline $\begin{array}{l}\text { An- } \\
\text { zahl }\end{array}$ & Gruppe & Dafür & $\begin{array}{l}\text { Da- } \\
\text { gegen }\end{array}$ & $\begin{array}{l}\text { Enthal- } \\
\text { tung }\end{array}$ & $\begin{array}{l}\text { Abwe- } \\
\text { send }\end{array}$ \\
\hline 43 & Féderation républicaine & - & 38 & 5 & - \\
18 & Groupe républicain et sociale & - & 18 & - & - \\
16 & Démocrates populaires & - & 1 & 15 & - \\
61 & Républicains de gauche & - & 26 & 35 & - \\
20 & Indépendants de gauche & 8 & - & 11 & 1 \\
44 & Gauche radicale & 31 & - & 11 & 2 \\
15 & Républicains indépendants de gauche & 15 & - & - & - \\
160 & Radicaux-socialistes & 158 & - & 1 & 1 \\
11 & Républicains-socialistes & 11 & - & - & - \\
12 & Socialistes français & 12 & - & - & - \\
132 & SFIO & 131 & - & 1 & - \\
9 & Groupe de l'unité ouvrière & - & 1 & 8 & - \\
10 & Communistes & - & 10 & - & - \\
63 & Aucun groupe & 18 & 21 & 23 & 1 \\
\hline & & 384 & 115 & 110 & 5 \\
\hline
\end{tabular}

\section{Die Außenpolitik der Regierung Herriot}

Wie bereits bei seinem Regierungsantritt im Juni 1924, führte Herriot auch 1932 die erste Amtshandlung seiner Regierung zu einer internationalen Konferenz über die Reparationsfrage. Auf dem Programm standen die Konferenzen von Lausanne ${ }^{369}$, auf der die Reparationsfrage und die interalliierten Schulden verhandelt werden sollten, sowie die Konferenz von Genf ${ }^{370}$, die sich mit der Abrüstungsund Sicherheitsthematik beschäftigte. Die Konferenz von Lausanne begann am 16. Juni $1932^{371}$, aber bereits im Vorfeld dieser Konferenz hatte der englische Premierminister MacDonald mit Herriot Gespräche aufgenommen, um das Terrain für Lausanne vorzubereiten. Die Ausgangssituation von 1932 erinnerte Herriot sicherlich sehr stark an die von 1924, denn das Verhältnis zu England war durch das rigorose Verhalten der rechten französischen Kabinette in der Reparationsfrage wieder einmal abgekühlt. Deshalb galt auch dieses Mal Herriots Aufmerksamkeit ganz dem Bemühen um eine Annäherung an den englischen Allianzpart-

${ }^{369}$ Zur Konferenz von Lausanne siehe R. Smiley, The Lausanne Conference. The Diplomacy of the End of Reparations, New Brunswick 1972.

370 S. E. Balzarini, Britain, France, and the "German problem" at the world disarmament conference: 1932-1934, Washington (D.C.) 1979; G. Besier, Krieg, Frieden, Abrüstung. Die Haltung der europäischen und amerikanischen Kirchen zur Frage der deutschen Kriegsschuld 1914-1933. Ein kirchenhistorischer Beitrag zur Friedensforschung und Friedenserziehung, Göttingen 1982; G. Bonnet, Le Quai d'Orsay sous trois Républiques. 1870-1961, Paris 1961; C. Loosli, Die Abrüstungskonferenz in Genf. 1. Tagung, Febr.-Juli 1932, Zürich 1932; C. Loosli-Usteri, Geschichte der Konferenz für die Herabsetzung und die Begrenzung der Rüstungen. 1932-1934. Ein politischer Weltspiegel, Zürich 1940; S. Nadolny, Abrüstungsdiplomatie 1932/33: Deutschland auf der Genfer Konferenz im Übergang von Weimar zu Hitler, München 1978; J. Neré, The foreign policy of France from 1914-1945, London 1975; Ph. J. Noel-Baker, The first world disarmament conference 1932-1933 and why it failed, Oxford 1979; A. Schumacher, La politique de sécurite française à face de l'Allemagne. Les controverses de l'opinion française entre 1932 et 1935, Frankfurt a.M. 1978; J. W. Wheeler-Bennett, Disarmament and security since Locarno (1925-1931), London 1973.

${ }^{373}$ Zur Konferenz von Lausanne siehe außerdem Ph. Heyde, Reparationen, S. 402-456. 
ner. MacDonald und Simon ${ }^{372}$ kamen am 11. Juni 1932 zu Sondierungsgesprächen nach Paris. Beide Seiten versuchten, jeweils den Verhandlungspartner von den eigenen Vorstellungen zu überzeugen oder zumindest zu beeinflussen, was ein ziemlich schwieriges Unterfangen war, weil beide Verhandlungspartner in der Reparationsproblematik sehr unterschiedliche Positionen vertraten. Herriot hielt an den Reparationszahlungen fest und lehnte ihre Annullierung entschieden ab, wie er bereits in seiner Regierungserklärung angekündigt hatte. Darüber hinaus unterstrich er die Forderung, weltwirtschaftliche Fragen in die Agenda der Verhandlungen in Lausanne aufzunehmen. Damit intendierte Frankreich nicht nur, die Vereinigten Staaten in die Verhandlungen einzubeziehen, sondern es hoffte, damit auch Deutschland zur Weiterführung der Zahlungen bewegen zu können. Die Franzosen wünschten vor allem Sicherheiten für die Einhaltung der deutschen Reparationszahlungen. Herriot sprach sich deshalb für eine Suspensivklausel aus. Für den Fall, daß Amerika die Kriegsschulden nicht senken würde, sollte das Abkommen von Lausanne nicht mehr gelten, sondern der Youngplan wieder greifen ${ }^{373}$. England hingegen dachte nur an einen Vorbehalt bei der Ratifizierung des Lausanner Abkommens. Das Kabinett Herriot entschied am 10. Juni 1932 kurz und knapp: keine Annullierung der Reparationen ${ }^{374}$. Dennoch war der neuen Regierung klar, daß sie sich zu Konzessionen bereit erklären mußte, deshalb faßte sie verschiedene Zugeständnisse ins Auge. Sie griff dabei auf die Empfehlungen der Expertenkommission ${ }^{375}$ für Reparationsfragen zurück, die die alte Regierung unter Tardieu noch entschieden abgelehnt hatte. Folgende Punkte wurden in das Programm möglicher Konzessionen aufgenommen: Die Regierung Herriot räumte Deutschland ein „moratoire du travail“ ein; dazu sollte bis zum Herbst 1932 eine definitive Regelung der Reparationsfrage ausgearbeitet werden. Deutschland sollte zur Vermeidung von Transferproblemen keine Annuitäten mehr leisten, sondern kommerzialisierbare Obligationen abführen, die auch zur Unterstützung der Donaustaaten herangezogen werden sollten. Herriot wollte sich in Lausanne auch mit Währungsproblemen auseinandersetzen. Der Goldstandard sollte beim Pfund und bei den anderen floatenden Währungen wieder eingeführt werden, außerdem beabsichtigte man in den mitteleuropäischen Staaten, die Bewirtschaftung der Devisen einzustellen. Kritisch begegnete Herriot den Abrüstungsgesprächen, die er in Lausanne zu umgehen suchte; eine militärische Gleichberechtigung Deutschlands lehnte er entschieden $\mathrm{ab}^{376}$.

Der englische Allianzpartner trug in Paris Vorstellungen vor, die wesentlich gemäßigter waren. England sprach sich dafür aus, daß ein endgültiger Verzicht auf Reparationszahlungen erst zur Ratifizierung gelangen solle, wenn auch die interalliierten Schulden annulliert würden. Bis zu diesem Zeitpunkt müßte Deutschland ein Moratorium erhalten. Im Gegenzug dazu sollte es sich bereit erklären, in

372 John Simon (1873-1954) war von 1931-1935 englischer Außenminister. Einen Schwerpunkt seiner Amtszeit bildeten seine Bemühungen in den Abrüstungsverhandlungen.

${ }_{373} \mathrm{Zu}$ den Verhandlungen zwischen Herriot und MacDonald in Paris siehe Ph. Heyde, Reparationen, S. 402-408; E. Herriot, Jadis, S. 315-318.

374 Le Temps vom 12.6. 1932, S. 1, 3.

${ }^{375}$ Zum Expertenplan, den Tardieu noch vehement abgelehnt hatte, siehe $\mathrm{Ph}$. Heyde, Reparationen, S. 395-397.

376 Vgl. E. Herriot, Jadis, S. 313/314. 
den nächsten 15 Jahren auf jegliche Revision der Grenzen zu verzichten. Herriot erhob dagegen sofort Einspruch, denn Deutschland würde dadurch gegenüber Frankreich eine vorteilhaftere Position erhalten. Mit der Streichung der Reparationen erringe Deutschland gegenüber Frankreich zwei Konkurrenzvorteile: Zum einen würde die Reichsbahn dadurch ihre Tarife um 30 Prozent herabsetzen können und zum anderen ermögliche diese Regelung auch eine Preisminderung beim Kohleexport. Obwohl Herriot neben diesen Einwänden auch innenpolitische Hinderungsgründe anführte, stimmte er kurze Zeit später doch den beiden englischen Forderungen $\mathrm{zu}^{377}$. Herriot hatte weitreichende Zugeständnisse gemacht, denn ohne zu wissen, wie sich die interalliierte Schuldenfrage entwickeln würde, stimmte er zu, daß Deutschland mit dem neuen Moratorium keine Reparationen mehr zahlen mußte. Die Revision des Youngplanes und die des Mellon-Bérenger Abkommens wurden nun nicht mehr voneinander abhängig gemacht, sondern die Revision beider Abkommen sollte nacheinander erfolgen. Das Verhalten Herriots ist erstaunlich, denn zwischen seiner ursprünglich vertretenen Ausgangsposition, der Forderung einer Suspensivklausel, und der Zustimmung zu einem bloßen Ratifizierungsvorbehalt, lag doch ein erheblicher Unterschied. Dieser Wandel in der Haltung Herriots gab Anlaß für verschiedene Erklärungsversuche. Ein Grund dafür wurde darin gesehen, daß MacDonald die Eitelkeiten Herriots auszunutzen wußte ${ }^{378}$. Ein anderer Erklärungsversuch führte das Verhalten Herriots auf mangelnde Kompetenz in Detailfragen der Außen- und Finanzpolitik zurück. Im Vergleich zu den eben genannten Gründen scheint ein weiteres Motiv sehr viel wahrscheinlicher zu sein: Herriot glaubte, wie bereits 1924, mit einer den Engländern entgegenkommenden Reparationspolitik in der Sicherheitspolitik für Frankreich mehr erreichen zu können, als mit einer harten Konfrontationspolitik, die seine Vorgänger Tardieu und Laval betrieben und die damit Frankreich erneut isoliert hatten. Die Hoffnung Herriots, mit seinem Entgegenkommen in der Reparationsfrage die Unterstützung Englands für die französischen Sicherheitsinteressen gewinnen zu können ${ }^{379}$, schien berechtigt zu sein, denn bei einem Treffen in Genf mit MacDonald und Simon, das zur Vorbereitung der Abrüstungskonferenz diente, kamen England und Frankreich darin überein, daß sich die Siegermächte unter Ausschluß Deutschlands beraten sollten. Damit hatte Herriot erreicht, daß Frankreich nicht länger isoliert blieb, wie das noch unter Tardieu in Bessinge der Fall war ${ }^{380}$. Obwohl in Vorgesprächen zwischen Frankreich und England eine politische Linie vereinbart werden konnte, wurden die Verhandlungen der Lausan-

377 Ph. Heyde, Reparationen, S. 404-408; E. Herriot, Jadis, S. 317/318.

378 Philipp Heyde verweist in seiner Studie über das Ende der Reparationen auf Untersuchungen, die für die These der Eitelkeit Herriots sprechen: J.-B. Duroselle, Décadence, S. 32/33. Für das Argument der mangelnden Kompetenz Herriots siehe J. Néré, Foreign Policy of France from 1914 to 1945, London 1976, S. 66; S. Schuker, The End of French Predominance, S. 232 f., S. 299 f. Siehe Ph. Heyde, Reparationen, S. 405, wie auch Anmerkung 7.

${ }_{379} \mathrm{Zu}$ Herriots „Entgegenkommen in der Reparationsfrage gegen Zugeständnisse in der Sicherheitspolitik“ siehe derselbe, Jadis, S. 314, S. $318 \mathrm{ff}$. Außerdem die Anhörungen Herriots vor der Commission des Finances wie auch der Commission des Affaires étrangères in A.N. C 14990, hier die Sitzungen vom 4. 7. 1932 und vom 13.7.1932.

$380 \mathrm{Zu}$ den Gesprächen in Bessinge bei Genf in der Villa des amerikanischen Außenministers Stimson siehe W. Deist, Brüning, Herriot und die Abrüstungsgespräche von Bessinge 1932, in: VfZ 5 (1957), S. 265-272; S. Nadolny, Abrüstungsdiplomatie 1932/33, S. 136-142. 
ner Konferenz von allen Beteiligten mit Skepsis betrachtet, denn verschiedene Faktoren, die für eine Einigung unerläßlich waren, bedurften noch der Klärung381. Es galt, eine Verständigung zwischen den beiden gegensätzlichen Verhandlungspositionen herbeizuführen: jene ${ }^{382}$, die eine Streichung der Reparationen anstrebten, und diejenige ${ }^{383}$, die an ihren Reparationsansprüchen festhielt. Es mußte eine definitive Lösung gefunden werden, die sowohl von Frankreich wie auch von Deutschland akzeptiert werden konnte. Hinzu kam noch, daß die USA sich bisher nicht zur Lösung der interalliierten Schuldenfrage geäußert hatten. Entsprechend schwierig und kritisch gestalteten sich die verschiedenen Verhandlungsetappen der Lausanner Konferenz ${ }^{384}$, die aber letztendlich doch am 9. Juli 1932 mit einem Abkommen beendet werden konnte.

Trotz der oben genannten Schwierigkeiten, mit denen die Verhandlungen in Lausanne, aber auch in Genf zu kämpfen hatten, schien Herriot weitgehend mit dem für Frankreich Erreichten zufrieden. Herriot äußerte sich in der Anhörung vor der Auswärtigen Kommission am 17. September $19322^{385}$ und in seiner Rede vor der Kammer am 28. Oktober 1932386 sowohl zu den Lausanner wie auch zu den Genfer Verhandlungen sehr ausführlich. Das Ergebnis der Lausanner Verhandlungen stellte in den Augen Herriots einen beachtlichen Erfolg dar, denn immerhin hatte er für Frankreich deutsche Reparationszahlungen in Höhe von drei Milliarden Reichsmark aushandeln können ${ }^{387}$; und dies obwohl sich die französische Ausgangsposition auf der Lausanner Konferenz verhältnismäßig ungünstig dargestellt hatte, denn sowohl Großbritannien wie auch Italien hatten sich zunächst für den von Deutschland gewünschten Erlaß der Reparationszahlungen ausgesprochen. Einen weiteren Erfolg sah Herriot im Abschluß des Gentlemen's Agreement, das eine Korrelation zwischen den Zahlungen Frankreichs und Deutschlands in dem Sinne herstellte, daß Frankreich erst dann seine interalliierten Schulden begleichen mußte, wenn Deutschland seinen Reparationszahlungen an Frankreich nachgekommen war.

Auch in dieser Rede stellte Herriot einen Zusammenhang zwischen Abrüstungs- und Reparationspolitik her. Er bezeichnete Frankreichs Rolle bezüglich der Abrüstungsverhandlungen von 1924 bis 1932 als die eines "Spiritus rector“. Denn 1924 habe Frankreich die drei Grundprinzipien „arbitrage, sécurité und désarmement" in die Friedens- und Sicherheitsdebatte eingeführt und damit die internationalen Abkommen über weite Strecken nachhaltig geprägt. Außerdem habe Frankreich auch einen wichtigen Beitrag zur Abrüstungsdebatte durch eine entsprechende Verteidigungspolitik, wie die sukzessive Verkürzung der Wehrdienstzeit, geleistet. In einer abschließenden Passage seiner Rede vor der Deputiertenkammer am 28. Oktober 1932 betonte Herriot, daß die Verhandlungen in

381 Zur Einschätzung der Lausanner Konferenz durch die teilnehmenden Mächte siehe Ph. Heyde, Reparationen, S. 407/408.

382 England, Deutschland und Italien teilten diese Verhandlungsposition.

383 Frankreich und Belgien vertraten diese Interessen.

384 Ausführlich zu den verschiedenen Verhandlungssträngen und auch -problemen siehe $\mathrm{Ph}$. Heyde, Reparationen, S. 408-455.

385 A. N. Commission des Affaires Etrangères, C 14978, Sitzung vom 17. 9. 1932.

386 Vgl. dazu Le Temps vom 30. 10. 1932, S. 3/4.

387 Ebenda: „De Lausanne, j'ai rapporté 3 milliards de reichsmarks.“ 
Genf und die angestrebten Ziele wie die Abrüstung und die Vorkehrungen zur Friedenssicherung auf jeden Fall aufmerksamer Vorbereitung bedurften. Falls man in Genf nicht zu einem definitiven Durchbruch kommen sollte, hätte Frankreich wenigstens sein Bestes gegeben ${ }^{388}$. Zu den wichtigsten Verhandlungszeichen Frankreichs in Genf zählte Herriot die Ächtung des Angriffskrieges, die Umwandlung der europäischen Armeen zu Defensivarmeen, Rüstungsbeschränkungen und die Anerkennung der obligatorischen Schiedsgerichtsbarkeit ${ }^{389}$. Herriot unterstrich, daß er diese Position parteiübergreifend in Genf vertreten werde.

\section{Herriot und die Lausanner Verhandlungen}

Herriots außenpolitische Position bezüglich der Reparationsfrage war seit längerem sowohl innerhalb als auch außerhalb der Partei bekannt und fand nicht nur Zustimmung. Bereits auf dem Parteitag des Parti radical vom 5. bis 8. November $1931^{390}$ war es zu einer intensiven Diskussion über diese problematische Thematik gekommen. Zwar schloß sich die Mehrheit der Partei Herriots außenpolitischem Kurs an, dennoch blieb eine linke Gruppe gegenüber der außenpolitischen Konzeption Herriots kritisch eingestellt. Der Parteivorsitzende zeigte sich gegenüber Amerika sehr mißtrauisch und rekurrierte besonders auf das Recht Frankreichs, Reparationszahlungen und die Unantastbarkeit der Verträge zu fordern. Er verwies vor allem darauf, daß 1924 durch seine Politik der Dawesplan zustande gekommen sei, der immerhin die deutsch-französischen Beziehungen auf eine neue Grundlage gestellt habe. Nach dem Sturz seiner Regierung führte die Außenpolitik der rechten politischen Kräfte in Frankreich zum Youngplan, der für Frankreich keine erfreuliche Bilanz aufweise. Herriot verteidigte außerdem die Position des Parti radical gegen die Kritik der extremen Linken, die den Radikalsozialisten vorhielten, daß sie den Hoover-Plan nicht vorbehaltlos unterstützten: „N'avaientils pas le droit et le devoir d'exposer leurs craintes, de faire des réserves, de demander des contreparties, d'être payés ,en paix““" 391

Mit dieser Position konnte Herriot zwar die Mehrheit seiner Partei hinter sich vereinen, aber eine kleine Gruppe um François-Albert beurteilte die Vorschläge des Hoover-Moratoriums weniger skeptisch. Im Gegenteil, sie regten an, daß über einen allgemeinen Schuldenerlaß aller Kriegsteilnehmer nachgedacht werden sollte. Ähnlich äußerte sich auch Caillaux und die gemäßigte Dépêche de Toulouse, nach deren Auffassung ein starres Festhalten an den Reparationsforderungen Frankreich nur dem Vorwurf des Imperialismus aussetze und den Aufstieg Hitlers fördere ${ }^{392}$. Das Einlenken Herriots in der Reparationsfrage, das sich darin zeigte, daß Herriot sukzessive von den strikten Reparationsforderungen abrückte, war

${ }^{388}$ Le Temps vom 30. 10.1932, S. 4: „(...) sa volonté de collaborer jusqu’à l'extrême limite du possible à l'œuvre d'organisation de la paix.“

389 Ebenda.

390 Herriot entfaltete am 7. 11. 1931 sein außenpolitisches Programm; vgl. L'Oeuvre vom 8. 11. 1931, S. 4.

${ }^{391}$ L'Oeuvre vom 8. 11. 1931, S. 4.

392 La Dépêche de Toulouse vom 3. 1. 1932, S. 1; L'Oeuvre vom 11. 1. 1932, S. 1; L'Ere Nouvelle vom 9.1.1932, S. 1. 
allmählich durch die Verhandlungen mit England im Vorfeld der Lausanner Konferenz eingeleitet worden.

Umstritten war innerhalb des Parti radical auch die Abrüstungsthematik. Die Bewegung der Jeunes Turcs sprach sich unter ihrem Wortführer Pierre $\operatorname{Cot}^{393}$ für die Revision des Versailler Vertrags aus und bemühte sich gleichzeitig sehr um eine deutsch-französische Annäherung. Cot lehnte auf dem Parteitag 1931 eine Trennung der Abrüstungsfrage von der Sicherheitsdebatte vehement $a b$ und verwies auf deren Interdependenz, die bereits in einer Resolution von 1928, noch unter der Regierung der Union nationale, betont worden sei. Er forderte ferner, daß Frankreich auf einer Abrüstungskonferenz zwei Pläne vorlegen und deren Durchsetzung erreichen müsse. In einem ersten Schritt solle eine progressive und kontrollierte Abrüstung greifen. Dieser Plan konnte nach Meinung Cots in der aktuellen Situation sofort realisiert werden. Ein zweiter Schritt müsste einen umfassenderen und radikaleren Abrüstungsplan beinhalten, der den Aufbau kollektiver Sicherheitsstrukturen und die Gleichheit der Rechte aller Staaten garantieren müsse ${ }^{394}$.

Herriot hielt auch in der Abrüstungs- und Sicherheitsfrage an den bestehenden Verträgen fest und sprach sich gegen eine Revision aus. Er machte deutlich, daß es keine Abrüstungsvereinbarungen ohne entsprechende gleichzeitige Sicherheitsmaßnahmen geben werde. Eine unilaterale Abrüstung lehnte er entschieden ab ${ }^{395}$.

Diese heterogenen Positionen innerhalb des Parti radical in der Reparationsund Abrüstungsthematik blieben auch während der Verhandlungen von Lausanne und Genf bestehen. Als Hoover am 22. Juni 1932 seinen Vorschlag, die bestehenden Rüstungen um ein Drittel zu reduzieren, in die Verhandlungen einbrachte, reagierten Herriot und Paul-Boncour, der die Verhandlungen für Frankreich in Genf führte ${ }^{396}$, sehr konsterniert und lehnten dieses Ansinnen ab ${ }^{397}$. Das Verhalten Herriots in der Reparationsfrage gab innerhalb des Parti radical erneut Anlaß zu Diskussionen. Am 28. Juni 1932 versammelten sich die Mitglieder der parlamentarischen Gruppe des Parti radical, um die Position Frankreichs bei diesen beiden Verhandlungen zu diskutieren. Aus den spärlichen Berichten ${ }^{398}$, die in der Presse darüber verbreitet wurden, geht dennoch hervor, daß es innerhalb der Gruppe unterschiedliche Auffassungen zur Position Herriots gab. Nogaro, einer der Redner betonte nochmals, daß die absolute Priorität für Frankreich darin bestehen müsse, selbst einen Schuldenerlaß zu erzielen, dann könne man sich der Position Englands durchaus anschließen ${ }^{399}$.

Bergery meldete sich ebenfalls zu Wort. An seine Ausführungen schloß sich eine heftige Debatte an, die zu dem Ergebnis führte, Herriot über die Standpunkte

${ }^{393} \mathrm{Zu}$ Pierre Cot siehe J. Jolly, Dictionnaire, vol. 3, S. 1148-1150.

394 Die Ausführungen Pierre Cots auf dem Parteitag des Parti radical von 1931 finden sich in L'Oeuvre vom 8.11.1931, S. 4.

395 Zur Position Herriots auf dem Parteitag von 1931 siehe L'Oeuvre vom 8. 11. 1931, S. 4 und vom 9.11.1931, S. 1, 4.

396 Vgl. zur Tätigkeit Paul-Boncours bei den Genfer Verhandlungen den Nachlaß Paul-Boncour in: A.N. Paris, 424 AP/14 und seine Memoiren: J. Paul-Boncour, Entre deux-guerres. Souvenirs sur la Troisième République, Bd. 2: Les lendemains de la victoire 1919-1934, Paris 1946, S. 182-235.

$397 \mathrm{Ph}$. Heyde, Reparationen, S. 414/415.

398 Vgl. hier z. B. L'Oeuvre vom 29. 6. 1932, S. 1/2; L'Ere nouvelle vom 29. 6. 1932, S. 1.

${ }^{399}$ L'Oeuvre vom 29. 6. 1932, S. 1. 
der parlamentarischen Gruppe zu informieren. Es wurde sogar angeregt, eine Delegation nach Lausanne zu Herriot zu senden. Nach Interventionen von Fribourg und Lamoureux kam man überein, von einer Delegation abzusehen, da dies die Position Herriots in Lausanne nur zusätzlich erschweren würde. Man wollte im Gegenteil alles vermeiden, was die Autorität Herriots beeinträchtigen konnte ${ }^{400}$. Deshalb wurde der Regierung Herriot einstimmig das Vertrauen ausgesprochen. Aus Diskretionsgründen mußten sich die Mitglieder der Versammlung verpflichten, keine Detailinformationen an die Öffentlichkeit dringen zu lassen. Die innerparteiliche Opposition des Parti radical und ihre Kritik konnte während der Verhandlungen von Lausanne und Genf vor der Öffentlichkeit geheim gehalten werden, blieb aber weiterhin bestehen und wurde nach Abschluß der Verhandlungen wieder deutlich hörbar.

Am 9. Juli 1932 endete die Lausanner Konferenz mit der Festlegung folgender Bestimmungen: Deutschland mußte sich zu Reparationszahlungen im Wert von drei Milliarden Goldmark verpflichten. Mit diesem Beschluß wurden alle früheren Bestimmungen aufgehoben, und die Reparationsthematik war damit definitiv geregelt worden. Das Moratorium, das gleich zu Beginn der Lausanner Konferenz ${ }^{401}$ zwischen den Teilnehmern vereinbart worden war, sollte bis zur Ratifikation des Lausanner Abkommens in Kraft bleiben. Deutschland mußte nur seinen Verpflichtungen aus der Dawes- und Younganleihe nachkommen ${ }^{402}$.

Das Ergebnis der Lausanner Verhandlungen wurde bei den Beteiligten sehr unterschiedlich aufgenommen. England und Deutschland zeigten sich über den $\mathrm{Be}-$ schluß zufrieden, für andere Teilnehmerstaaten wie Italien und auch Frankreich fiel das Resultat weniger erfreulich aus ${ }^{403}$.

Frankreich war der Teilnehmerstaat, für den das Lausanner Abkommen Nachteile brachte, denn es mußte seine bisherige Politik, die eigenen interalliierten Schulden mit entsprechenden Reparationszahlungen begleichen zu können, aufgeben, ohne ein Äquivalent zu erhalten. Frankreich wurde lediglich eine noch unsichere Restzahlung in Aussicht gestellt. Unsicher war diese Restzahlung deshalb, da noch drei Voraussetzungen geklärt werden mußten. Zum einen mußte dieses Abkommen die Zustimmung des deutschen Reichstages erhalten. Falls die Nationalsozialisten die nächsten Wahlen gewannen und über eine Mehrheit im Reichstag verfügten, war davon auszugehen, daß das Abkommen abgelehnt würde. Die beiden anderen Prämissen, die zur Umsetzung des Abkommens erfüllt sein mußten, gestalteten sich weitaus schwieriger und waren mit mehr Unwägbarkeiten verbunden: Bevor die deutschen Bons auf den Markt kommen konnten, mußte erst der deutsche Auslandskredit wiederhergestellt werden. Hier war eine gewisse Besorgnis durchaus angebracht, denn die deutschen Wertpapiere konnten auch

400 L'Ere nouvelle vom 29.6. 1932, S. 1.

401 Am 15./16. Juni 1932 faßten die Delegationen der fünf Gläubigermächte, Frankreich, England, Italien, Belgien und Japan, den Beschluß, für die Dauer der Lausanner Verhandlungen ein Moratorium für die Reparationen und die interalliierten Schulden einzurichten; vgl. Ph. Heyde, Reparationen, S. 408.

402 Akten zur Deutschen Auswärtigen Politik, B XX, Göttingen 1995, Nr. 148; E. Klöss (Hg.), Von Versailles zum zweiten Weltkrieg. Verträge zur Zeitgeschichte 1918-1939, München 1963, S. 180184; Documents of British Foreign Policy 2/III, London 1949, S. 595-601.

403 Vgl. Ph. Heyde, Reparationen, S. 443. 
nach der Lausanner Konferenz kaum einen Kursanstieg verbuchen. Dennoch gab es eine gewisse Hoffnung, daß die Weltwirtschaftskonferenz zum Abbau von Devisen- und Handelsbarrieren beitragen könnte, um Deutschland die Integration in das internationale Wirtschafts- und Währungssystem zu ermöglichen. Eine letzte Hürde, die vor der Umsetzung des Lausanner Abkommens genommen werden mußte, war die Ratifizierung dieser Beschlüsse durch die Gläubigerstaaten. Da die Realisierung der Beschlüsse mit Unsicherheiten verbunden war, kam es für Herriot darauf an, in Frankreich die Öffentlichkeit und das Parlament für das Lausanner Ergebnis zu gewinnen.

Die rechte Presse ${ }^{404}$, aber auch die sozialistische Parteizeitung Le Populaire ${ }^{405}$ standen den Verhandlungsergebnissen Herriots kritisch bis skeptisch gegenüber, denn die französische Rechte befürchtete, daß Deutschland erneut Revisionsforderungen anmelden würde. Und auch die Sozialisten äußerten größte Bedenken hinsichtlich der Revision der Kriegsschulden. Der Grundtenor in der französischen Presse läßt sich folgendermaßen zusammenfassen: Herriot wurde zwar zugebilligt, daß er im Grunde das Prinzip der Reparationsansprüche Frankreichs durchgesetzt habe, denn der Youngplan war nun endgültig außer Kraft gesetzt worden; jedoch wurde die Summe von drei Milliarden, die Frankreich von Deutschland noch erhalten sollte, nicht als angemessen bewertet ${ }^{406}$. Herriot gelang es immerhin, bei seiner Rückkehr nach Paris die zunächst skeptische Stimmung umzudrehen und letztlich eine Zustimmung für seine Verhandlungsergebnisse zu erhalten. Er verwies mit gewissem Stolz auf den in seinen Augen besonderen Verhandlungserfolg, nämlich den Ratifikationsvorbehalt. Mit einem weiteren Detail, das Herriot zuerst in einer gemeinsam abgehaltenen Sitzung der Finanzkommission und der Kommission für Auswärtige Angelegenheiten 407 bekanntgab, verstand er seinen Erfolg entsprechend hervorzuheben. Denn Herriot teilte den Kommissionsmitgliedern mit, daß er in Lausanne auch eine Vereinbarung mit England unterzeichnet habe, einen „Accord de confiance“ bzw. „Accord

404 Stellvertretend seien hier zwei Artikel in Le Figaro genannt, die im wesentlichen die Hauptkritikpunkte, die die politische Rechte am Lausanner Abkommen vorbrachte, widerspiegeln: Le Figaro vom 10. 7. 1932, S. 1 und Le Figaro vom 12. 7. 1932, S. 1. Die Hauptkritikpunkte lassen sich mit folgenden Stichworten zusammenfassen: Blauäugigkeit Herriots, denn Ziel von Lausanne sei die „Zerstörung“ der Reparationen gewesen. Die Amerikaner hätten sich durch deutsche Propaganda beeinflussen lassen; der Erlaß der Reparationen würde von Deutschland als Schuldeingeständnis Frankreichs interpretiert werden; durch „la faiblesse, l'aveuglement et les divisions“ der „Ex-Alliierten " würde Deutschland in seinen Wiederbewaffnungsplänen bestärkt; MacDonald sehe die sich daraus ergebende Kriegsgefahr nicht - Deutschland werde nun auch die Revision der im Versailler Vertrag festgesetzten Grenzen fordern; durch Lausanne werde Frankreich in die Isolation getrieben, da es seinen Verbündeten Polen und „La Petite Entente“ vernachlässigt habe.

405 Blums Darlegungen in Le Populaire vom 18. 6. 1932, S. 1 und auch in Le Populaire vom 7. 7. 1932, S. 1: „Pourquoi donc continuent-ils à lutter avec tant de ténacité? Voilà ce qu'il faut bien marquer et bien comprendre. Les délégués français sont partis de l'hypothèse suivante: si le solde forfaitaire allemand est fixé à un chiffre suiffisant, les Ėtats-Unis accepteront tout ou partie de ce solde en compensation de leurs créances sur l'Europe. Supposons que cette conjoncture se vérifie: les réparations seraient annulées en fait, mais les dettes interalliées le seraient du même coup. Or, comme le disait fort bien le prudent Senatus: ,Le peuple français, fatigué de ces éternelles conférences, consent, en haussant les épaules, à ne rien recevoir de l'Allemagne, pourvu qu'il n'ait rien à donner aux Etats-Unis $(\ldots)^{c}$.“

$406 \mathrm{Ph}$. Heyde, Reparationen, S. 445.

to7 Protokoll der Sitzung vom 13. 7. 1932 in A.N., Commission des Finances, C 14990, Sitzung vom 13. 7. 1932. 
franco-britannique“, in dem die beiden Mächte England und Frankreich sich in vier Punkten über ihre Zusammenarbeit geäußert und folgendes festgelegt hatten: 1) Im Sinne des Völkerbundes wollten beide Mächte, England und Frankreich, sich um Lösungen von Problemen bemühen, die aus der Reparationsfrage resultierten; 2) beide Staaten bekräftigten, zusammen mit anderen Delegationen in Genf zu kooperieren, um eine für alle Beteiligten vorteilhafte und gerechte Lösung des Abrüstungsproblems zu erreichen; 3) England und Frankreich erklärten sich bereit, mit den anderen interessierten Staaten die Weltwirtschaftskonferenz sorgfältig vorzubereiten; 4) Schließlich versicherten sie, daß sie bis zum baldigen Abschluß eines bilateralen Handelsvertrages diskriminierende Maßnahmen gegen andere Staaten vermeiden würden ${ }^{408}$.

Herriot sah in diesem Abkommen eine Erneuerung der „Entente cordiale“ und glaubte darin auch ein Einvernehmen darüber erkennen zu können, daß England in Absprache mit Frankreich die Verhandlungen über die interalliierten Schulden mit Amerika führen werde ${ }^{409}$.

England und Frankreich forderten in dieser Vereinbarung die anderen Staaten, die an der Konferenz teilgenommen hatten, auf, sich ihrem Abkommen anzuschließen und beizutreten ${ }^{410}$. Herriot kommentierte in der Presse den Inhalt dieses englisch-französischen Abkommens nur mit knappen Worten. Er hob besonders darauf $a b$, daß mit dieser Vereinbarung wieder ein Zeichen für ein gemeinsames Handeln dieser beiden Mächte gesetzt worden sei411.

Ein weiteres Übereinkommen, das die Gläubigermächte Frankreich, England, Belgien und Italien mit Deutschland abgeschlossen hatten, war das sogenannte „Gentlemen's Agreement“. Es beinhaltete den Ratifikationsvorbehalt, der den Gläubigermächten eine Garantie bot, die vorhergehenden Bestimmungen mit Deutschland nur dann ratifizieren zu müssen, wenn auch ihre eigene Schuldenfrage in ihrem Interesse gelöst sein würde ${ }^{412}$.

${ }_{408}$ Zum Wortlaut des Textes des Accord de confiance siehe Le Temps vom 15./16. 7. 1932, S. 1 und auch die Kommissionsunterlagen, siehe Anmerkung 407.

409 Vgl. dazu die Stellungnahme Herriots in der Anhörung vom 13. 7. 1932 vor den beiden wichtigsten Kommissionen - der Kommission der auswärtigen Angelegenheiten und der Finanzkommission -, in der Herriot u. a. betonte, daß er zu Beginn der Verhandlungen deutlich die Gefahr der Isolierung Frankreichs spürte. Diese sei durch die Ergebnisse und das Gelingen der Verhandlungen in Lausanne gebannt worden: „J'avais de mon côté senti durement les dangers de l'isolement de la France au debut de la conference. Aussi ai-je pensé que le mieux serait de transformer en accord durable cette collaboration de Lausanne et nous avons établi l'accord ci-dessous, qui à dixneuf heures, sera publié à Londres et à Paris."; ebenda.

410 Punkt 1 des Abkommens in Le Temps vom 15./16. 7. 1932, S. 1

411 Presseerklärung Herriots in Le Temps vom 15./16.7. 1932, S. 1: „(...) qu'il marque à la fois la loyale amitié de la Grande-Bretagne et de la France et leur ardente volonté de mettre en commun leurs efforts; leur travail, leur expérience, pour contribuer à la bonne entente des peuples, dans l'Europe et dans le monde et à l'organisation de la paix."

412 Zur Schlüsselpassage in diesem Gentlemen's agreement: „(...) en ce qui concerne les gouvernements créditeurs, au nom desquels ce procès-verbal est paraphé, la ratification ne sera pas effectuée avant qu'un réglement satisfaisant ait été obtenu entre eux et leurs propres créanciers. Ils auront toute liberté d'expliquer leur position à leurs Parlement respectifs; mais aucune réference précise au président arrangement n'apparaîtra dans le texte de l'accord avec l'Allemagne. Si, par la suite, un règlement satisfaisant de leurs propres dettes est obtenu, les gouvernements des susdits pays créditeurs procéderont à la ratification et l'accord avec l'Allemagne prendra son plein effet. Mais dans le cas où le réglement en question ne pourrait être obtenu, l'accord avec l'Allemagne ne sera pas ratifié."; ebenda. 
Im Laufe dieser Anhörung vor den beiden wichtigsten Kommissionen äußerte sich Herriot auch zum Verhandlungsverlauf. Er betonte die Schwierigkeiten, denen er während der letzten Wochen begegnet war, und gliederte seinen Rechenschaftsbericht in zwei Teile: In einem ersten Schritt entwickelte er einen historischen Abriß der Reparationsverhandlungen, in einem zweiten Abschnitt legte er die Ergebnisse von Lausanne dar. Herriot verstand es, sehr anschaulich die Widrigkeiten der französischen Ausgangsposition zu Beginn der Lausanner Verhandlungen zu schildern; er verwies z.B. auf die Bestimmungen des Hoovermoratoriums, die er deutlich mißbilligte, und auf die Zahlungsunfähigkeit Deutschlands. $\mathrm{Um}$ seine Leistungen und die seiner Kollegen ${ }^{413}$ angemessen herausstreichen zu können, versuchte er zu vermitteln, wie es ihnen gelungen war, aus dieser unerfreulichen Ausgangsposition heraus das Blatt zu wenden. Durch „la vieille méthode française", darunter verstand Herriot das analytische Vorgehen, stand für die französische Delegation fest, daß sie zuerst einmal zwei prinzipielle Fragen zu klären hatte. Es handelte sich 1) um die Dauer des Moratoriums und 2) um die Verbindung zwischen Schulden- und Reparationsfrage. Herriot umschrieb diesen letzten Punkt folgendermaßen: „Deuxième question et deuxième principe: nous entendions faire admettre par tous, spécialement par les Anglais, que le règlement de Lausanne ne pouvait être que provisoire, que c'était un règlement européen dans le cadre d'un règlement universel. " 414 In diesem Punkt fanden laut Herriot England und Frankreich sehr schnell einen Konsens, denn bereits in den ersten Tagen der Verhandlungen konnte Herriot sein Hauptziel erreichen: „(...) nous avons obtenu satisfaction sur ce principe que le règlement de Lausanne ne pouvait être qu'un règlement sous condition suspensive, dans le cadre d'un règlement universel. " ${ }_{115} \mathrm{Um}$ die eigene Durchsetzungskraft wirkungsvoll hervorzuheben, schilderte Herriot den beiden Kommissionen auch die neuralgischen Momente in Lausanne. Nur mit größten Mühen habe sich Frankreich gegen die Front bestehend aus England, Italien und Deutschland, die sich für eine Annullierung der Reparationen ausgesprochen hatte, behaupten können. Bezüglich dieses Problems bestand zwischen England und Frankreich ein gravierender Dissens. England habe der französischen Delegation erklärt, daß es in der Reparationsfrage nach reiflicher Überlegung zu dem Beschluß gekommen sei, die Reparationen ersatzlos zu streichen, da dem Geldtransfers zwischen den Nationen kein handelswirtschaftliches Äquivalent entsprach. ${ }^{416}$ Herriot versicherte, sich heftig gegen diese Sichtweise Englands gewehrt und darauf verwiesen zu haben, daß Frankreich wesentlich stärker von der Reparationsproblematik betroffen sei als alle anderen Staaten in Europa. Denn im Vergleich zu England, das 68 Millionen, und Italien, das 38 Millionen Goldmark erhalten sollte, standen Frankreich immerhin 360 Millionen Goldmark zu. Er habe England den französischen Problemhorizont dargelegt, der sich vom englischen deutlich unterschied, denn: „L'Angleterre a quelque difficulté à envisager les choses ainsi. Elle part sur stade national pour aller directe-

413 Herriot war mit einer Delegation, der Germain-Martin, Julien Durant, Georges Bonnet angehörten, gereist.

414 A.N. Paris, Commission des Finances, C 14990, Sitzung vom 13. 7. 1932.

415 Ebenda.

416 Ebenda. 
ment au stade mondiale. La France est obligée d'envisager un stade intermediaire, stade national, stade européen, stade mondial. “ ${ }^{417}$ Daraus resultiere für Frankreich ein anderes Interesse an der Lösung der Reparationsfrage als für England, und gleichzeitig leitete Herriot auch ein unterschiedliches Engagement beider Staaten hinsichtlich eines Wiederaufbaues von Europa ab; d.h. für Frankreich konkret, wenn England nicht bereit war, sich dafür federführend einzusetzen, dann wollte Frankreich diese Aufgabe selbst in die Hand nehmen. Ein weiteres Argument, das Herriot in seiner Haltung hinsichtlich der Reparationsproblematik bestätigte, war das Verhalten Amerikas, das einer generellen Annullierung der Kriegsschulden ablehnend gegenüberstand und dies auch Frankreich unmißverständlich mitteilen ließ418. Als er habe erkennen müssen, daß sich zwischen England und Frankreich in dieser Angelegenheit kein Kompromiß abzeichnete, habe er sogar den Abbruch der Lausanner Verhandlungen in seine Überlegungen mit einkalkuliert und für diesen Fall bereits ein Dokument redigiert, in dem er die Gründe für das Ende der Verhandlungen dargelegt hatte. Unerwarteterweise habe England plötzlich in dieser angespannten Situation eingelenkt und sei mit einem Kompromißangebot auf Frankreich zugegangen ${ }^{419}$. Es gestand eine Restzahlung oder Abschlagszahlung zu. Gerade bei diesem zentralen Aspekt der Verhandlungen zitierte Herriot die Formulierung Englands, um den Kommissionsmitgliedern aufzuzeigen, daß nicht nur inhaltliche Schwierigkeiten, sondern auch sprachliche Klärungen vonnöten gewesen seien: „Nous avons réflechi. Nous sommes d'accord avec vous pour vous donner un forfait, un solde substanciel, disaient certains. " 420 Ein ganzer Vormittag sei darauf verwandt worden, die unterschiedliche Interpretation des Terminus "forfait" zu klären, denn aus diesem Begriff gehe noch nicht eindeutig hervor, wie er zu definieren war. Es bestanden immerhin zwei Möglichkeiten: Zum einen "Payement en capital“ oder „en annuités“. So wie England der französischen Delegation in diesem Aspekt der Reparationsfrage entgegengekommen sei, so habe es die Übernahme einer Vermittlerrolle gegenüber Deutschland entschieden abgelehnt und Frankreich aufgefordert, direkt mit der deutschen Delegation zu verhandeln. Mit diesem Resultat endete die erste Verhandlungsetappe in Lausanne.

Herriot skizzierte in einem zweiten Schritt die Gespräche mit dem Reichskanzler von Papen, die von beiden Seiten, d.h. sowohl von französischer wie auch von deutscher Seite, stark taktischen Gesichtspunkten unterlagen. Frankreichs Ministerpräsident schilderte, daß die ersten Begegnungen zwischen ihm und von $\mathrm{Pa}$ pen sehr höflich verlaufen seien, jedoch nicht zu einem konkreten Ergebnis geführt hätten. Im Gegenteil, zunächst schien die Taktik von Papens darauf ausgerichtet gewesen zu sein, durch großes Entgegenkommen gegenüber Frankreich in Nebensachen, sich dem zentralen Punkt, d.h. der Festlegung der Summe für eine Restzahlung der Reparationen, entziehen zu können. Als von Papen nach Rücksprache mit seinem Kabinett aus Berlin zurückgekehrt sei, habe er Frankreich mit

417 Ebenda.

418 Ebenda: „L'Amérique nous a bien prévenus par son ambassadeur. Elle nous a dit: „Annulez si vous voulez, mais nous considerons que vous l'aurez fait pour des raison d'intérêt ou des convenances, et nous ne vous en tiendrons aucun compte."

${ }^{419}$ Herriot deutete in der Anhörung bei den beiden Kommissionen gewisse Beweggründe der englischen Delegation nur an, ohne konkret zu werden; ebenda.

420 Ebenda. 
der Forderung einer Annullierung der Reparationszahlungen konfrontiert. Zwischen der deutschen und der französischen Delegation sei es zu einer Verhandlungsblockade gekommen, da beide Parteien nicht bereit gewesen seien, einen Zoll breit von ihrem Standpunkt abzuweichen. Erst mit der Intervention Englands ${ }^{421}$ sei wieder Bewegung in die Verhandlungen der beiden Mächte gekommen. Von Papen habe Frankreich eine Restzahlung unter zwei Bedingungen angeboten: 1) Deutschland müsse bei der Abrüstungsdebatte dieselben Rechte wie alle anderen Teilnehmerstaaten erhalten und 2) Teil VIII des Versailler Friedensvertrages ${ }^{422}$ müsse aufgegeben werden. Herriot versicherte den Kommissionsmitgliedern, beide Forderungen entschieden abgelehnt zu haben. Denn die Abrüstungsfrage sei nicht Gegenstand der Verhandlungen in Lausanne, sondern in Genf. Noch wesentlich schärfer habe er aber die zweite Forderung kritisiert, hinter der der Wunsch des Reichskanzlers stand, die Kriegsschuldfrage zu revidieren, und überhaupt habe er darauf hingewiesen, $\mathrm{da} ß$ er die gesamte Verhandlungssituation missbillige und für grotesk halte: „(..) que venu pour demander une partie de la dette envers la France, je me voie, pour des conditions et que le debiteur me dise: ,Je consens à ce que vous me remettiez votre créance, amis j'y mets telles conditions'." 423

Der französische Ministerpräsident ging in seinen Ausführungen vor der Finanz- und der außenpolitischen Kommission vor allem auf diese Phase der Verhandlungen ein, da er hier seine Durchsetzungskraft und sein erfolgreiches Verhandlungsgeschick besonders unter Beweis hatte stellen können. Immerhin verwies Herriot stolz auf die Schlußverträge der Lausanner Verhandlungen, die in keiner Weise der zweiten Forderung von Papens Rechnung trugen. In diesem $\mathrm{Zu}$ sammenhang teilte er noch einen weiteren Wortwechsel mit, der ein bezeichnendes Licht auf die Vorbehalte gegenüber Parteien in Frankreich wirft: „M. von Papen cherchait visiblement un succès pour son parti contre d'autres partis et je lui ai déclaré que j'entendais traiter avec le chancelier d'Allemagne et non devant un homme de parti gouvernant contre d'autres partis." ${ }^{424}$

Herriot schloß seine Ausführungen mit einem Kommentar der einzelnen Verträge, die in Lausanne erarbeitet worden waren. Das gesamte Vertragswerk verglich er mit einem Triptychon: Im Zentrum dieses Triptychons stand für ihn die Vereinbarung mit Deutschland, die nun eine endgültige Regelung der Reparationsfrage beinhaltete. Den einen Flügel des Triptychons stellte das Gentlemen's agreement dar, dessen Inhalt laut Herriot keine Wünsche mehr offen ließ. Das Vertragswerk wurde komplettiert durch die englisch-französische Vereinbarung. Resümierend urteilte Frankreichs Regierungschef, daß die Verträge von Lausanne nicht nur die Reparationsfrage zur Klärung gebracht, sondern auch die Freundschaft zwischen Deutschland und Frankreich wiederhergestellt hätten.

421 Herriot zitierte MacDonald: „Cela ne peut pas continuer ainsi. Nous allons voir si l'on peut aboutir à un accord. “; ebenda.

422 In Teil VIII des Versailler Vertrages wurden die Reparationszahlungen fixiert, siehe S. Haffner u.a. (Hg.), Der Vertrag von Versailles, München 1978, S. 238-264.

${ }^{423}$ Kommissionsprotokoll vom 13.7. 1932 in A.N. Paris, Commission des Finances, C 14990, Sitzungen vom 22. 6.-18. 10. 1932.

424 Ebenda. 
An diese Ausführungen des Ministerpräsidenten schloß sich eine Diskussion mit den Kommissionsmitgliedern an. Nur Auriol ${ }^{425}$, der für die Sozialisten sprach, und Bergery, der als Vertreter des linken Flügels des Parti radical auftrat, setzten sich sehr kritisch mit Herriots Verhandlungsergebnis auseinander, die übrigen Kommissionsmitglieder stimmten dem Ministerpräsidenten geschlossen zu.

Bergery, der bereits während der Verhandlungen in Lausanne am außenpolitischen Konzept Herriots Kritik geübt hatte, brachte seine Bedenken auch bei der Anhörung Herriots in den beiden Kommissionen vor. Zunächst hielt er fest, daß sich wohl alle Anwesenden in einem Punkt einig seien: Die Frage in dieser Anhörung laute nicht, ob man an einer Zahlung der Reparationen festhalten sollte oder nicht, denn weder die englische Lösung, die die Annullierung aller Kriegsschulden vorsah, noch die französische Option, die Eingang in die Lausanner Verträge gefunden habe, beinhalte eine Fortsetzung der Reparationszahlungen. Bergery versuchte darzulegen, daß sich angesichts der Ergebnisse der Lausanner Konferenz eine völlig neue Frage aufdränge, nämlich: Wenn es keine Reparationen mehr gab, wie konnte man eine adäquate Lösung für die Annullierung der Kriegsschulden bei den Amerikanern erwirken und gleichzeitig ganz allgemein den Frieden wiederherstellen?426 Aus dieser Erkenntnis heraus hielt er die Lösung, für die Herriot sich in den drei Verhandlungswochen in Lausanne eingesetzt hatte, nicht für die richtige. Im Gegenteil, er bezeichnete den Vorschlag Englands als den besseren Weg, um Frankreichs angestrebtes Ziel - Schuldenerlaß der Amerikaner - zu erreichen. Für Bergery war das Festhalten Herriots an einem "forfait" ein unbegreiflicher Fehler, dessen Durchsetzung für Frankreich in keiner Weise einen Gewinn oder Erfolg bedeutete. Er legte in einer Kurzanalyse dar, daß die erzielte Einigung in Lausanne in der Reparationsfrage seiner Meinung nach für alle Beteiligten keine wirklich erfolgreiche Lösung darstelle ${ }^{427}$. Bergery stand auf dem Standpunkt, daß eine Annullierung der deutschen Reparationen Frankreich gegenüber Amerika in eine wesentlich günstigere Ausgangsposition gebracht hätte, als eine Reduzierung der Reparationszahlungen auf $7 / 8$. Er ging in seiner Kritik noch einen Schritt weiter und warf Herriot vor, daß dieser gegenüber Amerika durch seine Ablehnung des englischen Planes eine ganz große Chance vertan habe: „Si, au contraire, on avait mis, au moment le plus opportun - Ce n'est certainement pas maintenant l'Amérique en presence d'un message, qui vienne non seulement de vous, mais d'autres états européens, d'un message qui eut la brutalité, mais aussi la grandeur des deux messages de M. Hoover, je voudrais savoir si en Amérique, comme d'ailleurs, il eut été possible de s'opposer à une mesure qui avait vraiement l'allure d'une mesure destinée à ramener la paix dans le monde. “428 Letztlich beurteilte Bergery das Ergebnis von Lausanne als Fehlschlag, der Frankreich keinen Vorteil einbringen werde.

\footnotetext{
${ }^{425}$ Vgl. zur Kritik der Sozialisten an Herriots Außenpolitik Unterpunkt 4 dicses Prozeßbeispiels II. 426 Bergerys Ausführungen während der Sitzung vom 13. 7. 1932; ebenda.

${ }_{427}$ Bergery prüfte die Lösung Herriots unter vier Aspekten und kam jeweils zu einem negativen Ergebnis: „Je ne comprends ne si je me place au point de vue de l'intérêt budgetaire de la France, ni si je me place au point de vue de l'Amerique, ni si je me place au point de vue de l'Allemagne et de la pacification generale. Au point de vue de la France dans un cas comme dans l'autre, il nous reste zéro."; ebenda.

${ }^{428}$ Ebenda.
} 
Verständlicherweise widersetzte sich Herriot der Argumentation Bergerys und versuchte, ihm gewisse Fehlannahmen nachzuweisen. Zunächst stellte Herriot klar, daß die zentrale Frage nicht, wie Bergery behauptete, dem Erhalt eines „forfaits" in Höhe von drei, vier, oder fünf Milliarden Francs galt, sondern die zentrale Frage lautete, wie man die Meinung Amerikas am besten in der Diskussion um den Erlaß der Kriegsschulden beeinflussen konnte - mit der englischen Methode, der totalen Annullierung, oder mit dem französischen Vorschlag. In einem zweiten Schritt gestand Herriot ein, daß ihm eine Entscheidung zwischen diesen beiden Optionen sehr schwer gefallen sei, er sich aber für den zweiten Lösungsweg entschieden habe, weil er mit dieser Option dem nationalen Bewußtsein Frankreichs Rechnung tragen konnte. Seine Entscheidung begründete er weiter mit der starren Haltung Amerikas, das ihm auf seine Frage, welche Alternative die bessere sei, mehrmals folgendes zur Antwort gegeben habe: „Moi, je n'admets pas l'annulation. Je ne l'admets pas, non pas seulement pour des raisons materielles, que je ne cache pas, mais pour des raisons morales. " 429 Herriot führte auch einen zweiten nationalen Aspekt ins Feld: den französischen "Idealismus“, den er - seiner Meinung nach - ebenfalls zu verteidigen hatte. Er gab zu, daß er manchmal verunsichert gewesen sei, wenn er argumentierte, daß die Verträge respektiert werden müßten. Jedoch fühlte er sich in seinem Argument, an den Verträgen festzuhalten, bestätigt, als MacDonald in seiner Eröffnungsrede bei den Verhandlungen in Lausanne ihm attestiert habe: „Vous aviez raison, l'esprit des contrats, c'est la condition de la paix international! " ${ }^{430}$ Solche internationale Anerkennung und Bestätigung ermutigte ihn, auch während der Verhandlungen auf diesen Aspekt sein Hauptaugenmerk zu legen, auch wenn er sich dabei durchaus bewußt war, daß er mit dieser Haltung Kritik auf sich zog. Dennoch ließ er sich nicht von seiner Überzeugung abbringen und verwies als Bestätigung für die Richtigkeit seines Handelns nochmals auf die Haltung Amerikas bei den Verhandlungen zum Hoover-Moratorium, wo Amerika unerschütterlich an jedem Prozentpunkt der zu zahlenden Summe des Moratoriums festgehalten habe. Herriot beendete seine Replik damit, daß er aus den Verhandlungen mit Amerika Anstöße erhalten habe und „(...) comme Français, j'ai voulu donner ma part à l'idéalisme, comme je la donnerai toujours, mais après avoir fait tout ce qui dépendait de moi, pour assurer leur part aux droits de chacun à la justice et à la réalité. “431

Dem Ministerpräsidenten gelang es ebenso in der Deputiertenkammer ${ }^{432}$, überwiegend Zustimmung für die Beschlüsse von Lausanne zu erhalten, indem er auch hier kräftig unterstrich, daß das Lausanner Abkommen erst in Kraft treten werde, wenn Amerika auf die Kriegsschulden verzichte433. Damit sah Herriot eindeutig

\footnotetext{
429 Ebenda.

430 Ebenda.

431 Ebenda.

432 Vor der Sommerpause des Parlaments nahm Herriot am 17. 7. 1932 auf Aufforderung Marins kurz zu den Verhandlungen von Lausanne Stellung, betonte aber, daß im Moment noch kein ausführlicher Diskussionsbedarf bestünde, da die Ratifikation der Verträge erst noch zu erfolgen habe; vgl. Le Temps vom 18. 7. 1932, S. 2.

433 Zur Rede Herriots im Parlament siehe ebenda.
} 
sein wichtigstes Ziel, eine Korrelation zwischen der Reparations- und der Kriegsschuldenfrage hergestellt zu haben, erreicht ${ }^{434}$.

\section{Das finanzpolitische Programm der Regierung Herriot}

Wie Herriot bereits in seiner Regierungserklärung hervorgehoben hatte, galt sein Bemühen besonders zwei Problemfeldern. Zum einen der definitiven Klärung der Reparations- und Kriegsschuldenfrage und zum anderen der Sanierung des Staatshaushaltes. Noch während der Verhandlungen von Lausanne fanden die Prüfungen des vom Finanzminister Germain-Martin für das Jahr 1933 vorgelegten Haushaltsplanes durch die Finanzkommission statt. Der vorgelegte Haushalt führte zu heftigen Diskussionen innerhalb der Finanzkommission, in denen vor allem Änderungsvorschläge von seiten der sozialistischen und einiger radikalsozialistischer Mitglieder vorgebracht wurden ${ }^{435}$. Die Wiederberufung Germain-Martins ${ }^{436}$, der bereits unter der konservativen Regierung des zweiten Kabinetts Tardieu ${ }^{437}$ dem Finanzressort vorgestanden hatte, machte deutlich, daß Herriot gewillt war, mit traditionell konservativen Methoden den Staatshaushalt zu sanieren. GermainMartin wollte die Wiederherstellung des budgetären Gleichgewichts durch zwei Maßnahmen erreichen: Einerseits durch Einsparungen im Bereich der Militärausgaben wie im Verwaltungsbereich und andererseits durch Erhöhung der Einnahmen, die er einmal durch Steuererhöhungen und zum anderen durch die Erhöhung der Posttarife zu erzielen suchte ${ }^{438}$. Es handelte sich dabei eindeutig um Maßnahmen einer Deflationspolitik, der sich die Regierung verschrieben hatte. Verständlicherweise löste dieses Finanzprojekt Kritik des linken Flügels der Radikalsozialisten aus, denn für ihn war es unverständlich, wie nun eine radikalsozialistische Regierung die Finanzpolitik, die sie noch unter der Führung der Konservativen verurteilt hatte, selbst umzusetzen suchte. Immerhin war es den sozialistischen und einigen radikalsozialistischen Mitgliedern der Finanzkommission der Deputiertenkammer gelungen, im Détail einige Änderungen durchzusetzen, wie z. B. bei der Kürzung der Renten und der fünfprozentigen Kürzung der Beamtengehälter. Auf Initiative von Nogaro forderten die Radikalsozialisten in der Finanzkommission die Wiedereinführung einer Steuer auf Börsengeschäfte, Einsparungen bei den Militärausgaben und Gehaltsreduzierungen bei den höheren Gehaltsgruppen ${ }^{439}$.

Schon zuvor war es in der Kammer anläßlich eines Zusatzantrages zum Gesetzentwurf zur Wiederherstellung des Budgetgleichgewichts, der die Abschaffung

434 Ebenda: „Jamais, je le répète, aucune déliberation n'avait établi de lien, en dépit du synchronisme indiqué dans le plan Young, entre les réparations et les payements."

435 Vgl. zu den heftigen Debatten in der Finanzkommission über den Haushaltsplan für 1933, den Germain-Martin vorgelegt hatte: A.N. Paris, Commission des Finances, C 14990 (22. 6.-18. 10. 1932) und C 14991 (20. 10.-6. 12.1932), hier besonders die Sitzungen vom 4. 7. 1932 und vom 7.7. 1932 und später auch die Sitzungen vom 20. 10. 1932, vom 25. 10. 1932 und vom 27. 10. 1932.

${ }_{436} \mathrm{Zu}$ Germain-Martin siehe J. Jolly, Dictionnaire, vol. 5, S. 1824/1825.

${ }_{437}$ Das zweite Kabinett Tardieu regierte vom 2.3.-4. 12. 1930.

438 Zum Haushaltsvorhaben Germain-Martins siehe A.N. Paris, Commission des Finances, C 14991, Sitzung vom 20. 10. 1932. Außerdem auch A. Sauvy, L'Histoire économique, vol. 2, S. 46.

${ }_{439}$ Vgl. dazu die Sitzung der Finanzkommission vom 17.11. 1932 in A.N. Paris, Commission des Finances, C 14991. 
der Reservistenübungen für zwei Jahre vorsah, zwischen den Sozialisten, dem linken Flügel der Radikalsozialisten und Herriot zu einer heftigen Kontroverse gekommen, denn der französische Ministerpräsident betonte in der Kammerdebatte angesichts der angespannten internationalen Lage die Notwendigkeit von Reservistenübungen. Herriot war die Angelegenheit so wichtig, daß er die Vertrauensfrage stellte. Am 11. Juni wurde der Regierung mit $360 \mathrm{zu} 175$ Stimmen das Vertrauen ausgesprochen. In der Fraktion der SFIO, die während der Debatte keinen Hehl aus ihrer Enttäuschung über die in ihren Augen nur die Politik Tardieus fortführenden Finanzmaßnahmen Herriots gemacht hatte, stimmten 130 von 131 Abgeordneten gegen den französischen Ministerpräsidenten ${ }^{440}$.

\begin{tabular}{rlrccc}
\hline $\begin{array}{c}\text { An- } \\
\text { zahl }\end{array}$ & Parlamentarische Gruppe & Dafür & $\begin{array}{l}\text { Da- } \\
\text { gegen }\end{array}$ & $\begin{array}{l}\text { Enthal- } \\
\text { tung }\end{array}$ & $\begin{array}{l}\text { Abwe- } \\
\text { send }\end{array}$ \\
\hline 14 & Indépendants & 12 & - & 2 & - \\
41 & Fédération Républicaine & 36 & - & 4 & 1 \\
18 & Groupe républicain et social & 18 & - & - & - \\
8 & Action économique, sociale et paysanne & 7 & - & 1 & - \\
36 & Centre républicain & 33 & 1 & - & 2 \\
28 & Républicains de gauche & 28 & - & - & - \\
16 & Démocrates populaires & 13 & - & 3 & - \\
6 & Républicains du centre & - & - & 6 & - \\
23 & Indépendants de gauche & 19 & - & 2 & 2 \\
47 & Gauche radicale & 42 & 1 & 1 & 3 \\
160 & Radicaux et radicaux socialistes & 115 & 11 & 33 & 1 \\
15 & Gauche indépendante & 9 & 4 & 1 & 1 \\
12 & Républicains socialistes & 4 & 4 & 3 & 1 \\
13 & Socialistes français & 3 & 7 & 2 & 1 \\
131 & SFIO & - & 130 & 1 & - \\
9 & Unité ouvrière & - & 9 & - & - \\
10 & Communistes & - & 10 & - & - \\
28 & Isolés & 21 & 2 & 4 & 1 \\
\hline 615 & & 360 & 179 & 63 & 13 \\
\hline
\end{tabular}

Auch die parlamentarische Gruppe des Parti radical hatte nicht geschlossen für die Regierung Herriot gestimmt, vielmehr kam es zu erheblichen Abweichungen. Die innerparteiliche Opposition des linken Flügels, die bereits im außenpolitischen Politikfeld hervorgetreten war, vertrat auch in der Finanzpolitik eine andere politische Richtung. Herriot, der vor der großen Haushaltsdebatte in der Abgeordnetenkammer eigens mit der parlamentarischen Gruppe des Parti radical das Gespräch gesucht hatte, hatte versucht, den linken Flügel seiner Partei von einer gemeinsamen Aktion mit der SFIO, die sich für die Abschaffung der Reservistenübungen einsetzte, abzuhalten, und hatte an sie appelliert, die Abstimmungsdisziplin zu wahren ${ }^{441}$. Mit seinem Appell an die Abstimmungsdisziplin schnitt Her-

440 Vgl. J.O., Chambre des Députés vom 11. 7. 1932, S. 2613 und Le Temps vom 13. 7. 1932, S. 4.

441 Zur Diskussion zwischen Herriot und der parlamentarischen Gruppe siche Le Temps vom 13. 7. 1932, S. 3. 
riot einen neuralgischen Punkt an, denn bereits Daladier, der Ende der zwanziger Jahre den Versuch unternommen hatte, die radikalsozialistische Fraktion diesbezüglich zu disziplinieren, war daran kläglich gescheitert. Die Freiheit des Abgeordneten, das nicht-imperative Mandat, gehörte zu den konstitutiven Elementen der radikalsozialistischen Doktrin, die die Abgeordneten des Parti radical leidenschaftlich verteidigten ${ }^{442}$. François Albert, der Sprecher der parlamentarischen Gruppe des Parti radical, kam Herriot insofern entgegen, als er ihm beruhigend versicherte, daß „la fraction avancée du groupe radical se rallierait certainement à sa majorité pour soutenir le gouvernement dans le cas où la question de confiance serait posée." 443

Die Tatsache, daß die Regierung Herriot nur mit Hilfe der rechtsliberalen Kräfte ihre Finanzmaßnahmen durchsetzen konnte, kommentierte Bergery mit bitterer Ironie indem er erklärte, daß die Union des gauches, die die Wahlen 1932 gewonnen hatte, sich nun endlich formiert habe - wenn auch in der Opposition ${ }^{444}$. Diese Differenzen innerhalb des Parti radical manifestierten erneut deutlich, daß die Heterogenität des Parti radical groß war und es weder einer linken Mehrheit noch einer rechten Mehrheit in der Partei gelang, sich langfristig dergestalt durchzusetzen, daß sie die politische Richtung der Partei inhaltlich definitiv festlegen konnte. Herriot hatte 1924/1925 gestützt auf eine linke Mehrheit im Parti radical und mit Hilfe des Cartel des gauches versucht, eine erfolgreiche Regierungspolitik zu gestalten. 1932 ging er den umgekehrten Weg und hoffte, den Parti radical, dieses Mal gestützt auf eine gemäßigte Mehrheit in der radikalsozialistischen Partei, auf eine Position der Mitte festzulegen. Aber auch dieser Versuch führte nicht zum angestrebten Ziel, denn zum einen spitzte sich die Auseinandersetzung zwischen der Regierung bzw. Herriot und der innerparteilichen Opposition im Parti radical zu, die sich personell in einem Duell Herriot - Bergery auf dem Parteitag im Oktober 1932 entlud. Und zum anderen gelang es Herriot nicht, den Verlust der sozialistischen Unterstützung durch eine dauerhafte rechtsliberale Unterstützung auszugleichen; diese wurde ihm nur punktuell gewährt.

\section{Die zunehmende Opposition des linken Flügels innerhalb des Parti radical im Herbst 1932}

Der Parteitag des Parti radical, der vom 3. bis 6. November $1932^{445}$ in Toulouse stattfand, geriet zur großen Auseinandersetzung zwischen dem rechten und dem linken Flügel, d.h. es kam zum Duell zwischen Herriot und Bergery, der als großer Gegner Herriots auf diesem Parteitag auftrat. Auffallend war, daß die innerparteiliche Opposition sich zahlreich zu Wort meldete; denn gewöhnlich wurde im Vorfeld eine Auswahl an Rednern getroffen, die unter dem Gesichtspunkt erfolgte, einen gewissen Konsens zwischen den Flügeln herzustellen. Die politische

$442 \mathrm{Vgl}$. hierzu Unterpunkt 1 des 2. Prozeßbeispiels.

${ }^{443}$ Le Temps vom 13. 7. 1932, S. 3.

444 S. Berstein, Parti radical, vol. 2, S. 243.

$44529^{e}$ Congrès du Parti républicain radical et radical-socialiste tenu à Toulouse les 3, 4, 5, 6 novembre 1932, Paris 1932. Vgl. dazu aber auch die Berichterstattung in L'Oeuvre vom 3. 11.-7.11. 1932, jeweils S. 1, 2, 4. 
Diskussion auf dem Parteitag wurde durch die Eröffnungsrede des Abgeordneten Delbos ${ }^{446}$ eingeleitet, der über die allgemeine Politik sprach und dabei besonders auf die Rolle des Parti radical in der Geschichte der Dritten französischen Republik bzw. des parlamentarischen Systems einging und auch gleichzeitig an die damit verbundene Verantwortung erinnerte ${ }^{447}$. Obwohl er auf die radikalsozialistische Doktrin rekurrierte und die Einheit der Partei zu stärken versuchte, räumte er auch das Recht auf kritische Auseinandersetzung mit der Regierungsarbeit ein und eröffnete damit der innerparteilichen Opposition den Weg zur kritischen Diskussion mit der Parteiführung. Nachdem Delbos sich überwiegend auf die Rolle des Parti radical im politischen System Frankreichs und auf die bisherigen Erfolge der Partei konzentriert hatte, brachte der nachfolgende Redner Jacques Kayser ${ }^{448}$ deutlich kritische Töne in die Debatte ein. Kayser kritisierte vor allem die Bestrebungen innerhalb der Partei, eine neue politische Orientierung für den Parti radical in einem Regierungsbündnis der concentration zu suchen. Er erinnerte an den Wahlerfolg der Union des gauches von 1932 und appellierte an die Verantwortung der Radikalsozialisten gegenüber dem Wählerwillen. Außerdem verwies er darauf, daß die Mehrheit der Union des gauches zahlenmäßig noch nie so groß war wie 1932 und daraus auch verschiedene Pflichten für die Mitglieder dieses politischen Bündnisses resultierten. 1924 sei das Bündnis der Linkskräfte gescheitert, weil es durch seinen Wahlsieg die Stabilität der Mehrheit überschätzt habe, nun aber, warnte er, solle man nicht einen ähnlichen Fehler begehen und die Stabilität der Mehrheit unterschätzen ${ }^{449}$. Kayser kritisierte zwar Herriot nicht direkt, dennoch zeigten seine Ausführungen deutlich, daß er eine Allianz mit den Linkskräften als politische Konsequenz aus den Wahlen von 1932 für richtig gehalten hätte ${ }^{450}$. Neben diesen Kritikpunkten spielte er auch auf die von der Regierung praktizierte Finanz- und Wirtschaftpolitik an, die er, wenn er es auch nicht offen aussprach, nicht für den richtigen Weg hielt; vielmehr forderte er neue Lösungen, um die anhaltende Wirtschaftskrise zu bewältigen ${ }^{451}$.

Verglichen mit dem nachfolgenden Redner Gaston Bergery schienen die Einwände Kaysers noch sehr gemäßigt, denn Bergerys Urteil fiel wesentlich härter aus, wie er selbst gleich zu Beginn seiner Rede zugab452. Bergery unterzog zunächst die Außenpolitik Herriots schärfster Kritik. In seinen Augen hatte Herriot

446 Vgl. hier auch die Berichterstattung über die Rede Delbos auf dem Parteitag in L'Oeuvre vom 4. 11. 1932, S. 1, 4.

${ }^{447}$ Ebenda, S. 1.

${ }^{448}$ Kayser gehörte zur Gruppe der Jeunes Turcs innerhalb des Parti radical und galt hier als einer der führenden Köpfe der jüngeren Generation. Zu Kayser siehe auch seinen Nachlaß in A.N. Paris, 465 AP/ 1-6, Papiers Kayser. Zu Jacques Kayser: B. Béthouart, La vie politique en France, hommes et débats: 1930-1960, in: Revue d'histoire moderne et contemporaine 43 (1996), S. 5-167. Kayser selbst hat sehr wichtige Publikationen zur französischen Politik vorgelegt: J. Kayser, La paix en péril, Paris 1931; derselbe, L'affaire Dreyfus, Paris 1946; derselbe, Mort d'une liberté, Paris 1955; derselbe, Les grandes batailles du radicalisme 1820-1901. Des origines aux portes du pouvoir, Paris 1962.

${ }_{449} \mathrm{Zu}$ den Ausführungen Jacques Kaysers siehe L'Oeuvre vom 4. 11. 1932, S. 4.

450 Zitat aus der Rede Kaysers: „Notre devoir, c'est d'être fidèles aux élections. A majorité de gauche, gouvernement de gauche et majorité de gauche! (...) Pour la première fois dans l'histoire de la troisième République, les partis de gauche, les vrais forment à la Chambre la majorité absolue."; L'Oeuvre vom 4. 11. 1932, S. 4.

451 Ebenda.

${ }_{452} \mathrm{Zu}$ den Kritikpunkten Bergerys siehe L'Oeuvre vom 4. 11. 1932, S. 4. 
in allen drei Aspekten der Außenpolitik versagt: 1) Bei den Verhandlungen von Lausanne, 2) mit der Reaktion auf den Vorschlag Hoovers in der Moratoriumsfrage und 3) bei den Verhandlungen zur Abrüstung und in der Sicherheitsdebatte. Gleichzeitig legte Bergery seine Lösungsvorschläge vor: 1) Aufgabe der Reparationsforderungen, 2) sofortige Abrüstung und 3) Revision der Verträge. Als besonders nachteilig für Frankreich hielt Bergery die Haltung Herriots bei den Verhandlungen von Lausanne, bei denen dieser einen "solde" für Frankreich erkämpfte, anstatt der Streichung der Reparationen zuzustimmen. Mit seinem Verhalten habe Herriot dem Image Frankreichs international sehr geschadet, weil er damit Frankreich in ein sehr ungünstiges Licht gerückt habe ${ }^{453}$. In seine Vorwürfe gegen die Regierung bezog er auch die Finanzpolitik ein, die er für undemokratisch hielt. Fundamental griff er an, daß sich das Wahlergebnis in keiner Weise in der jetzigen Politik niederschlage, sondern vielmehr die Politik der vorausgegangenen konservativen Regierung fortgesetzt werde. Er rückte damit Herriot in eine politische Linie mit seinen konservativen Vorgängern Tardieu und Laval. Genauso monierte er die Kontinuität an der Spitze von Polizei und Armee, da nach den Wahlen kein personeller Wechsel stattgefunden habe ${ }^{454}$. Neben den politischen Inhalten bemängelte Bergery auch die innerparteiliche Struktur bzw. den Habitus im Parti radical und attestierte einen Mangel an innerparteilicher Demokratie, denn es gäbe keinen Raum für eine offene innerparteiliche Opposition: „Alors, il sera dit qu'on peut parler ici que pour chanter les louanges du gouvernement? C'est ça le Parti radical?" 455

Der schonungslose Angriff, den Bergery gegen Herriot führte, gipfelte in der ketzerischen Frage: „Il s'agit de savoir si un gouvernement est là pour servir les idées du parti qui le soutient, ou bien pour entraîner le parti à abandonner ses idées?" 456 .

Bergery spielte mit dieser Frage auf einen der Gründerväter des Parti radical, Camille Pelletan, an ${ }^{457}$. Mit diesem massiven Angriff gegen den Parteivorsitzenden, den er in die Nähe der reaktionären wie der antirepublikanischen Kräfte rückte, hatte Bergery eindeutig den Bogen überspannt und schadete der innerparteilichen Opposition, da Herriot die Sympathie der Parteimehrheit auf seiner Seite wußte, schon bevor er zu den Attacken Bergerys Stellung nehmen konnte ${ }^{458}$.

Atmosphärisch war die Stimmung auf dem Parteitag nach dem Beitrag von Bergery sehr aufgeheizt. Mit großer Sympathie erwarteten die Parteidelegierten die Replik Herriots, der sogleich zum Rednerpult schritt. Zu Beginn seiner Rechtfertigung schüttelte er ganz beiläufig zunächst den Vorwurf der Kontinuität in Poli-

453 Ebenda.

454 Bergery spielte dabei auf den Präfekten Chiappe und General Weygand an, die beide in der linken Presse als Symbolfiguren der antirepublikanischen Strömungen galten. Chiappe verkörperte die Polizeidiktatur und Weygand galt als Exponent der Antidreyfus-Generalstäbe, gegen die der Parti radical bereits vor mehr als 40 Jahren gekämpft hatte; vgl. S. Berstein, Parti radical, vol. 2, S. 246.

455 Ebenda.

$45629^{\mathrm{e}}$ Congrès du Parti républicain radical et radical-socialiste von 1932, S. 58-90, hier S. 73.

$457 \mathrm{Zu}$ Camille Pelletan: G. Berstein/S. Berstein (Hg.), Dictionnaire historique de la France contemporaine, vol. 1: 1870-1945, S. 597/598.

$458 \mathrm{Vgl}$. hierzu auch die Aufnahme der Attacken Bergerys in radikalsozialistischen Presseorganen, wie z. B. La Dépêche de Toulouse vom 4. 11. 1932, S. 1/2 und vom 5. 11. 1932, S. 1, 2, 4, die Bergery bescheinigten, daß er die Grenzen bei weitem überschritten habe. 
zei und Armee ab, indem er lapidar anführte, daß er als Chef der Polizei nur den Bürger Chautemps ${ }^{45}$ und als Chef der Armee nur den Bürger Paul-Boncour 460 kenne. Hinsichtlich der historischen Anspielung auf Pelletan bemerkte Herriot, daß dieser sich - im Gegensatz zu Bergery - keiner "répugnante démagogie“ bemächtigt habe. In einem zweiten Schritt setzte sich Herriot Punkt für Punkt mit den Vorhaltungen Bergerys in rhetorisch sehr geschicktem, höchst pathetischem Ton auseinander. So ging er nacheinander auf die als antidemokratisch bezeichneten Maßnahmen zur Sanierung des Staatshaushaltes ein sowie auf seine außenpolitische Konzeption, die er bei den Verhandlungen von Lausanne und Genf verfolgt hatte. Herriot verstand es rhetorisch sehr gewandt, sich als Retter der Rechte Frankreichs zu stilisieren: „Je suis, citoyens, pour l'organisation internationale. Mais je demande pour la France sa part de justice. En défendant son intérêt, c'est aussi célui de tous les peuples que défend la France. Et, je vous le déclare sans aucune équivoque, je n'accepterai jamais de capituler. Je vous le demande, citoyens, ne vous contentez pas de solutions verbales, de solutions de paresse, de complaisance. Si vous voulez me suivre dans l'accomplissement de mon rude et douloureux devoir, dans dix ou quinze ans, quand je ne serai plus, vous n'aurez pas à rougir de l'homme que j'aurai été." 461

Anhand dieses fulminanten Finales wird deutlich, wie Herriot die Delegierten für sich einzunehmen vermochte. Als Herriot die Vertrauensfrage stellte, stimmte eine überwältigende Mehrheit per Hand dafür. Nur einige wenige Gegenstimmen aus der innerparteilichen Opposition blieben noch übrig. Auch André Guerin, der über den Parteitag in L'Oeuvre Bericht erstattete, wertete bereits diese Abstimmung als Entscheidung für Herriot und gegen die innerparteiliche Opposition ${ }^{462}$. Im weiteren Verlauf des Parteitages standen vor allem zwei Themenbereiche im Mittelpunkt: 1) Finanz- und Wirtschaftmaßnahmen zur Bewältigung der Wirtschaftskrise und 2) Friedenssicherung und Abrüstungspolitik ${ }^{463}$. Neben diesen politischen Inhalten wurde erneut die Forderung nach Einführung der Abstimmungsdisziplin zur Diskussion gestellt. Auslöser dafür war vor allem das abweichende Votum der radikalsozialistischen Fraktion über die Reservisteneinsätze und die damit von Herriot verbundene Vertrauensfrage ${ }^{464}$. Aber auch auf dem Parteitag von 1932 wurde deutlich, daß eine Forderung nach strikter Abstimmungsdisziplin sich im Parti radical nicht durchsetzen ließ, da sie mit einem Grundwert der radikalsozialistischen Doktrin, dem nicht-imperativen Mandat, nicht vereinbar war, welches die radikalsozialistischen Abgeordneten stets vehement verteidigten ${ }^{465}$. Vor allem Jammy Schmidt setzte sich gegen diese Bestrebungen einiger Parteimitglieder zur Wehr ${ }^{466}$. Immerhin konnte eine Minimallösung in

\footnotetext{
459 Chautemps war Innenminister im Kabinett Herriot.

${ }^{460}$ Paul-Boncour stand dem Kriegsministerium im Kabinett Herriot vor.

${ }^{461}$ Replik Herriots auf dem Parteitag vom 3. 11. 1932 in L'Oeuvre vom 4. 11. 1932, S. 4.

$462,(. .$.$) et on a bien l'impression que dès ce premier soir la partie, au congrès de Toulouse, est jouée et$ gagnée" in: L'Oeuvre vom 4. 11. 1932, S. 4.

${ }_{463} \mathrm{Zu}$ den Diskussionsbeiträgen darüber siehe L'Oeuvre vom 6. 11. 1932, S. 1, 4.

${ }^{464} \mathrm{Vgl}$. dazu den entsprechenden Abschnitt in Unterpunkt 6 dieses Fallbeispiels II.

${ }_{465}$ Zur Debatte über die Abstimmungsdisziplin siehe L'Oeuvre vom 5. 11. 1932, S. 1, 4.

${ }_{466}$ Zur Argumentation Jammy Schmidts siehe L'Oeuvre vom 5. 11. 1932, S. 1; La Dépêche de Toulouse vom 5. 11. 1932, S. 1: „Sur la question de la discipline nous sommes entièrement d'accord et, depuis la présidence de Daladier, elle a toujours été respectée à de rares unités près. Il ne faut pas
} 
dieser Diskussion gefunden werden, die allerdings auch nur von der Hälfte der Delegierten befürwortet wurde. Man einigte sich darauf, daß jedes Mal, wenn die Regierung sich vor dem Parlament zu verantworten habe, die radikalsozialistische Fraktion entscheiden sollte, ob sie die Frage nach der Abstimmungsdisziplin stellen wolle ${ }^{467}$.

Obwohl sich Herriot im Duell mit Bergery durchsetzen konnte, wurde in der Schlußresolution den Vorstellungen des linken Flügels Rechnung getragen. Dies schlug sich im Festhalten an der Union des gauches, der Überwindung der Wirtschaftskrise mittels einer gelenkten Wirtschaft und der Friedenssicherung und der Abrüstung im Rahmen des Völkerbundes als Ziele der Außenpolitik ${ }^{468}$ nieder. Herriot konnte sich auf diesem Parteitag zwar behaupten, dennoch machte die Schlußresolution deutlich, daß die Partei nicht geschlossen den politischen Zielen Herriots zustimmte, sondern ihm vielmehr nur dank seiner Autorität gegen Bergery gefolgt war. Es gab eine kleine, aber qualitativ starke innerparteiliche Opposition im Parti radical.

Eine wirkliche Entscheidung über die politische Richtung innerhalb des Parti radical wurde auf dem Parteitag nicht getroffen, aber trotz der kontroversen Debatten versuchte man, durch die Schlußresolution verbal ein gewisses Gleichgewicht der Flügel innerhalb der Partei herzustellen. Herriot, der die Mehrheit für sich gewinnen konnte, beurteilte den Parteitag in Toulouse sehr optimistisch: „On y compris la nécessité de certains sacrifices et il n'est pas douteux que cette compréhension confère au gouvernement une autorité encore accrue dans les décisions à prendre prochainement. " 469 Noch während des Parteitages hatte sich der exponierteste Kontrahent Herriots, Bergery, zurückgezogen. Spekulationen deuteten an, daß er die Partei verlassen werde, da er sich politisch nicht mehr mit dem Parti radical identifizieren könne ${ }^{470}$. Die kommenden Monate sollten zeigen, wie gestärkt die Regierung Herriot wirklich aus diesem Parteitag hervorgegangen war.

\section{Die Unterstützungspolitik der SFIO für die Regierung Herriot trotz Divergenzen in der Außen- und Finanzpolitik}

Obwohl Herriot das sozialistische Angebot für eine Zusammenarbeit auf Regierungsebene abgelehnt hatte, sprach Blum im Namen der sozialistischen Fraktion $^{471}$ in der Aussprache über die Regierungserklärung der neuen Regierung Herriot am 7. Juni 1932 das Vertrauen aus. Dennoch unterließ er nicht, bereits auf vorhandene Divergenzen in einzelnen Politikfeldern zwischen der Regierung und der SFIO hinzuweisen ${ }^{472}$. In einem weiteren Schritt spezifizierte er die Meinungsverschiedenheiten und erläuterte die Ziele der SFIO. 1) Eine neue Abrüstungs-

oublier que nous sommes un parti de liberté et que nous ne posons nous-mêmes la question de discipline (...)."

467 Ebenda, S. 4.

${ }_{468}$ Zur Schlußresolution siehe L'Oeuvre vom 6. 11. 1932, S. 1, 4.

${ }^{469}$ L'Oeuvre vom 8. 5. 1932, S. 1.

$470 \mathrm{Vgl}$. dazu einen kurzen Artikel in L'Oeuvre vom 7. 11. 1932, S. 4.

${ }_{471}$ Zur Intervention Blums während der Regierungsdebattc siehe Le Temps vom 9. 6. 1932, S. 3.

${ }^{472}$ Blum formulierte hier sehr vorsichtig, daß „(...) des divergences de vues pourront subsister" $\mathrm{zwi}$ schen seiner Partei und dem Kabinett Herriot; ebenda. 
und Wirtschaftspolitik Frankreichs bei internationalen Verhandlungen; 2) Festlegung geeigneter Maßnahmen zur Wiederherstellung des budgetären Gleichgewichts. Abschließend erklärte Blum, daß die sozialistische Fraktion für die Regierung Herriot votiere, da die Sozialisten sich verpflichtet fühlten, dem Wählerwillen vom Mai 1932 Rechnung zu tragen, denn die Wahlen waren von den Linkskräften des französischen Parteienspektrums gewonnen worden ${ }^{473}$.

Trotz dieser Erklärung war von Anfang an klar, daß die Stabilität der Linksmehrheit in der Kammer fragil war und es bei bestimmten Sachthemen zwischen den Sozialisten und der radikalsozialistischen Regierung spätestens mittelfristig zum Bruch kommen würde. Gleich zu Beginn des Regierungsantrittes Herriots lösten Maßnahmen zur Wiederherstellung des budgetären Gleichgewichts gröBere Divergenzen aus, was sich in der Finanzkommission und später bei der Haushaltsdebatte in der Kammer fortsetzen sollte.

\section{Konfliktfeld: Finanzpolitik}

Im sozialistischen Lösungsansatz der Finanzprobleme trat die eigentliche und größte Differenz zwischen der Regierung Herriot und den Sozialisten symptomatisch zutage. Die Sozialisten hatten die seit 1932 im Finanzbereich praktizierte Deflationspolitik stets vehement abgelehnt, da sie diese Methode nicht für geeignet hielten, die Auswirkungen der Weltwirtschaftskrise in Frankreich wirksam zu bekämpfen. Vor allem Blum stand der Deflationspolitik ablehnend gegenüber, da sie seiner Meinung nach die eigentlichen Ursachen der Wirtschaftskrise nicht beheben konnte, denn das Fehlen des budgetären Gleichgewichts werde als Grund für die Krise gesehen, sei aber vielmehr die Folge der Krise. Infolgedessen hielt Blum den Ansatz, das Finanzbudget mit deflationistischen Maßnahmen auszugleichen, für ungeeignet. Er verglich diese Methode mit einer Art Sisyphusarbeit, da man das vorhandene Defizit zwar abbauen wolle, jedoch mit der Deflationspolitik dieses Defizit stets vergrößere. In seinen Augen konnte sich ein gesundes Gleichgewicht erst dann einstellen, wenn die Wirtschaft Frankreichs wieder gesundet war. Diesen Moment sah er gegeben, wenn der Konsum sich wieder auf sein normales Niveau eingependelt hatte. Dann stelle sich der regulierende Mechanismus ein, denn die Einnahmen würden wieder steigen und das Gleichgewicht würde damit automatisch wiederhergestellt werden ${ }^{474}$.

Konsequenterweise führe aber eine ständige Politik nach den oben dargelegten Prämissen zu einer steten Verminderung der Einkommen, dies wiederum mußte die Folgewirkung nach sich ziehen, daß die Kaufkraft sank und ein Rückgang der Nachfrage an Verbrauchsgütern einsetzte. Daraus resultiere dann konsequenterweise ein verstärkter Rückgang der Investitionstätigkeit. Da die Deflationspolitik von Blum und der Mehrheit der Sozialisten derart kritisch beurteilt wurde, war es offensichtlich, daß sie die Finanzmaßnahmen der Regierung Herriot nicht billigen konnten, sondern sich hier eine größere Diskrepanz auftat, die die Sozialisten in Opposition zur Regierung Herriot brachten.

473 Ebenda.

474 G. Ziebura, Blum, S. 285. 
Wie nicht anders zu erwarten, war es bereits in der Finanzkommission von seiten der Sozialisten, aber auch von Vertretern des linken Flügels der Radikalsozialisten zu heftiger Kritik an der Finanzvorlage der Regierung gekommen ${ }^{475}$. Während der Finanzdebatte in der Abgeordnetenkammer meldeten sich dann für die Sozialisten Renaudel476, Auriol477 und Blum ${ }^{478}$ mit grundsätzlicher Kritik zu Wort. Zum einen forderte die sozialistische Fraktion die Abschaffung der Reservisteneinsätze und zum anderen setzte sie sich gegen eine Erhöhung der Getränkesteuer für Kaffee ein ${ }^{479}$. Kurz vor der entscheidenden Abstimmung über die Budgetvorlage der Regierung begründete Blum nochmals nachdrücklich, warum die sozialistische Fraktion gegen den Regierungsentwurf stimmen werde. Er führte an, daß die von der Regierung vorgesehenen Maßnahmen nicht zur Lösung der vorliegenden Finanzprobleme führten, sondern nur den psychologischen Effekt hätten, das Vertrauen der Anleger wiederherzustellen, und damit kurzfristig für ein Gleichgewicht des Budgets sorgen würden. Die Sozialisten jedoch sahen die eigentlichen Probleme damit nicht gelöst: „(...) le grand péril c'est la marche croissante des moins-values et le vrai problème qui se pose, c'est de ranimer la vie économique du pays. " 480 Auriol wiederholte nochmals seine Forderung an die Regierung, die Bilanzen des französischen Staatshaushaltes ab dem 1. Juni 1932 zu veröffentlichen, um zu zeigen, welche Schulden von den Vorgängerregierungen übernommen worden seien. Außerdem drohte er an, falls diese Forderung nicht erfüllt werde, „(...) le groupe s'abstiendra ou même votera contre l'émission supplémentaire de Bons du Trésor." 481

$\mathrm{Da}$ aber die Forderung nach der Abschaffung der Reservisteneinsätze - wie bereits mehrfach erwähnt - keine Mehrheit im Parlament finden konnte, denn Herriot lehnte sie ab und stellte darüber gleichzeitig auch die Vertrauensfrage, stimmten die Sozialisten, wie angekündigt, gegen die Finanzvorlage der Regierung. Blum unterließ es jedoch nicht, in seiner Rechtfertigung des Abstimmungsverhaltens der sozialistischen Fraktion rhetorisch sehr geschickt zu bedauern, daß sich keine Einigung zwischen der Regierung Herriot und den Sozialisten im Bereich der Finanzpolitik erzielen ließ ${ }^{482}$.

Obwohl sich hier schon eine unüberbrückbare Differenz offenbart hatte, versuchten die Sozialisten unter Blum zunächst noch an der Regierung Herriot festzuhalten, besonders da sie sich auf dem außenpolitischen Feld einen gemeinsamen

475 A.N. Paris, Commission des Finances, C 14990, Sitzungen vom 4. 7. 1932 und vom 7. 7. 1932; später auch in A.N., Paris, Commission des Finances, C 14991, Sitzungen vom 20.10. 1932; vom 25. 10. 1932 und vom 27. 10. 1932.

476 Vgl. dazu Le Temps vom 13. 7. 1932, S. 3.

477 Le Temps vom 12.7. 1932, S. 8.

${ }^{478}$ Le Temps vom 13. 7. 1932, S. 3. Vgl. aber auch die verschiedenen Leitartikel, die Blum im Zusammenhang mit der Finanzpolitik in Le Populaire vorgelegt hat: Le Populaire vom 4. 7. 1932, vom 9. 7. 1932, vom 14. 7. 1932, jeweils S. 1 .

479 Vgl. Le Temps vom 12. 7. 1932, S. 8.

480 Vgl. Le Temps vom 13. 7. 1932, S. 8.

481 Vgl. Le Temps vom 17. 7. 1932, S. 6. Die Forderung, die Bilanzen zu veröffentlichen, hatte Auriol bereits im Ausschuß der Finanzen aufgeworfen, wo sie auch befürwortet worden war.

482 „Vis-à-vis de vous, nous faisions fléchir volontairement notre opposition de principe pour une pensée politique, parce que nous désirons, sincèrement, croyez-le, vous aider, vous faire vivre, parce que vous étiez pour nous le gouvernement qui incarnait la volonté du suffrage universel, telle qu'elle s'était manifestée le 1er et le 8 mai“ in: Le Populaire vom 13. 7. 1932, S. 3. 
Erfolg erhofften. Dennoch grenzte Blum in seiner Rede in Romans am 24. Juli 1932 klar ab, wie weit die Tolerierungspolitik der Sozialisten gegenüber der Regierung Herriot gehen würde: "Jamais le Parti radical n'a tenté ses chances au pouvoir dans de meilleures conditions, avec un gouvernement aussi homogène, réunissant tous ses chefs. Nous le soutiendrons tant qu'il restera fidèle à son programme. ${ }^{483}$

\section{Zunehmender Dissens zwischen SFIO und Parti radical auch in der Außenpolitik}

Im Vergleich zu 1924 herrschte 1932 auch in der Außenpolitik zwischen den Sozialisten und der Regierung Herriot weniger Konsens. Dennoch hielt sich die SFIO mit ihrer Kritik zunächst noch zurück, weil sie erst die Verhandlungsergebnisse von Lausanne und Genf abwarten wollte. Das Verhandlungsergebnis von Lausanne beurteilten die Sozialisten unter einem zweifachem Aspekt: Zum einen bewerteten sie die Verhandlungen an sich als positiv und erfolgreich, da sie in ihren Augen eine Fortsetzung bzw. eine Wiederbelebung des Geistes von Locarno darstellten ${ }^{484}$. Zum anderen standen sie dem materiellen Ergebnis äußerst kritisch gegenüber, denn ihrer Meinung nach hätte erstens die Regelung der Reparationsfrage viel früher erfolgen müssen und zweitens war es auch in Lausanne noch nicht zu einer definitiven Lösung dieser Problematik gekommen, da die Vereinbarungen alle durch die Einfügung der Vorbehaltsklausel vom Handeln Amerikas abhängig gemacht wurden. Wie das Handeln Herriots in Lausanne letztlich zu bewerten sei, hänge von Amerika ab. Für den Fall, daß Amerika die „versements forfaitaires" akzeptieren würde, hätte sich für Frankreich die Schuldenfrage definitiv geklärt und Herriot könnte sich rühmen, ein großer Diplomat zu sein. Die Sozialisten hielten sich während der Anhörung Herriots am 13. Juli 1932 vor den beiden wichtigsten Kommissionen, der für außenpolitische Angelegenheiten und der Finanzkommission, zurück. Lediglich Vincent Auriol stellte in der anschließenden Diskussion verschiedene juristische Detailfragen, die aber im Vergleich zu den Beiträgen Bergerys, der an der Verhandlungsstrategie und dem -ergebnis Herriots massive Kritik übte, keinen ernsthaften Angriff darstellten. Das vorläufige Ergebnis von Lausanne stieß bei den Sozialisten auf Zustimmung.

Ein weiterer Grund für die Bereitschaft der SFIO, die Regierung Herriot zu unterstützen, lag vor allem in der Hoffnung der SFIO, mit dieser Regierung zu neuen Ergebnissen bei der Abrüstungskonferenz in Genf zu kommen. Um zu verstehen, welche Erwartungen die Sozialisten an die Verhandlungen von Genf knüpften, muß kurz geklärt werden, welche Bedeutung die Sozialisten dem Völkerbund in ihrer außenpolitischen Konzeption beigemessen haben, bzw. welche politische Vorstellung die SFIO über Organisation, Aufgabe und Funktion dieser

${ }^{483}$ Le Populaire vom 25. 7. 1932, S. 2.

${ }^{484}$ Siche Le Populaire vom 10.7. 1932 und vom 16. 7. 1932. Außerdem muß hier auch die Position der Sozialisten in der Kammerdebatte vom 16. 7. 1932 herangezogen werden. Zur Problematik der außenpolitischen Konzeption der SFIO in der Zwischenkriegszeit siehe R. Gombin, Les socialistes et la guerre. La SFIO et la politique étrangère française entre les deux guerres mondiales, hier insbesondere S. 120-150. 
Einrichtung entwickelt hatte. Der exponierteste Vordenker der SFIO, Léon Blum, äußerte sich bereits 1925 in zwei ausführlichen Reden ${ }^{485}$ dezidiert zur Konzeption des Völkerbundes. Die Forderung nach einer funktionierenden internationalen Organisation, die durch Abrüstung und Schiedsgerichtsbarkeit Sicherheit gewährt, beruhte auf Blums Erkenntnis, daß nur noch im Rahmen einer internationalen Solidarität die wesentlichen Probleme bewältigt werden könnten, da die einzelnen Nationen diese umfangreichen Aufgaben nicht mehr zu leisten vermochten. Damit der Völkerbund allerdings funktionieren konnte, hielt Blum es für unerläßlich, daß ihm einige Kompetenzen, die bisher im nationalen Kompetenzbereich lagen, überantwortet würden.

Obwohl Blum sich im Laufe der zwanziger und dreißiger Jahre kontinuierlich für den Völkerbund eingesetzt hatte, war selbst innerhalb der SFIO die Haltung gegenüber dieser Organisation nicht homogen. Stellvertretend sei hier auf die Auseinandersetzung von 1926/27 um die Tätigkeit Paul-Boncours als Vertreter Frankreichs beim Völkerbund verwiesen, die innerparteilich besonders auf dem Parteitag der SFIO in Lyon vom 17. bis 20. April 1927486 zu heftigen Diskussionen $z$ wischen dem linken ${ }^{487}$ und rechten ${ }^{488}$ Parteiflügel geführt hatte. Trotz verschiedener Enttäuschungen ${ }^{489}$ hinsichtlich der Funktionsfähigkeit des Völkerbundes hielt Blum es für seine Aufgabe, die sozialistische Partei anzuhalten, sich für den Völkerbund einzusetzen. Blums zentrales Interesse am Völkerbund konzentrierte sich auf zwei essentielle Aufgabenbereiche: die Schiedsgerichtsbarkeit und die Abrüstung. Beide Punkte hielt er für unerläßliche Faktoren, um den Frieden in Europa und die Sicherheit Frankreichs wahren zu können. Während Blum bis 1930 in seiner Konzeption die Schiedsgerichtsbarkeit ${ }^{490}$ im Rahmen des Völker-

${ }^{485}$ Blum sprach zu diesem Thema im Parlament am 3. 2. 1925, vgl. J.O., Chambre des Députés vom 4. 2. 1925, S. 526-533, und auf dem Kongreß der Sozialistischen Internationale, der vom 22.-27.8. 1925 in Marseille stattfand, vgl. Le Populaire vom 31. 8. 1925, S. 1-3.

486 Zum Parteitag der SFIO vom April 1927 vgl.: 24e Congrès National à Lyon de 17-20 avril 1927, Paris 1927 und die Berichterstattung in Le Populaire vom 17. 4.-21. 4. 1927, jeweis S. 1, 2, 4.

${ }^{487}$ Der linke Flügel, repräsentiert durch Zyromski und Bracke, hatte einen Antrag formuliert, in dem die zweifache Problematik thematisiert wurde: 1) Die Tatsache, daß ein Sozialist die Politik einer rechten Regierung im Völkerbund zu vertreten hatte, schien äußerst problematisch und 2) der Völkerbund selbst wurde kritisch gesehen, da diese Organisation nach Ansicht des linken SFIOFlügels das Produkt eines imperialistischen Friedens und einer ebensolchen Politik war; vgl. Le Populaire vom 20. 4. 1927, S. 1, 4 und das Parteitagsprotokoll der SFIO von 1927 in: 25e Congrès National à Toulouse, 26.-30. 5. 1928, S. 11-13.

${ }^{488}$ Der rechte Parteiflügel hingegen, der durch Emile Kahn und Grumbach vertreten wurde, beurteilte den Völkerbund sehr positiv und hielt ihn vor allem für entwicklungsfähig; vgl. Le Populaire vom 20.4. 1927, S. 1 und das Parteitagsprotokoll der SFIO von 1927 in: 25e Congrès National à Toulouse 26.-30. 5. 1928, S. 5-11.

489 Z.B. äußerte sich Blum im März/April 1927 äußerst kritisch darüber, daß England und Frankreich den italienisch-jugoslawischen Krieg um Albanien nicht vor das Schiedsgericht des Völkerbundes brachten, nur weil sie wußten, daß Mussolini sich dem Urteil dieses Gremiums nicht unterwerfen wollte. Blum sah darin eine schwere Mißachtung der Autorität und des Ansehens des Völkerbundes; vgl. dazu Le Populaire vom 24. 3. 1927, S. 1 und Le Populaire vom 5. 4. 1927 und vom 18.4. 1927, jeweils S. 1, sowie auch G. Ziebura, Blum, S. 312.

490 Blum war zunächst davon überzeugt, daß eine fundierte Grundlage für den Völkerbund geschaffen werden mußte, die auf dem Abschluß möglichst zahlreicher und umfangreicher universaler Schiedsgerichtsabkommen basieren sollte. Er äußerte sich zu dieser These in verschiedenen Leitartikeln im Populaire vom 22. 9. und 23.9. 1927, vom 8.10., vom 11.10., vom 14. 10 und vom 13. 11. 1927, jeweils S. 1. 
bundes im Vergleich zur Abrüstung für bedeutender hielt, kam er zu Beginn der dreißiger Jahre zu einem deutlichen Wandel in seinem Urteil. Mehr und mehr kam er zu der Überzeugung, daß die Abrüstung die wichtigere Aufgabe des Völkerbundes sei.

Der Grund für diesen Paradigmawechsel im Denken Blums hing mit der Entwicklung des Völkerbundes zusammen. Ein Schlüsselerlebnis für Léon Blum stellte dabei das Scheitern des Genfer Protokolls ${ }^{491}$ zur friedlichen Streitschlichtung dar. Da die Regierungen diesem Text nicht folgten, glaubte Blum, daß der Völkerbund nur dann gerettet werden könne, wenn er sich die europäische Abrüstung zur Aufgabe mache. So rückte in den Überlegungen Blums zum Völkerbund immer mehr der Abrüstungsgedanke in den Mittelpunkt; nur auf dieser Grundlage sah er eine wirkliche Möglichkeit, den Frieden zu realisieren. Die Abrüstungsthematik dominierte das Konzept, das Blum von der Organisation eines kollektiven Sicherheitssystems entwickelt hatte.

Im Zeitraum zwischen November 1930 und Februar 1931 legte Blum in mehr als 35 Artikeln ${ }^{492}$ seine Konzeption dar. Alle seine Forderungen, wie z. B. Revision der Friedensverträge ohne Kriegsrisiko, Abschaffung von geheimen Allianzen und die Verhinderung der deutschen Aufrüstung, fußten auf dem Prinzip der progressiven Abrüstung. Wichtig war in diesem Zusammenhang auch, daß es gelang, der Öffentlichkeit eine Abrüstung zu vermitteln, die keine neuen Sicherheitsmaßnahmen erforderlich machte, sondern ohne sie auskam. Blum stand dem Argument, nur in einer sich ständig perfektionierenden Bewaffnung könnten Garantien für ein kollektives Sicherheitssystem gewährleistet werden, ablehnend gegenüber. Er stellte sich dabei in die Tradition von Jaurès, der bereits argumentiert hatte, daß „die Waffen zum Krieg führen und nicht der Krieg die Waffen erzeuge. “493 Darin lag für Blum eine weitere Bestätigung seiner Erkenntnis, daß die Abrüstung die zentrale Säule des kollektiven Sicherheitssystems bilden mußte. Dem zweiten Prinzip, der Schiedsgerichtsbarkeit, mangelte es in seinen Augen an Effizienz. Zwar war er der „pazifistischen Diplomatie“ grundsätzlich nicht abgeneigt, sah aber dennoch ganz deutlich die Schwächen dieses Mechanismus. Denn mehrere Prämissen mußten gegeben sein, um ein erfolgreiches Handeln zu garantieren. Zum einen setzte das System der Schiedsgerichtsbarkeit voraus, daß es allgemeine und universale Verbindlichkeit besaß, und zum anderen mußte die Sicherheit durch Garantien und Sanktionen gewährleistet sein. Genau hierin lag zugleich die Schwäche des Systems, da diese Prämissen in der letzten Konsequenz weder eingefordert noch abgesichert werden konnten. Das ganze Sicherheitssystem basierte auf einem Vertragsnetz unter den Staaten, das nie eine absolute Absicherung garantieren konnte. Auch die von Frankreich erhobene Forderung, eine

491 Zum sogenannten "Genfer Protokoll“ vom 2.10. 1924 siehe das Protokoll zur friedlichen Regelung internationaler Konflikte bei K. Schwendemann, Abrüstung und Sicherheit, Bd. 1, Leipzig 21933 , S. 510-522.

492 Alle Artikel sind in Le Populaire zwischen dem 18.11. 1930 und dem 6. 2. 1931 erschienen. Sie wurden zusammenhängend in der Broschüre "Les problèmes de la paix", Paris 1931, publiziert. Diese Broschüre erschien auch in deutscher Sprache: Ohne Abrüstung kein Friede. Die französische Sozialdemokratie im Kampf um die Organisation des Friedens, Berlin 1931.

493 Vgl. G. Ziebura, Blum, S. 314. 
Völkerbundsarmee einzurichten, konnte nach Meinung Blums keine wirkliche Sicherheit geben. Die Idee der Einführung einer Völkerbundsarmee implizierte zu viele Komplikationen: 1) Eine Völkerbundarmee schien nur sinnvoll, wenn die nationalen Streitkräfte aufgegeben würden, denn eine Koexistenz zwischen nationalen und Völkerbundarmeen schien ihm praktisch unmöglich; 2) Als Grundlage für die Schaffung eines solchen Organs war eine militärische Einheit unabdingbar und dies wiederum setzte eine politische Einheit voraus; 3 ) Außerdem ging von einer Völkerbundsarmee die Gefahr aus, daß sie sich zugunsten der bestehenden Ordnungsmacht auch in innenpolitische Konflikte einmischen könnte, z.B. bei einer Revolution.

So räumte Blum der Abrüstung Priorität ein, was innerhalb der SFIO nicht unumstritten war.

Der rechte Flügel der SFIO hielt nicht die Abrüstung für einen geeigneten Weg, um den internationalen Frieden zu sichern, sondern befürwortete dezidiert die Schaffung einer internationalen Armee. Außerdem setzte er sich sehr für den Völkerbund ein, weil er durch ihn nicht nur die internationale Sicherheit, sondern auch die Frankreichs gewährleistet sah. Er glaubte, der Völkerbund könne mit Hilfe einer Armee den Frieden sichern ${ }^{494}$. Der rechte Flügel hielt an dieser Lösung auch nach den Enttäuschungen über das Genfer Protokoll fest. Hierin unterschied sich der rechte Flügel um Renaudel nicht nur von Blum, sondern auch vom linken Flügel wesentlich, da letzterer der Idee einer Völkerbundsarmee äußerst mißtrauisch gegenüberstand. Als Blum sich in seinem Sicherheitskonzept immer mehr auf die Abrüstung fixierte und er definitiv die Idee einer internationalen Armee ablehnte, setzten sich Vertreter des rechten Flügels wie Paul-Boncour dazu öffentlich in Opposition ${ }^{495}$.

Die Abrüstungsfrage hatte innerhalb der sozialistischen Partei mehrere Entwicklungsphasen durchlaufen. In den Jahren von 1918 bis 1924 vertrat die sozialistische Partei die Ansicht, daß nach der Unterzeichnung des Versailler Friedensvertrages die ersten außenpolitischen Schritte der Abrüstung gelten müßten, und Frankreich eine Vorreiterrolle zu spielen habe, da es als Siegermacht aus dem Krieg hervorgegangen war, außerdem über militärische Stärke verfügte und somit mit gutem Beispiel vorangehen konnte. Die ersten vier Jahre nach dem Krieg standen ganz unter der Maxime der allgemeinen und gleichen Abrüstung. Die Forderung nach einer progressiven Verkürzung der Militärzeit auf acht Monate gehörte zum festen Kanon der sozialistischen Außenpolitik ${ }^{496}$. Erstaunlicherweise nahm die Radikalität der sozialistischen Forderung etwas ab, als Herriot 1924 die Regierung übernahm und die SFIO ihm ihre Unterstützung gewährte. Dennoch nahm das Thema Abrüstung weiterhin einen wichtigen Platz ein, wenn es auch mit weit weniger Radikalität verfolgt wurde. Die Sozialisten sprachen sich dafür aus, daß die Abrüstungsdebatte auf einer internationalen Konferenz geführt werden sollte.

494 Siehe dazu Paul-Boncour in Le Populaire vom 25.9. 1924 und vom 2. 10. 1924, jeweils S. 1, aber auch Renaudel in La Vie socialiste vom 21. 7. 1928, S. 1.

495 R. Gombin, Les socialistes et la guerre, S. 155.

496 Ausführlich zur Außenpolitik der SFIO in der Zwischenkriegszeit bei R. Gombin, Les socialistes et la guerre, hier besonders S. 136-139. 
In der Zwischenzeit betrieben sie weiterhin Propaganda für eine Teilabrüstung. 1928 kam es in der SFIO hinsichtlich dieser Thematik zu einer weiteren Zäsur. Da die Sozialisten beobachten mußten, daß die Vorbereitungen für die Genfer Konferenz nur sehr schleppend vorangingen, setzten sie sich verstärkt für eine allgemeine Abrüstung, die auf internationaler Ebene vorbereitet und durchgesetzt werden sollte, ein. Konsens herrschte bei einem großen Teil der SFIO über folgende Punkte: 1) Frankreich müsse in der Abrüstungsfrage die Initiative ergreifen und die führende Rolle einnehmen, da es die stärkste Militärmacht, Deutschland hingegen abgerüstet und das Rheinland neutralisiert sei. 2) Unilateral oder simultan, die Abrüstung müsse auf jeden Fall nach dem Prinzip der Reduzierung und nicht nach dem der Limitierung vonstatten gehen; 3) Durch strikte Kontrollen müsse diese Abrüstung überwacht werden, entweder in Form einer Herstellungsoder einer Budgetkontrolle. Alle diese Komponenten sollten auf einer internationalen Konferenz verhandelt werden.

Ab 1930/1931 brachen die Differenzen zwischen dem rechten Flügel und dem Rest der Partei, der weitgehend den Standpunkt Blums adaptiert hatte, wieder stärker auf. Dabei handelte es sich nun nicht mehr um einzelne Aspekte des Völkerbundes, die unterschiedlich beurteilt wurden, sondern mittlerweile wurde das Gesamtsystem Völkerbund und sein Nutzen unterschiedlich bewertet. Blum und der Großteil der SFIO standen dem Völkerbund inzwischen sehr skeptisch gegenüber, auch wenn sie ihn der klassischen Diplomatie, die auf den Säulen Geheimdiplomatie und bilaterale Verträge ruhte, vorzogen. Der rechte Flügel um Renaudel hingegen verteidigte die Völkerbundidee leidenschaftlich. Die Divergenz im Hinblick auf den Völkerbund stand in engem Zusammenhang mit dem wesentlich umfassenderen Problem der Sicherheitsfrage. Ein Gegensatz zwischen dem Großteil der Partei und dem rechtem Flügel der SFIO war deshalb entstanden, weil die Mehrheit der Partei von ihrem ursprünglichen Standpunkt, daß Frankreich genug Sicherheiten besitze, um mit gutem Beispiel voranzugehen und einseitig abzurüsten, gegen Ende der zwanziger Jahre abgerückt war. Der rechte Flügel um Renaudel hielt die ursprüngliche Idee der einseitigen Abrüstung Frankreichs für Häresie, da sie die Unabhängigkeit Frankreichs angreife und die simultane Abrüstung ohne gewisse Grundvoraussetzungen, wie z.B. die Einrichtung einer internationalen Völkerbundsarmee, nicht durchführbar sei. Die innerparteiliche Opposition in der SFIO erstreckte sich auch auf die Frage der nationalen Verteidigung. Über diese Thematik wurde zu Beginn der dreißiger Jahre auf den Parteitagen der SFIO heftig und vor allem kontrovers diskutiert. Die Sicherheitsfrage und die nationale Verteidigung schied den rechten Flügel vom Rest der Partei und führte dazu, daß zunächst Paul-Boncour ${ }^{497}$ die Partei verließ und sich 1933 die Neosozialisten abspalteten.

497 Paul-Boncour trat nach dem Parteitag von Tours 1931 aus der SFIO aus, weil er die Resolution zur nationalen Verteidigung ablehnte. Hierzu ist im Nachlaß Paul-Boncour $424 \mathrm{AP} / 16$ ein interessanter Brief von Paul-Boncour vom 2.7. 1931 überliefert, wo er bereits diesen Austritt in Erwägung zog: „(...) mais encore faut-il qu'à l'heure grave où je suis, je sache exactement où elle nous mène, c'est-à-dire ce qui se passera si, dans l'hypothèse, non pas seulement possible mais probable, où le Parti s'orientant décidément dans une voie contraire à la politique que nous avons défendue, nous sommes obligés de quitter le Parti pour rester fidèles à cette politique." Ausführlich legte Paul- 
Vor dem Hintergrund des oben entwickelten Blumschen Standpunktes, dem die Mehrheit der Partei anhing, wird deutlich, wie sehr Blum von der Abrüstungskonferenz, die am 2. Februar 1932 in Genf eröffnet wurde, enttäuscht sein mußte, denn die konservative Regierung Tardieu, die den Tardieu-Plan vorlegte, schlug weder Maßnahmen zur Abrüstung noch zu einer Rüstungsbegrenzung vor. Die wenigen Punkte, die dieser Plan beinhaltete ${ }^{498}$, waren in Wirklichkeit von geringer Bedeutung. Aber viel schwerwiegender war nach Meinung Blums, daß Tardieu als Vorbedingung für eine Abrüstung nicht realisierbare Sicherheitsgarantien forderte, z.B. den Abschluß von Schiedsgerichtsverträgen oder die Errichtung einer Völkerbundsarmee, die im Einklang mit den Friedensverträgen zum Einsatz kommen sollte ${ }^{499}$. Da der Tardieu-Plan sich mit Überlegungen Paul-Boncours und Renaudels deckte, kommentierte der rechte Flügel der SFIO ihn in seinem Presseorgan La vie socialiste sehr freundlich ${ }^{500}$. Nachdem Blum vom französischen Angebot sehr enttäuscht war, schöpfte er neue Hoffnung, als der amerikanische Präsident Hoover ${ }^{501}$ seinen Vorschlag zur Diskussion stellte. Blum erblickte darin einen Schritt zur Rüstungsreduzierung und damit in Richtung Friedenssicherung502. Der Vorschlag Hoovers konnte sich auf der Genfer Konferenz gegen den Plan Tardieus behaupten, jedoch wurde eine endgültige Entscheidung auf einen Zeitpunkt nach den Wahlen in Frankreich vertagt.

Nach dem Wahlsieg der Linkskräfte in Frankreich setzte Blum große Hoffnung in die Genfer Konferenz, denn seiner Meinung nach sollte man sich nun ganz darauf konzentrieren, das Prinzip „Gleichheit in der Abrüstung“ zu etablieren, um nicht der Forderung Deutschlands "Gleichberechtigung in der Aufrüstung “ folgen zu müssen. Blum sah es als Aufgabe der Genfer Konferenz, zwischen diesen beiden Prinzipien zu entscheiden ${ }^{503}$. Daher befürwortete Blum auch das neue Hoover-Memorandum, das der amerikanische Präsident bei den Genfer Verhandlungen im Juni 1932 einbrachte. Dieses Memorandum beinhaltete zwei verschiedene Kategorien von Abrüstung. Unter der erstgenannten Kategorie wurden konkrete Maßnahmen subsumiert, wie z.B. die Abschaffung und das absolute Verbot von Panzerwagen, schwerer mobiler Artillerie, Bombenflugzeugen und chemischen Waffen. Die zweite Kategorie umfaßte eine pauschale Reduzierung der ge-

Boncour in seinen Memoiren seine Entscheidung, aus der SFIO auszutreten, dar: J. Paul-Boncour, Entre deux-guerres. Souvenir sur la Troisième République. Bd. 2, S. 268-271.

${ }^{498}$ Zum französischen Abrüstungsplan Tardieus für die Abrüstungsverhandlungen vom 5. 2. 1932 in Genf siehe K. Schwendemann, Abrüstung und Sicherheit, Bd.1, S. 774-783. U. a. wurde vorgeschlagen, daß die gesamte zivile Luftfahrt und schwere Bombenflugzeuge dem Völkerbund unterstellt werden sollten. Dies betraf Nationen, die eine starke Zivilluftfahrt besaßen, aber keine militärische Luftwaffe, somit blieben die militärischen Apparate der Nationen unangetastet.

${ }^{499}$ Diese Konditionen sind unter Punkt III, Schaffung einer internationalen Streitmacht, aufgeführt; vgl. K. Schwendemann, Abrüstung und Sicherheit, S. 779/780.

$500 \mathrm{Vgl}$. Renaudel in La Vie socialiste vom 19. 3. 1932, S. 1.

501 Zum Vorschlag Hoovers bzw. zur Hooverbotschaft vom 22. 6. 1932 siehe K. Schwendemann, Abrüstung und Sicherheit, S. 820-823.

502 Zum Urteil Blums über den Vorschlag Hoovers auf der Genfer Abrüstungskonferenz siehe L'Oeuvre de Léon Blum, Bd. 3.2, Paris 1972, S. 196-225 und zum kritischen Urteil Blums über den Abrüstungsplan Tardieus Le Populaire vom 13.4.-15. 4. 1932 und vom 28. 4. 1932, jeweils S. 1.

${ }^{503}$ Le Populaire vom 13.6. 1932, S. 1.: „Le principe de l'égalité peut s'entendre en deux acceptions bien différentes: égalité par le réarmement de l'Allemagne, et c'est ainsi que la réaction allemande le comprend; égalité par le désarmement progressif de toutes les nations, et c'est ainsi que la socialdémocratie et l'Internationale l'ont toujours compris." 
samten Land- und Seestreitkräfte. Blum begrüßte summa summarum das HooverMemorandum, obwohl er einräumte, daß es gewisse Lücken aufwies. So fehlten seiner Meinung nach das Verbot der Waffenherstellung und des privaten Waffenhandels oder auch die Internationalisierung der zivilen Luftfahrt. Außerdem merkte Blum an, daß komplementäre Maßnahmen, wie die Einrichtung einer mit den nötigen Machtmitteln versehenen Kontrollinstanz, die eine unerläßliche Maßnahme aller Abrüstungskonventionen darstellte, fehlen würden 504 . Trotz dieses Mangels stellte der Vorschlag für Blum eine ernsthafte Verhandlungsbasis dar für die Errichtung eines Systems kollektiver Sicherheit, denn vor allem proklamierte er das Prinzip der sogenannten „Interdependenz der Waffen“, worauf die französische Öffentlichkeit stets größten Wert legte. Blum betrachtete es als Aufgabe Frankreichs, diese Chance augenblicklich zu nutzen, um unter französischer Führung den Frieden zu sichern ${ }^{505}$.

In zahlreichen Leitartikeln zwischen dem 13. Juni und dem 31. Juli $1932^{506}$ versuchte Blum, der französischen Öffentlichkeit nahe zu bringen, welch große Chancen die Zustimmung Frankreichs zum Hoover-Memorandum in sich barg. Als Herriot aber dem Hoover-Memorandum nicht zustimmte, sondern neue Sicherheitsgarantien forderte ${ }^{507}$, bedauerte Blum zutiefst, daß Frankreich diese große Chance ungenutzt vorübergehen ließ ${ }^{508}$. Vor diesem Hintergrund ist auch die Rede Blums vom 24. Juli 1932 in Romans zu werten, in der er die Frage aufwarf, ob Herriots Politik noch den Vorstellungen des französischen Volkes entspreche. Blum hoffte auf einen Sturz Herriots und die Regierungsübernahme durch die Sozialisten, um die Abrüstungsverhandlungen vorantreiben zu können: „Mais s'il devait être renversé, la règle parlementaire conduirait à confier le gouvernement au Parti socialiste, qui, loin de se dérober, revendiquerait, soit seul, soit avec des radicaux, les responsabilités du pouvoir et aurait la volonté de réaliser, conformement aux mêmes indications du suffrage universel, certaines réformes essentielles et notamment batterait l'effort pour le désarmement. “509

${ }^{50+}$ Blum in seinem Leitartikel in Le Populaire vom 23. 6. 1932, S. 1.

505 Blum formulierte in diesem Leitartikel sehr pathetisch: „(...) nous crions aux hommes qui ont mandat de répondre au nom de la France: ,Ne vous obstinez pas davantage. Dites oui, Dites oui sans nouveau retard. Dites oui sans restriction et sans réticence. Ne discutez plus que pour combler les lacunes. N'amendez que pour étendre et améliorer' (...) Et nous ajoutons à part nous: ,Ah! Si c'était la France qui eut ait cela!'; vgl. ebenda.

506 Blum bezog in folgenden Leitartikeln für das Hoover-Memorandum leidenschaftlich Stellung: Le Populaire vom 24. 6. 1932, vom 10. 7. 1932, vom 16. 7. 1932, vom 20. 7. 1932, vom 23., 24., 26., 27., 28. und 31. 7. 1932, jeweils S. 1.

${ }^{507}$ Darstellungen zur Genfer Konferenz: S. Nadolny, Abrüstungsdiplomatie 1932/33, S. 90-189; M. Geyer, Die Konferenz für die Herabsetzung und Beschränkung der Rüstungen und das Problem der Abrüstung, in: J. Becker/K. Hildebrand (Hg.), Internationale Beziehungen in der Weltwirtschaftskrise 1929-1933, München 1980, S. 155-202; G. Craig, Die Regierung Hoover und die Abrüstungskonferenz, in: ebenda, S. 101-127; E. W. Bennett, German Rearmament and the West 1932-1933, Princeton 1979, S. 131-207; M. Vaisse, Sécurité d'abord. La politique française en matière de désarmement. 9 décembre 1930-17 avril 1934, Paris 1981,S. 180-276; zur speziellen Position und den Forderungen Herriots vgl. die entsprechenden Abschnitte in Unterkapitel 4 dieses Prozeßbeispiels II. Zur Position der Sozialisten siehe R. Gombin, Les socialistes et la guerre, S. 148.

${ }^{508}$ Le Populaire vom 24. 6. 1932, S. 1: „Voilà pourquoi nous déplorons amèrement que les représentants de la France n'y aient pas adhéré spontanément qu'ils aient pas adhéré le bénéfice de cette adhésion immédiate. “

509 Le Populaire vom 25. 7. 1932, S. 1/2, hier S. 2. 
Trotz dieser Zweifel und der Vorbehalte der Sozialisten gegenüber der Politik Herriots bei den Genfer Verhandlungen ${ }^{510}$ unterstützte die sozialistische Fraktion die Regierung weiterhin, denn sie setzte große Hoffnungen auf einen neuen Abrüstungsplan, den die französische Regierung in Genf vorlegen wollte. Im Hinblick auf die innenpolitische Entwicklung Deutschlands ${ }^{511}$ schien den Sozialisten eine Einigung in Abrüstungsfragen dringlicher denn je.

Als Herriot sich am 28. Oktober 1932 im Parlament zu den Verhandlungen bzw. zum neuen französischen Plan für Genf äußerte, beteiligten sich auch die Sozialisten an der Kammerdebatte, und trotz unterschiedlicher Gewichtung einzelner Schwerpunkte sprach sich Blum im Namen der sozialistischen Gruppe für den Vorschlag der französischen Regierung aus, was sich auch in der Abstimmung niederschlug.

Unterschiedliche Auffassungen zwischen den Sozialisten und der Regierung Herriot gab es in der Festlegung des Schwerpunktes. Während für die Sozialisten die Abrüstungsfrage entscheidend war, legte Herriot den Hauptakzent auf die kollektive Sicherheit und deren Garantie. Blum trat grundsätzlich für die von Deutschland geforderte "Gleichheit der Rechte" ein, denn er räumte ein, daß die besiegten Mächte durch den Versailler Friedensvertrag in eine unterlegene Position gedrängt worden waren. Für ihn war klar, daß diese Situation nur vorübergehender Natur sein konnte. Blum rechtfertigte die Forderung Deutschlands mit dem Prinzip der politischen Moral, nach der alle Nationen gleich an Rechten und an Pflichten sein sollten ${ }^{512}$. Um eine Wiederaufrüstung Deutschlands zu verhindern, forderte Blum aber gleichzeitig die progressive Abrüstung, die auf dem Prinzip der absoluten Gleichheit beruhen sollte. Er propagierte vor allem, daß der neue Plan, den Frankreich in Genf vorlegen würde, so konzipiert sein müsse, daß er die größtmögliche Zustimmung der anderen Nationen erhalte. Dann sei Deutschland gezwungen, sich dafür oder dagegen zu entscheiden. Für den Fall, daß Deutschland sich weigern würde, würde es sich dem allgemeinen Konsens widersetzen. Trotz der veränderten innenpolitischen Situation der Weimarer Republik hatte Blum ein positives Deutschlandbild, denn die Anhänger der Demokratie und die Arbeiterschaft seien noch immer ernstzunehmende Kräfte in der Weimarer Republik, auch wenn sie im Moment in ihrem Handlungsradius durch das Bündnis zwischen Stahlhelm und Hitler sehr eingeschränkt seien. In den Augen Blums hatten die demokratischen Kräfte und die Arbeiterschaft großen Mut bewiesen, weil sie zu Beginn der Weimarer Republik durch ihren Einsatz einen Bür-

510 Im Leitartikel des Populaire vom 31. 7. 1932, S. 1 legte Blum ausführlich die Differenzen zwischen Herriot und der SFIO in der Abrüstungsthematik dar.

511 Zur Zeit der Genfer und Lausanner Konferenzen fungierte Franz von Papen als Reichskanzler. Zu seiner Regierungsbildung und zum Urteil der Parteien über die Regierung von Papen siche M. Zahn, Öffentliche Meinung und Presse während der Kanzlerschaft von Papens, Münster 1953, S. 63-70; E. R. Huber, Deutsche Verfassungsgeschichte seit 1789, Bd. 7: Aufbau, Schutz und Untergang der Weimarer Republik, Stuttgart 1984, S. 971-994; G. Schulz, Zwischen Demokratie und Diktatur, Bd. 3: Von Brüning zu Hitler, Berlin 1992, S. 859-866; S. 877-881.

512 Zur Intervention Blums in der Kammerdebatte vom 28. 10. 1932 siehe Le Temps vom 30. 10. 1932, S. 3; J.O., Chambre des Députés vom 28. 10. 1932, S. 2905-2910, hier besonders S. 2906-2909: hier setzte sich Blum vor allem für die Abrüstung ein, um die deutsche Wiederaufrüstung zu verhindern und um den Frieden zu sichern, wobei er Bezug auf Locarno nahm. 
gerkrieg verhindert hätten ${ }^{513}$. Seinen Beitrag schloß Léon Blum mit der für ihn grundlegenden Forderung nach einer allgemeinen Abrüstung, der generellen gegenseitigen Kontrolle und dem Verbot der privaten Herstellung von Waffen. AuBerdem sollten die Luftstreitkräfte abgeschafft und die zivile Luftfahrt internationalisiert werden. Besonders offensichtlich war die Differenz zwischen Herriot und den Sozialisten in der Einschätzung der Gefahr, die von der zunehmend problematischen Entwicklung in Deutschland ausging. Bei Herriot führte dies zu neuen Sicherheitsforderungen, bei den Sozialisten, vertreten durch Blum, war dies ein zusätzliches Argument für die Abrüstung. Der sozialistische Sprecher sicherte am Ende seiner Ausführungen der Regierung Herriot seine Zustimmung zu, merkte jedoch an, daß das nicht im Sinne einer Blankovollmacht zu verstehen $\operatorname{sei}^{514}$.

Herriot maß den Sicherheitsgarantien für Frankreich erstrangige Bedeutung bei. In der Abrüstungsfrage war er weit zurückhaltender als der sozialistische Sprecher, denn Herriot argumentierte, daß sich Frankreich seit dem Versailler Friedensvertrag mehr als jedes andere Land für die Abrüstung eingesetzt habe. Als Beweis dafür verwies er auf die drastische Verkürzung der Wehrdienstzeit, die von drei Jahren auf zunächst 18 Monate und nun sogar auf ein Jahr herabgesetzt worden sei515. In einem größeren Zusammenhang versuchte Herriot zu begründen 516 , warum für ihn die Frage der Sicherheit das Kernstück der Verhandlungen in Genf darstelle. Herriot begann mit einem Rückgriff auf seine Verhandlungen von 1924, als er einen breiten Konsens für sein Sicherheitskonzept herstellen konnte. Wie damals vertrat er auch 1932 die Devise „Abrüstung ja - aber nur nach gewährleisteter Sicherheit“. Warum die Sicherheitsfrage für Herriot 1932 noch dringlicher und essentieller war, begründete er zum einen mit der Vorsicht gegenüber Deutschland, das in Genf auf Gleichberechtigung gepocht hatte. In diesem Zusammenhang muß unbedingt auch das Deutschlandbild Herriots berücksichtigt werden, da es seine Grundhaltung zur Sicherheitspolitik erklärt. Der französische Ministerpräsident beäugte Deutschland äußerst kritisch und hielt die Forderung nach „l'égalité des droits" für eine geschickte Taktik der deutschen Politik, um die bisher heimliche Aufrüstung offen betreiben zu können. Ihm schien diese Terminologie äußert unpräzis zu sein und damit weitläufig interpretierbar, wie Herriot in seinen Ausführungen darlegte: „L'égalité des droits (...), elle renferme toutes sortes de sens. Et ce qui complique étrangement la difficulté à laquelle se heurtent les négociateurs dont je suis l'un, c'est que cette formule, qui séduit tant les foules, et en particulier une partie si importante de l'opinion britannique, par cette sorte d'appel qu'elle adresse à la conscience juridique du fait qu'elle enferme

513 Ebenda.

514 Ebenda.

515 Am 7. 8. 1913 wurde in einem Gesetz die Militärdienstzeit in Frankreich auf drei Jahre festgesetzt. Nach dem Waffenstillstand vom 11.11. 1918 wurde dieses Gesetz bereits nicht mehr strikt angewandt, da es zum einen keine Bedrohung mehr durch den Krieg gab und zum anderen wegen der durch den Krieg verursachten schwierigen Finanzlage Frankreichs. Am 1.4. 1923 erfolgte eine Festsetzung des Militärdienstes auf 18 Monate, der aber nochmals durch das Gesetz vom 31.3. 1928 auf ein Jahr reduziert wurde vgl. G. M. Chauveau, Le Service national, Paris 1990.

516 Herriot in seiner Kammerrede vom 22. 10. 1932 vgl. Le Temps vom 30. 10. 1932, S. 3; J.O., Chambre des Députés vom 28. 10. 1932, S. 2911-2914. 
ces deux mots chers au coeur des hommes: „égalité et droits“, couvre toute une série de solutions differentes. “517

Der zweite Grund für Herriots Vorsicht hing mit der veränderten Situation des Völkerbundes zusammen. Seiner Meinung nach hatte sich die Atmosphäre im Völkerbund im Vergleich zu 1924/25 gewandelt. Dies führte er einmal auf den Beitritt Deutschlands und Rußlands sowie auf die neue Haltung Italiens zurück. Einen weiteren Kritikpunkt Herriots stellte die zunehmende innenpolitische Komponente der Völkerbundpolitik dar, denn man böte Außenministern oder Regierungschefs Kandidaturen an, damit diese sich profilieren könnten. Alle diese von Herriot vorgebrachten Faktoren hatten seiner Meinung nach dazu beigetragen, die Institution „Völkerbund“ zu verändern. Nachdem Herriot seine Bedenken gegenüber der Abrüstungsforderung geäußert hatte, präsentierte er zum Schluß seiner Ausführungen dem Parlament den neuen Plan, den Paul-Boncour im Namen der französischen Regierung in Genf am 4. November 1932 vorlegen sollte. Frankreich erklärte sich darin bereit, eine kurze Militärdienstzeit für alle Landstreitkräfte unter folgenden acht Bedingungen zu akzeptieren: 1) daß die Reichswehr in Deutschland als bewaffnete Kraft aufgelöst werde; 2) daß eine internationale Kontrolle organisiert werde; 3) daß für den Ernstfall ein gegenseitiger Beistandspakt unter den europäischen Staaten abgeschlossen werde; 4) daß die Vereinigten Staaten Sicherheitsgarantien zustimmen, die sie selbst vorgeschlagen haben; 5) daß alle Mitgliedstaaten des Völkerbundes sich bereit erklären, den Artikel 16 des Paktes, der Sanktionen und kriegerische Maßnahmen gegen Aggressoren vorsah, zu erfüllen; 6) daß die Schiedsgerichtsbarkeit verpflichtend ist; 7) daß die Abrüstung wechselseitig ist; 8) daß die Staaten, die Kolonien haben, ihre Spezialkräfte weiterhin beibehalten können ${ }^{518}$.

Nach eingehender Debatte stimmte das Parlament über, den französischen Abrüstungs- und Sicherheitsplan ab. Folgender Beschluß, den Herriot mit der Vertauensfrage verband, wurde mit $425 \mathrm{zu} 25$ Stimmen gefaßt: Die Regierung Herriot wurde bevollmächtigt, sich auf der Genfer Konferenz einzusetzen für 1) die Einhaltung der im Völkerbundvertrag festgelegten Prinzipien, insbesondere Verurteilung jeglicher Aggression; 2) die effiziente Kontrolle der allgemeinen Reduzierung der Waffen und Ausdehnung der Befugnisse des Völkerbundes, um die Gleichheit der Völker im Hinblick auf die internationale Sicherheit zu gewährleisten; 3) die Abschaffung der privaten Waffenindustrie, die Kontrolle aller Waffenproduktionen sowie die Kontrolle des Handels mit Waffen- und Kriegsmaschinen in allen Ländern ${ }^{519}$.

Wie wichtig dem Großteil des französischen Parlaments die Sicherheitsthematik war, zeigte diese Abstimmung. Das Abstimmungsverhalten der einzelnen Gruppen war wie folgt:

\footnotetext{
517 Ebenda.

518 Vgl. J.O., Chambre des Députés vom 28. 10. 1932, S. 2914.

519 Siehe Ebenda, S. 2922.
} 


\begin{tabular}{rlrcrc}
\hline $\begin{array}{c}\text { An- } \\
\text { zahl }\end{array}$ & Parlamentarische Gruppe & Dafür & $\begin{array}{l}\text { Da- } \\
\text { gegen }\end{array}$ & $\begin{array}{l}\text { Enthal- } \\
\text { tung }\end{array}$ & $\begin{array}{l}\text { Abwe- } \\
\text { send }\end{array}$ \\
\hline 15 & Indépendants & 2 & 3 & 7 & 3 \\
41 & Fédération républicaine & 1 & 11 & 29 & - \\
18 & Groupe républicain et social & - & - & 17 & 1 \\
7 & Action économique, sociale et paysanne & 1 & - & 6 & - \\
34 & Centre républicain & - & - & 32 & 2 \\
29 & Républicains de gauche & 1 & - & 27 & 1 \\
16 & Démocrats populaires & 15 & - & 1 & - \\
6 & Républicains du centre & 6 & - & - & - \\
23 & Indépendants de gauche & 22 & - & 1 & - \\
48 & Gauche radicale & 36 & - & 8 & 4 \\
160 & Radicaux et radicaux socialistes & 155 & - & 1 & 4 \\
15 & Gauche indépendante & 14 & - & - & 1 \\
13 & Républicains socialistes & 13 & - & - & - \\
13 & Socialistes français & 12 & - & - & 1 \\
129 & Socialistes & 122 & - & 7 & - \\
9 & Unité ouvrière & 8 & - & 1 & - \\
10 & Communistes & - & 10 & - & - \\
28 & Isolés & 17 & 1 & 9 & 1 \\
\hline 614 & & 425 & 25 & 146 & 18 \\
\hline
\end{tabular}

Nachdem die SFIO noch am 28. Oktober 1932 bei der Vertrauensfrage für den französischen Abrüstungsplan gestimmt hatte, wandelte sich im November 1932 die Stimmung in der SFIO gegenüber dem Kabinett Herriot. Ausgelöst wurde dieser Stimmungsumschwung durch den Abrüstungsplan ${ }^{520}$, den Paul-Boncour am 5. November 1932 in Genf präsentierte. Nach eingehender Analyse durch Blum, die dieser in verschiedenen Leitartikeln im Parteiorgan Le Populaire ${ }^{521}$ vorgelegt hatte, zeigten sich grundsätzliche Differenzen in der Abrüstungsthematik zwischen den Sozialisten und der Regierung Herriot. Die Kritik, die Blum übte, war sowohl formaler wie grundlegend inhaltlicher Natur. Er kam zu dem Ergebnis, daß die einzelnen Vorschläge nicht auf eine Gleichberechtigung in der Abrüstung, sondern auf eine Gleichberechtigung in der Aufrüstung zielten. Dieses Resultat stand diametral entgegensetzt zu den Absichten, die die Sozialisten vertraten, weil Deutschland faktisch wieder aufgerüstet werde. Nach dem Plan PaulBoncours, der eine Vereinheitlichung der Heeressysteme zum Ziel hatte, hatte jeder Staat ein nationales Heer mit begrenzter Truppenstärke und kurzer Dienstfrist aufzustellen, was den Aufbau einer Berufsarmee ausschloß. Darüber hinaus sollte jeder Staat ein Kontingent für eine Völkerbundsarmee, das mit schweren Waffen ausgerüstet und den Charakter eines Berufsheeres haben sollte, stellen.

520 Zum Textlaut des französischen Abrüstungsplanes vom 14. 11. 1932 siehe K. Schwendemann, Abrüstung und Sicherheit, S. 849-862. Zur Genfer Konferenz ab Juni 1932 vgl. S. Nadolny, Abrüstungsdiplomatie 1932/33, S. 159-263. Außerdem zum französischen Abrüstungsplan Le Populaire vom 5. 11. 1932, S. 3.

521 Zur analytischen Auseinandersetzung Blums mit dem französischen Abrüstungsplan siehe Le Populaire vom 6.11., 17. 11., 20.11., 22.11,23.11., 24. 11., 27.11., 29. 11. und 30.11.1932 sowie vom 1.-8. 12. 1932, jeweils S. 1 . 
Nach Meinung Blums bildete der Konnex zwischen Abrüstung und der Errichtung eines kollektiven Sicherheitssystems die Achillesverse des französischen Planes, da allen Beteiligten klar sein mußte, daß ein kollektives Sicherheitssystem sich unter den gegenwärtigen Bedingungen kaum realisieren ließ. Dies entwertete nach Auffassung der Sozialisten den französischen Plan; damit fielen die durchaus positiven Ansätze wie die Annullierung der einseitigen Abrüstungsklauseln im Versailler Vertrag, das Streben nach Einheitlichkeit hinsichtlich des militärischen Status und die Abschaffung der Bomber nicht mehr sonderlich ins Gewicht. Besonders widersetzten sich die Sozialisten der Schaffung einer Berufsarmee, die sie stets abgelehnt hatten ${ }^{522}$.

Aber nicht nur die Sozialisten stellten zunehmende Divergenzen mit der Regierung fest, sondern auch innerhalb des Parti radical hatte sich eine Opposition um Bergery gebildet. Aus diesem Grund verfolgten die Sozialisten mit großer Erwartung den Parteitag der Radikalsozialisten vom 3. bis 6. November 1932 in Toulouse. Gleich zu Beginn des Parteitages wurde spekuliert, welche Mitglieder des Parti radical mit welchen Themen die Regierung in Bedrängnis bringen würden $^{523}$. Der Parteitag des Parti radical wurde als ein politisches Ereignis bewertet, das wie in den vergangenen Jahren weitreichende politische Konsequenzen für das Parlament und die Regierung haben könnte. Damit wurde auf den Parteitag von Angers von 1928 angespielt, als die radikalsozialistischen Minister aus der Regierung Poincaré aufgrund eines Parteitagsbeschlusses austreten mußten. Jedoch räumte der Autor des Artikels, Pierre Laine, ein ${ }^{524}$, daß die politische Situation von 1932 nicht mit der von 1928 vergleichbar sei und deshalb auch nicht mit solch spektakulären Ereignissen wie auf jenem Parteitag von 1928 zu rechnen sei. Dieses Mal stelle der Parti radical die Regierung und der amtierende Regierungschef sei gleichzeitig auch der Parteivorsitzende des Parti radical, der auf die Partei einen sehr ausgleichenden Einfluß ausübe. Aber viel schwerwiegender war seiner Meinung nach, daß der Parti radical mehr eine Partei der "cadres“ als der „militants“ war, was sich vor allem aus der Organisationsform ableite. Sie bestehe aus „comités“ und nicht aus „sections“ wie etwa die SFIO. Sogar Joseph Caillaux, einer der wichtigsten Repräsentanten des Parti radical, bezeichnete den Radikalismus folgendermaßen: „Le radicalisme n'était ni un parti, ni une doctrine, mais un état d'âme." 525

In der weiteren Berichterstattung über den Parteitag des Parti radical wird deutlich, daß die Sozialisten die innerparteiliche Opposition mit größter Aufmerksamkeit verfolgten und eine so weitreichende Gegenposition wie sie von Kayser, aber vor allem auch von Bergery bezogen wurde, nicht erwartet hatten ${ }^{526}$. Auch wenn sie anerkennend feststellten, daß Herriot sich trotz massiver Einwände des linken Flügels auf dem Parteitag durchsetzen konnte, hielten sie die

522 Vgl. dazu auch R. Gombin, Les socialistes et la guerre, S. 148.

523 Vgl. dazu Le Populaire vom 3. 11. 1932, S. 3: „Parmi les questions inscrites à l'ordre du jour du Congrès, trois d'entre elles ne manqueront pas de donner lieu à une discussion et ainsi de révéler sinon des oppositions nettes et tranchées, du moins certaines divergences apparentes."

524 Pierre Laine in Le Populaire vom 3. 11. 1932, S. 1, 3.

525 Ebenda, S. 1.

526 Le Populaire vom 4. 11. 1932, S. 1: „Le Congrès de Toulouse aura donc été plus important qu’on n'avait pu le supposer." 
Fortsetzung des radikalsozialistischen Parteitages für problematisch. Nach ihrem Parteiverständnis, das vor allem auch das Element der innerparteilichen Demokratie mit einbezog, war diese nun nicht mehr gewährleistet, da die Oppositionsstimmen von Bergery ${ }^{527}$ und Kayser ${ }^{528}$ keinerlei Eingang in die verschiedenen Resolutionen zu den einzelnen Politikfeldern, wie z. B. in die Resolution zur Finanzpolitik ${ }^{529}$, gefunden hatten. Besondere Aufmerksamkeit richteten die Sozialisten auch auf die Abrüstungsdebatte des radikalsozialistischen Parteitags, aus der unmißverständlich hervorging, daß Herriot auf keinen Fall in Genf Beschlüssen zustimmen würde, die die Sicherheitsfrage von der Abrüstungsthematik trennen würden ${ }^{530}$.

Obwohl die sozialistische Partei die Regierung Herriot trotz Divergenzen in der Außen- und Finanzpolitik weitgehend stützte, entstanden auch innerhalb der $S F I O$ von seiten des linken Flügels immer größere Vorbehalte, die auch öffentlich von Vertretern des linken Flügels wie Zyromski geäußert wurden. In einem Artikel in der sozialistischen Parteizeitung Le Populaire legte dieser seine Bedenken dar. Er monierte, daß die sozialistische Gruppe viel zu weitreichende Zugeständnisse gegenüber der Regierung Herriot mache. Anhand verschiedener Beispiele unterstrich er die vorhandene Divergenz zwischen den politischen Vorstellungen der Sozialisten und denen anderer Parteien. Er warnte vor einer zu großen Nachgiebigkeit, da das sozialistische Profil auf keinen Fall Schaden nehmen dürfe. Deshalb schloß er mit der Warnung: „En vérité, depuis notre dernier Congrès, les preuves expérimentales s'accumulent et va-t-on, le cas échéant, nous parler encore de participation ministerielle?" ${ }^{331}$ Nachdem nicht nur in der Finanzpolitik gröBere Differenzen zwischen dem Parti radical und der SFIO herrschten, sondern im November 1932 auch noch in der Außenpolitik die Meinungsverschiedenheiten immer größer wurden, drängte sich die Frage auf, wie lange die Sozialisten ihre Unterstützungspolitik noch aufrechterhalten würden.

\section{Das außenpolitische Scheitern Herriots und das Ende seiner Regierung am 14. Dezember 1932}

Am 14. Dezember 1932 stürzte die Regierung Herriot über die Abstimmung über die Schuldenzahlung an Amerika. Herriot hatte im Zuge der Verhandlungen von Lausanne, die zu einem Ende der Reparationszahlungen geführt hatten, gehofft, daß Amerika, England und Frankreich ebenfalls ihre interalliierten Schulden erlassen würde. Zusammen mit England stand Herriot über den französischen Botschafter in Washington, Paul Claudel, in ständigen Verhandlungen mit der amerikanischen Regierung. Ein großer Teil der französischen Abgeordneten hatte erwartet, daß mit der für den 15. Dezember 1932 von Amerika geforderten Zahlung

\footnotetext{
${ }_{527}$ Zur Rede Bergerys siehe Le Populaire vom 4. 11. 1932, S. 3.

528 Ebenda.

529 Le Populaire vom 5. 11. 1932, S. 1: „(...) il ne saurait plus être question de résolutions catégoriques après la manifestation d'attachement que le congrès a donnée à $M$. Herriot. C'est ainsi, que si le débat sur la politique financière a révélé de nombreuses oppositions aux projets financiers du Gouvernement, l'ordre du jour qui a voté en conclusion n'en tient aucun compte."

530 Ebenda.

531 Le Populaire vom 30. 11. 1932, S. 6.
} 
die interalliierte Schuldenfrage analog zur Reparationsfrage gelöst werden würde. Leider erfüllte sich diese Hoffnung nicht, sondern zerbrach jäh mit der Note, die die amerikanische Regierung am 8. Dezember 1932532 England zukommen ließ. Darin wies Amerika die Bitte Englands um eine Revision der interalliierten Schulden zurück. Trotz der enttäuschenden Antwort Amerikas hielt Herriot an seiner Position fest, d. h. er setzte sich für die Zahlung am 15. Dezember 1932 ein, weil er sich den Verträgen bzw. seinen Vertragspartnern gegenüber verpflichtet fühlte und, vor allem, weil er die Beziehungen Frankreichs zu Amerika nicht gefährden wollte ${ }^{533}$. Im Parlament setzte eine sehr lebhafte und kontroverse Diskussion ${ }^{534}$ ein, die sich auch innerhalb der parlamentarischen Gruppen fortsetzte. Die verschiedenen Standpunkte, die während der Kammerdebatte miteinander konkurrierten, hatten sich bereits in den Diskussionen über die Regierungsvorlage in der Kommission der Auswärtigen Angelegenheiten und der Finanzkommission herauskristallisiert ${ }^{535}$. Die Regierungsvorlage, die in beiden Kommissionen beraten worden war, sah folgende Lösung vor: 1) Die französische Regierung nimmt Kenntnis von der Antwort des amerikanischen Außenministers vom 8. Dezember 1932, in der die Regierung der USA einer Prüfung des französischen Revisionsverlangens durch den amerikanischen Kongreß und das amerikanische Volk zustimmt; 2) die französische Regierung fordert eine sofortige Eröffnung von Verhandlungen zur Revision der früher vereinbarten Regelung, da durch das von Hoover vorgeschlagene Moratorium eine neue Rechts- und Tatsachensituation geschaffen worden ist, die mit der früher getroffenen Regelung nicht mehr kompatibel ist; denn in Folge des Hoovermoratoriums wurden neue Ergebnisse erzielt, die zur Aufhebung der Reparationszahlungen geführt haben; 3) die Regierung Frankreichs wird am 15. Dezember 1932 19.261.432,50 Dollar überweisen. Sie verlangt, daß diese Zahlung auf die neu zu treffenden Vereinbarungen angerechnet werden; 4) außerdem teilt Frankreich der amerikanischen Regierung mit, daß, solange die durch das Moratorium geschaffene Situation anhält und kein neues allgemeines internationales Schuldenabkommen vereinbart wird, sich Frankreich de facto wie auch de jure außerstande sieht „de supporter désormais la charge d'un régime qui ne peut se justifier de bonne foi que par l'acquittement des réparations. “536

Die Punkte eins, zwei und vier dieses Kabinettsbeschlusses wurden von beiden Kommissionen angenommen ${ }^{537}$, nur Punkt drei stieß mehrheitlich auf Ableh-

532 Le Temps vom 11. 12. 1932, S. 1, 2. Zum Text der amerikanischen Note vom 8. 12. 1932 vgl. Le Temps vom 10.12. 1932, S. 1.

533 J.O., Chambre des Députés vom 13. 12. 1932, S. 3520-3531 und auch Le Temps vom 15. 12. 1932, S. $3 / 4$.

${ }_{534}$ Vgl. J.O., Chambre des Députés vom 13. 12. 1932, S. 3531/3532, die Sitzung wurde fortgesetzt am nächsten Tag, vgl. J.O., Chambre des Députés vom 14. 12. 1932, S. 3539-3585.

535 A.N. Paris, Commission des Finances, C 14991, Sitzung vom 9. 12. 1932, 10.12. 1932 und vom 13. 12. 1932. Diese Sitzungen wurden von der Commission des Finances wie auch der Commission des Affaires étrangères zusammen ausgerichtet.

${ }_{536}$ Zum Text dieser Regierungsvorlage siehe Le Temps vom 15. 12. 1932, S. 2.

537 Siehe hierzu die ausführlichen Verhandlungen in der Kommission der Finanzen und der Auswärtigen Angelegenheiten in der Sitzung vom 13.12. 1932; A.N. Paris, Commission des Finances, C 14991, Sitzung vom 13.12. 1932 und Commission des Affaires étrangères, C 14978, Sitzung vom 13. 12. 1932 . 
nung. Verschiedene Mitglieder der Finanzkommission, die unterschiedliche politische Parteien vertraten, reichten Vorschläge für Punkt drei ein. Letztlich erhielt in der Finanzkommission die Vorlage Auriols, der eine Verschiebung der französischen Zahlung vom 15. Dezember 1932 und die sofortige Einberufung einer internationalen Schuldenkonferenz forderte, mehrheitlich die Zustimmung. Immerhin wurde diese Eingabe mit 21 zu 14 Stimmen, überwiegend mit den Stimmen von Sozialisten und einigen Radikalsozialisten, befürwortet ${ }^{538}$, die anderen beiden Anträge wurden mehrheitlich abgelehnt ${ }^{539}$.

Die Regierungsvorlage, die die vier oben genannten Punkte enthielt, wurde nach den Beratungen in den beiden wichtigsten Kommissionen der Abgeordnetenkammer zur Diskussion und Abstimmung vorgelegt. Nachdem Punkt 3 der Regierungsvorlage bereits in der Finanzkommission und der Kommission der Auswärtigen Angelegenheiten abgelehnt worden war, fand er auch in der Deputiertenkammer keine Mehrheit und führte nach heftigen Debatten letztlich zum Sturz der Regierung Herriot.

Vincent Auriol vertrat auch während der Kammerdebatte im Namen der sozialistischen Fraktion den von ihm bereits in der Finanzkammer eingeführten Standpunkt, daß die Zahlungen Frankreichs an Amerika ${ }^{540}$ terminlich verschoben werden sollten. Aber auch die parlamentarische Rechte lehnte das Festhalten Herriots an der Zahlung vom 15. Dezember $1932 \mathrm{ab}$, wenn auch aus anderen Gründen als die Sozialisten.

Die parlamentarische Gruppe des Parti radical versammelte sich mehrmals an diesem 14. Dezember 1932, um über die bevorstehende Abstimmung zu beraten $^{541}$. Ein Teil der radikalsozialistischen Abgeordneten sprach sich aus Loyalitätsgründen für die Vorlage der Regierung Herriot aus, auch wenn es inhaltliche Differenzen gab. Innerhalb der radikalsozialistischen Gruppe brach erneut eine kontroverse Debatte aus, bei der sich Henri Clerc, Bertrand Nogaro, Gaston Bergery, Pierre Cot und George Bonnet zu Wort meldeten ${ }^{542}$. Bergery plädierte für eine Verweigerung der Zahlung. Pierre Cot hingegen sprach sich für die Haltung der Regierung aus, jedoch bemängelte er, daß Herriot nicht daran gearbeitet habe, alle Argumente zugunsten einer Zahlung mit unilateralem Vorbehalt ins Spiel zu bringen. Er verwies dabei auf das Vorbild Großbritannien, das seine Verhandlungen nach diesem Prinzip geführt habe. George Bonnet schloß sich dem Regierungsvorschlag an und appellierte an alle radikalsozialistischen Mitglieder, ihm zu folgen. Einige Mitglieder der radikalsozialistischen Gruppe vereinbarten, sich zu gesonderten Beratungen zurückzuziehen, da sie eventuell gegen die von der Regierung vertretene Lösung ${ }^{543}$ votieren wollten. Bevor es zur entscheidenden Abstimmung im Parlament kam, versammelten sich erneut einige parlamentarische

538 Vgl. dazu die Sitzung der Finanzkommission vom 13.12. 1932 in: A.N. Paris, Commission des Finances, C 14991, Sitzung vom 13. 12. 1932.

539 Es waren außerdem Vorschläge von Patenôtre-Desnoyers, Nogaro und Joseph Denais eingegangen; vgl. dazu ebenda.

540 Zum Redebeitrag Auriols während der Diskussion in der Deputiertenkammer siehe Le Temps vom 15. 12. 1932, S. 2.

541 Zur Fraktionssitzung des Parti radical siehe Le Temps vom 14. 12. 1932, S. 8.

542 Le Temps vom 14. 12. 1932, S. 8.

543 Zum Textlaut der Resolution der Regierung siehe Le Temps vom 15. 12. 1932, S. 2. 
Gruppen, um über ihr Abstimmungsverhalten zu beraten. Herriot stellte sich sogar nochmals seiner Fraktion für verschiedene Fragen zur Verfügung und zeigte sich verwundert, daß noch immer Widerstände gegen seine Regierungsvorlage vorhanden waren. Innerhalb der radikalsozialistischen Gruppe entstand erneut eine Debatte über die Abstimmungsdisziplin. Malvy regte an, daß diejenigen radikalsozialistischen Abgeordneten, die aus Amtsgründen, d.h. weil sie parlamentarische Ämter innehatten ${ }^{544}$, der Neutralität unterlagen, sich der Stimme enthalten könnten. Diese Forderung fand Zuspruch, d.h. die Amtsträger unterlagen keinem Fraktionszwang, aber generell wurde ein Gegenvotum abgelehnt. Bergery, der fest entschlossen war, gegen die Regierungsvorlage zu stimmen, verließ daraufhin die parlamentarische Gruppe des Parti radical.

In der sozialistischen Fraktion bestand ebenfalls Diskussionsbedarf ${ }^{545}$, da etwa 17 Mitglieder für die Regierung votieren wollten. Die sozialistische Fraktion entschied sich aber in einer internen Debatte, die Abstimmungsdisziplin einzuhalten. So stand fest, daß die SFIO gegen die Regierung stimmen würde, da sie sich während der Parlamentsdebatte dezidiert für eine Verschiebung der Zahlung an Amerika ausgesprochen hatte. Die Vorlage der Regierung wurde mit 402 zu 187 Stimmen ${ }^{546}$ abgelehnt, damit war das Kabinett Herriot gestürzt worden.

\begin{tabular}{rlrrrr}
\hline $\begin{array}{c}\text { An- } \\
\text { zahl }\end{array}$ & Parlamentarische Gruppe & Dafür & $\begin{array}{l}\text { Da- } \\
\text { gegen }\end{array}$ & $\begin{array}{l}\text { Enthal- } \\
\text { tung }\end{array}$ & $\begin{array}{l}\text { Abwe- } \\
\text { send }\end{array}$ \\
\hline 15 & Indépendants & - & 15 & - & - \\
41 & Fédération Républicaine & - & 40 & 1 & - \\
18 & Groupe républicain et social & - & 18 & - & - \\
7 & Action économique, sociale et paysanne & - & 7 & - & - \\
34 & Centre républicain & - & 33 & 1 & - \\
29 & Républicains de gauche & 4 & 25 & - & - \\
16 & Démocrates populaires & - & 16 & - & - \\
6 & Républicains du centre & - & 6 & - & - \\
23 & Indépendants de gauche & 7 & 15 & 1 & - \\
49 & Gauche radicale & 15 & 31 & - & 3 \\
160 & Radicaux et radicaux socialistes & 137 & 10547 & 11 & 2 \\
14 & Gauche indépendante & 1 & 13 & - & - \\
14 & Républicains socialistes & 6 & 7 & - & 1 \\
13 & Socialistes français & 10 & 1 & - & 2 \\
128 & SFIO & - & 127 & 1 & - \\
9 & Unité ouvrière & - & 9 & - & - \\
10 & Communistes & - & 10 & - & - \\
28 & Isolés & 7 & 19 & 2 & - \\
\hline 614 & & 187 & 402 & 17 & 8 \\
\hline
\end{tabular}

544 Z.B. war der Präsident der Deputiertenkammer zur Abstimmungsneutralität angehalten.

545 Zur Fraktionssitzung der SFIO siehe Le Populaire vom 14. 12. 1932, S. 1/2.

${ }_{546}$ Zur Abstimmung in der Abgeordnetenkammer siehe Le Temps vom 15. 12. 1932, S. 3.

${ }_{547}$ Folgende Abgeordnete des Parti radical stimmten gegen die Regierung Herriot: Bergery, Colomb, Creyssel, Dezarnaulds, Garat, Gratien, Grisoni, Martinaud-Deplat, Mendès-France, Romastin; siehe Le Populaire vom 15. 12. 1932, S. 3. 
Die Regierung Herriot, die seit Beginn ihrer Amtszeit in einem Dilemma steckte, scheiterte in dieser Abstimmung an den Gegenstimmen aus der sozialistischen Fraktion. Grundsätzlich gesehen standen die Sozialisten der Regierung Herriot wohlwollend gegenüber, aber in der Finanz- und Außenpolitik gab es gravierende Differenzen.

Die Gemäßigten und die Rechte hingegen votierten für die Finanzpolitik Herriots, standen aber grundsätzlich der politischen Richtung der Regierung Herriot äußerst reserviert gegenüber. Bei der Abstimmung um die Zahlung der Schulden Frankreichs an Amerika fanden sich die Sozialisten, die Gemäßigten und die Rechte, wenn auch aus vollkommen unterschiedlichen Motiven, in der Opposition gegen die Regierung zusammen. Auch innerhalb des Parti radical votierten zehn Mitglieder gegen die Regierungsvorlage, trotz der vorausgegangenen intensiven Diskussion um die Abstimmungsdisziplin.

Da der Sturz Herriots durch eine Opposition, die sich auf der einen Seite aus politischen Kräften der Rechten ${ }^{548}$ und der Gemäßigten, auf der anderen Seite aus der sozialistischen Partei zusammensetzte, herbeigeführt wurde, faßten Teile des Parti radical die Verantwortung für die politische Krise in die prägnante Formel „Blum-Marin"549. Léon Blum sah sich deshalb zu einer Stellungnahme im Populaire genötigt, um das sozialistische Votum dem Wähler gegenüber zu rechtfertigen. Blum hielt es für dringlich, die sozialistische Motivation für dieses Votum zu begründen, da sich die Gründe für das Nein der sozialistischen Fraktion grundlegend von denen der Rechten unterschieden. Er verwies darauf, daß die rechten politischen Kräfte die SFIO stets mit ihren Tiraden verunglimpften. Der essentielle Unterschied zwischen den Sozialisten und der Rechten bestand laut Blum darin, daß die rechten Kräfte mit diesem Votum ihren Nationalismus pflegten. Im Gegensatz dazu hatte sich die SFIO stets als Gegnerin aller nationalistischen Versuchungen ausgewiesen und war deutlich als Verfechterin internationaler Kooperationen aufgetreten. Aus diesem Grund wäre es nur verständlich gewesen, wenn die SFIO für die Zahlung gestimmt hätte, aber die sozialistische Fraktion war sich auch bewußt, daß sie mit diesem Votum nur dem rechten $\mathrm{Na}$ tionalismus Vorschub geleistet hätte, weil die rechten Kräfte aus der Zahlung Frankreichs an Amerika ein Recht auf deutsche Reparationszahlungen ableiteten. Damit wäre letztlich die Ratifikation des Lausanner Abkommens in Frage gestellt worden. Die SFIO sehe ihre Aufgabe darin, die Friedensarbeit der letzten 14 Jahre nicht zu gefährden, deshalb habe sie gegen die Regierungsvorlage gestimmt. Blum drückte die Beweggründe der SFIO sehr anschaulich aus: „Nous avons voulu, que l'on me passe l'expression, retirer au nationalisme français le pain de la bouche. Nous avons voulu préserver le travail de pacification internationale auquel l'effort du Parti est attaché dépuis quatorze ans." ${ }^{550}$ Blum unterließ es auch nicht, darauf hinzuweisen, daß sogar radikalsozialistische Ab-

\footnotetext{
5+8 Die Gegenstimmen von rechts kamen von den Gruppen um Tardieu und um Marin, vgl. dazu die Abstimmungstabelle.

${ }_{549}$ L'Ocuvre vom 15. 12. 1932, S. $1 / 2$.

s50 Blum in Le Populaire vom 15. 12. 1932, S. 1.
} 
geordnete zusammen mit Sozialisten in den beiden Kommissionen gegen die Regierungsvorlage gestimmt hatten 551 .

Blum wollte einen vollständigen Bruch mit dem Parti radical vermeiden. Der Parteivorsitzende der SFIO führte in einer kurzen Stellungnahme kurz nach dem Sturz Herriots aus, daß die momentane Regierungskrise darauf zurückzuführen sei, daß die beiden Parteien SFIO und Parti radical, die bisher zusammengearbeitet hatten, nun in Opposition zueinander geraten seien. Blum sah zur Behebung der Regierungskrise die Möglichkeit, daß beide Parteien wieder eine Zusammenarbeit anstreben sollten ${ }^{552}$, indem sie ein gemeinsames Programm, in dem sozialen Reformen und vor allem der Abrüstung zentrale Bedeutung eingeräumt werden müsse, ausarbeiteten. Außerdem signalisierte er dem Staatspräsidenten, daß die sozialistische Fraktion seit dem Sturz der Regierung zwar noch keinen Beschluß gefaßt habe, es aber sicher sei, daß sie sich einstimmig gegen eine Regierung der concentration aussprechen würde ${ }^{553}$.

Der Parti radical hielt die Sozialisten ${ }^{554}$ für den Sturz der Regierung Herriot verantwortlich und bezeichnete das Votum der sozialistischen Fraktion als nicht nachvollziehbar. Immerhin wurde eingeräumt, daß ein Scheitern der Regierung Herriot in der Finanzpolitik durch die Sozialisten noch verständlich gewesen wäre, aber eine sozialistische Opposition auf dem Feld der Außenpolitik sei nur schwer zu begreifen, wie Albert Milhaud in einem Artikel in L'Ere Nouvelle 555 zum Ausdruck brachte. Die erste parlamentarische Gruppe, die über die Konsequenzen des Sturzes der Regierung Herriot nachdachte, war die radikalsozialistische, die sich zu einer fraktionsinternen Besprechung am 15. Dezember 1932 versammelte. Es entwickelte sich eine sehr lebhafte Debatte, denn diejenigen Fraktionsmitglieder, die gegen die Regierung gestimmt hatten, reichten ihre Austrittsgesuche ein. Entgegen jeglicher Erwartung wurden die Austrittsgesuche der Fraktionsmitglieder zurückgewiesen und damit konnten sie weiterhin der radikalsozialistischen Fraktion angehören. Die Fraktionssitzung endete mit dem Beschluß, eine Unterkommission einzurichten, die zukünftig prüfen sollte, unter welchen Bedingungen die Abstimmungsdisziplin eingehalten werden müsse $\mathrm{e}^{556}$.

551 Vgl. dazu weiter oben die Diskussion in der Finanzkommission und der Kommission für Auswärtige Angelegenheiten, außerdem Le Populaire vom 15. 12. 1932, S. 1.

552 Die Bereitschaft der SFIO zur Kooperation trotz des Sturzes der Regierung Herriot wurde in den Tagen nach dem 15.12. 1932 nochmals in Fraktionssitzungen der SFIO bekräftigt; vgl. Le Temps vom 16. 12. 1932, S. 3.

553 Le Populaire vom 15. 12. 1932, S. 3.

${ }_{554}^{5}$ L'Ere Nouvelle vom 14.12. und 15. 12. 1932, jeweils S. 1.

555 L'Ere Nouvelle vom 14. 12. 1932, S. 1.

556 Le Populaire vom 15. 12. 1932, S. 3; Le Temps vom 16. 12. 1932, S. 3. Hier wurden die Umstände graduell differenzierter dargestellt. Die Rücktritte wurden abgelehnt, da das Votum unter bestimmten Bedingungen stattgefunden hatte, jedoch wurde für die Zukunft beschlossen, daß Sanktionsmöglichkeiten für die Verletzung der Abstimmungsdisziplin Anwendung finden sollten. 


\title{
5. Vergebliche Bemühungen des Parti radical um eine stabile Mehrheit in der Kammer 1933/1934
}

\author{
Konvergenz und Divergenz zwischen Parti radical und SFIO
}

Nach dem Scheitern der Regierung Herriot am 14. Dezember 1932 sollte zunächst Camille Chautemps ein neues Kabinett bilden. Chautemps gehörte zum engeren Umfeld von Herriot. Staatspräsident Albert Lebrun erteilte ihm einen Auftrag zur Regierungsbildung57, in der Hoffnung, daß Chautemps die Politik der Regierung Herriot fortsetzen könne; denn Lebrun glaubte, daß das Kabinett Herriot nur an der Schuldenproblematik gescheitert, und für die allgemeine politische Linie dieser Regierung eine Mehrheit im Parlament vorhanden sei. Aber wie sich im Laufe der nächsten eineinhalb Jahre herauskristallisieren sollte, blieb die Grundproblematik bestehen, die der Parti radical zu lösen hatte. Der heterogenen Partei gelang es weder, eine Mehrheit aus linken politischen Kräften zu bilden, noch war sie in der Lage, ihr Streben nach einer Mehrheit in der Mitte mit Erfolg zu realisieren. Diese Grundproblematik der wichtigsten Partei des französischen Parteiensystems in der Legislaturperiode 1932 bis 1936 weitete sich in den Jahren 1933 bis Anfang 1934 zur Krise des französischen Parlamentarismus aus.

$\mathrm{Da}$ Chautemps sein Kabinett nicht ohne Herriot bilden wollte, und dieser wiederum verkünden ließ, daß er nur einem Kabinett angehören könne, das an der Schuldenzahlung an Amerika festhalte, wurde schnell deutlich, daß Chautemps seinen Regierungsauftrag nicht erfüllen konnte558. Denn die Mehrheit der parlamentarischen Gruppen gab unmißverständlich zu verstehen, daß sie dieser Forderung nicht zustimmen werde 559 . Lebrun erteilte daraufhin Paul-Boncour, einem ehemaligen Mitglied der SFIO560, den Auftrag zur Regierungsbildung561. Paul-

557 Chautemps bekam bereits am Nachmittag des 16.12. 1932 den Auftrag zur Regierungsbildung von Staatspräsident Lebrun erteilt; siehe Le Temps vom 17. 12. 1932, S. 3.

558 Nachdem Chautemps mit einigen politischen Freunden Regierungsgespräche geführt hatte, gab er noch am selben Abend den Regierungsauftrag zurück. Chautemps begründete seine Entscheidung folgendermaßen: Die conditio sine qua non wäre für ihn die Lösung der interalliierten Schuldenfrage gewesen, die er aber im Moment nicht sehe; denn die Lösung dieses Problems hätte mit einem Kompromiß zwischen dem Standpunkt der Kammermehrheit und Herriots gefunden werden müssen. Diesen erforderlichen Kompromiß konnte Chautemps jedoch nicht erkennen. Außerdem wollte Chautemps auf Herriot als Kabinettsmitglied nicht verzichten. „(...) je me suis loyalement efforcé de rechercher entre la thèse de la Chambre et celle du précédent cabinet une formule de conciliation qui aurait permis le retour aux affaires du président Herriot, soit comme chef, soit au sein du gouvernement."; Le Temps vom 18. 12. 1932, S. 3.

${ }_{559}$ Le Temps vom 15. 12. 1932, S. 8.

560 Paul-Boncour war 1931 aus der SFIO ausgetreten, da er in der Frage der Landesverteidigung eine andere Position als die sozialistische Partei vertrat. Er ließ sich in den Senat wählen und gehörte der Gruppe "non-inscrits“ an. Der Nachlaß Paul-Boncour dokumentiert über weitere Strecken seine politische Laufbahn; vgl. A.N. Paris, 424 AP, der um die 30 Schachteln umfaßt; außerdem auch J. Paul-Boncour, Entre deux guerres, souvenirs sur la IIIe République, Bd. I: Les luttes républicaines 1877-1918, Bd. II: Les lendemains de la victoire 1919-1934, Paris 1945/46.

561 Paul Boncour erklärte gegen 23.30 Uhr nach Gesprächen im Elysée-Palast: „J'ai été l'objet d'une offre officielle de la part du président de la République (...) Ce n'est que demain matin après que j'aurai vu quelques amis personnels (...), que je ferai savoir au président si j'accepte son offre.“ Le Temps vom 18. 12. 1932, S. 3. 
Boncour verhandelte auch mit den Sozialisten über eine Regierungsbeteiligung ${ }^{562}$, da diese aber wiederum die Forderungen der „Cahiers de Hugyhens“ 563 zur Verhandlungsgrundlage bestimmten, wurde rasch klar, daß sie sich nicht an der zukünftigen Regierung beteiligen würden. Denn auch für Paul-Boncour waren die Forderungen der Sozialisten nicht akzeptabel, da er sein Kabinett größtenteils mit Radikalsozialisten bildete, die diesen Inhalten nicht zustimmen würden. Obwohl auch Paul-Boncour überwiegend mit Radikalsozialisten zusammenarbeitete, stellte sein Kabinett eine Erweiterung nach links dar, denn er nahm auch Mitglieder des linken Flügels des Parti radical 564 in seine Regierungsmannschaft auf. Am 23. Dezember 1932 stellte Paul-Boncour sein Kabinett dem Parlament vor und verlas seine Regierungserklärung ${ }^{565}$, in der er als primäre Aufgabe seiner Regierung die Sanierung der Staatsfinanzen bezeichnete. Die Regierung Paul-Boncour wurde mit 379 zu 166 Stimmen ${ }^{566}$ vom Parlament bestätigt. Die sozialistische und auch die radikalsozialistische Fraktion sprachen der Regierung ihr Vertrauen aus. Obwohl die Radikalsozialisten für das neue Kabinett gestimmt hatten, erhoben sich bald einige Stimmen des linken Parteiflügels, die die Maßnahmen des Finanzministers Chéron kritisierten. Damit meldete sich die innerparteiliche Opposition des Parti radical erneut zu Wort. Aber auch in der SFIO urteilten die beiden Flügel unterschiedlich über die neue Regierung. Auch dieses Mal war Léon Blum als Mittler zwischen den Parteiflügeln gefordert. Blum selbst war sich allerdings bewußt, daß die Regierung Paul-Boncour schon sehr rasch an ihre Grenzen stoßen würde ${ }^{567}$, spätestens dann, wenn der konservative Finanzminister seine Sanierungsmaßnahmen für den Staatshaushalt vorlegte. Dennoch hoffte er, daß es in dieser Legislaturperiode nach dem Wahlsieg der Linksmehrheit gelingen würde, eine Regierung der concentration zu verhindern. Der Ernstfall trat kurze Zeit später ein, als der Finanzminister seine von deflationistischen Maßnahmen geprägte Vorlage zur Wiederherstellung des budgetären Gleichgewichts ${ }^{568}$ der Deputiertenkammer einbrachte. Um den drohenden Sturz der Regierung abzuwenden, hatte Blum versucht, einige Artikel aus dem sozialistischen Gegenprojekt vom Dezember 1932 in die Regierungsvorlage aufzunehmen, denn er hoffte, daß dadurch die sozialistische Fraktion der Regierungsvorlage zustimmen könnte. PaulBoncour hingegen stellte während der Finanzdebatte die Vertrauensfrage über

${ }_{562} \mathrm{Zu}$ den Verhandlungen mit der SFIO und den fraktionsinternen Diskussionen siehe Le Temps vom 19.12.1932, S. $1 / 2$.

$563 \mathrm{Zu}$ den einzelnen Forderungen, die in den "Cahiers de Hugyhens" zusammengefaßt worden sind, siehe das entsprechende Unterkapitel in Kapitel 3 dieses Fallbeispiels.

564 Pierre Cot wurde Unterstaatssekretär im Außenministerium und François de Tessan übernahm das Amt des Unterstaatssekretärs im Sozialministerium („Travail et Prévoyance sociale“); vgl. dazu die Kabinettsliste Paul Boncours in Le Temps vom 20.12. 1932, S. 1, bzw. die Kabinettslisten im Anhang dieser Arbeit.

${ }^{565}$ Zum Wortlaut der Regierungserklärung siehe Le Temps vom 23. 12. 1932, S. 6.

566 Ausführlich zum Abstimmungsergebnis über die Regierung Paul-Boncour siehe Le Temps vom 24. 12. 1932, S. 3/4 sowie L. Boissier/B. Mirkine-Guetzévitch, Annuaire interparlementaire, Supplément 1933, Paris 1933, S. 61.

567 Zur Einschätzung der Regierung Paul Boncour durch Blum siehe Le Populaire vom 20.12. 1932, S. 1.

568 Zur Budgetvorlage des Finanzministers Chéron siehe vor allem die zweite Sitzung vom 18. 1. 1933 und auch die Sitzung vom 20.1. 1933 in A.N. Paris, Commission des Finances, C 14993. Siehe dazu auch Le Temps vom 25. 1. 1933, S. 4. 
den Artikel 6 der Vorlage, der eine Erhöhung aller direkten Steuern um fünf Prozent vorsah. Er scheiterte an der Vertrauensfrage. Das Kabinett wurde am 28. Januar 1933 mit 401 zu 171 Stimmen gestürzt ${ }^{569}$. Die Sozialisten konnten diesem Artikel nicht zustimmen und votierten geschlossen dagegen, während sich die Mehrheit des Parti radical für diesen Artikel aussprach. 131 ihrer Abgeordnete stimmten dafür, neun Abgeordnete dagegen und 14 enthielten sich der Stimme. Auch diese Abstimmung verdeutlichte die Heterogenität innerhalb des Parti radical 570 . Kurze Zeit nach dem Fall der Regierung Herriot bedingte dieselbe Situation und Konstellation, die das Ende des Kabinett Herriots herbeigeführt hatte, auch den Sturz der Regierung Paul-Boncour.

Wie schwierig mittlerweile die Bildung einer stabilen mehrheitsfähigen Regierung im französischen Parlament geworden war, wurde in einem Artikel von François Piétri in der Zeitschrift Revue de France thematisiert. Piétri zeigte auf, daß der Dreh- und Angelpunkt eines funktionsfähigen politischen Systems in der Klärung des Verhältnisses zwischen den Radikalsozialisten und den Sozialisten läge: „Le dilemme, pour tout esprit rassis, est le suivant: ou bien les radicaux imposeront aux socialistes leur formule de gouvernement, qui est proprement celle du centre gauche, et c'est alors la fin parlementaire du socialisme; ou bien les socialistes plieront les radicaux à leur conception spéciale de l'Etat, et le radicalisme sombrera par définition, dans l'instant même de son apogée politique. (...) Quoi qu'on ait voulu espérer du change donné par la passion politique le Parlement comme le pays vont à une scission franche des forces de conservation sociale et de celles, lentement grandissantes, de la révolution. Le socialisme est désormais assez puissant pour gouverner seul sa destinée. Il l'a conduite jusqu'ici avec une adresse infinie. $" 571$

Blum, der ebenfalls zu Gesprächen mit dem Staatspräsidenten gebeten worden war, berichtete seinen Parteikollegen, daß er bei Lebrun gefordert habe, eine neue Regierung ins Amt zu berufen, die sich auf die Mehrheit der letzten Wahlen vom 8. Mai 1932 stützen könne ${ }^{572}$. Den Sozialisten war vor allem daran gelegen, eine Linksmehrheit im Parlament zu erhalten und die Bildung eines Kabinetts der Union nationale, wie es 1926 nach dem Wahlsieg der Linkskräfte von 1924 geschehen war, zu verhindern ${ }^{573}$. Die rechten Kräfte ${ }^{574}$ im Parlament hingegen arbeiteten genau auf dieses Ziel hin, denn sie erklärten nach dem Sturz der Regierung PaulBoncour, daß ein zukünftiges Kabinett sich eindeutig zu entscheiden hätte, mit welchen Kräften es eine mehrheitsfähige Regierung gestalten wolle. Die beiden letzten Regierungen seien gescheitert, weil sie versucht hätten, mit einer Links-

${ }^{569}$ Zum Abstimmungsergebnis siehe Le Temps vom 29. 1. 1933, S. 3.

570 Ebenda.

571 L'Oeuvre vom 29. 1. 1933, S. 4.

572 Vgl. dazu L'Oeuvre vom 29. 1. 1933, S. 4.

573 Vgl. dazu die Äußerungen Blums am 29. 1.1933 nach einem Gespräch mit dem Staatspräsidenten: „(...) qu'après un échange de vues, le groupe s'est montré opposé à tout renversement de majorité, et que la prochaine réunion aura lieu lundi après-midi.“; Le Temps vom 30. 1. 1933, S. 3.

574 Sogar aus den Reihen der Gemäßigten, wie z.B. der Gauche radicale, wurden Stimmen nach einer Regierung der concentration oder der Union nationale laut, so wie dies auch der Abgeordnete Riché (Gauche radicale) forderte: „Le bon sens veut que l'on constitue un ministère de concentration peut-être d'abord rétréci, mais qui ouvrira la voie à un ministère de concentration élargi, sinon même d'union nationale." Le Temps vom 30. 1. 1933, S. 3. 
mehrheit zu regieren, aber in der Finanzpolitik konservative Maßnahmen zu ergreifen, die dann vor allem von den Sozialisten abgelehnt worden seien. Aber auch Teile der Rechten stimmten gegen die konservativen Finanzmaßnahmen, weil sie nicht bereit waren, ein Kabinett der Linkskräfte zu stützen, sondern vielmehr hofften, selbst in einem Kabinett der Union nationale regieren zu können. Die Mehrheit des Parti radical hielt die Sozialisten für die beiden letzten Regierungsstürze für verantwortlich und sprach sich deshalb dafür aus, die $S F I O$ zu einer eindeutigen Entscheidung zu zwingen, wie dies in den Äußerungen von Jammy Schmidt besonders deutlich wird: „(...) je crois que la première solution qui s'offrira au chef du gouvernement de demain sera d'offrir la participation aux socialistes sur un programme nettement défini. S'ils refusent, le futur président du conseil n'aura plus alors qu'à faire appel à toutes les bonnes volontés d'où qu'elles viennent, et je n'ai pas besoin d'ajouter que notre concours lui est tout acquis. Ce qui s'est passé ce matin, avec les moyens d'équilibre, rappelle ce qui s'est produit il y a six semaines, sur l'affaire des dettes, et il convient d'en tirer les conséquences: nous ne voulons pas renouveler l'expérience du soutien socialiste qui a provoqué en six semaines deux crises. “ 575

Die innerparteiliche Opposition hingegen, eine Minderheit, die sich im linken Flügel des Parti radical formierte, schätzte die Krise anders ein. Bergery befand, daß beiden Regierungen eine Gemeinsamkeit anhaftete, die sie letztlich zu Fall brachte. Er spielte dabei auf das Paradoxon an, daß beide Kabinette versucht hatten, mit einer linken Mehrheit im Parlament eine Politik der Mitte zu betreiben: „Le deuxième ministère de la législature vient de s'effondrer; à cinq semaines d'intervalle, nous aurons conduit en terre deux combinaisons qui se ressemblaient fraternellement - deux combinaisons par lesquelles on a essayé de faire faire une politique „centriste“ par la majorité de gauche issue des élections de mai. Car c'est là la cause commune des deux crises ministérielles." 576 Damit sah Bergery weniger die Schuld bei den Sozialisten als bei der eigenen Partei, die bemüht war, diesen widersprüchlichen politischen Kurs zu meistern.

Der Parti radical stand vor dem geradezu unlösbarem Problem, trotz dieser Gegensätze eine einheitliche politische Linie finden müssen. Damit dieser Versuch nur annähernd eine realistische Chance erhalten konnte, galt es in erster Linie, den Konflikt zwischen dem rechten und linken Flügel zu lösen. Um die innerparteiliche Opposition des linken Flügels zu beseitigen, sollte Daladier die nächste Regierung bilden. Daladier galt in der Partei als Repräsentant des linken Flügels ${ }^{577}$, und man hoffte, daß es ihm gelingen würde, diesen in die Regierung einzubinden und damit wieder eine Geschlossenheit in der Partei herzustellen. Ein zweiter Schritt galt der Klärung des Verhältnisses zwischen SFIO und Parti radical. Die Regierungszeit Daladiers, der mit seinem Kabinett am 3. Februar 1933578 antrat, veran-

575 Le Temps vom 30. 1. 1933, S. 3.

576 Zitiert nach S. Berstein, Parti radical, vol. 2, S. 255.

577 Dies geht vor allem auf seine Zeit als Parteivorsitzender von 1927 bis 1931 zurück, als er in dieser Funktion versuchte, die Partei organisatorisch zu reformieren; vgl. dazu das Unterkapitel 1 dieses zweiten Prozeßbeispiels. Außerdem auch E. du Reau, Édouard Daladier 1884-1970, Paris 1993, S. 66-74.

578 Zur Bestätigung der Regierung Daladiers in der Deputiertenkammer am 3. 2. 1933 siehe Le Temps vom 5. 2. 1933, S. 4. 
schaulicht zum einen deutlich die Krise des Parti radical und zum anderen ebenso die Krise der SFIO, die einander wechselseitig beeinflußten und das parlamentarische Regierungssystem der Dritten Republik in den dreißiger Jahren ernsthaft paralysierten.

\section{Die Regierung Daladier als Katalysator des Konfliktes zwischen Parti radical und SFIO}

\section{Innerparteiliche Reaktionen auf die Regierung Daladier}

Nachdem dem unabhängigen Paul-Boncour nur ein Intermezzo in der Regierungsverantwortung beschieden war und der Parti radical erneut sehen mußte, daß ein alleiniges Regieren nicht möglich war, fiel die Wahl des zukünftigen Regierungschefs auf Edouard Daladier. Daladier schien aus mehreren Gründen für diese Aufgabe in der aktuellen Situation geeignet zu sein. Es galt zum einen, die innerparteiliche Opposition, den linken Flügel, in die Regierungsarbeit einzubinden, zum anderen sollte, wenn auch nur in unterstützender Funktion, die SFIO für die neue Regierung gewonnen werden. Es gelang Daladier, beide Vorhaben, wenn auch mit unterschiedlicher Dauer, zu realisieren. Albert Lebrun erteilte $\mathrm{Da}$ ladier am 30. Januar 1933 den Regierungsauftrag, den er schließlich annahm ${ }^{579}$. Daladier bot den Sozialisten die Regierungsbeteiligung mit fünf Ministerämtern und dem Posten des stellvertretenden Regierungschefs an ${ }^{580}$. Nachdem die Sozialisten zunächst mitteilten, daß sie erst den Conseil national einberufen wollten, um eine Entscheidung zu treffen, wies Daladier unmißverständlich daraufhin, daß er unverzüglich eine Antwort erwarte und keine Verzögerung akzeptieren könne. Die sozialistische Fraktion diskutierte über das Regierungsangebot Daladiers und stimmte für die Regierungsbeteiligung. Sie begründete diese Entscheidung damit, daß die aktuelle politische Lage eine Ausnahmesituation darstelle, präsentierte aber abermals die "Cahiers de Huyghens" als Grundlage für ein gemeinsames Regierungsprogramm. Daladier lehnte daraufhin eine Zusammenarbeit mit der SFIO ab, da die sozialistischen Forderungen der "Cahiers de Huyghens" nicht mit dem Programm des Parti radical vereinbar seien.

Unmittelbar nach der Absage an die Sozialisten erklärte Bergery, der für den linken Flügel sprach und stets eine Zusammenarbeit mit der SFIO befürwortet hatte, daß Daladier nach dieser Aktion nun nicht mehr mit dem Vertrauen der gesamten radikalsozialistischen Fraktion rechnen könne. Um weiterhin die Einheit der Fraktion zu sichern, versuchte Daladier, den linken Flügel in die Regierungsverantwortung mit einzubinden, und nahm in seine Regierung Vertreter dieses Parteiflügels auf. Es gelang ihm, Pierre Cot für das Luftfahrtministerium, Fran-

579 Le Temps vom 31. 1. 1933, S. 3: „M. le président de la République a bien voulu me faire l'honneur de me demander de former le nouveau cabinet. J'ai accepté cette mission (...).“

580 Le Populaire vom 31. 1. 1933, S. 3, Zitat aus der Presseerklärung Daladiers: (...) Puis j’ai reçu le bureau du Parti radical, et, ensuite la délégation du Parti socialiste, à qui j’ai proposé et offert de participer au gouvernement. (...) Je leur ai offert cinq portefeuilles, dont la vice-présidence du Conseil. Les délegués socialistes ont bien voulu réunir leur parti qui prendra une décision dans le courant de l'après-midi (...)." vgl. zu den Regierungsverhandlungen Daladiers mit den Sozialisten L'Oeuvre vom 31. 1. 1933, S. 1, 4; Le Populaire vom 31. 1. 1933, S. 3 und vom 1. 2. 1933, S. 2, sowie die Berichte im Nachlaß Daladier in: A.N. Paris, $496 \mathrm{AP} / 3$. 
çois-Albert für das Arbeitsministerium und Gaston Hulin für das Amt des Unterstaatssekretärs im Kriegsministerium ${ }^{581}$ zu gewinnen. Mit der Aufnahme der Vertreter des linken Parteiflügels in sein Kabinett konnte Daladier, die innerparteiliche Opposition ausschalten. Bergery, der sich seit seiner heftigen Auseinandersetzung mit Herriot auf dem Parteitag von $1932^{582}$ auf dem Rückzug befand, trat im März 1933 mit einem letzten Affront aus dem Parti radical aus, indem er in einem öffentlichen Schreiben der Partei mitteilte, daß er nicht einer Politik zustimmen könne, die die innerparteiliche Opposition ausgegrenzt und verurteilt habe ${ }^{583}$. Mit dem Austritt Bergerys war der letzte Störfaktor im linken Flügel endgültig beseitigt worden, da wichtige Vertreter dieses Flügels in der Regierung saßen und somit diese Strömung zufriedengestellt war. Um auch dem rechten Flügel entgegenzukommen, setzte sich Daladier dafür ein, daß Herriot zum Vorsitzenden der Fraktion gewählt wurde. Durch die Regierung Daladier konnten parteiinterne Widerstände überwunden werden. Sie konnte zudem Unterstützung von Seiten der SFIO für ihre Politik erreichen. In der SFIO brachen allerdings große innerparteiliche Konflikte aus, die schließlich im Herbst 1933 mit der Abspaltung der Neosozialisten endeten 584 .

Bei seiner Regierungsbildung war Daladier sehr auf Ausgewogenheit bedacht. Von 23 Regierungsämtern besetzte er elf wichtige Kabinettsstühle mit Radikalsozialisten ${ }^{585}$. Besonders auffallend war, daß das Finanzministerium und das Haushaltsministerium zwei Radikalsozialisten ${ }^{586}$, die dem rechten Flügel angehörten, anvertraut wurden, während die Vorgängerregierungen das wichtige Finanzministerium mit Politikern aus der rechten Mitte besetzt hatten ${ }^{587}$. Gerade die Beset-

581 Vgl. die Kabinettsliste Daladiers in Le Temps vom 1. 2. 1933, S. 8; L'Oeuvre vom 1. 2. 1933, S. 1, 4. Siehe auch die Kabinettslisten im Anhang dieser Arbeit.

582 Vgl. den entsprechenden Abschnitt in Unterkapitel 4 dieses zweiten Prozeßbeispiels.

${ }^{583}$ Bergery publizierte dieses Schreiben in Maintes-Républicain vom 8. 3. und 15. 3. 1933. Außerdem auch bei S. Berstein, Parti radical, vol. 2, S. 260.

${ }^{584}$ Ausführlich dazu siehe den entsprechenden Abschnitt in Unterkapitel 5 dieses zweiten Prozeßbeispiels. Weitere Literatur zur Abspaltung der „Neosozialisten“ 1933: D.N. Baker, Two Paths to Socialism: Marcel Déat and Marceau Pivert, in: Journal of Contemporary History 1 (1966), S. 107128; A. Bergounioux, Le néo-socialisme. Marcel Déat: réformisme traditionnel ou esprit des années trente, in: Revue historique 260 (Juli-Sept. 1978), S. 389-412; M. Bilis, Socialistes et pacifistes. L'intenable dilemme des socialistes français (1933-1939), Paris 1979; J.-P Cointet, Marcel Déat: Du socialisme au national-socialisme, Paris 1998; E. Goodman, The Socialism of Marcel Déat, Stanford 1973; S. Grossmann, L'évolution de Marcel Déat, in: RHDGM 97 (1975), S. 3-29; J. T. Marcus, French Socialism in the Crisis Years 1933 to 1936. Fascism and the French Left, New York 1958; R. Schwarzer, Vom Sozialisten zum Kollaborateur. Idee und politische Wirklichkeit bei Marcel Déat, Pfaffenweiler 1987; Z. Sternhell, Du socialisme au fascisme. Le cas de Marcel Déat, in: L'Histoire 53 (1983), S. 20-34; J. Touchard, L'esprit des années 30: une tentative de renouvellement de la pensée politique française, in: Tendances politiques de la vie française depuis 1789, Paris 1960, S. 89-121; D. White, Lost Comrades: Socialistes of the Front Generation. 1918-1945, Cambridge 1992; G. Ziebura, Léon Blum et le Parti socialiste, 1927-1934, Paris 1967.

${ }^{585}$ Folgende Radikalsozialisten haben Regierungsämter im ersten Kabinett Daladier übernommen: Camille Chautemps (Innenministerium), Georges Bonnet (Finanzministerium), Lucien Lamoureux (Haushalt), Pierre Cot (Luftfahrt), Joseph Paganon (Öffentliche Arbeiten), Henri Queuille (Landwirtschaft), François-Albert (Arbeit und Soziale Vorsorge), Edmond Miellet (Renten), Gaston Hulin (Unterstaatsekretär Krieg), Hyppolite Ducos (Unterstaatsekretär Nationale Erziehung), Pierre Appell (Unterstaatssekretär Tourismus); vgl. L'Oeuvre vom 1. 2. 1933, S. 1; E. Bonnefous, Histoire politique, vol. 5, S. $437 \mathrm{f}$.

586 Georges Bonnet war das Finanzministerium und Lucien Lamoureux das Haushaltsressort anvertraut worden.

${ }^{587}$ Sowohl die Regierung Herriot wie auch die von Paul-Boncour waren damit aufgefallen, daß sie das 
zung dieser beiden Ministerien mit radikalsozialistischen Abgeordneten führte vorübergehend auch zu gewissen Hoffnungen bei den Linkskräften im Parlament, wie z.B. den Sozialisten, die der Regierung zugute kamen.

Als Daladier mit seiner Regierung am 3. Februar 1933 im Parlament antrat, wurde er mit 376 zu 181 Stimmen im Amt bestätigt ${ }^{588}$.

\begin{tabular}{rlrccc}
\hline $\begin{array}{c}\text { An- } \\
\text { zahl }\end{array}$ & Parlamentarische Gruppe & Dafür & $\begin{array}{l}\text { Da- } \\
\text { gegen }\end{array}$ & $\begin{array}{l}\text { Enthal- } \\
\text { tung }\end{array}$ & $\begin{array}{l}\text { Abwe- } \\
\text { send }\end{array}$ \\
\hline 15 & Indépendants & - & 12 & 1 & 2 \\
18 & Groupe républicain et social & - & 18 & - & - \\
7 & Action économique, sociale et paysanne & - & 5 & 1 & 1 \\
38 & Fédération républicaine & - & 36 & 1 & 1 \\
34 & Centre républicain & - & 33 & - & 1 \\
29 & Républicains de gauche & - & 22 & 4 & 3 \\
16 & Démocrates populaires & - & 15 & - & 1 \\
6 & Républicains du centre & - & 6 & - & - \\
23 & Indépendants de gauche & 10 & 9 & 3 & 1 \\
49 & Gauche radicale & 30 & 3 & 9 & 7 \\
160 & Radicaux et radicaux socialistes & 157 & - & - & 3 \\
15 & Gauche indépendante & 14 & - & 1 & - \\
14 & Républicains socialistes & 14 & - & - & - \\
13 & Socialistes français & 12 & - & - & 1 \\
129 & Socialistes & 128 & - & 1 & - \\
9 & Unité ouvrière & - & - & 9 & - \\
10 & Communistes & - & 10 & - & - \\
26 & Isolés & 11 & 12 & 2 & 1 \\
\hline 611 & & 376 & 181 & 32 & 22 \\
\hline
\end{tabular}

Trotz einer parteiinternen Krise stimmte die SFIO für das Kabinett Daladier und war zunächst gewillt, dieses zu unterstützen. In der Regierungserklärung ${ }^{589}$ konzentrierte sich Daladier in erster Linie auf die Finanzpolitik und die Wiederherstellung des budgetären Gleichgewichts. Der zweite Schwerpunkt seiner Regierungspolitik lag auf der Außenpolitik, wobei sein Interesse hier besonders der Sicherheits- und der Abrüstungsfrage galt. Als letzten Punkt erwähnte Daladier den Bereich der Kulturpolitik, der sein Programm abrunden sollte, gleichzeitig aber wie eine Verbeugung vor der radikalsozialistischen Doktrin wirkte: „Nous, messieurs, nous avons la fierté des institutions laïques et sociales de la République." 590

Finanzministerium in eher konservative Hände gelegt hatten. Germain-Martin war Finanzminister der Regierung Herriot und Chéron hatte dieses Amt im Kabinett Paul-Boncour inne.

588 Le Temps vom 5. 2. 1933, S. 4.

589 Ausführlicher Text der Regierungserklärung Daladiers in Le Temps vom 4. 2. 1933, S. 8.

590 Ebenda. 
Vorübergehende Wiederherstellung einer regierungsfähigen Mehrheit im Parlament

Daladier konnte vorübergehend eine konsensfähige Politik in den beiden wichtigsten Politikfeldern - der Außen- und der Finanzpolitik - betreiben. Kurz nach Regierungsantritt stellte sich die erste Bewährungsprobe für dieses Kabinett, denn am 7. Februar 1933 präsentierten der Finanz- und der Budgetminister ihren dreistufigen Finanzplan in der Deputiertenkammer. Dieser dreistufige Plan umfaßte folgende Komponenten: 1) Kontrolle und Verabschiedung des Budgetzwölftels des aktuellen Haushaltsplanes für März; 2) ein Finanzgesetz, durch das noch einige zusätzliche Maßnahmen in den Haushalt 1933 aufgenommen werden sollten und 3) eine Anleihe zur Konsolidierung des Haushaltes ${ }^{591}$. Trotz langwieriger Debatten in der Finanzkommission und der Deputiertenkammer konnte die erste Komponente des dreistufigen Haushaltsplanes mit 356 zu 215 Stimmen am 13. Februar 1933592 verabschiedet werden. Die zwei wichtigsten linksrepublikanischen Parteien - der Parti radical und die SFIO - stimmten dafür. Bereits im Vorfeld waren beide parlamentarischen Gruppen bemüht, zu einer gemeinsamen Entscheidung zu kommen, deshalb hatten regelmäßig Gespräche zwischen führenden Vertretern beider Gruppen stattgefunden ${ }^{593}$. Das Abstimmungsverhalten der einzelnen parlamentarischen Gruppen sah aus wie folgt ${ }^{594}$ :

\begin{tabular}{rlrccc}
\hline $\begin{array}{c}\text { An- } \\
\text { zahl }\end{array}$ & Parlamentarische Gruppe & Dafür & $\begin{array}{l}\text { Da- } \\
\text { gegen }\end{array}$ & $\begin{array}{l}\text { Enthal- } \\
\text { tung }\end{array}$ & $\begin{array}{l}\text { Abwe- } \\
\text { send }\end{array}$ \\
\hline 15 & Indépendants & - & 14 & - & 1 \\
18 & Groupe républicain et social & - & 17 & - & 1 \\
7 & Action économique, sociale et paysanne & - & 7 & - & - \\
38 & Fédération républicaine & - & 37 & - & 1 \\
34 & Centre républicain & - & 34 & - & - \\
29 & Républicains de gauche & - & 22 & 4 & 3 \\
16 & Démocrates populaires & - & 15 & - & 1 \\
6 & Républicains du centre & - & 6 & - & - \\
22 & Indépendants de gauche & 9 & 11 & 1 & 1 \\
49 & Gauche radicale & 21 & 17 & 9 & 2 \\
159 & Radicaux et radicaux socialistes & 153 & - & - & 6 \\
15 & Gauche indépendante & 12 & 2 & - & 1 \\
15 & Républicains socialistes & 13 & 1 & - & 1 \\
14 & Socialistes français & 13 & - & - & 1 \\
129 & Socialistes & 128 & - & 1 & - \\
9 & Unité ouvrière & - & 9 & - & - \\
10 & Communistes & - & 10 & - & - \\
25 & Isolés & 7 & 13 & 5 & - \\
\hline 610 & & 356 & 215 & 20 & 19 \\
\hline
\end{tabular}

591 Zum dreistufigen Finanzplan Bonnets und Lamoureux' siehe L'Oeuvre vom 7. 2. 1933, S. 1, 4.

592 Vgl. dazu Le Temps vom 15. 2. 1933, S. 4.

${ }^{593}$ Vgl. dazu die Berichte über dieses Treffen in Le Temps vom 12. 2. 1933, S. 2 und vom 13.2.1933, S. 4.

${ }^{594}$ Abstimmung zum ersten Punkt des dreistufigen Haushaltsplans vom 13. 2. 1933 in Le Temps vom 15. 2. 1933, S. 4. 
Auch über Punkt zwei des dreistufigen Finanzplanes der Regierung Daladier herrschte Konsens zwischen dem Parti radical und der SFIO, denn beide parlamentarischen Gruppen stimmten einer zusätzlichen einmaligen steuerlichen Belastung der Beamtengehälter ${ }^{595} \mathrm{zu}$. So konnte auch der zweite Teil mit 329 zu 254 Stimmen verabschiedet werden.

Bei der Verabschiedung des Haushaltes in der Deputiertenkammer am 3. Juni 1933 kann ebenfalls weitgehend eine Übereinstimmung zwischen der SFIO und dem Parti radical festgestellt werden, da der Haushalt mit 375 zu 141 Stimmen ${ }^{596}$ verabschiedet wurde. Die radikalsozialistische Gruppe stimmte geschlossen dafür, wohingegen sich bei den Sozialisten die parteiinterne Krise in der Abstimmung manifestierte: Es stimmten 100 sozialistische Abgeordnete dafür und 29 dagegen ${ }^{597}$.

Der Konsens mit der sozialistischen Fraktion erstreckte sich nicht nur auf die Finanz-, sondern auch auf die Außenpolitik. Die außenpolitische Übereinstimmung muß vor dem Hintergrund der veränderten internationalen Situation betrachtet werden. Nach der Ernennung Hitlers zum Reichskanzler am 30. Januar 1933 hatte sich das außenpolitische Umfeld Frankreichs entscheidend verändert. Frankreich sah sich nun einer totalitären Bedrohung durch faschistische und kommunistische Staaten ausgesetzt, und war um so mehr am Erhalt der demokratischen Systeme interessiert ${ }^{598}$. Daladier mußte nun einen außenpolitischen Balanceakt zwischen dem italienischen Angebot eines Viermächte-Paktes und der Aufrechterhaltung des Völkerbundes bewältigen. Die rigorose Position der Regierung Herriot in der Reparations- und Abrüstungsfrage hatte zunächst zu keinem Ergebnis geführt. Es lag nun an Daladier, wieder Bewegung in die französische Außenpolitik zu bringen. Die Gelegenheit dazu bot sich für Daladier am 6. April 1933 bei einer ausführlichen Parlamentsdebatte ${ }^{599}$, in der er seinen außenpolitischen Standpunkt darlegte. Daladier schnitt in seiner Grundsatzrede alle wichtigen außenpolitischen Aspekte an, die in der aktuellen Situation zu berücksichtigen waren. Hinsichtlich der Abrüstungskonferenz vertrat Daladier den Standpunkt, daß Frankreich weiterhin die Idee der kontinuierlichen Abrüstung unter internationaler Kontrolle verfolgen sollte, jedoch nur unter der Voraussetzung, daß keiner aufrüstet. Dabei betonte er auch, daß die effektive Kontrolle der Waffenherstellung und des Waffenhandels eingehalten werden müsse. Mussolinis Vorschlag eines Viermächte-Paktes hielt Daladier, wenn auch mit einer gewissen Reserviertheit, für diskussionswürdig, aber angesichts der ökonomischen Krisen der

595 Zum Abstimmungsverhalten über „L'établissement d'une surtaxe exceptionnelle sur les traitements" siehe Le Temps vom 15. 2. 1933, S. 4.

596 Zum detaillierten Abstimmungsergebnis siehe Le Temps vom 3. 6. 1933, S. 3.

597 Vgl. die namentliche Aufführung derjenigen sozialistischen Abgeordneten, die gegen den von der Regierung vorgelegten Haushalt gestimmt hatten, in Le Temps vom 3. 6. 1933, S. 3.

598 Vgl. hierzu die Grundsatzrede Daladiers am 6. 4. 1933 in der Deputiertenkammer, die er im Rahmen der Haushaltsdebatte hielt; J.O., Chambre des Députés vom 6.4. 1933, 2. Sitzung, S. 1929/ 1930.

599 Diese Parlamentsdebatte über die außenpolitischen Grundlinien der Regierung Daladier fand im Rahmen der Haushaltsverhandlungen statt, als es darum ging, das Budget für die Auswärtigen Angelegenheiten zu diskutieren; J.O., Chambre des Députés vom 6. 4. 1933, 2. Sitzung, S. 1929/1930 und die sich daran anschließende Parlamentsdiskussion, ebenda, S. 1930-1951, sowie Le Temps vom 8. 4. 1933, S. 3 . 
letzten Jahre begrüße er eine stärkere internationale Zusammenarbeit, die auch zur Überwindung der vorhandenen Schwierigkeiten zwischen den vier Mächten Europas sehr hilfreich sein könnte. Daladier gab jedoch deutlich zu verstehen, daß er an einer Neuauflage einer „Heiligen Allianz“, die womöglich Revisionen territorialer Art vorzunehmen plane, nicht interessiert sei. Er unterstrich unmißverständlich, daß in seinen Augen neu abzuschließende Verträge nur auf dem bereits Erreichten (Locarnoverträge, Kellog-Briand-Pakt und Völkerbund) aufbauen könnten. Daladier verstand es, in dieser Rede den Anschein zu erwecken, daß der Beitritt Frankreichs zum Viermächte-Pakt als Beispiel einer Friedensaktion innerhalb des Völkerbundes zu werten sei. Außerdem unterstrich er gleichzeitig, daß Frankreich nach wie vor der Idee des Völkerbundes anhänge und sich dementsprechend engagieren wolle ${ }^{600}$. Diese Argumentation ermöglichte ihm, zwei Aspekte gleichzeitig zu berücksichtigen. Zum einen brachte sie Daladier den Konsens mit den Sozialisten, wie Blum in seinem Artikel vom 8. April 1933 in Le Populaire darlegte: „Réduire progressivement nos armements à condition que personne ne réarme, telle est, dit $\mathrm{M}$. Daladier, une des données caractéristiques de la politique que nous ne cesserons de défendre. C'est la première fois qu'un interprète officiel du gouvernement français adhère ainsi à la thèse que nous n'avons cessé de défendre ici-même (...).“601

Zum anderen wirkte sich die außenpolitische Haltung Daladiers innerhalb des Parti radical sehr positiv aus. Er erhielt im Gegensatz zur Regierung Herriot für seine Außenpolitik nicht nur die Zustimmung des rechten, sondern auch des linken Flügels des Parti radical. Vor allem Caillaux ${ }^{602}$ unterstützte die außenpolitischen Entscheidungen Daladiers sehr, weil sich dieser entscheidend für den Viermächte-Pakt eingesetzt hatte, um damit die Aussöhnung Frankreichs mit Italien ${ }^{603}$ voranzutreiben. Wie sehr Daladier innerhalb seiner Partei eine Konsensfähigkeit für seine Politik herstellen konnte, wurde besonders auf dem Parteitag des Parti radical, der vom 5. bis 8. Oktober 1933 in Vichy ${ }^{604}$ stattfand, deutlich. Denn

600 "Cette collaboration des Etats occidentaux, membres permanents du conseil de la Société des nations, Etats voisins qui ont des frontières communes, si l'on observe que les progrès de l'aviation rendent presque négligeable l'éxistence du Détroit qui sépare le continent de la Grande-Bretagne, Etats signataires des accords de Locarno, cette entente qui mettrait fin à des rivalités ou à des dissentiments qui paralysent trop souvent la société des nations, pourrait etre extrêmement féconde. Nous l'avons étudiée avec une entière sympathie (...).“; L’Oeuvre vom 7. 4. 1933, S. 4.

601 Le Populaire vom 8. 4. 1933, S. 1.

${ }^{602}$ Caillaux sprach sich auf einem Bankett des Friedens in diesem Sinne aus; vgl. L'Oeuvre vom 6. 4. 1933, S. 4.

${ }^{603}$ Der Viermächte-Pakt ging auf eine Initiative Mussolinis zurück und sollte ein Abkommen zwischen Italien, Frankreich, dem Deutschen Reich und Großbritannien sein. Der Viermächte-Pakt sollte die Gleichberechtigung garantieren, die Revision der Friedensverträge ermöglichen und eine Friedenspolitik einleiten. Mussolini verfolgte mit diesem Abkommen eine Annäherung Italiens an Frankreich, denn es war Ende 1932/Anfang 1933 zu einer deutlichen Abkühlung der Beziehungen zwischen diesen beiden Staaten gekommen, weil Mussolini in der Abrüstungsdiskussion offen für Deutschland Partei ergriffen hatte. Seine Forderung lautete, entweder eine allgemeine Abrüstung oder eine Aufrüstung für Deutschland. Vgl. dazu auch Le Temps vom 3. 3. 1933, S. 1/2. Zur Außenpolitik Frankreichs in diesem Zeitraum siehe U. Bannies, Die französische Außenpolitik von Januar 1933 bis April 1936. Der Abbau des französischen Widerstandes gegenüber Deutschland, Hamburg 1957. Zum Text des Viermächte-Paktes siehe E. Klöss (Hg.), Von Versailles zum Zweiten Weltkrieg. Verträge zur Zeitgeschichte 1918-1939, München 1965, S. 196-198.

${ }^{604}$ Vgl. ausführlich zum Parteitag vom 5.-8.10.1933 die Parteitagsprotokolle 30 Congrès du Parti 
die stets vorhandene Heterogenität der Partei wurde auf diesem Parteitag - wenn auch sichtlich bemüht - kaschiert. So zeigte sich nicht nur der Flügel um Caillaux, sondern auch der linke Parteiflügel um Kayser und Cudenet mit den außenpolitischen Leitlinien Daladiers sehr zufrieden, was sich in der einstimmigen Resolution zur Außenpolitik eindrucksvoll widerspiegelte605. Nur von Herriot kamen Einwände gegen die von Daladier praktizierte Außenpolitik; Herriot sah in dem Beitritt Frankreichs zum Viermächte-Pakt einen Rückschritt in die Zeiten vor dem Völkerbund, d.h. in ein System der Bündnisse und Allianzen. In seinen Augen schien diese Bündnispolitik kein den Völkerbund stärkendes Friedensinstrument zu sein, sondern es wirkte nach seiner Einschätzung eher kontraproduktiv. In diesem Sinne äußerte sich Herriot in einem Zeitungsartikel im Juni 1933: „Pour moi, le Pacte à quatre, s'il n'a été très fortement amendé, représenterait un retour au passé, un retour à la vieille politique des alliances et des coalitions (...). Il est en contradiction avec la politique moderne de la Société des Nations." "606

Das Engagement Herriots für den Völkerbund war relativ leicht nachvollziehbar, denn Herriot hatte schon während seiner Regierungszeiten stets unterstrichen, daß er sich für den Völkerbund und seine Stärkung federführend eingesetzt habe. Er verwies dabei besonders auf seine Politik seit dem Juni 1924, als er Frankreich aus seiner außenpolitischen Isolation geführt und seitdem stets den Ausbau des Völkerbundes als eine seiner Hauptaufgaben betrachtet hatte ${ }^{607}$. Natürlich mußte der Beginn einer erneuten Allianz- und Bündnispolitik seinen Zielen entgegenlaufen. Immerhin versuchte Herriot auch in der Kammer Widerstand gegen den Viermächte-Pakt ${ }^{608}$ zu leisten.

Daladier hatte am 9. Juni 1933609 in seiner Rede in der Deputiertenkammer über die bevorstehende Weltwirtschaftkonferenz und über die Beweggründe seiner Regierung, den Viermächte-Pakt zu unterzeichnen, gesprochen. Er unterstrich, daß der Beitritt Frankreichs eine wichtige Bedeutung für den Frieden habe und deshalb seine Regierung den Viermächte-Pakt unterstützen werde. Mit dem Beitritt würde Frankreich einerseits eine Teilung der internationalen Staaten in zwei

républicain radical et radical-socialiste tenu à Vichy les 5, 6, 7, 8 octobre 1933, Paris 1933 und auch L'Oeuvre vom 5. 10.-9. 10. 1933, jeweils S. 1, 3, 4 .

605 Vgl. dazu L'Oeuvre vom 8. 10. 1933, S. 1, 4 sowie auch den 30e Congrès du Parti républicain radical et radical-socialiste tenu à Vichy, les 5, 6, 7, 8, octobre 1933, Paris 1933, S. 383-421, hier besonders S. 397-404 und auch S. 415-420.

${ }^{606}$ Herriot in Le Petit Parisien vom 10.6. 1933, S. 1. Vgl. dazu auch S. Berstein, Parti radical, vol. 2, S. 262.

${ }^{607}$ Zur Bedeutung des Völkerbundes in der außenpolitischen Konzeption Herriots vgl. entsprechenden Abschnitt in Unterkapitel 6 des ersten Prozeßbeispiels dieser Studie.

608 Zum Text des Viermächte-Paktes siehe Le Temps vom 9. 6. 1933, S. 1. Außerdem auch E. Klöss (Hg.), Von Versailles zum Zweiten Weltkrieg, S. 196-198. Zur Geschichte des Viermächte-Paktes siehe U. Bannies, Die französische Außenpolitik von Januar 1933 bis April 1936; P. Du Vivier, A Study in Diplomacy from Disarmament to Rearmament. Franco-German Relations from February 1932 through June 1935, Ann Arbor 1977; A. H. Furnia, The Diplomacy of Appeasement. Anglo-French Relations and the Prelude to World War II. 1931-1938, Washington 1960; Ch. Kimmich, Germany and the League of Nations, Chicago 1976; L. Krecker, Die diplomatischen Verhandlungen über den Viererpakt vom 15. Juli 1933. Ein Beitrag zum Anfangsstadium der Außenpolitik des 3. Reiches, in: Welt als Geschichte 21 (1961), S. 227-237; G. L. Weinberg, The foreign Policy of Hitler's Germany. Diplomatic Revolution in Europe 1933-1936, Chicago 1970.

${ }^{609}$ Zur Rede Daladiers in der Deputiertenkammer vom 9.6. 1933 siehe J.O., Chambre des Députés vom 9. 6. 1933, 2. Sitzung, S. 2823-2826; Le Temps vom 11.6. 1933, S. 3. 
feindliche Lager verhindern, aber andererseits auch die Interessen des Völkerbundes besser wahrnehmen können. Daladier betonte vor allem das verbindende Element zwischen Völkerbund und Viermächte-Pakt und versuchte die Argumente der Viermächte-Pakt-Gegner zu widerlegen, die glaubten, daß der ViermächtePakt den Völkerbund aushöhle. Daladier hob ausdrücklich hervor, daß die Mächte des Viererpaktes sich in Form eines Direktoriums zusammenschließen wollten, jedoch nur um sich gegenseitig abzustimmen, und nicht, um Entscheidungen zu treffen. Um die enge Verbindung mit dem Völkerbund zu unterstreichen, verwies Daladier darauf, daß die Artikel 10, 18 und 19 des Völkerbundvertrages ${ }^{610}$ eine enge Anknüpfung des Viererpaktes ermöglichten. Auch die Bedenken wegen einer Wiederaufrüstung Deutschlands versuchte Daladier zu zerstreuen, denn Artikel 3611 des Viererpaktes verhindere jegliche Versuche in diese Richtung. Er beendete sein Plädoyer für die Unterzeichnung des Viererpaktes mit dem Argument, daß eine indifferente oder abweisende Haltung Frankreichs der Demokratie großen Schaden zufügen würde, denn es sei wichtig, zwischen den Völkern die Verständigung zu sichern und nicht Distanz zu schaffen ${ }^{612}$. In der Diskussion, die sich an die Rede Daladiers vor der Abstimmung über den Viermächte-Pakt anschloß, hatte Herriot entgegen seiner ursprünglichen Absicht einen Antrag eingebracht ${ }^{613}$, in dem er die Unterzeichnung des Viermächte-Paktes befürwortete. Herriot rechtfertigte seinen Meinungsumschwung hinsichtlich der Kritik am Viermächte-Pakt folgendermaßen: „Le gouvernement a fait tout ce qu'il a pu pour le rendre inoffensif. C'est pourquoi je le soutiendrai ce soir, convaincu qu'il a fait pour le mieux. En agissant ainsi, je n'aliène pas ma liberté de discuter le moment venu." 614 Daladier war es mit seinem vehementen Einsatz gelungen, auch ursprüngliche Gegner in der eigenen Partei wie Herriot für den Vertrag einzunehmen. Die Sozialisten unterstützten auch in dieser außenpolitischen Frage die Re-

$610 \mathrm{Zu}$ den genannten Artikeln des Völkerbundvertrages - Artikel 10, 18, 19-vgl. E. Klöss (Hg.), Von Versailles bis zum Zweiten Weltkrieg, S. 45, 48, und zur Völkerbundsatzung ebenda, S. 42-51. Außerdem auch Le Temps vom 11.6. 1933, S. 3. Zum Völkerbund sind außerdem erwähnenswert: U. Hochschild, Sozialdemokratie und Völkerbund. Die Haltung der SPD und SFIO zum Völkerbund, Karlsruhe 1982; A. Pfeil, Der Völkerbund, Darmstadt 1976.

611 Artikel 3: „Die Hohen Vertragsabschließenden Teile verpflichten sich, alle Anstrengungen zu machen, um den Erfolg der Abrüstungskonferenz sicherzustellen; sie behalten sich vor, falls Fragen, die sie besonders betreffen, bei der Beendigung der Konferenzen offengeblieben sein sollten, deren Prüfung in Anwendung dieses Vertrages unter sich wiederaufzunehmen, um sicherzustellen, daß sie auf gecignetem Wege gelöst werden.“ Vgl. E. Klöss (Hg.), Von Versailles zum Zweiten Weltkrieg, S. $197 \mathrm{f}$.

612 Daladier beendete seine Rede mit folgenden Worten: „Il faut choisir. Nous croyons heureux, quant à nous, que les négociations aient abouti. Lorsque les hommes responsables de tous les pays considèrent les périls qui menacent l'ordre, l'équilibre du monde, la civilisation elle-même, comment pourraient-ils se dérober à leur devoir et s'abstenir de tout mettre en oeuvre afin de rétablir entre tous les peuples cet esprit de collaboration hors duquel il n'aura pas de salut. “; J.O., Chambre des Députés vom 9. 6. 1933, 2. Sitzung, S. 2823-2826, hier S. 2826; Le Temps vom 11. 6. 1933, S. 3.

613 Zum Antrag Herriots „La Chambre, approuvant les déclarations du gouvernement, et repoussant toute addition, passe à l'ordre du jour" siehe J.O., Chambre des Députés vom 9.6. 1933, 2. Sitzung, S. 2834 und auch Le Temps vom 11.6. 1933, S. 3.

614 Zur Rechtfertigung Herriots hinsichtlich seines Meinungsumschwunges in puncto ViermächtePakt siehe L'Oeuvre vom 10. 6. 1933, S. 4. Immerhin hatte sich Herriot noch einige Tage vor dieser Debatte äußerst kritisch über den Viermächte-Pakt geäußert, den er als einen Rückfall in die Bündnispolitik des 19. Jahrhunderts bezeichnet hatte. 
gierung Daladier und votierten für die Annahme des Viermächte-Paktes ${ }^{615}$. Dieser wurde mit 413 zu 163 Stimmen bestätigt ${ }^{616}$. Die einzelnen Fraktionen verhielten sich wie folgt:

\begin{tabular}{rlrccc}
\hline $\begin{array}{l}\text { An- } \\
\text { zahl }\end{array}$ & Parlamentarische Gruppe & Dafür & $\begin{array}{l}\text { Da- } \\
\text { gegen }\end{array}$ & $\begin{array}{l}\text { Enthal- } \\
\text { tung }\end{array}$ & $\begin{array}{l}\text { Abwe- } \\
\text { send }\end{array}$ \\
\hline 15 & Indépendants & 2 & 12 & 1 & - \\
17 & Groupe républicain et social & - & 17 & - & - \\
7 & Action économique, sociale et paysanne & 1 & 6 & - & - \\
38 & Fédération républicaine & - & 35 & 2 & 1 \\
33 & Centre républicain & - & 32 & - & 1 \\
29 & Républicains de gauche & 3 & 23 & 2 & 1 \\
16 & Démocrates populaires & 15 & 1 & - & - \\
6 & Républicains du centre & 5 & - & - & 1 \\
22 & Indépendants de gauche & 10 & 7 & 2 & 3 \\
48 & Gauche radicale & 36 & 7 & 2 & 3 \\
160 & Radicaux et radicaux socialistes & 157 & - & 1 & 2 \\
15 & Gauche indépendante & 12 & - & 3 & - \\
15 & Républicains socialistes & 13 & - & - & 2 \\
12 & Socialistes français & 12 & - & - & - \\
130 & Socialistes & 129 & - & 1 & - \\
9 & Unité ouvrière & 2 & - & 7 & - \\
10 & Communistes & - & 10 & - & - \\
31 & Isolés & 16 & 13 & 2 & - \\
\hline 613 & & 413 & 163 & 23 & 14 \\
\hline
\end{tabular}

Obwohl die Regierung Daladier von Beginn an von einer Linksmehrheit getragen wurde, darf nicht übersehen werden, daß es sich dabei nicht um eine wirklich stabile Mehrheit handelte. Denn zum einen befand sich die sozialistische Partei seit Beginn der Regierung Daladier in einer Krise, die sich mehr und mehr zu einer ernsthaften Bedrohung der Einheit der SFIO ausweitete und damit auch ein Risiko für die Stabilität der Linksmehrheit darstellte. Und zum anderen war auch die Geschlossenheit des Parti radical nur von begrenzter Dauer. Beides führte dazu, daß die Regierung Daladier letztlich im Oktober 1933 nach einer neunmonatigen Amtszeit scheiterte.

615 Für die Sozialisten ergriffen in dieser Debatte Bedouce, Frossard, Renaudel und Varenne das Wort; vgl. J.O., Chambre des Députés vom 9.6. 1933, 2. Sitzung, S. 2829, 2832, 2842; L'Oeuvre vom 10. 6. 1933, S. 1, 4, hier S. 4. Frossard argumentierte im Namen der sozialistischen Fraktion: „(...) maintenant, on a le choix entre la revision par des procédures de conciliation et la revision par la force. Les socialistes ont choisi; c'est la Société des Nations qui étudiera ce grave problème."

616 Abstimmung über den Viermächte-Pakt am 10.6. 1933 in Le Temps vom 11.6. 1933, S. 4. 


\section{Politischer Richtungskampf in der SFIO: Von der Krise zur Abspaltung der Neosozialisten}

Für die sozialistische Partei stellte die Regierung Daladier eine entscheidende Wegmarke in ihrer Geschichte dar. Bereits zu Beginn, noch in der Phase der Regierungsbildung Daladiers, wurde offensichtlich, daß die bisherige Parteitaktik der SFIO dieses Mal die Kluft zwischen dem linken und dem rechten Flügel in der Frage der Regierungsbeteiligung nicht mehr überwinden konnte. Als Daladier den Sozialisten ein Regierungsangebot unterbreitet hatte ${ }^{617}$, schien dem rechten Flügel der Zeitpunkt für eine sozialistische Regierungsbeteiligung aus mehreren Gründen besonders günstig zu sein. Zum einen hielten die Sozialisten Daladier von den möglichen radikalsozialistischen Ministerpräsidenten für den geeignetsten, um mit ihm eine sozialistische Regierungsbeteiligung zu realisieren. Daladier galt als der Vertreter des linken Flügels des Parti radical, der sich für die Sozialisten vor allem deshalb empfahl, da er den Parti radical unter seinem Parteivorsitz aus der Regierung der Union nationale in die Opposition geführt hatte ${ }^{618}$. Ein weiterer essentieller Aspekt, der einen Großteil der sozialistischen Fraktion für eine Regierungsbeteiligung votieren ließ, waren auch die äußeren Umstände der aktuellen Situation. Der rechte Flügel der Sozialisten befürchtete, wenn eine weitere Regierung nach dem Wahlsieg der Linkskräfte scheitere, daß es dann zu einer Neuauflage der Verhältnisse von 1926 kommen könnte. Denn obwohl 1924 das Cartel des gauches die Wahlen gewonnen hatte, übernahm nach mehreren gescheiterten Linksregierungen in einer akuten Krisensituation 1926 ein Kabinett der Union nationale die Regierungsgeschäfte. Eine Wiederholung dieser Ereignisse mußte auf jeden Fall vermieden werden. Und ein dritter Aspekt war die Hoffnung, daß in der aktuellen Krisensituation mit Hilfe einer sozialistischen Regierungsbeteiligung innovative Maßnahmen zur Behebung der Krise ermöglicht werden könnten.

Aber schon nach kurzer Verhandlungsphase ${ }^{619}$ zwischen Daladier und einer sozialistischen Delegation, bestehend aus Auriol, Blum, Bracke, Compère-Morel, Frossard, Morizet und Renaudel620, wurde klar, daß es keine Basis für die sozialistischen Vorstellungen gab. Daladier hatte bei dem ersten Gespräch mit der sozialistischen Delegation zwar dargelegt, daß sein Programm eine Reduzierung der militärischen Ausgaben und finanzpolitische Maßnahmen beinhalten würde, die durchaus im sozialistischen Sinne wären ${ }^{621}$. Dennoch wurde im Gespräch mit den

${ }^{617}$ Daladier hatte noch am 30.1. 1933 den Sozialisten die Regierungsbeteiligung und fünf Ministerposten angeboten; vgl. den entsprechenden Abschnitt in Unterkapitel 5 dieses zweiten Prozeßbeispiels.

618 Vgl. dazu Kapitel 1 dieses zweiten Prozeßbeispiels.

619 Eine ausführliche Schilderung der Verhandlungen zwischen der sozialistischen Delegation und

Daladier sowic der internen Vorgänge über die erneute Frage der Regierungsbeteiligung werden in

La Vie du Parti, einer Beilage der Parteizeitung Le Populaire, vom 13.2.1933 gegeben. Ferner geben über die Vorgänge Auskunft: La Vie du Parti vom 11. 2. 1933; L'Oeuvre vom 31.1.1933; Le Populaire vom 31. 1. und 1. 2. 1933, sowie G. Ziebura, Blum, S. 437-459.

620 L'Oeuvre vom 31. 1. 1933, S. 1.

621 Hinsichtlich des Regierungsprogrammes hatte Daladier der sozialistischen Delegation folgende Angaben gemacht: „Je considère d'abord qu'il faut libérer l'Etat républicain des difficultés de trésorerie que vous connaissez (...). Si nous ne libérons pas l'Etat, il sera dans les mains des banques 
sozialistischen Vertretern deutlich, daß Daladier nicht bereit war, die in den "Cahiers de Huyghens" zusammengefassten Forderungen der Sozialisten, auf deren Berücksichtigung die sozialistischen Verhandlungspartner drängten, zur Grundlage seines Regierungsprogramms zu machen. Als Blum mit dem Einwand einer Einberufung des Conseil national Zeit zu gewinnen hoffte, lehnte Daladier dies $\mathrm{ab}$, da er angesichts der politischen Situation keine Zeit verlieren wollte, und schließlich verwies er auf seine schlechten Erfahrungen, die er bereits 1929 mit den Sozialisten in diesem Punkt gemacht hatte ${ }^{622}$. Es zeigte sich deutlich, daß Daladier es aus parteiinternen Gründen doch bevorzugte, nur mit einer sozialistischen Unterstützung, nicht aber gemeinsam mit der SFIO zu regieren.

Nach dem Gespräch mit Daladier zog sich die Fraktion der SFIO zu internen Beratungen zurück. Es kristallisierten sich drei Tendenzen innerhalb der sozialistischen Fraktion heraus, die sich in drei Resolutionsanträgen niederschlugen. Eine Strömung, die sich um die führenden Köpfe Renaudel, Compère-Morel und Marquet gruppiert hatte, sprach sich für die sofortige Annahme des Regierungsangebotes aus, also ohne Einberufung des Conseil national, und unterstrich dabei vor allem die Bedeutung einer stabilen Linksmehrheit und die eventuellen Konsequenzen für den Fall eines erneuten Scheiterns ${ }^{623}$. Eine zweite Gruppe, die sich um Blum und Lebas sammelte, lehnte das Angebot Daladiers ohne eine vorherige Einberufung des Conseil national ab und verwies außerdem darauf, daß das Programm Daladiers zu sehr von den sozialistischen Vorstellungen der "Cahiers de Huyghens" abweiche624. Die dritte Gruppe, deren Wortführer Auriol und Déat waren, schlug vor, ein erneutes Gespräch mit Daladier zu führen und ihn direkt auf die sozialistischen Vorstellungen der "Cahiers de Huyghens" anzusprechen. Falls er ihnen zustimme, empfahlen sie, ohne Einberufung des Conseil national das Regierungsangebot Daladiers anzunehmen. Die Formulierung, die sie zur Begründung einer Zustimmung wählten, war jedoch sehr ambivalent gehalten: „Le Groupe Socialiste (...) se déclare prêt à accorder sa collaboration au nouveau gouvernement, s'il est bien entendu que l'action ministérielle s'inspirera à la fois du caractère exceptionnel des circonstances présentes, et des directions générales proposées au Parti radical-socialiste après la victoire du 8 mai (1932) par le congrès national du Parti socialiste."625 Gerade diese Formulierungen des letzten Abschnittes ließen einen größeren Interpretationsspielraum offen, der wohl dazu führte, daß der Antrag sich bei der Abstimmung in der sozialistischen Fraktion

(...). Je prendrai pour base de l'équilibre budgétaire le projet de la commission des finances, texte sur lequel les radicaux et les socialistes sont tombés d'accord. J'accepte le texte même qu'Auriol la rédigé l'autre nuit sur la question des impôts, sur les gros revenus non entamés par la crise. Je fais sculement des réserves sur le titre à endos (...). Je crois qu'il faut réprimer la fraude, mais il ne faut pas laisser échapper l'armée des petits possédants, des petits épargnants (...). Pour ce qui est des dépenses militaires, je poursuivrai la réforme du statut militaire, des lois organiques (...); je poursuivirai également les travaux de la commission nommée par Paul-Boncour en ce qui concerne la fabrication privée des armes. Enfin je dirai qu'il faut développer l'œuvre scolaire aujourd'hui inachevée."; siehe L’OURS, Cahiers et Revue Nr. 58 (März 1975), S. 40.

622 Vgl. dazu Kapitel 1 dieses zweiten Prozeßbeispiels.

${ }^{623}$ Diese Tendenz war innerhalb der SFIO ziemlich stark, vgl. dazu L'OURS, Cahiers et Revue 58 (März 1975), S. 41.

${ }_{624}$ Die zweite Gruppe stellte innerhalb der SFIO eine Minderheit dar; ebenda.

${ }^{625}$ Zum ausführlichen Textlaut der Resolution Auriols und Déats siehe ebenda sowie Le Populaire vom 6. 2. 1933, S. 1 . 
mit 64 zu 17 Stimmen durchsetzen konnte. Die fehlende Präzision wiederum war auch der Grund, warum sich Blum vor der Abstimmung gegen diese Resolution wandte. Er monierte, daß es diesem Antrag an Eindeutigkeit fehle.

Aufgrund der Resolution von Auriol und Déat fanden noch zwei weitere Gespräche mit Daladier statt, in deren Verlauf Daladier zunächst bereits gegebene Zusagen in programmatischen Fragen zurücknahm und sich schließlich eindeutig dahingehend äußerte, daß die Forderungen der Sozialisten in den „Cahiers de Huyghens" für ihn nicht akzeptabel seien. Nach dieser unmißverständlichen Absage Daladiers hatten auch diejenigen unter den Sozialisten, die sich für eine Regierungsbeteiligung stark gemacht hatten, kein Interesse mehr an einer Regierungsteilnahme. So beschloß die sozialistische Fraktion einstimmig, nicht an der Regierung Daladiers teilzunehmen ${ }^{626}$. Als Grund gab sie vor allem die unterschiedlichen Vorstellungen in der Finanzpolitik an ${ }^{627}$. Vordergründig schien mit dieser einstimmigen Entscheidung in der sozialistischen Fraktion die Einheit wiederhergestellt zu sein, aber schon kurze Zeit später sollte sich herausstellen, daß die wiedergefundene Einheit trügerisch war.

Dies offenbarte sich in besonders markanter Weise, als es parteiintern in der SFIO zu einem Nachspiel wegen der vorübergehenden Zusage der sozialistischen Fraktion zu Daladiers Koalitionsangebot kam. Kurz nach dem Verzicht der Sozialisten auf eine Regierungsbeteiligung äußerten sich Sprecher der verschiedenen Tendenzen in der SFIO zu den Vorgängen in dieser Angelegenheit, denn der Conseil national wurde für den 5. Februar 1933 einberufen. Paul Faure gab in seinen Äußerungen zu verstehen, daß der alte Konflikt zwischen Partei und Fraktion, und damit der Konflikt zwischen den Anhängern der Regierungsbeteiligung und ihren Gegnern wieder aufgebrochen war. Diese Tatsache war an sich eigentlich kein Novum für die SFIO, aber jetzt war die Mehrheit der Fraktion einen Schritt weiter gegangen und hatte sich - ohne den Conseil national einzuberufen - für eine Regierungsbeteiligung entschieden. Schon damit hatte die Fraktion eindeutig ihre Kompetenzen überschritten, was Paul Faure nicht versäumte zu monieren: „Il suffisait d'un coup de chaupeau poli de $M$. Daladier aux directions générales de Huyghens - dont le mot n'était même pas prononcé - et le Parti apprenait par voie de presse que la participation était un fait accompli, en dehors de toutes les règles et conditions établies et voulues par lui."“28

Auch Pierre Renaudel, der als dezidierter Befürworter einer Regierungsbeteiligung aufgetreten war, meldete sich im Populaire vom 2. Februar $1933 \mathrm{zu}$ Wort. Er ließ es ebenso wenig an Deutlichkeit fehlen und unterstrich die schweren Konsequenzen, die aus dem Verzicht auf die Regierungsverantwortung seiner Meinung nach resultieren konnten, nämlich das Ende der linken Mehrheit ${ }^{629}$. Darüber hin-

626 „Mais après les trois entrevues qu'ont eues ses déléguées avec M. Daladier, il est obligé de constater que non seulement sur aucun point d'un programme qui pouvait pourtant se recommander de la tradition républicaine (...). Dans ces conditions, le Groupe socialiste unanime a constaté que les conversations engagées avec M. Daladier ne pouvaient plus avoir d'objet (...). “ Zur Resolution in extenso siehe L'OURS, Cahiers et Revue 58 (März 1975), S. 42 und auch Le Populaire vom 6. 2. 1933, S. 1.

627 Vgl. dazu auch die Resolution, ebenda.

${ }^{628}$ Le Populaire vom 2. 2. 1933, S. 1. Außerdem L'OURS, Cahiers et Revue 58 (März 1975), S. 43.

629 Ebenda. 
aus deutete Renaudel bereits zu diesem Zeitpunkt an, welche Konsequenzen er persönlich daraus ziehen werde, auch wenn bis zur Realisierung dieses Schrittes noch ein halbes Jahr vergehen sollte. Er verkündete: „Pour moi, mon choix est fait." $630 \mathrm{Im}$ Oktober trat Renaudel mit anderen sozialistischen Abgeordneten aus der SFIO aus. Die beiden Positionen, die sich innerhalb der SFIO im Laufe der Zwischenkriegszeit immer weiter verfestigt hatten, schienen nun immer mehr unüberbrückbar zu werden, wie sich auch im weiteren Verlauf der Angelegenheit zeigen sollte. Als am 5. Februar 1933 der Conseil national einberufen wurde, um das Vorgehen der 64 Abgeordneten, die für eine Beteiligung gestimmt hatten, zu beurteilen, war keine Einheit in der SFIO herzustellen. Im Gegenteil, vier Resolutionsanträge ${ }^{631}$ mit unterschiedlicher Beurteilung des Vorfalls wurden eingereicht. Von den vier Anträgen ${ }^{632}$ setzte sich der von Séverac, Blum, Faure und Lebas verfasste mit 2636 zu 1070 Stimmen durch. Damit konnte sich diejenige Gruppe behaupten, die das Vorgehen der Fraktionsmehrheit mit folgender Begründung verurteilte: Zum einen beanstandete der Conseil national, daß die Fraktion ohne Rücksprache eine Entscheidung dieser Tragweite nicht beschließen könne. Ein solches Verhalten verstoße gegen die Parteigrundsätze. Ein weiterer Kritikpunkt betraf die Feststellung, daß die "Cahiers de Huyghens" vom Parteitag von 1932 verbindlich verabschiedet worden seien und daher die Richtlinie für jedes politische Handeln darstellten. Die Verhandlungen mit Daladier hätten auf dieser Grundlage erfolgen müssen, da aber diese Grundlage nicht gegeben war, habe sich die Fraktion in ihrem weiteren Vorgehen außerhalb der Parteitagsbeschlüsse von 1932 bewegt. Darüber hinaus wurde der Fraktionsmehrheit vorgeworfen, das Parteistatut, eine ständige Zusammenarbeit mit bürgerlichen Parteien zu vermeiden, weil das gegen den Charakter der SFIO als Klassenpartei verstoße ${ }^{633}$, verletzt zu haben. Dem Antrag unterlag die von Marquet, Renaudel und Grumbach eingereichte Resolution, die das Vorgehen der 64 Abgeordneten rechtfertigte und verteidigte. In diesem Resolutionsantrag wurde vorgebracht, daß die besonderen politischen Umstände ein außergewöhnliches Handeln der sozialistischen Fraktion notwendig gemacht hätten. Darüber hinaus habe die Verantwortung für den Erhalt der Linksmehrheit im Parlament eine Beteiligung der Sozialisten an der Regierung Daladier gerechtfertigt ${ }^{634}$. Obwohl der Antrag Séveracs, der das Verhalten der 64 Abgeordneten getadelt hatte, die Mehrheit der Stimmen erhielt, war das Problem der Regierungsbeteiligung nicht gelöst, denn die 64 Abgeordneten ak-

${ }^{630}$ Ebenda. Dies ist eine Anspielung auf Jaurès und seine Rolle bzw. Verteidigung Dreyfus' in der Dreyfus-Affäre; vgl. dazu M. Gallo, Le Grand Jaurès, Paris 1984, S. 211-219.

${ }_{631} \mathrm{Zu}$ den vier Resolutionsanträgen in extenso siehe L'OURS, Cahiers et Revue Nr. 58 (März 1975), S. 44-47.

${ }_{632}$ Von den vier Anträgen erhielt der von Séverac, Blum, Faure und Lebas die meisten Stimmen. An zweiter Stelle lag derjenige von Marquet, Renaudel und Grumbach. 83 Stimmen konnte eine Resolution von Blumel auf sich vereinen, der sich offen für eine Regierungsbeteiligung auf der Basis der "Cahiers de Hugyhens" ausgesprochen hatte, und 36 Stimmen erzielte der Antrag von d'Alleaume, der den extremen linken Flügel in der SFIO vertrat und der nicht nur jegliche Regierungsbeteiligung ablehnte, sondern auch jegliche Regierungsunterstützung. Siehe dazu ebenda und auch Le Populaire vom 6. 2. 1933, S. 1, 6.

633 Ausführlicher Text dieser Resolution in L'OURS, Cahiers et Revue 58 (März 1975), S. 44/45 und auch Le Populaire vom 6. 2. 1933, S. 1.

${ }^{634}$ Der Resolutionsantrag in extenso in L'OURS, Cahiers et Revue 58 (März 1975), S. 45/46. 
zeptierten die „Verurteilung“ ihres Verhaltens nicht. Im Gegenteil, sie hielten die Angelegenheit nicht für gelöst und forderten, daß auf dem außerordentlichen Parteitag, der im April in Avignon abgehalten werden sollte, diese Frage geklärt werde. Renaudel, der erneut als Sprecher der „Participationnistes“635 auftrat, begründete den Vorstoß mit dem Argument, daß die Mehrheit, die sich für den Antrag Séveracs auf der Tagung des Conseil national entschieden hatte, nicht die komplexen Zusammenhänge jener Entscheidung für die zukünftige demokratische Entwicklung und für die Entwicklung der sozialistischen Partei in Frankreich erkannt habe und daher dringend Diskussions- und Klärungsbedarf bestehe ${ }^{636}$.

Weil die Mehrheit der Fraktion ihre unbedingte und feste Überzeugung unterstreichen wollte, verabschiedete sie eine Resolution, in der sie betonte, daß sie an einem guten Verhältnis zur Partei sowie an der Einheit der sozialistischen Partei festhalten wolle. Sie betonte außerdem, daß sie im Einklang mit der sozialistischen Doktrin gehandelt habe, wenn auch die Tagespolitik besondere Formen der Taktik und Aktion verlange. Abschließend kündigte sie an, zum besseren Verständnis ihres Handelns ein Protokoll zu veröffentlichen, das über alle Schritte der Fraktion seit dem 30. Januar 1933 Rechenschaft ablege, so daß der Fraktion auf dem außerordentlichen Parteitag wieder das Vertrauen ausgesprochen werden könne, „(...) dont il a besoin pour servir le Parti dans les conditions d'autorité et d'efficacité conformes aux intérêts de la classe ouvrière, de la démocratie et du socialisme."637 Dieses Vorgehen der „Participationnistes“ kann in zweierlei Hinsicht interpretiert werden: 1) Zum einen als Kampf für ihre Überzeugung. Denn angesichts der politischen Umstände hielten sie es für dringend erforderlich, daß die sozialistische Partei zum Erhalt der Demokratie in Frankreich Regierungsverantwortung übernahm. Außerdem schien ihnen dies auch wichtig, um die sozialistischen Reformvorstellungen in die politische Praxis umsetzen zu können. 2) Zum anderen als Versuch, die Einheit der sozialistischen Partei zu bewahren. Aber die Gegensätze zwischen den beiden Flügeln in der SFIO waren mittlerweile sehr stark ausgeprägt. Dies unterstreicht z. B. die Gegenreaktion von Lebas, der sich im Populaire am 12. Februar $1933638 \mathrm{zu}$ Wort meldete, um seinem Erstaunen Ausdruck zu verleihen, daß die Diskussion um die Regierungsbeteiligung noch immer anhalte, obwohl doch der Conseil national bereits eine Entscheidung getroffen habe. Es entspann sich im Vorfeld des außerordentlichen Parteitages in der Parteizeitung Le Populaire ein Schlagabtausch zwischen den Gegnern und Befürwortern einer Regierungsbeteiligung ${ }^{639}$, der sich von Februar bis April 1933 erstreckte und zunehmend schärfer wurde 640 . Zusätzlichen Zündstoff bekam die Auseinan-

${ }^{635}$ Damit waren die Anhänger einer Regierungsbeteiligung gemeint.

${ }_{636}$ Renaudel in Le Populaire vom 10. 2. 1933, S. $1 / 2$.

637 Le Populaire vom 10. 2. 1933, S. 2, und auch L'OURS, Cahiers et Revuc 58 (März 1975), S. 47/48.

${ }^{638}$ Lebas in Le Populaire vom 12. 2. 1933, S. 1.

${ }_{639}$ Vgl. hierzu die Leitartikel von Lebas in Le Populaire vom 22. 2. 1933, S. 1; vom 6. 3. 1933, S. 1; vom 13. 3. 1933, S. 1/2; vom 20. 3. 1933, S. 1; vom 27.3.1933, S. 1/2; vom 3. 4. 1933, S. 1/2, sowie die Artikel von Renaudel in Le Populaire vom 17.2. 1933, S. 1/2; vom 26. 2. 1933, S. 1; vom 3. 3. 1933, S. 1; vom 18. 3. 1933, S. 1/2; vom 23. 3. 1933, S. 1; vom 30. 3. 1933, S. 1/2; vom 6. 4. 1933, S. 1; vom 13. 4. 1933, S. 1. Vgl. dazu auch L'OURS, Cahiers et Revue 58 (März 1975), S. 48 ff.

${ }^{640}$ Den großen Dissens zwischen den beiden Parteiflügeln verdeutlicht die Auseinandersetzung zwischen Lebas und Renaudel. Lebas schrieb in Le Populaire vom 3. 3. 1933, S. 1: „(..) le Parti aura à 
dersetzung zwischen den beiden Tendenzen durch das Handeln der Mehrheit der sozialistischen Fraktion, die die Regierung Daladier in Abstimmungen unterstützte. Sogar die Finanzpolitik ${ }^{641}$, die Daladier mit deflationistischen Maßnahmen bestritt, wurde von der Mehrheit der sozialistischen Fraktion gebilligt, obwohl diese Politik eindeutig gegen die sozialistischen Vorstellungen verstieß. Nur eine Minderheit von 23 Abgeordneten, die sich um Blum und Lebas gruppierten, votierte gegen das finanzpolitische Programm Daladiers. Durch dieses Verhalten, das die Mehrheit der Fraktion für notwendig hielt, um die Regierung Daladier vor dem Sturz zu bewahren und damit eine Rechtsregierung zu verhindern, war die Abstimmungsdisziplin, die zu den elementaren Säulen der SFIO gehörte, nicht mehr gewahrt und somit die Einheit der Fraktion ernsthaft gefährdet. Um die Abstimmungsdisziplin wiederherzustellen, griffen Blum und auch Auriol, die nicht immer einer Meinung innerhalb der SFIO waren, zum äußersten Druckmittel und legten ihre Fraktionsämter nieder, d.h. Auriol trat vom Fraktionsvorsitz und Blum vom Posten des Fraktionssekretärs zurück ${ }^{642}$. Auf einer Versammlung, die vom linken Flügel organisiert wurde, versuchte Blum, die Fraktion für seinen Standpunkt zu gewinnen. Er war der Meinung, daß es sich bei der Frage Regierungsbeteiligung oder Unterstützung nicht um eine Entweder - Oder - Entscheidung, sondern um eine Lösung des Sowohl - Als - Auch handle643. Mit seiner Formel brachte Blum zum Ausdruck, daß er es ablehnte, eine Entscheidung zu treffen, die entweder auf eine generelle Zustimmung oder eine generelle Ablehnung der Regierungsvorschläge hinauslief. Er plädierte für ein stetes Abwägen von Abstimmung zu Abstimmung. Blum sah darin eine Möglichkeit, um die Position der Fraktion gegenüber der Regierung zu stärken. Allerdings gelang es ihm nicht, die Mehrheit der Fraktion davon zu überzeugen, und so stimmte diese weiterhin für die Regierung.

Nachdem sich in den Wochen zwischen Februar und April 1933, also zwischen der Einberufung und dem Zusammentreten des außerordentlichen Parteitages, der Graben zwischen den beiden Parteiflügeln der SFIO vertieft hatte und in den Zeitungen sogar das Wort Abspaltung bzw. Trennung zu lesen war, setzte sich

choisir entre deux politiques toutes différentes, et nous disons tout de suite que le désaccord entre elles est tel qu'il ne saurait être question de les concilier." Und Renaudel antwortete darauf in Le Populaire vom 6. 4. 1933, S. 1: „Pas de conciliation? A votre aise, (...) je persiste à penser (...) que lorsqu'on est conduit (...) à mettre le Parti lui-même en opposition avec la grande majorité des élus parlementaires, on risque d'un coeur léger les plus graves périls pour l'unité elle-même. “ $\mathrm{Zu}$ den einzelnen Etappen und der letztendlichen Abspaltung der "Neo-Sozialisten“ siehe L'OURS, Cahiers et Revue 58 ( März 1975), S. 50-63 und L'OURS, Cahiers et Revue 59 (April 1975), S. 6-70.

${ }^{6+1}$ Vgl. dazu Le Populaire vom 31.5. 1933, S. 3; vom 1.6. 1933, S. 1, 3; vom 2. 6. 1933, S. 1/2, sowie auch L'Oeuvre vom 31. 5. 1933, S. 1, 4; vom 1. 6. 1933, S. 1, 4; vom 2. 6. 1933, S. 1, 2, 4. Siehe auch Unterkapitel 5 dieses zweiten Prozeßbeispiels.

642 Bei einer Sitzung der sozialistischen Fraktion am 16.5. 1933 standen zwei Resolutionen auf der Tagesordnung: Eine von Hubert Rouger und die andere von Pierre Renaudel, wobei sich die Resolution von Rouger mit 64 zu 36 Stimmen bei vier Enthaltungen durchsetzen konnte; vgl. Le Populaire vom 17. 5. 1933, S. 3/4. Der Text der Resolution von Rouger lautete: „Le groupe socialiste confirmant ses décisions antérieures prises à l'unanimité, demande à Léon Blum et à Vincent $\mathrm{Au}$ riol de reprendre leurs places au bureau du groupe et charge sa délégation exécutive de présenter à une très prochaine séance un projet de réorganisation de fonctionnement du groupe (...).“; vgl. Le Populaire vom 17.4. 1933, S. 3; Le Temps vom 17. 5. 1933, S. 8.

${ }^{643} \mathrm{Vgl}$. dazu die Rede Blums, die in La Vie Socialiste vom 8. 4. 1933, S. $17 \mathrm{f}$. abgedruckt ist, sowie auch G. Ziebura, Blum. S. 442. 
diese Atmosphäre zunächst auf dem außerordentlichen Parteitag in Avignon ${ }^{644}$ fort. Wie groß bereits die Kluft zwischen den beiden Flügeln war, zeigte sich darin, daß sich die beiden innerparteilichen Gegner getrennt in Vorgesprächen berieten. Obwohl aber auch auf diesem außerordentlichen Parteitag der SFIO des öfteren das Wort von der Spaltung fiel ${ }^{645}$, gelang es, diese vorerst noch zu verhindern. Denn von den drei eingereichten Anträgen ${ }^{646}$ konnte sich der von Léon Blum behaupten, der sich durch sehr gemäßigte Formulierungen auszeichnete, die er wohl bewußt gewählt hatte, um damit eine Brücke zwischen der Fraktion und der Partei schlagen zu können. Im Grundsatz spiegelte dieser Antrag die Haltung der Mehrheit in der SFIO wider, denn er kann als Plädoyer für die sozialistische Doktrin gesehen werden und unterstreicht auch nochmals das Parteiverständnis der SFIO. Allen drei Antragstexten war gemeinsam, daß sie das Agieren der Mehrheit der sozialistischen Fraktion nicht tadelten oder verurteilten. Der Antrag Blums, der 2807 Stimmen auf sich vereinen konnte, versuchte nochmals, die Mehrheit der Fraktion zu disziplinieren, indem er die wichtigsten Elemente der sozialistischen Taktik und Doktrin verband. Der Text kann als eine Art Gedächtnisstütze für die Fraktion gelesen werden, die daran erinnert wurde, daß eine Regierungsbeteiligung nicht ohne Einverständnis des Conseil national und des Parteitages erfolgen könne. Gleichzeitig versuchte Blum, der Fraktion die diffizielle Position der SFIO im parlamentarischen Leben vor Augen zu führen, denn das Agieren der SFIO, so Blum, müsse als eine Gratwanderung begriffen werden. Einerseits dürfe die SFIO nicht dauerhaft mit bürgerlichen Parteien zusammenarbeiten, da sie sonst ihre Aufgaben als Klassenpartei nicht mehr wahrnehmen und ihren Charakter nicht mehr wahren könne, aber andererseits dürfe sie nicht in die Rolle einer permanenten Oppositionspartei verfallen, da sie auch Verantwortung für die parlamentarische Demokratie trage. Obwohl er die Fraktion ermutigte, mit ihrem Handeln am Erhalt der demokratischen Regierungsform in Frankreich mitzuwirken, betonte Blum, daß dieses Motiv nicht zum alleinigen Handlungsmotor werden dürfe. Entscheidendes Kriterium für die Zustimmung zu Regierungsvorlagen müsse die Nähe zur sozialistischen Position sein oder zumindest müßten die Regierungsvorlagen der radikal-sozialistischen Doktrin entsprechen. Er lehnte strikt ab, daß die sozialistische Fraktion der Regierung zustimme, nur um damit die Regierungsmehrheit aufrechtzuerhalten. Oberste Devise sei, daß die Einheit der Partei eindeutige Priorität vor dem Erhalt der Regierungsmehrheit besitze. Blum machte in seinem Schlußsatz nochmals deutlich, daß er auf keinen Fall bereit war, die Einheit der Partei zu opfern, nur um im Parlament eine Linksmehrheit zu sichern. In seinen Augen sollten auch die anderen Fraktionen zu Kompro-

${ }^{644}$ Siehe dazu das Parteitagsprotokoll der SFIO vom 30 Congrès National à Paris 14-17 juilliet 1933, Paris 1933. Hier sind auch die Protokolle vom außerordentlichen Parteitag der SFIO vom 16. 4.17. 4. 1933 abgedruckt. Außerdem vgl. auch die Berichterstattung über den außerordentlichen Parteitag in Le Populaire vom 16. 4.-19. 4. 1933, jeweils S. 1, 3, 4.

${ }^{645}$ So z. B. in Le Populaire vom 17. 4. 1933, S. 1 .

646 Neben dem Antrag von Léon Blum wurden noch zwei weitere Antragstextc zur Abstimmung vorgelegt. Für die beiden anderen Anträge waren einmal Pierre Renaudel, der die Unterstützungspolitik der Mehrheit der Fraktion rechtfertigte und zum anderen Maurice Maurin, der die extreme Linke in der SFIO repräsentierte, verantwortlich. Zum Textlaut in extenso der beiden Resolutionen siehe L'OURS, Cahiers et Revue Nr. 58 (März 1975), S. 60-62 und S. 62/63. 
missen gegenüber der $S F I O$ bereit sein, um eine regierungsfähige Mehrheit mit sozialistischer Hilfe aufrechterhalten zu können ${ }^{647}$. Obwohl die Mehrheit des außerordentlichen Parteitages sich für den Antrag Blums entschied, fand keine direkte Kritik am Verhalten der sozialistischen Fraktionsmehrheit statt, wenn auch die von Blum geforderte Taktik der von der Mehrheit der Fraktion praktizierten diametral entgegenstand. So führte dieser Parteitag von Avignon zu einer Pattsituation innerhalb der SFIO, denn zu einer wirklichen Entscheidung war es nicht gekommen. Es schien, daß sich der Graben zwischen der Partei und der Fraktion noch vergrößert hatte, wie die Stellungnahmen Renaudels und Séveracs verdeutlichen. Renaudel, der für den rechten Flügel sprach, meinte nach der Abstimmung, die zugunsten der Blumschen Resolution ausging, daß die Fraktion ihre bisherige Haltung dennoch fortsetzen werde ${ }^{648}$; Séverac dagegen äußerte, daß die Partei den notwendigen Schritt einer Spaltung vornehmen müsse, da dieser in seinen Augen unumgänglich sei649. In dieser äußerst kritischen Situation hoffte Blum, mit diversen Leitartikeln 650 die akute Gefahr der Spaltung von der SFIO nochmals abwenden zu können. In verschiedenen Artikeln appellierte Blum an die Einheit der Partei und verurteilte jegliche Abspaltungsbestrebungen, die vor allem dem Parti radical zugute kommen würden. Blum unterstellte den Radikalsozialisten skrupelloses politisches Kalkül: Daladier habe von Beginn an mit seinem Regierungsangebot an die SFIO versucht, den Flügel der „Participationnistes“ von der SFIO abzuspalten, um über eine regierungsfähige Mehrheit im Parlament zu verfügen. Mit der Entlarvung dieses Kalküls hoffte er, die Mehrheit der Fraktion zur Räson zu bringen. Obwohl für seine Vermutungen keine eindeutigen Beweise vorlagen, kann zumindest als Indiz für den Verdacht angeführt werden, daß die Zeitung L'Oeuvre das Verhalten des rechten Flügels der SFIO in einer Kampagne würdigte und damit zu stärken versuchte ${ }^{651}$. Die Situation in der SFIO blieb unverändert ernst, auch wenn die Mehrheit der sozialistischen Fraktion sich für die Rückkehr Blums und Auriols in ihre Fraktionsämter aussprach ${ }^{652}$. Zum entscheidenden und endgültigen Ereignis, das den Bruch der Anhänger um Renaudel mit der

${ }_{647}$ Zitat aus dem Antrag Blum: „Le Parti Socialiste est un Parti de lutte de classe. (...) Les ćlus du Parti forment au Parlement un groupe unique en face de toutes les fractions politiques bourgeoises. $\mathrm{Ni}$ le bloc de gauches, ni le ministérialisme, condamnés, ne trouveront dans les rangs du Parti Socialiste la moindre chance de succès." L'OURS, Cahiers et Revue 58 (März 1975), S. 54/55.

${ }_{648}$ Le Populaire vom 18. 4. 1933, S. 1; vgl. dazu den Artikel in L'Oeuvre vom 19. 4. 1933, S. 1.

${ }^{649}$ Séverac hatte sich dahingehend geäußert, „(...) que si le parti socialiste devait continuer d'être ce qu'il est, c'est-à-dire à la remorque d'un parti bourgeois, s'il devait continuer comme règle de sauver toujours un gouvernement bourgeois, de voter les crédits de guerre, j'estimerais, en effet, que les hommes qui pensent le contraire, ne pourraient rester ensemble (...)." Le Populaire vom 17.4. 1933, S. 2.

650 Vgl. dazu Blum in Le Populaire vom 20. 4., 21. 4., 26. 4. und 27. 4. 1933, jeweils S. 1.

651 Vgl. z.B. zu diesem Thema folgende Artikel: L'Oeuvre vom 1. 5. 1933, S. 1/2: „Mais le danger, les chefs socialistes belges le connaissent. Et c'est pour cela qu'ils ne séparent pas leur action de celle de tous les démocrates de bonne volonté. Ils savent que la défense contre le fascisme est, à l'heure où nous sommcs, la tâche primordiale, qu'elle prime les considérations doctrinales, et qu'elle peut être menée à bien que par l'union, dont le souci exclut les intransigeances dogmatiques. Mais ce soucice souci de défense démocratique - n'est pas précisement celui que M. Paul Faure est M. J.-B Séverac reprochent à $M$. Renaudel et à ses amis de mettre en avant de tout, au détriment des, principes'?"; außerdem auch L'Oeuvre vom 5. 5. 1933, S. 1/2 und vom 15. 5. 1933, S. 1.

652 Beide wurden mit 64 zu 34 Stimmen in ihr jeweiliges Amt wiedereingesetzt; Le Populaire vom 17. 4. 1933, S. 3 . 
SFIO nach sich zog, kam es Ende Mai 1933, als die Mehrheit der sozialistischen Fraktion auch bei der zweiten Lesung der Haushaltsvorlage für den Entwurf der Regierung stimmte und ihre Haltung mit dem Hinweis rechtfertigte, daß an dieser Budgetvorlage alle Fraktionen der parlamentarischen Mehrheit mitgewirkt hätten. Blum trat entschieden dagegen auf, und forderte grundsätzlich die Wahrung der Abstimmungsdisziplin. Um diese zu gewährleisten, sprach er sich für eine Stimmenthaltung aus ${ }^{653}$. Aber er konnte damit die Mehrheit der Fraktion nicht überzeugen, denn sie entschied sich, mit $45 \mathrm{zu} 32$ Stimmen für die Haushaltsvorlage zu votieren ${ }^{654}$. Dieses Verhalten wurde unverzüglich vom obersten Parteigremium CAP scharf verurteilt, da dieses Votum gegen den Beschluß des außerordentlichen Parteitages von Avignon verstieß655. In einer weiteren Sitzung der Fraktion versuchte Blum, einen erneuten Vorstoß für die Wahrung der Abstimmungsdisziplin zu unternehmen, verlangte dieses $\mathrm{Mal}$ aber die Ablehnung der Budgetvorlage ${ }^{656}$. Eine deutliche Mehrheit, d.h. 63 gegen 28 Abgeordnete, beschlossen, die Regierungsvorlage zu unterstützen, und lehnten gleichzeitig die Entschuldigung der $C A P \mathrm{ab}^{657}$. Mit diesem Vorgehen bekam der schon seit längerem im Raum stehende Konflikt eine neue Schärfe, d.h. der Entschluß des rechten Flügels bzw. eines Teiles des rechten Flügels, notfalls gegen die Vorgaben der sozialistischen Doktrin zu handeln und damit auch eine Trennung von der Partei in Kauf zu nehmen, wurde jetzt ganz offensichtlich und sollte bald in die Tat umgesetzt werden.

Obwohl Léon Blum versucht hatte, nochmals einen Ausgleich zwischen den beiden Richtungen in der SFIO zu schaffen, indem er eine Brücke zwischen der Resolution von Avignon und dem Handeln der Fraktion zu schlagen hoffte, trat die unüberbrückbare Distanz schonungslos zutage. In einigen sehr gewagten theoretischen Überlegungen entwickelte Blum schließlich eine Konstruktion, die die Zustimmung der Mehrheit der sozialistischen Fraktion zu der von der Regierung vorgelegten Budgetvorlage rechtfertigen sollte. Obwohl sich Léon Blum vor der Abstimmung über die Budgetvorlage gegen diese ausgesprochen hatte, votierte er letztlich dafür ${ }^{658}$, da er im Vorfeld sehen konnte, daß die Mehrheit der

${ }^{653}$ Blum hatte sich in der Fraktionssitzung am 25. 5. 1933 für cine Stimmenthaltung ausgesprochen; siche Le Temps vom 25. 5. 1933, S. 8.

${ }^{654}$ Am 27. 5.1933 beschloß die sozialistische Fraktion in einer Fraktionssitzung mit 45 zu 32 Stimmen gegen den Willen Blums „de voter l'ensemble du budget“; vgl. Le Temps vom 27. 5. 1933, S. 8.

655 Zum Tadel der CAP siehe L'OURS, Cahiers et Revue Nr. 59 (April 1975): „La CAP, ayant appris que le Groupe Parlementaire a décidé, ce matin, par 45 voix contre 32, de voter l'ensemble du budget, estime que cette décision est contraire à la résolution d'Avignon et croit devoir en informer le Groupe Parlementaire."; ebenda, S. 6.

${ }^{656}$ In der Fraktionssitzung, die am Morgen des 27.5. 1933 angesetzt worden war, sprach sich Blum für eine Ablehnung des Haushaltes aus; siche Le Temps vom 27. 5. 1933, S. 8.

657 Die Fraktion entschied sich in der Fraktionssitzung vom 27.5. 1933, mit 63 zu 28 Stimmen für den Haushalt zu stimmen und lehnte gleichzeitig auch den CAP-Tadel mit folgender Erklärung ab: "Le groupe socialiste au Parlement prend l'acte de la communication de la CAP. Le groupe, ayant régulièrement délibéré et soigneusement envisagé la situation politique, dans ce qu'il juge être le cadre de la motion d'Avignon, estime, en présence des manoeuvres de la droite et des certaines intrigues évidentes, que, pour la navette budgetaire actuelle, son vote doit être conforme à sa décision antérieure."; vgl. Le Temps vom 27. 5. 1933, S. 8.

${ }^{658}$ Der Haushalt wurde am Vormittag des 27.5. 1933 mit 401 zu 78 Stimmen bei 116 Enthaltungen und 18 abwesenden Parlamentariern angenommen. Zum namentlichen Abstimmungsergebnis, aus 
Fraktion beabsichtigte, dafür zu stimmen. Aber alle seine Bemühungen, die aktuelle Situation durch Interpretationsdiskussionen zu klären, gingen an der Realität und damit an der eigentlichen Ursache des Konfliktes vorbei. Trotz der Vermittlungsversuche Blums wurde der vorhandene Dissens zwischen der Mehrheit der Partei, vertreten durch Paul Faure, und dem rechten Flügel, repräsentiert durch Déat, Renaudel und Marquet, deutlich. Wie üblich fanden im Vorfeld des großen Parteitages die kleinen Parteitage der einzelnen Föderationen statt, und auch sie standen ganz im Zeichen der akut gewordenen Krise. Die Auseinandersetzungen auf diesen kleinen Parteitagen ließen bereits erahnen, wie sich die Gewichte auf dem großen nationalen Parteitag verteilen würden. Paul Faure formulierte stellvertretend für die Mehrheit der Partei einen Antrag für den bevorstehenden Parteitag, der die Haltung der Mehrheit der Fraktion scharf kritisierte und verurteilte659. Seine Resolution, die in deutlichen Worten Stellung bezog, konnte auf den kleinen Parteitagen der verschiedenen Föderationen meist eine Mehrheit auf sich vereinen. Als Alternative zum Antrag von Faure gab es eine Resolution von Auriol, die zwar Elemente in sich vereinte, die sowohl den rechten als auch den linken Flügel zufriedenstellen sollten, aber in den verschiedenen Föderationen nicht die Mehrheit erhalten konnte660. Blum, der zunächst keinen eigenen Antrag formuliert hatte, schaltete sich, als sich abzeichnete, daß es auf dem Parteitag zur Konfrontation kommen würde, doch wieder in vermittelnder Funktion ein, auch wenn er gleichzeitig versuchte, die Reinhaltung der sozialistischen Doktrin zu verteidigen. Er entschied sich für diesen Vermittlungsversuch, weil er die verschiedenen Anträge, die inhaltlich sehr stark vom neosozialistischen Konzept beeinflußt waren, ablehnte. Blum verwarf die sogenannte neosozialistische Konzeption ebenso entschieden wie 1920 den Bolschewismus. Er verglich die Machteroberungsstrategien des Faschismus, von dem sich die Neosozialisten inspirieren lassen wollten, mit denen des Marxismus und warnte vor revolutionärer Ungeduld in der eigenen Partei. ,Je crois sentir tout d'abord, comme élément neuf, l'impatience révolutionnaire, ou plutôt, ainsi que le note si justement une des motions de la Seine - celle que j’ai déjá citée hier et qui émane du groupe de Monde - importance déterminante attachée au facteur «Temps». Cette tendance d'esprit est, sans nul doute, un produit direct du fascisme. L'examen de l'Europe actuelle laisse l'im-

dem hervorgeht, daß auch Blum für den Haushalt, trotz im Vorfeld anders lautender Aussagen, gestimmt hatte, siehe Le Temps vom 28. 5. 1933, S. 3.

${ }^{659}$ Paul Faure schlug in Le Populaire am 22. 6. 1933, S. 1, folgendes vor: "1) Un blâme à ceux qui en ont décidément pris trop à leur aise avec les décisions de nos congrès et la volonté de nos militants; 2) Qu'à l'avenir, si les cas d'indiscipline se renouvellent, la $C A P$ convoque d'urgence un Conseil National chargé d'appliquer les sanctions devenues nécessaires." Sein Antrag, der auch von Séverac, Zyromski und anderen Mitgliedern der sogenannten „Gruppe der Bataille Socialiste“, unterzeichnet wurde, lehnte jegliche Form eines Kompromisses ab und verurteilte scharf die Politik, dic ihren Höhepunkt in der Zustimmung zum Haushalt fand. Zum Textlaut des Resolutionsantrages siehe Lc Populaire vom 23.6. 1933, S. 6. Dort wurden alle wichtigen Resolutionsanträge im Vorfeld des Parteitages abgedruckt, damit in den verschiedenen Föderationen darüber diskutiert werden konnte.

660 Der Antrag von Auriol, Bedouce und anderen wurde ebenfalls in Le Populaire vom 23.6. 1933, S. 6 abgedruckt. Inhaltlich kann diese Resolution dergestalt zusammengefaßt werden, daß Auriol forderte, auf jeden Fall an der Einheit der Partei festzuhalten, da er keinen Grund für eine Spaltung sehen konnte: „Ce fait même exige plus que jamais l'unité du Parti dans l'esprit de discipline de tous ses membres et aussi le respect des opinions contraires (...).“; ebenda. 
pression d'une course au pouvoir engagée entre le fascisme et le socialisme, et l'on en vient ainsi, à demander, non sans une certaine anxiété, lequel prendra d'autre de vitesse. (...) Je lis par exemple dans la motion de la Bataille: ,Quels que soient les moyens par lesquels il parviendra au pouvoir, le Parti entend, non pas en assurer l'exercice dans le cadre de la sociéte capitaliste, mais l'utiliser pour détruire l'Etat bourgeois (...). Ce qui signifie que, chargé d'exercer légalement le pouvoir, le Parti devra en profiter pour transformer, par une sorte de coup d'Etat, l'exercise légal en conquête révolutionnaire. C'est ce que le fascisme a fait, de son point de vue propre, partout où il l'a pu, et il s'agit de lui couper l'herbe sous le pied (...)."661

Der rechte Flügel um Renaudel, Déat und Marquet konzentrierte sich zunehmend auf die Herausarbeitung der Unterschiede, die es zwischen ihrem sozialistischen Konzept und dem der Mehrheit der SFIO gab. Es zeigte sich deutlich, daß sie ein modernes Sozialismus-Konzept vertraten. So setzten sie auch bewußt ihr Sozialismus-Modell, das sie als einen "Sozialismus der Aktion“ bezeichneten ${ }^{662}$, dem Modell von Blum, das sie „politique du pire“ nannten, entgegen. Die Kritik, die dieser Kreis um Renaudel, Déat und Marquet am „alten“ Konzept übte, kann als Produkt einer Entwicklung gesehen werden, die bereits Ende der zwanziger Jahre eingesetzt hatte und von einer jüngeren intellektuellen Generation, wie z.B. von André Philip oder Marcel Déat ${ }^{663}$, nach und nach weiterentwickelt und vertreten wurde. Der zentrale Punkt, der ihrer Meinung nach geändert werden mußte, war der Primat der Theorie vor der Praxis, d.h. sie forderten die Überwindung der „revolutionären Routine“664. Ihr Schwerpunkt lag auf der politischen Aktion, dem Handeln, das bisher bei den Sozialisten immer wieder durch die Doktrin gebremst oder sogar vereitelt wurde. Für sie stellte Blum, der Verfechter und Bewahrer der Doktrin, ein Haupthindernis dar, das ihren Interessen im Wege stand. Ziebura jedoch weist in seiner Studie über Léon Blum diesen Vorwurf der „Neosozialisten“ zurück, die in seinen Augen die Haltung und das Anliegen Blums verkannt hätten; während der Sprecher der Fraktion den richtigen Zeitpunkt für die „Ausübung der Macht“ abwarten wollte, drängten die „Neosozialisten“ zum sofortigen Handeln.

Wie sich bereits im Vorfeld des Parteitages abgezeichnet hatte, stand dieser ganz im Zeichen der Konfrontation, wenn auch die neue Richtung nur eine Minorität darstellte 665 . Es kam, wie nicht anders zu erwarten war, zu einem Finale furioso zwischen Blum und den „Neosozialisten“, die diesen Parteitag nutzen wollten, um so viele Parteimitglieder wie möglich für ihre neue Richtung zu gewinnen.

Gleich zu Beginn des Parteitages, der vom 14. bis 17. Juli 1933 in Paris stattfand, kämpften die „Neosozialisten“ für ihre Sache und kritisierten die parlamentarische Taktik der SFIO. Marcel Déat, der den Rechenschaftsbericht der Fraktion

661 Blum in Le Populaire vom 14. 7. 1933, S. 1: „Le Pouvoir total“.

$662 \mathrm{Vgl}$. dazu L'Oeuvre vom 9. 6. 1933, S. 1.

${ }_{663}$ Ihre Vorstellungen legten sie in folgenden Werken dar: M. Déat, Perspectives socialistes, Paris 1930, S. 10; B. Montagnon, Grandeur et servitude socialistes, Paris 1929; A. Philip, Henri de Man et la crise doctrinale du socialisme, Paris 1928.

664 G. Ziebura, Blum, S. 447.

665 Vgl. dazu die Abstimmungsergebnisse auf den kleinen Parteitagen der einzelnen Föderationen in Le Populaire vom 4.7.-8.7.1933, jeweils S. 6, sowic vom 10. 7.-14. 7. 1933, jeweils S. 6. 
vorlegte, wies sofort darauf hin, daß die SFIO sich für eine eindeutige Strategie, Opposition oder Unterstützung, entscheiden müsse, denn die von der Mehrheit der SFIO geforderte Taktik des Lavierens, wie sie durch die ambivalent formulierte Resolution von Avignon vorgegeben worden war, zerstöre die parlamentarische Arbeit und gefährde die vorhandene Linksmehrheit im Parlament. Falls diese durch eine erzwungene Opposition der SFIO zerbreche, würde man damit einer Regierung der Mitte oder einer rechten Regierung den Weg bahnen. Déat kritisierte außerdem, daß die Mehrheit der Partei in der Diskussion über das Verhalten der sozialistischen Fraktion am eigentlichen Thema vorbeigehe, indem sie die Auseinandersetzung benutze, um sie auf eine Debatte über die Disziplin zu reduzieren, anstatt sich der eigentlichen Fragestellung zu widmen, nämlich der eindeutigen Klärung der Taktik und damit verbunden der Überprüfung der politischen Inhalte, d. h. der Prüfung der Gesamtpolitik der SFIO. An die Ausführungen Déats knüpfte sich eine sehr bewegte und zum Teil auch sehr kontroverse Diskussion zwischen den beiden Tendenzen innerhalb der SFIO an, die nunmehr einander frontal gegenüberstanden. Die Mehrheit der Partei reagierte entsprechend und verurteilte die Zustimmung der Fraktion zum Haushalt, die in ihren Augen eindeutig einen Verstoß gegen die Resolution von Avignon und die sogenannten "Cahier de Huyghens" darstellte. Als Beispiel für die harte Auseinandersetzung und um einen atmosphärischen Einblick zu vermitteln, sei hier nur auf die Reaktion Blums verwiesen, der den Redebeitrag Marquets, als dieser eine autoritäre Staats- und Wirtschaftsführung forderte, mit folgenden Worten kommentierte: „J'avoue que je suis epouvanté.“666 Bei einem anderen Redner der "neosozialistischen" Tendenz bemerkte Blum, „C'est fascisme“. Blum verteidigte in seiner Gegenrede die Grundsätze des Sozialismus und verwarf das "neosozialistische" Konzept, das sich zu sehr an die Methoden des Faschismus anlehne ${ }^{667}$.

Renaudel verteidigte gegen die Kritik der Parteimehrheit das Verhalten der Fraktion und bezichtigte das oberste Parteigremium, die CAP, des Machtmißbrauchs. Er reichte einen Antrag ein, der zwei Punkte einforderte: 1) Das „Vergessen der Vergangenheit"; - darunter verstand Renaudel, daß die SFIO nicht historisch argumentieren, sondern aus der Situation heraus entscheiden solle. Hinter diesem Argument stand der weiter oben schon erwähnte Vorwurf des Primats der Theorie vor der Praxis und der Versuch, sich aus diesen Fesseln zu befreien, damit die praktische Politik in den Mittelpunkt der sozialistischen Politik treten könne. 2) Renaudel schlug weiter die Gründung einer "commission de recherche“ vor, die zwischen den Parteiströmungen vermitteln sollte. Jedoch wurde sein Antrag zugunsten der Resolution von Bracke668, der sich für die Einhaltung der Parteitagsbeschlüsse aussprach, um damit die Einheit der Partei zu sichern, abgelehnt ${ }^{669}$.

666 Vgl. dazu Le Populaire vom 17. 7. 1933, S. 2.

667 Ausführlich zu dieser Rede Blums auf dem Parteitag: Le Populaire vom 17.7. 1933, S. $2 / 3$ und L'OURS, Cahiers et Revue Nr. 58 (März 1975), sowie in Auszügen in L'OURS, Cahiers et Revue Nr. 59 (April 1975), S. 22-24.

668 Die Resolution von Bracke erhielt folgendes Votum: 3379 stimmten dafür, 22 dagegen und 662 enthielten sich der Stimme; vgl. Le Populaire vom 18. 7. 1933, S. 2.

${ }_{669}$ Der Antrag von Renaudel wurde mit 2556 Stimmen abgelehnt, 815 stimmten für ihn und 692 Delegierte enthielten sich der Stimme; vgl. Le Populaire vom 18. 7. 1933, S. 2. 
Insgesamt wurden für die Schlußresolution vier verschiedene Anträge ${ }^{670}$ eingereicht; als selbst auch die an die Einheit der Partei appellierende "resolution d'unité" "671, der Gruppe um die „Vie socialiste“, also einer Gruppe des rechten Flügels der SFIO, eine Ablehnung erfuhr, kündigte Renaudel eine Spaltung der Partei an: „Mais nous sommes obligé de déclarer qu'en rendant impossible la recherche de textes nouveaux destinés à l'accord, en rejetant notre motion de sauvegarde d'unité d'abord, en maintenant la proposition de sanctions ensuite, en la votant enfin la majorité et les hommes responsables qui la dirigent ont rendu presque impossible toute entente véritable (....).“672

Da die Aufmerksamkeit des Parteitags ganz auf die Auseinandersetzung zwischen der Partei und dem rechten Flügel der Fraktion gerichtet war, wurde über die aktuelle politische Situation in Europa kaum gesprochen, was z.B. Georges Weill kritisierte. Er hielt den Delegierten vor, daß der Konflikt zwischen der Partei und der Mehrheit der Fraktion die eigentlichen Diskussionspunkte und Aufgaben vollkommen überlagere. Diese knappe Beleuchtung des Parteitages zeigt deutlich, daß sich die SFIO in einer tiefen Krise befand. Trotz der Intensität der Krise muß aber festgestellt werden, daß die innerparteiliche Demokratie in der SFIO noch funktionierte, d.h. der Parteitag galt nach wie vor als Forum der Auseinandersetzung, auf dem die Partei ihre verbindlichen Beschlüsse faßte. 2197 Delegierte und damit die große Mehrheit des Parteitages entschieden sich für den Antrag Paul Faures, der das Verhalten der Tradition tadelte.

Blum scheint bewußt geworden zu sein, daß eine Abspaltung nicht mehr abzuwenden und nur noch eine Frage der Zeit war. Er bemühte sich nun um Schadensbegrenzung und suchte die Zahl der Abtrünnigen so klein wie möglich zu halten. Aus diesem Grund wandte er sich mit aller Vehemenz gegen die „neosozialistische" Doktrin, über die er in einer längeren Artikelserie im Populaire673 zu einem vernichtenden Urteil gelangte. Er disqualifizierte den „Neosozialismus“ als eine „Kopie des Faschismus“. Zum einen kritisierte er den autoritären Charakter des von den Neosozialisten avisierten Systems und zum anderen die starke Konzentration auf den in Erosion geratenen Mittelstand, womit der Sozialismus sich von seinem Klassencharakter als einer Partei der Arbeiter entferne und dafür zum Fürsprecher der "Deklassierten" mutiere. Nach einer kurzen Phase massiver polemischer Attacken gegen den Neosozialismus kehrte Blum wieder zu seiner Methode der kritischen Analyse zurück und versuchte, den Unterschied zwischen den Chancen des traditionellen Sozialismus und denen des "Neosozialismus“ aufzuzeigen.

670 Alle vier Resolutionsanträge sind abgedruckt in L'OURS, Cahiers et Revue 59 (April 1975), S. 2530.

671 Der Wortlaut der „motion d'unité“ lautete: „Toutes les Fédérations, réunis dans leur Congrès National, s'engagent à ne trouver dans aucune décision prise par ce Congrès, en conformité des statuts du Parti SFIO, un motif de s'en séparer."; Le Populaire vom 16. 7. 1933, S. 1.

672 Le Populaire vom 18. 7. 1933, S. 2.

${ }^{673} \mathrm{Im}$ Juli und August 1933 meldete sich Blum zu diesem Thema ständig zu Wort, vgl. folgende Artikel: Le Populaire vom 13. 7.-15. 7. 1933; vom 19.7. und 20.7. 1933; vom 24. 7.-28. 7. 1933; vom 30. 7. und 31. 7. 1933; vom 1. 8.-3. 8. 1933; vom 6. 8. 1933 und vom 12. 8.-14. 8. 1933, jeweils S. 1 . Ebenso L'Oeuvre de Léon Blum, Paris 1972, S. 535-581. 
In fünf aufeinander folgenden Leitartikeln ${ }^{674}$ des Populaire bemühte sich Blum, die Charakteristika der aktuellen Lage, die er als "période intermédiare“, d.h. als eine Phase zwischen Kapitalismus und Sozialismus, interpretierte, aufzuzeigen, wobei er insbesondere auf die Gefahren für den Sozialismus hinwies, die nun leider zu Verirrungen wie dem „Neosozialismus“ geführt hätten. Blum konstatierte, daß in dieser „Zwischenphase" neue politische Kräfte entstanden seien, die folgende Merkmale aufwiesen: 1) Sie stellten "combinations hybrides“ dar, die weder als demokratisch, autokratisch, noch als diktatorisch zu bezeichnen seien; 2) sie verherrlichten die Regierung eines starken Mannes, wollten dabei aber ein formales Fortbestehen der bisherigen politischen Institutionen gewährleisten; 3) sie strebten eine Mischung aus legaler Machtausübung und revolutionärer Machtergreifung an und 4) sie gingen aus einer Krisenerscheinung des Kapitalismus hervor. Dazu analog stellte Blum die Entstehung neuer sozialer Kräfte fest, die sich in seinem Urteil folgendermaßen charakterisieren ließen: 1) Sie bildeten sich aus einem nationalen Umfeld heraus und verbanden nationale und soziale Ziele miteinander; 2) diese neuen Kräfte entwickelten sich meist aufgrund politischen Machtmißbrauchs; 3) sie appellierten an Autoritäts- und Fortschrittsdenken; 4) sie garantierten materielle Sicherheit statt Freiheit. Diesen Typus nannte Blum analog zur "période intermédiaire" den "typ social intermédiaire" ${ }^{675}$. In weiteren Artikeln warnte Blum davor, nicht wie die Neosozialisten in der "Zwischenphase“ eine sogenannte "Zwischenform“ zu praktizieren und eine sogenannte „revolutionäre Bewegung" zu begründen, denn dies würde den Sozialismus eher kompromittieren, als ihm zum Sieg zu verhelfen. Typische Charakteristika der Neosozialisten waren in den Augen Blums: 1) als starke Männer aufzutreten; 2) den unzufriedenen Massen eine bessere Zukunft zu versprechen; 3) Fortschritt und Innovation anzukündigen; 4) nationale und chauvinistische Propaganda zu betreiben ${ }^{676}$. In einem abschließenden Artikel bemühte sich Blum um eine befriedigende Antwort auf die Frage, inwieweit eine demokratisch gewählte sozialistische Partei den revolutionären Umsturz des politischen Systems anstreben könne. Er beantwortete die Frage damit, daß es zur Verwirklichung einer großen Anzahl von sozialistischen Zielen weder der "forme intermédiaire“, noch des Umsturzes des politischen Systems bedürfe, denn eine Herrschaft der „forme intermédiaire“ sei für deren Umsetzung eher kontraproduktiv. Sie würde diese eher gefährden als fördern. Abschließend erklärte Blum, daß die "conquête du pouvoir" ohne den Umweg der „formes intermédiares“ anzustreben und umzusetzen sei: „(...) c'est la vraie révolution sociale qu'il faudrait oser." 677

In all diesen Analysen traten die fundamentalen Unterschiede der politischen Konzepte der Anhänger des Sozialismus und des Neosozialismus hervor, die auch sehr stark mit der Problematik des Generationenkonfliktes zusammenhingen. Natürlich blieben die Angriffe Blums nicht unerwidert. Die „Neosozialisten“ verteidigten ihre Doktrin. Gelegenheit dazu erhielten sie in der Zeitung L'Oeuvre, die ein Sprachorgan der Radikalsozialisten war. In gewissem Sinne läßt dies den

${ }_{674}$ Vgl. Le Populaire vom 24.-28. 7. 1933, jeweils S. 1.

675 Vgl. hier den Leitartikel Blums in Le Populaire vom 24. 7. 1933, S. 1.

676 Vgl. hier den Leitartikel Blums in Le Populaire vom 25. 7. 1933, S. 1.

677 Blum in Le Populaire vom 28. 7. 1933, S. 1. 
Rückschluß zu, daß ein Teil des Parti radical mit den Neosozialisten sympathisierte, um sie von der SFIO abzuspalten und damit ihre Linksmehrheit im Parlament zu stabilisieren.

Nachdem der inhaltliche Bruch zwischen der Mehrheit der sozialistischen Partei und den „Neosozialisten“ auf dem Parteitag erfolgt war, mußte er auch formal vollzogen werden. Die endgültige Trennung vollzog sich in zwei zeitversetzten Etappen. Der äußere Anlaß für das definitive Ausscheiden der „Neosozialisten“ aus der sozialistischen Partei bot sich am 23/24. Oktober 1933. Der Ausschluß erfolgte auf der Tagung des Conseil national am 5. November 1933. Zunächst gilt es, das Ereignis vom 23/24. Oktober 1933678 in den Blick zu nehmen. Der von der Regierung Daladier vorgelegte Finanzplan, der eine weitere Kürzung der Beamtengehälter vorsah ${ }^{679}$, ließ sich mit den finanzpolitischen Konzepten der SFIO nicht vereinbaren und kündigte das Ende der Regierung Daladier an. Denn ohne die Zustimmung der SFIO verlor die Regierung Daladier die Mehrheit. Wie nicht anders zu erwarten, suchten die „Neosozialisten“ in der sozialistischen Fraktion eine Regierungskrise zu vermeiden. Selbstredend war ihr Handeln ganz von dem Leitsatz geprägt, einen Sturz der Regierung Daladier zu verhindern. Deshalb stand es außer Frage, daß sie für die Budgetvorlage stimmen wollten. Jedoch mußte den „Neosozialisten“ bewußt sein, daß diese Entscheidung zwangsläufig nicht nur zur Konfrontation innerhalb der sozialistischen Fraktion führen würde, sondern zum definitiven Bruch. Denn nach den Auseinandersetzungen auf dem Parteitag und den Diskussionen, die in der Nachfolgezeit über die Presse ausgetragen worden waren, war allen Beteiligten klar, daß sich ein Bruch nicht mehr vermeiden ließ.

Die Fraktion der SFIO berief zwar noch Sitzungen ein, um ein einheitliches Abstimmungsergebnis zu diskutieren und damit die Einheit der Partei zu retten; aber in der sozialistischen Fraktion hatten sich die Mehrheitsverhältnisse seit dem Parteitag im Juli 1933 entscheidend verändert, d.h. die Anhängerzahl der „Neosozialisten" hatte abgenommen und stellte mittlerweile nur noch eine Minderheit innerhalb der Fraktion dar. Die Mehrheit der sozialistischen Abgeordneten bekannte sich zum traditionellen Sozialismus, als deren Hauptvertreter Léon Blum galt. Blum hatte sich angesichts der kritischen Situation für einen Kompromiß mit der Regierung Daladier eingesetzt, da auch er zunächst eine Regierungskrise vermeiden wollte. Letztlich geriet die SFIO aber in einen Interessenskonflikt zwischen der Aufrechterhaltung der Regierung Daladier und ihrem eigenen Finanzprogramm. Anders ausgedrückt: die SFIO stand vor dem Dilemma Taktik versus Doktrin, wobei der Primat der Doktrin obsiegte, und dies bedeutete, daß die Mehrheit der Fraktion gegen die Finanzvorlage Daladiers zu stimmen bereit war. Trotz einer Fraktionssitzung vor dieser entscheidenden Abstimmung, in der Frossard, der zum gemäßigten rechten Flügel gehörte, an die Minderheit der Fraktion,

${ }_{678}$ Die Kammerdebatte um die neue Budgetvorlage ist abgedruckt in J.O., Chambre des Députés vom 22. 10. 1933, S. 3875-3891; Fortsetzung der Debatte in J.O., Chambre des Députés vom 23.10. 1933, 1. Sitzung, S. 3895-3908 und 2. Sitzung, S. 3914-3942.

679 Gemeint ist die Abstimmung um Artikel 37; vgl. J.O., Chambre des Députés vom 23. 10. 1933, 2. Sitzung, S. 3942. Hier kam es zur Abstimmung und Vertrauensfrage über Artikel 37 der Budgetvorlage der Regierung Daladiers, die mit 329 zu 241 gegen diesen Artikel ausfiel. 
also an die „Neosozialisten“, appellierte, die Abstimmungsdisziplin einzuhalten, zerfiel die sozialistische Fraktion bei der Abstimmung in drei Teile: 91 Abgeordnete stimmten dagegen, 28 („Neosozialisten“) dafür und elf enthielten sich der Stimme. Wie nicht anders zu erwarten stürzte die Regierung Daladier mit $329 \mathrm{zu}$ 241 Stimmen ${ }^{600}$. Im Parlament verhielten sich die einzelnen Parlamentsgruppen bei diesem Votum wie folgt:

\begin{tabular}{rlrrrr}
\hline $\begin{array}{c}\text { An- } \\
\text { zahl }\end{array}$ & Parlamentarische Gruppe & Dafür & $\begin{array}{l}\text { Da- } \\
\text { gegen }\end{array}$ & $\begin{array}{l}\text { Enthal- } \\
\text { tung }\end{array}$ & $\begin{array}{l}\text { Abwe- } \\
\text { send }\end{array}$ \\
\hline 12 & Indépendants & - & 12 & - & - \\
17 & Groupe républicain et social & - & 17 & - & - \\
5 & Action économique, sociale et paysanne & - & 3 & - & 2 \\
14 & Fédération républicaine & - & 40 & - & 1 \\
36 & Centre républicain & - & 34 & 2 & - \\
29 & Républicains de gauche & - & 29 & - & - \\
16 & Démocrates populaires & - & 16 & - & - \\
6 & Républicains du centre & - & 6 & - & - \\
23 & Indépendants de gauche & 5 & 13 & 4 & 1 \\
46 & Gauche radicale & 12 & 25 & 6 & 3 \\
162 & Radicaux et radicaux socialistes & 157 & - & 4 & 1 \\
14 & Gauche indépendante & 11 & 1 & 2 & - \\
15 & Républicains socialistes & 8 & 5 & 2 & - \\
12 & Socialistes français & 10 & 1 & - & 1 \\
130 & Socialistes & 28 & 91 & 11 & - \\
9 & Unité ouvrière & 1 & 8 & - & - \\
10 & Communistes & - & 10 & - & - \\
28 & Isolés & 9 & 18 & - & 1 \\
\hline 611 & & 241 & 329 & 31 & 10 \\
\hline
\end{tabular}

Durch das erneute eigenständige Handeln bzw. durch das Hinwegsetzen über die Abstimmungsdisziplin war auch formal der Bruch der "Neosozialisten“ mit der Mehrheit der SFIO vollzogen. Wie weit die Kluft zwischen beiden Gruppierungen aufgerissen war, manifestierte sich auch in den Begleitumständen der Abspaltung. Nach dem Sturz seiner Regierung richtete Daladier gegen die Vertreter der Mehrheitssozialisten Auriol und Blum heftige Vorwürfe, die von den „Neosozialisten“ noch unterstützt wurden. Außerdem demonstrierte die Gruppe der „28“, die sich um Renaudel formiert hatte, ihre Unabhängigkeit indem sie eigene Sitzungen abhielt und eigene Erklärungen verbreitete, in denen sie ihre Position verteidigte. Die Parteiführung wertete dies als Verstoß gegen die Parteidisziplin. Das Abstimmungsverhalten der „Neosozialisten “ führte dazu, daß ein Conseil national einberufen wurde, um über den bereits schon seit längerem im Raum stehenden Ausschluß der „Neosozialisten“681 zu beraten und zu beschließen.

680 Le Temps vom 25. 10. 1933, S. 4.

681 Der Ausschluß von vier führenden „Neosozialisten“ war bereits auf dem Parteitag von Dubois in einem Resolutionsantrag gefordert worden. Obwohl Marceau Pivert diesen Antrag im Resolutionsausschuß verteidigt hatte, wurde er mit 3619 gegen 149 und 620 Enthaltungen nicht in Betracht gezogen. Begründet wurde die Ablehnung damit, daß der Parteitag nicht das Recht habe, einen 
Obwohl zunächst auf der Tagung des Conseil national vom obersten Parteigremium CAP gefordert worden war, daß alle sozialistischen Parteimitglieder einen sogenannten Treueschwur ablegen sollten ${ }^{682}$, konnte durch die Vermittlung Blums eine Milderung erreicht werden, die dazu führte, daß die CAP letztlich von dieser rigiden Forderung abrückte ${ }^{683}$. Für die Milderung hatte sich Blum deshalb eingesetzt, weil er versuchte, damit so weit wie möglich den Schaden für die Partei zu begrenzen und die Zahl der sich abspaltenden Mitglieder so gering wie möglich zu halten. Letztlich waren es nur 28 „Neosozialisten“, die sich durch ihr Auftreten und Handeln abgespalten hatten. Die Gruppe der „28“ hoffte aber, noch weitere Mitglieder der SFIO auf ihre Seite ziehen zu können, in dem Bestreben, daß durch die neue Partei, die sie zu gründen beabsichtigte, eine gesicherte Linksmehrheit im Parlament zustande kommen könnte. Die „Neosozialisten“ bemühten sich deshalb sehr um eine Gruppe von ungefähr 30 sozialistischen Abgeordneten ${ }^{64}$, die meistens mit den „Neosozialisten“ gestimmt hatten; aber diese 30 Abgeordneten zogen es vor, sich vorübergehend auf eine Warteposition zurückzuziehen. Blum und die Mehrheit der Sozialisten hatten das Kalkül der „Neosozialisten“ durchschaut und versuchten nun ihrerseits die neutrale Gruppe von 30 Mitgliedern zu gewinnen. So erklärt sich auch das relativ milde Verhalten des Conseil national ${ }^{685}$. Dieser Rettungsversuch glückte der Mehrheit der SFIO, und so spalteten sich am 8. November 1933 tatsächlich nur 28 Abgeordnete und sieben Senatoren ab. Die neue Partei nannte sich „Parti socialiste de France“. Die Gründung wurde in einem Communiqué bekanntgegeben: „Les parlementaires dont les noms suivent, profondément émus et indignés de la décision prise par le Conseil national socialiste du 5 novembre, excluant du Parti des hommes qui, comme Pierre Renaudel, lui ont sacrifié toute leur existence, se déclarent entièrement solidaires avec des camarades ainsi frappés. En conséquence ils décident de se grouper aux contés des exclus du Conseil national pour fonder à la Chambre et au Sénat un nouveau groupe parlementaire, dont la constitution sera rendue officielle par toutes dispositions réglementaires utiles." ${ }^{686}$ Einige Mitglieder der SFIO traten aus Solidarität mit den vom Conseil national ausgeschlossenen Abgeordneten und Senatoren ${ }^{687}$

Ausschluß vorzunehmen, wenn der Fall nicht vorher dem Konfliktausschuß vorgelegen habe; vgl. L'OURS, Cahiers et Revue 59 (April 1975), S. 31.

682 „3) Enfin la CAP estime que les évenéments de ces derniers mois ont crée dans le Parti un malaise profond en opposant trop souvent une fraction du Groupe Socialiste à la majorité du Parti et qu'il est urgent de le dissiper. Elle suggère donc au Conseil national de réclamer de tous les élus du Parti le renouvellement solennel de l'engagement écrit qu'ils ont contracté comme candidat." Diese Forderung hatte die CAP bei einer Sitzung am 30.10.1933 mit 24 zu drei Stimmen verabschiedet, bevor sie den Conseil national für den 4./5. 11. 1933 einberief; vgl. dazu L'OURS, Cahiers et Revue 59 (April 1975), S. $53 \mathrm{f}$.

${ }^{683}$ Le Populaire vom 16. 11. 1933, S. 1; L'OURS, Cahiers et Revue 59 (April 1975), S. 64 f.

${ }^{684} \mathrm{Zu}$ dieser Gruppe gehörten Mitglieder des rechten Flügels der sogenannten „participationnistes“, wie z. B. Frossard, R. Evrard, Hussel, Payra, Félix, R. Brunet etc. Vgl. dazu L'OURS, Cahiers et Revue 59 (April 1975), S. 64.

${ }^{685}$ Zur Berichterstattung über den Conseil national siehe Le Populaire vom 5. 11. 1933, S. 1/2 und vom 6. 11. 1933, S. 1/2, sowie L'OURS, Cahiers et Revue 59 (April 1975), S. 56-62.

686 Vgl. dazu Le Populaire vom 9. 11. 1933, S. 1 und L'OURS, Cahiers et Revue 59 (April 1975), S. 62/ 63 .

${ }^{687}$ Bei den ausgeschlossenen Parteimitgliedern handelte es sich einerseits um Etcheverry, Thurotte, Poupy, Mallarte und Caillet. Mit ihnen solidarisch zeigten sich die Mitglieder des Zentralkomitées der Action socialiste, die auf dem Conseil national eine Resolution verabschiedeten, in der sie ihre 
aus der Partei aus. Zwar richtete Renaudel einen offenen Brief an die übrigen Fraktionsmitglieder, in dem er sie aufforderte, sich seiner Gruppe anzuschließen, um eine solide Linksmehrheit im Parlament zu gewährleisten, da ansonsten der Weg für eine Regierung der Union nationale oder der concentration frei sein würde 688 , doch blieb der erhoffte Erfolg seines Appells aus. So erreichte die Mehrheit der SFIO, daß sich nur die kleine Kerngruppe der „28“ abspaltete und damit die sogenannten Störelemente aus der SFIO ausschieden, was insgesamt gesehen der SFIO ermöglichte, wieder eine innere Homogenität herzustellen. Für die Partei stellte der Ausschluß der "Neosozialisten“ eher eine Reinigung dar, als daß er einen ernsthaften Schaden für die SFIO bedeutete, und war deshalb nicht mit den Vorgängen von $1920 \mathrm{zu}$ vergleichen ${ }^{689}$.

\section{Krise des französischen Parlamentarismus durch das Scheitern der radikal-sozialistischen Regierungstaktik}

Das Verhältnis zwischen den Radikalsozialisten und der SFIO war durch den Sturz der Regierung Daladier und die Abspaltung der „Neosozialisten“ erneut in eine kritische Phase getreten. Die Radikalsozialisten gaben der SFIO die Schuld, daß die Regierung Daladier zu Fall gebracht worden war690, da die Mehrheit der sozialistischen Fraktion gegen das Finanzprogramm der Regierung gestimmt habe. Wie sich auch bei den beiden nächsten Regierungen unter Albert Sarraut ${ }^{691}$

Solidarität mit den Ausgeschlossenen bekundeten: „S'élevant énergiquement contre la sentence d'exclusion prise par le Conseil national contre leurs camarades coupables de rester fidèles au socialisme; Déclarent se solidariser entièrement avec eux et préfèrent sortir du Parti plutôt que de renier leur position révolutionnaire." Diese Resolution wurde von folgenden sozialistischen Parteimitgliedern unterzeichnet: Alleaume, Auguet, Bréant, Caillet, Charreyron, Fié, Grandbastien, Laugier, Livet, Mallarte, Marthelin, Thérèse Maurin, Périgaud und Roglin. Vgl. dazu Le Populaire vom 6. 11. 1933, S. 1/2 und L'OURS, Cahiers et Revue 59 (April 1975), S. 56/57. Und andererseits wurden auch Renaudel, Déat, Marquet, Deschizeaux, Ernst Lafont, Cayrel und Montagnon ausgeschlossen mit 3046 gegen 863 Stimmen bei 101 Enthaltungen; siehe L'Oeuvre vom 6.11. 1933, S. 1, 4 und L'Oeuvre vom 7. 11. 1933, S. 1. Damit wurde sowohl eine extrem linke Gruppe wie eine extrem rechte Gruppe von der sozialistischen Partei ausgeschlossen bzw. trennte sich selbst von ihr.

688 Vgl. dazu Renaudel in L'Oeuvre vom 5. 11. 1933. S. 4.

${ }^{689}$ Von den einzelnen Föderationen waren am meisten die Föderationen Var und Gironde betroffen, insgesamt konnte die neue Partei nur 20000 Anhänger finden; vgl. L'OURS, Cahiers et Revue 59 (Avril 1975), S. 62/63.

690 Die Regierung Daladier scheiterte am Streit über Artikel 37, der weitere Kürzungen der Beamtengehälter und der Beamtenrenten vorsah. Zum Sturz der Regierung Daladier und die dramatischen Debatten zwischen dem 22. 10. und 24. 10. 1933 in der Deputiertenkammer siehe L'Oeuvre vom 23. 10. und 24. 10. 1933, jeweils S. 1, 4. Nachdem Auriol die Regierung Daladier als reaktionär bezeichnet und Blum sogar den Bruch mit der Regierung angekündigt hatte, indem er erklärte, daß die orthodoxen Sozialisten gegen den Gesetzesentwurf und damit gegen die Regierung stimmen würden, rechnete Daladier nach dem Sturz seiner Regierung seinerseits mit Auriol und Blum ab. Daladier warf den Sozialisten vor, daß sie trotz seiner Konzessionen seine Politik blockiert bzw. bekämpft hätten; vgl. Le Temps vom 25. 10. 1933, S. 3 f. und auch L'Oeuvre vom 24. 10. 1933, S. 4.

691 Die Regierung Albert Sarraut hatte nur eine kurze Lebensdauer: Sic regierte vom 26. 10.-23. 11. 1933; siehe E. Bonnefous, Histoire politique, vol. 5, S. 174-182. Zum Regierungsantritt Albert Sarrauts und zu seinem Sturz siehe L'Oeuvre vom 27. 10. 1933, S. 1, 4 und vom 24. 11. 1933, S. 1, 4. 
und Camille Chautemps ${ }^{692}$ zeigten sollte, war keine regierungsfähige Mehrheit mehr im Parlament herzustellen. Das französische parlamentarische System steckte in einer Krise, die der Parlamentarismuskritik Nahrung gab und antiparlamentarische Bewegungen entstehen ließ, weil keine wirklichen politischen Lösungen für die Finanz- und Wirtschaftskrise gefunden werden konnten. Nachdem weder eine Regierung der Linksmehrheit noch eine Regierung der concentration im französischen Parlament möglich war, obwohl letztere zunehmend von den führenden Persönlichkeiten des Parti radical sehr favorisiert wurde ${ }^{693}$, äußerte auch Blum die Befürchtung, daß die rechten Kräfte unter Tardieu versuchen würden, ein Kabinett der Union nationale zu bilden ${ }^{694}$. Er warf den Radikalsozialisten vor, daß sie diese Entwicklung durch ihre rechtsorientierte Finanzpolitik noch sehr fördern würden, denn die SFIO konnte eine solche Finanzpolitik auf keinen Fall mittragen und fiel damit als Mehrheitenbeschafferin aus. Außerdem kritisierte er, daß weder Sarraut noch Chautemps die Sozialisten um ihre Mitarbeit gebeten hätten. Da Blum sich vehement gegen die konservative Finanzpolitik aussprach und für die SFIO keine Möglichkeit einer Unterstützungspolitik sah, führte er die sozialistische Partei zurück in die Oppositionsrolle. Nachdem beide radikalsozialistisch geführten Regierungen, d. h. das Kabinett Sarraut und das Kabinett Chautemps, schon nach kurzer Zeit gescheitert waren, versuchte Daladier, eine Regierung der concentration zu bilden, deren Basis von der rechten Mitte bis zu den "Neosozialisten" reichen sollte ${ }^{695}$. Doch war auch dieser Regierung keine große Lebensdauer beschert, denn rechts- und linksextreme Kräfte sagten dem parlamentarischen System Frankreichs den Kampf an. Die Entwicklung zeigte abermals, daß in einer Legislaturperiode, die mit einem Wahlerfolg der politischen Kräfte der linken bzw. der linken Mitte begann, nach vergeblichen Versuchen mit einer Linksmehrheit zu regieren, sich das Blatt wieder zugunsten von Regierungen der Rechten bzw. der rechten Mitte wendete. Zum einen hängt dies auch mit der Rolle der SFIO zusammen, die sich nach dem Scheitern der Linksregierungen regelmäßig in die Rolle der Opposition zurückzog und damit den Weg für Regierungen der Mitte bzw. der rechten Mitte freigab. So konnten die Radikalsozialisten, die die wichtigste und die zahlenstärkste Fraktion bis zur Mitte der dreißiger Jahre stellten, mit den Kräften der rechten Mitte koalieren. Nachdem die Radikalsozialisten die gesamte Legislaturperiode von Juni 1932 bis Juni 1936 in der Regie-

692 Das Kabinett von Chautemps hatte immerhin zwei Monate regiert, vom 26.11. 1933 bis 27.1. 1934. Vgl. dazu E. Bonnefous, Histoire politique, vol. 5, S. 182-198.

${ }^{693} \mathrm{Zu}$ den verschiedenen Einschätzungen der möglichen regierungsfähigen Mehrheiten im Parlament siehe L'Oeuvre vom 25. 10. 1933, S. 4 und vom 26. 10. 1933, S. 4.

$694 \mathrm{Vgl}$. hierzu auch die Stellungnahme Blums zur Ablehnung des Artikel 37 durch die SFIO: „(...) toute entreprise contre l'unité du Parti pousse à la concentration par une pente inévitable. M. Daladier a ajouté hier, par surcroit, une petite préparation psychologique assez imprévue puisque, par l'esprit et par le langage, il s'est déjà rapproché de $\mathrm{M}$. Tardieu et de M. Flandin. La concentration est faite. Si ce n'est pas pour aujourd'hui elle est pour démain. Les seuls coupables resteront ceux qui ont voulu pousser jusqu'à un intolérable abus la bonne volonté dont le Parti n'avait peut-être donner que trop de gages. "Le Populaire vom 25.10. 1933, S. 1. Und zu dieser Thematik vor allem auch die Leitartikel von Léon Blum in Le Populaire vom 9. 12., 10. 12. und 12. 12. 1933, jeweils S. 1 .

695 Das Kabinett Daladier blieb nur sehr kurz im Amt, da sich Daladier durch die Ereignisse des 6. 2. 1934 zum Rücktritt entschloß. Zum Abstimmungsergebnis für die Bestätigung der Regierung Daladier im Amt am 30.1.1934 vgl. Le Temps vom 8. 2. 1934, S. 2. 
rungsverantwortung standen und sich die exogenen Rahmenbedingungen drastisch verändert hatten, kam es bei den Wahlen von 1936 zu starken Veränderungen des politischen Kräfteverhältnisses, das im dritten Prozeßbeispiel näher untersucht werden soll. 